Bad Apples, Bad Barrels, and the Structure of Marketing Channel Relationships: Analyses of the Propensity for Opportunism and Opportunistic Behaviors

\author{
Chiharu Ishida
}

Dissertation submitted to the Faculty of the

Virginia Polytechnic Institute and State University

in partial fulfillment of the requirements for the degree of

\author{
Doctor of Philosophy \\ in \\ Marketing
}

Dissertation Committee Members:

James R. Brown, Co-Chair

Noreen Klein, Co-Chair

Janet E. Keith

C. Jay Lambe

Kent Nakamoto

Richard E. Wokutch

April $27^{\text {th }}, 2007$

Blacksburg, Virginia

Copyright 2007, Chiharu Ishida 


\title{
Bad Apples, Bad Barrels, and the Structure of Marketing Channel Relationships: Analyses of the Propensity for Opportunism and Opportunistic Behaviors
}

\author{
Chiharu Ishida
}

\begin{abstract}
The theoretical frameworks of transaction cost economics and agency theory are widely used to design appropriate governance structure for constraining opportunism within marketing channels. These approaches generally assume that marketing channel managers are opportunistic, and only economic constraints deter opportunism in exchange relationships. However, some empirical studies have shown that managers do not always behave opportunistically even if conditions permit such behavior. In addition, some researchers have proposed a "cycle of self-fulfilling prophecy" and have argued that the uncritical assumption of opportunism and excessive use of control mechanisms such as monitoring only exacerbates the problem. Thus, it is important to identify conditions in which opportunism likely occurs.

The present research argues that marketing channel managers exhibit differing propensities for opportunism (PFO), and it spans three levels of analysis to identify contributing factors. The individual-level analysis treats marketing channel managers as a heterogeneous population and investigates the impact of individual traits on their behaviors in business relationships. At the dyadic level, I modify standard microeconomics models to incorporate norms of fairness. Finally, the extra-dyadic level of analysis goes beyond the traditional dyadic focus to include network-wide social influence on a relationship. Using the data collected from 162 unit franchieees. the hypotheses were tested using structural path analyses.

The findings of this dissertation provide guidance on the extent to which costly and potentially damaging control mechanisms are really necessary in a given marketing channel relationship. Overall, the research contributes to the existing literature by reexamining a fundamental behavioral assumption about marketing channel managers and providing an alternative framework that can meaningfully inform us as to when and why opportunism occurs.
\end{abstract}




\section{TABLE OF CONTENTS}

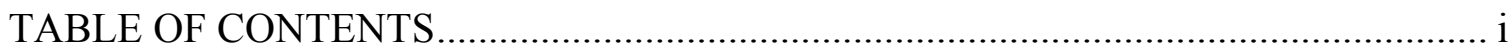

LIST OF TABLES

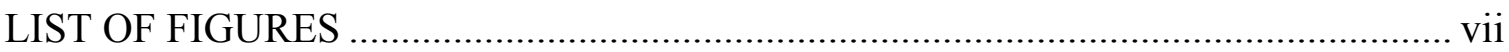

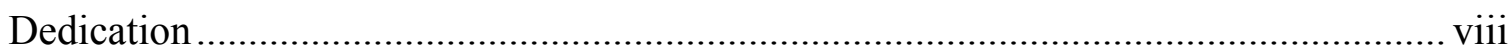

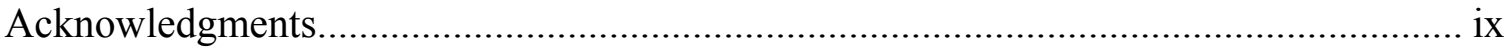

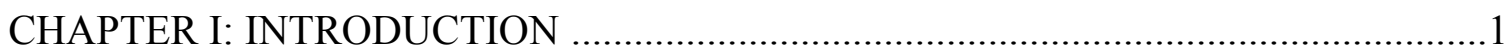

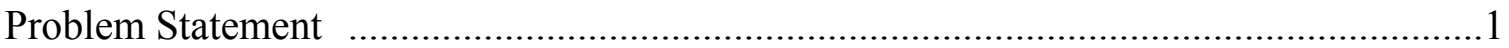

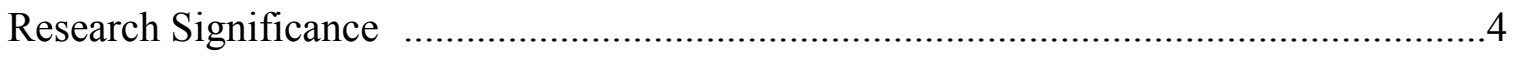

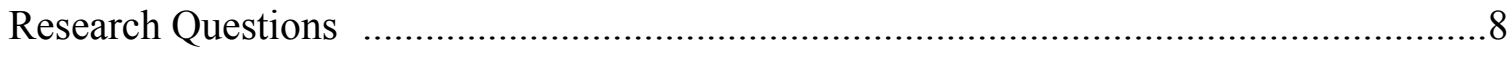

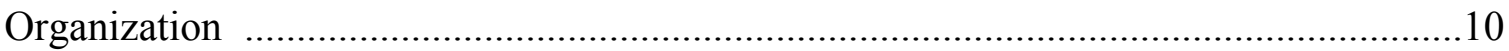

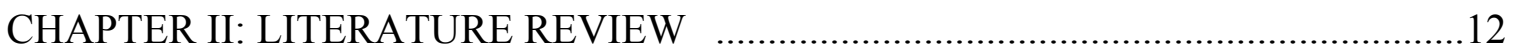

Opportunism Management in Marketing Channels ………............................................12

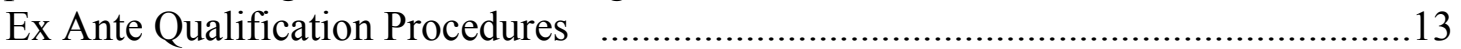

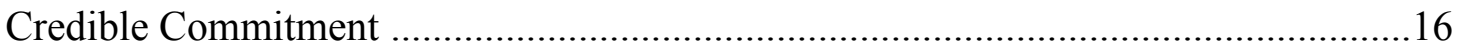

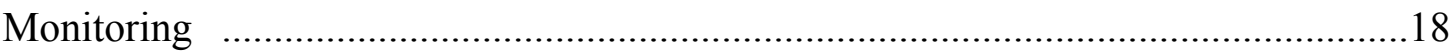

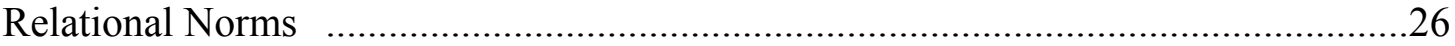

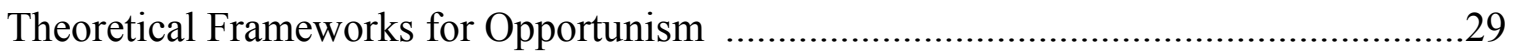

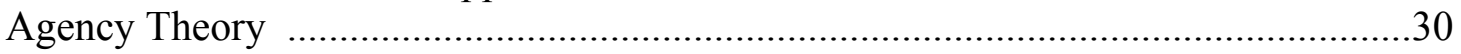

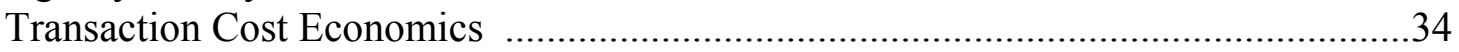

Organizational Justice Literature ..........................................................................43

Individual-Specific Characteristics and Opportunism …………...............................53

Cognitive Moral Development ...………………………...............................5

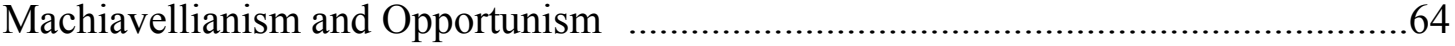

Locus of Control and Opportunism ……………………......................................67

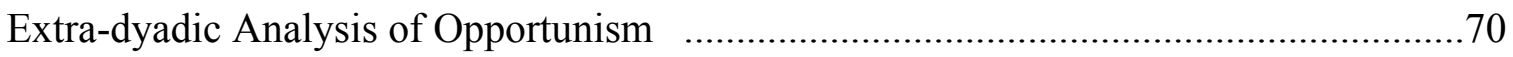

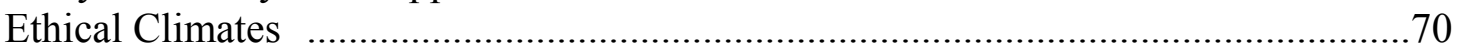

The Social Network Mechanism ...………………………...................................75 


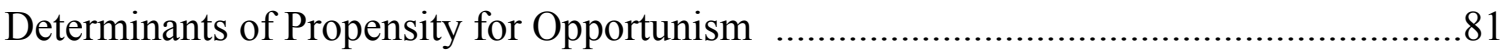

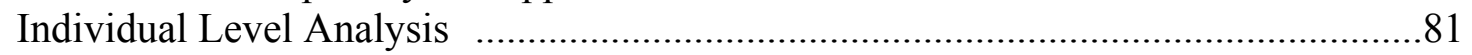

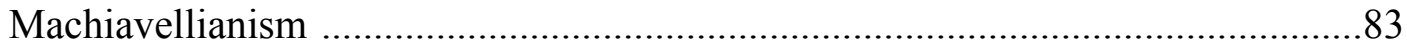

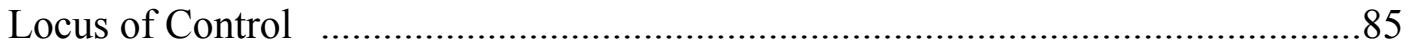

Cognitive Moral Development .......................................................................86

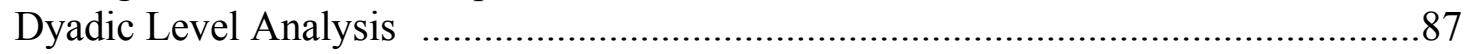

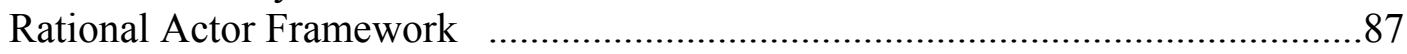

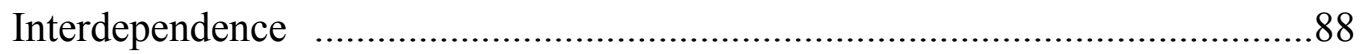

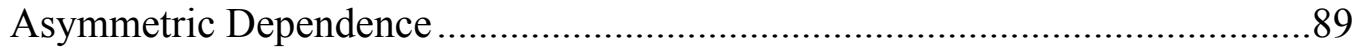

Transaction-Specific Investments ……………………...........................90

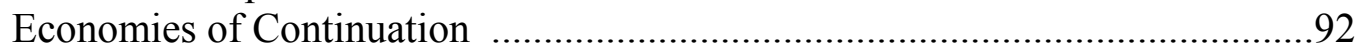

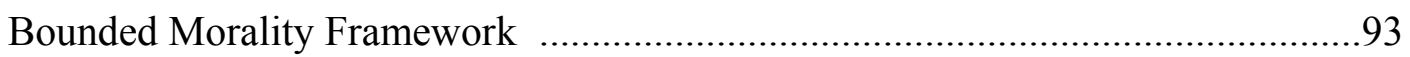

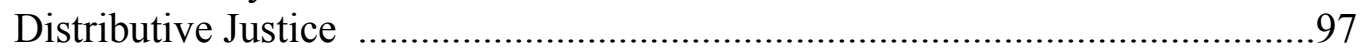

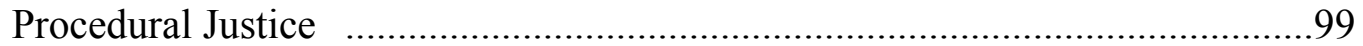

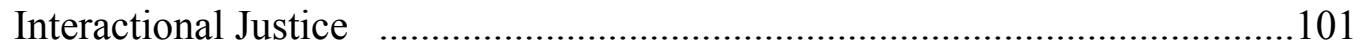

Crowding Out Effects of Monitoring .........................................................102

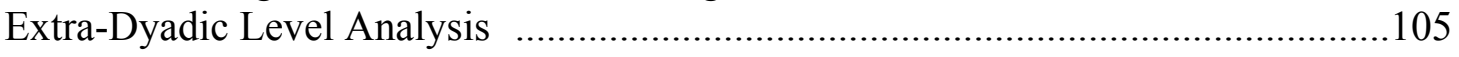

Negative Professional Ethical Climate ……………….....................................106

Interaction Between CMD and Professional Ethical Climate .......................................108

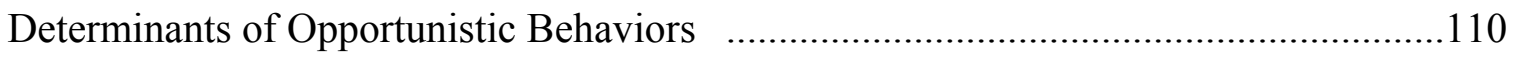

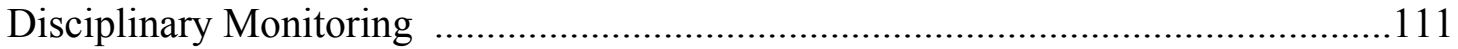

Network Density .....................................................................................112

CHAPTER IV: METHODOLOGY - SAMPLE AND DATA COLLECTION ............115

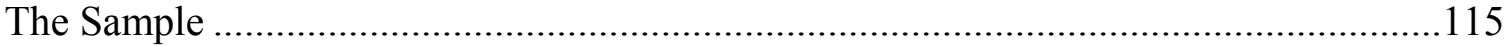

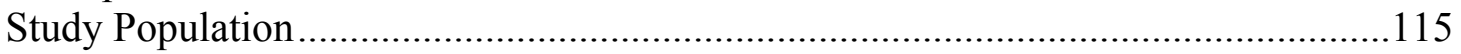

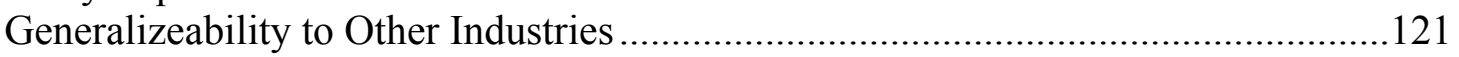

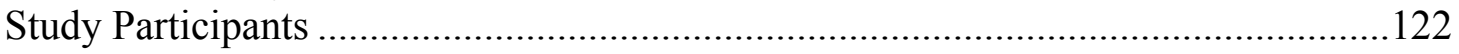

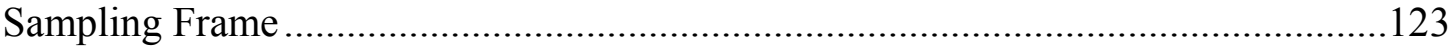

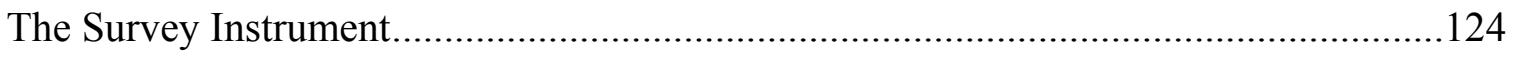

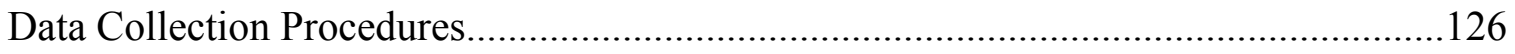

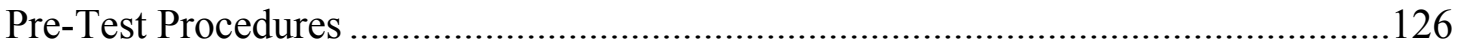

Pre-Test 1: Reduction of CMD Scale ………………......................................126

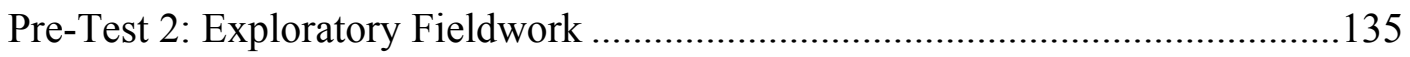

Pre-Test 3: Measurement Development.............................................................137

Primary Data Collection ………………………………….............................141

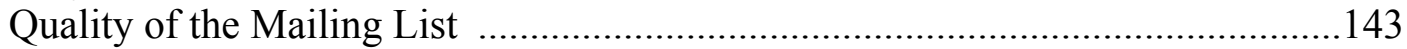

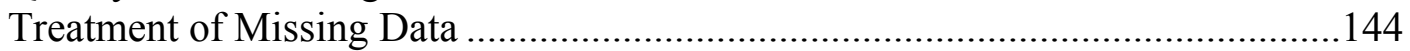


Response Rate Calculation .............................................................................144

Response Bias Estimation Procedures ..............................................................148

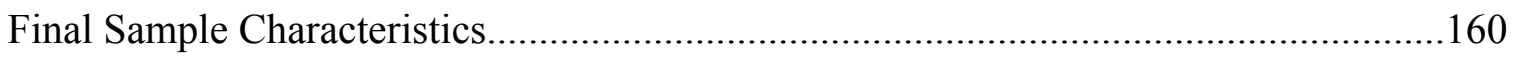

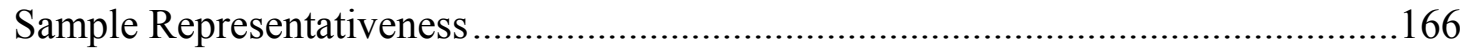

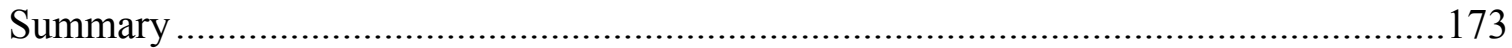

CHAPTER V: METHODOLOGY - SURVEY INSTRUMENT ……………………....174

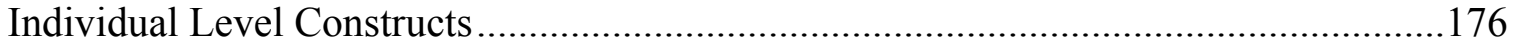

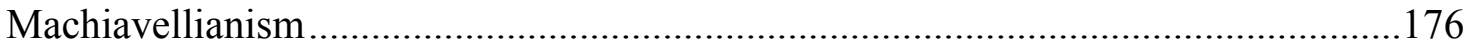

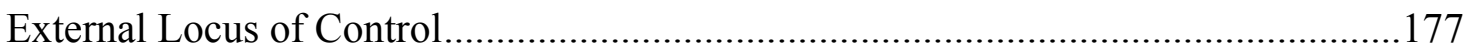

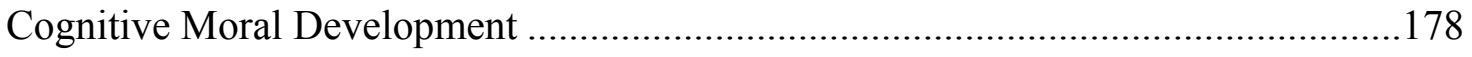

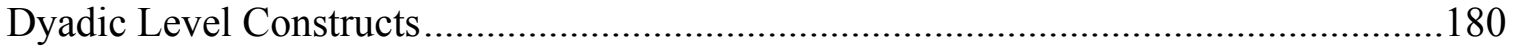

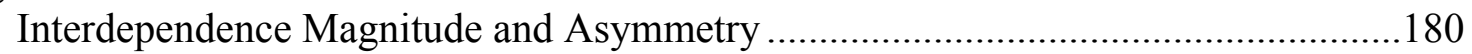

Franchisee Transaction-Specific Investments..........................................................182

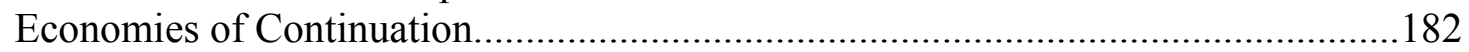

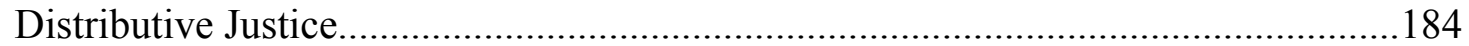

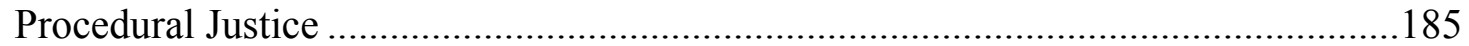

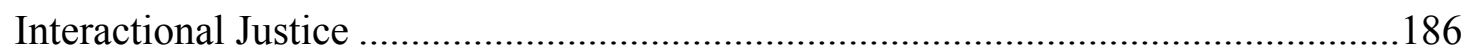

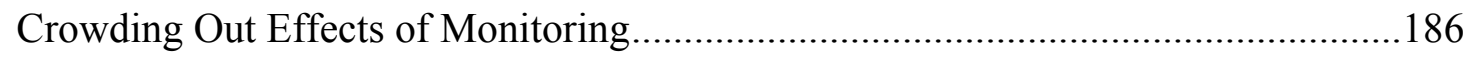

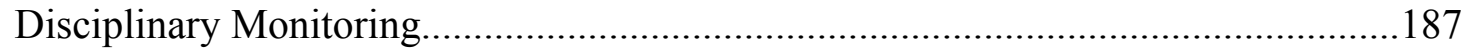

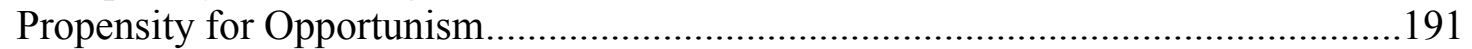

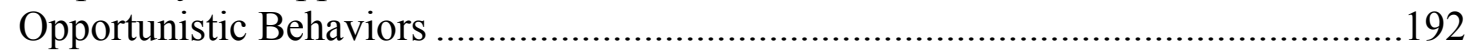

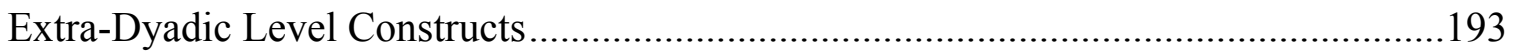

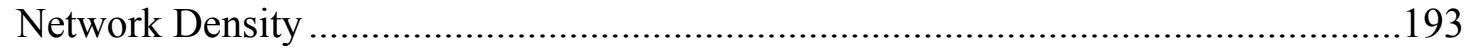

Negative Professional Ethical Climate ………………….........................................194

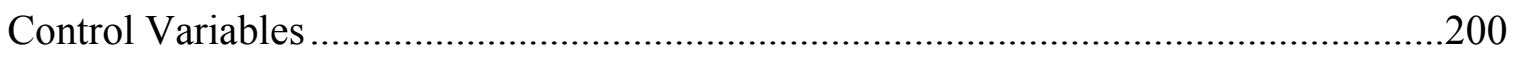

Additional Constructs Included in the Questionnaire ....................................................204

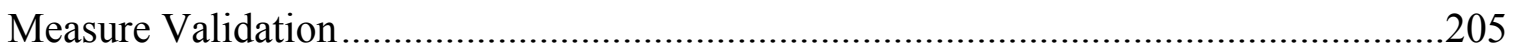

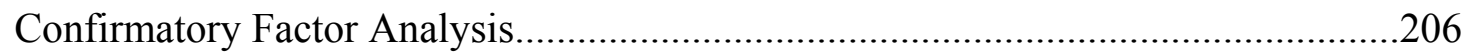

CFA Results - Dyadic Scales Group 1 ............................................................213

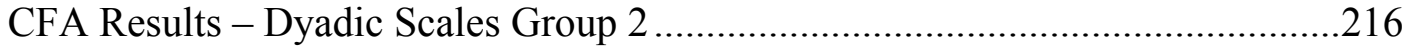

CFA Results - Extra-Dyadic Scales .................................................................222

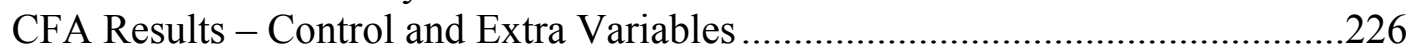

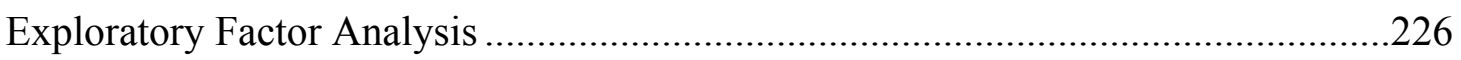

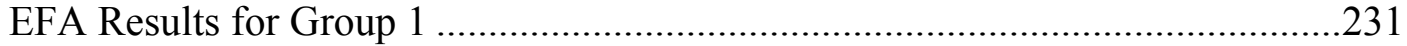

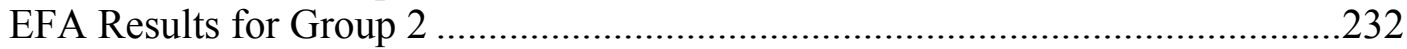

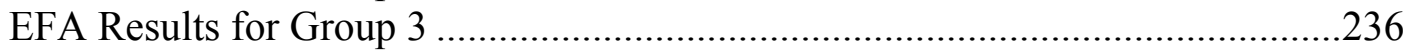




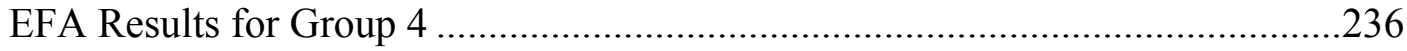

EFA Results for Common Factor (Harman's One Factor Test) .............................239

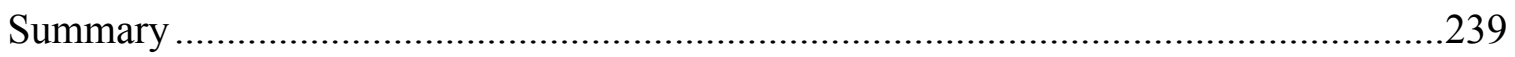

CHAPTER VI: STRUCTURAL MODEL RESULTS …..........................................246

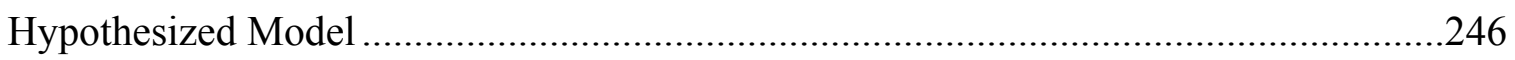

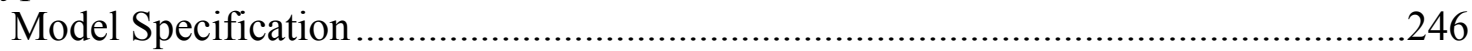

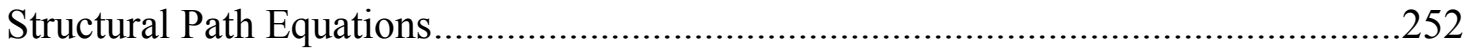

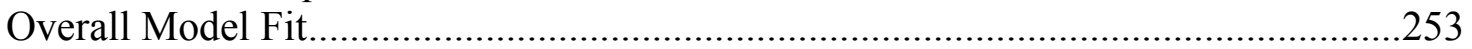

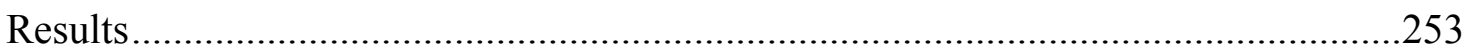

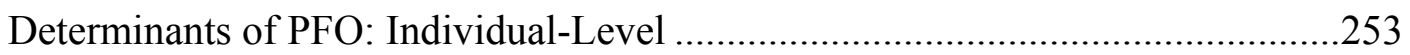

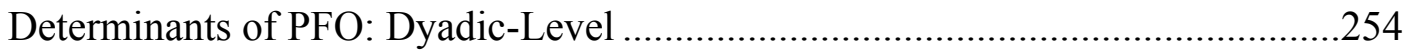

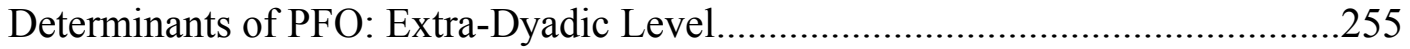

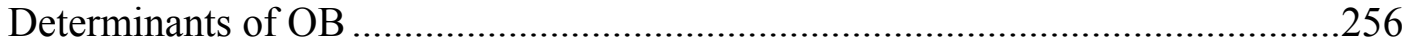

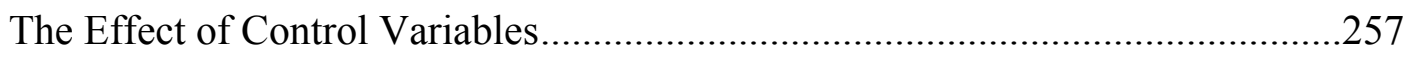

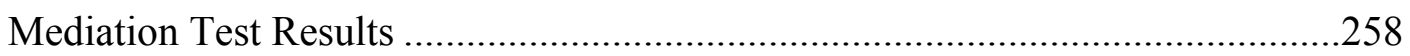

A Comparison with Bootstrapping Results...................................................259

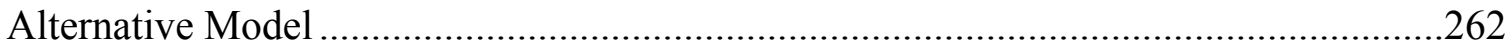

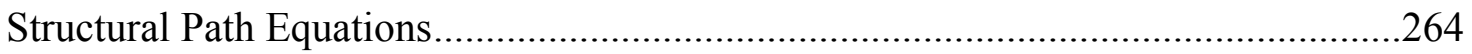

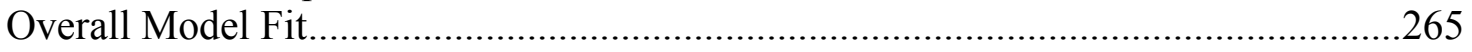

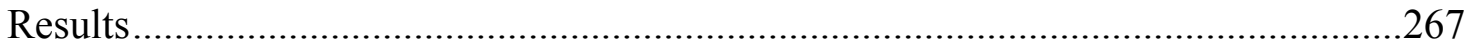

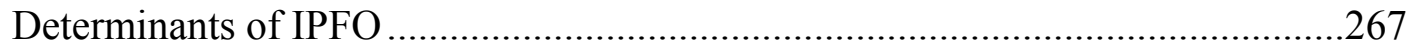

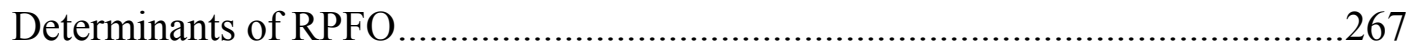

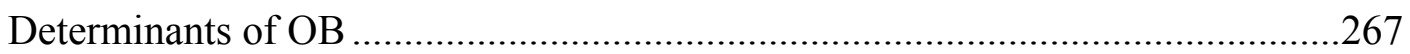

The Effect of Control Variables......................................................................268

Mediation Test Results .........................................................................268

A Comparison with Bootstrapping Results....................................................269

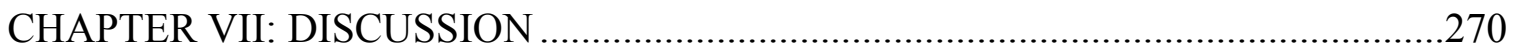

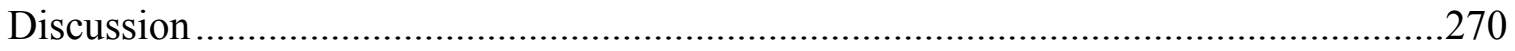

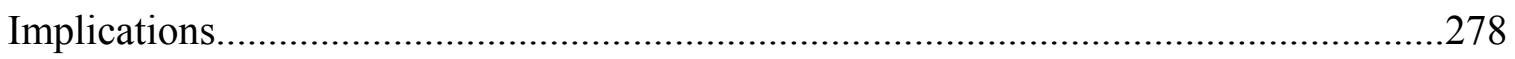

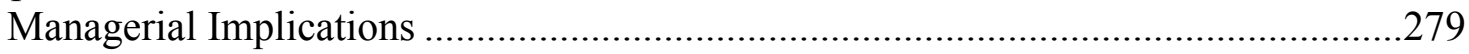

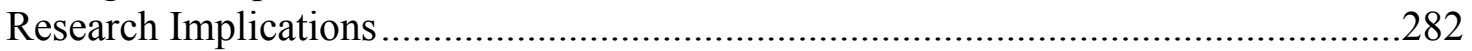

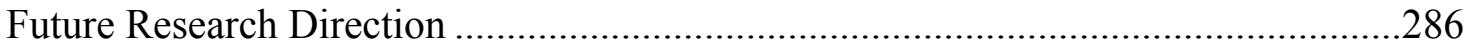

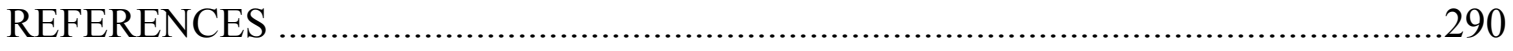


APPENDIX A (survey instrument)

APPENDIX B (summary of scales, their measurement, and descriptives) 


\section{LIST OF TABLES}

Table

Page

Table 2.1: Previous Research on the Determinants of Opportunism.............................14

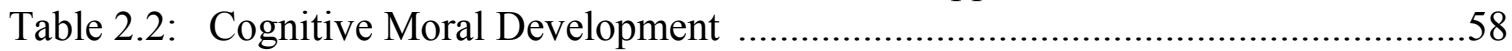

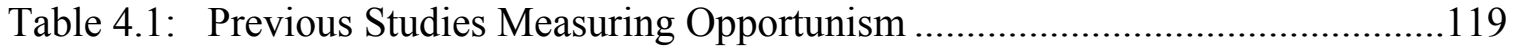

Table 4.2: Taxonomy of Ethical Ideologies.................................................................. 128

Table 4.3: Correlation Among 3-Story \& 2-Story DIT at Virginia Tech .......................133

Table 4.4: Correlation Among 3-Story \& 2-Story DIT at West VA University ...........134

Table 4.5: Measurement Scales, Developer, and Reliability References ......................138

Table 4.6: Non-Response Bias Results Using Time Trends T-Tests...........................150

Table 4.7: Non-Response Bias Results Using Concurrent Waves T-Tests ...................153

Table 4.8: Industry Sector Differences between Mail and In-Person Surveys ...............155

Table 4.9: Non-Response Bias Results Using Concurrent Waves by Location .............158

Table 4.10: Operational Measures: Franchise Unit and Subject Information ................161

Table 4.11: Primary Data Collection by State ............................................................... 164

Table 4.12: Industry Comparison between the Final Sample and the Original Mailing

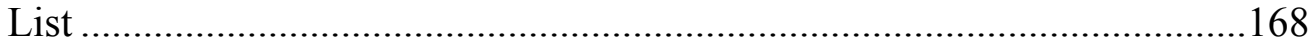

Table 4.13: Industry Comparison between the Final Sample and Nation-Wide Data

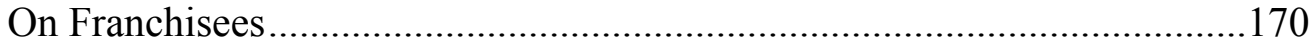

Table 4.14: State-by-State Comparison between the Final Sample and the Original Mailing List.

Table 5.1: Victor and Cullen's Ethical Climate Typology ..........................................198

Table 5.2: Univariate Descriptive Statistics for All Measurement Items ....................207

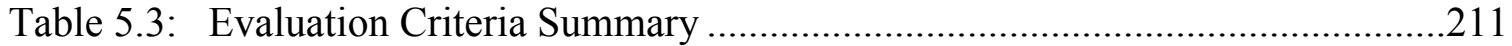

Table 5.4: Measurement Analysis - Dyadic Scales Group 1......................................214

Table 5.5: Discriminant Validity Test Results for Dyadic Group 1 .............................217

Table 5.6: Measurement Analysis - Dyadic Scales Group 2......................................219

Table 5.7: Discriminant Validity Test Results for Dyadic Group 2 ............................221

Table 5.8: Measurement Analysis - Extra-Dyadic Scales........................................223

Table 5.9: Discriminant Validity Test Results for Extra-Dyadic Scales ......................225

Table 5.10: Second-Order factor Analysis for Negative Professional Ethical Climate...229

Table 5.11: Measurement Analysis - Control Variables and Extra Variable (PFO).......230

Table 5.12: Factor Loadings for EFA Group 1 ….........................................................234

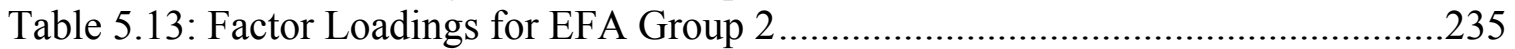

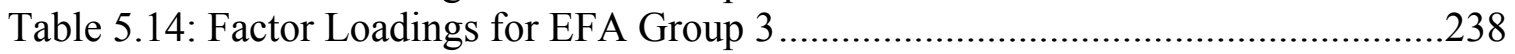

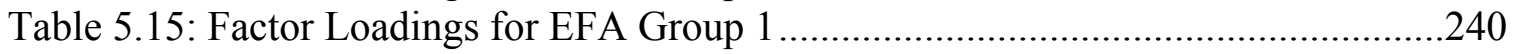

Table 5.16: Inter-Item Correlation between Individualism and Corporate Rules ...........241

Table 5.17: Harman's One Factor Test Results ................................................................242

Table 5.18: Correlation Matrix for All First-Order Scales ............................................245

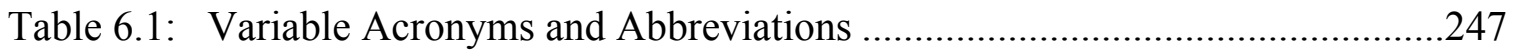

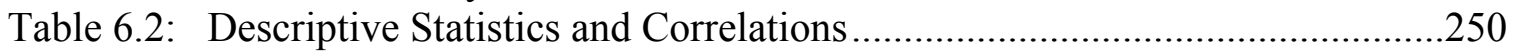

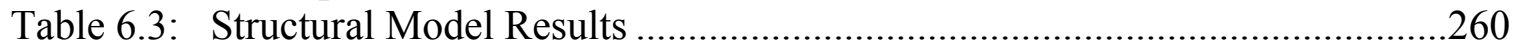

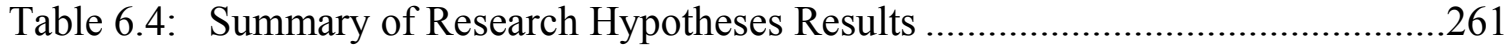

Table 6.5: Structural Model Results - Alternative Model .............................................266 
Figure 3.1: Conceptual Model .81

Figure 4.1: Mean Values Across Ethical Ideology Types .......................................131

Figure 4.2: The Final Sample by Industry Sector ..................................................... 165

Figure 5.1: Measurement Model for Negative Professional Ethical Climate.................228

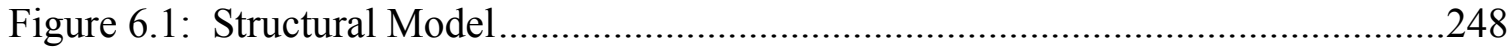

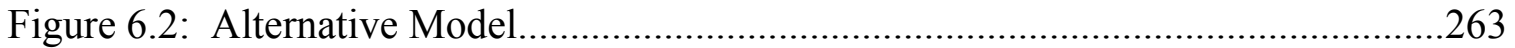




\section{Dedication}

I dedicate this dissertation to my family in Japan. To my parents, Shuzen and Michiko Ishida, who have always set a wonderful example about parenting and provided me unconditional love and support all my life. To Manami Ishida and Satoshi Nomoto, my big sisters, who have always given me the right words of encouragement and sisterly advice. 


\section{Acknowledgments}

The completion of this dissertation would have been impossible if not for the blessings of many people who have helped me along this unexpectedly long journey. I began working on this project in 2003 with my advisor and mentor, Dr. James Brown, who inspired me to pursue this research topic. From the beginning to the end, he always listened to my ideas, helped me clarify my thinking, and the most of all, always guided me in the right direction. He has been my guiding light, and without his wisdom, support, and encouragement through rough times, the dissertation would have never seen the daylight. More than once did I doubt my ability to complete the doctoral program, and I believe wholeheartedly that the journey would have ended prematurely without him.

Dr. Noreen Klein also provided me with a great deal of support that I needed during the long journey. Her insight and selfless dedication to the quality of the project inspired me to always do my best. Together, Dr. Brown and Dr. Klein were not only the co-chairs of my dissertation committee, but also my academic parents, whose devotion to me I cannot thank enough for. I am forever grateful for their setting the highest standard for me, and they will always be my role models. I can only hope that I will touch another student's life the way they touched mine.

I could not have asked for a nicer dissertation committee to work with. Their door was always open, and their professionalism and profound knowledge have greatly contributed to the study. I thank Dr. Janet Keith and Dr. Jay Lambe, whom I have coauthored research papers during and after my time at Virginia Tech. Thanks to their great 
insight, expertise, and patience in working with me I am a better researcher today. Many thanks are owed to Dr. Kent Nakamoto and Dr. Richard Wokutch for their support in completion of this dissertation.

I am also thankful for the members of the Marketing Department, including the fellow graduate students who have provided me with friendship and support. Dr. Stephan Grzeskowiak, in particular, deserves special thanks for helping me with data collection and for always being available for me when I needed advice. All the faculty members and staff have also been very supportive and always willing to help. I feel so fortunate to have made the decision to join the doctoral program at Virginia Tech. In fact, the entire Virginia Tech community deserves many thanks for providing such an excellent environment for learning. I am a better researcher and scholar due to the influence of people with whom I worked and met during my graduate school experience at Virginia Tech.

Finally, I thank the people who had little to do with my research yet who have been the most important part of my personal life. John, my husband-to-be next month, has been my biggest cheerleader who helped me survive the doctoral program. Last but not least, my family members in Japan are incredibly supportive people, and I owe them more than I can ever repay. They will always been the backbone of who I am. 


\section{CHAPTER I}

\section{INTRODUCTION}

\section{Problem Statement}

For over two decades, scholars have studied the management of opportunism in interfirm relationships. Opportunism generally refers to "self-interest seeking with guile" (Williamson 1975, p. 48). As reviewed by Wathne and Heide (2000), opportunism may take an active form (violating explicit or implicit agreements) or a passive form (quality shirking or withholding efforts, evading obligations). Opportunistic behaviors between marketing channel members may result in premature termination of the relationship, or, at the very least, lead to suboptimal relationship outcomes (Parkhe 1993; Pilling, Crosby, and Jackson 1994). Managing opportunism is one of the most critical tasks of marketing channels. To maintain a good, constructive relationship, Gundlach and Murphy (1993) suggest that ethical principles provide a necessary foundation for any transactions including discrete ones, noting that: "Without moral principles to guide conduct, even the simplest of exchanges risks failure" (p. 43). According to Noreen (1987), ethical behaviors are "a necessary lubricant for the functioning of markets" (p. 7).

Past research has widely utilized Transaction Cost Economics (TCE: Williamson $1985 ; 1996)$ as a useful framework for determining the most appropriate governance structure (hierarchy, market, or hybrid) to limit opportunism. Also widely used and related closely to TCE is agency theory (Jensen and Meckling 1976, Jensen 1983), which aims to identify the most efficient contract from the perspective of the principal, or the 
party which delegates specific tasks to the agents. Agency theory has extensively been used in the intrafirm context, mainly in salesforce compensation studies.

While both agency theory and TCE have been the dominant theories used to determine the most efficient form of governance (TCE) or contract (agency theory) given the nature of the potential for opportunism, they have also been criticized for their assumption of opportunism. Both theories assume that firms (or agents), when given the opportunity, may seek to serve their self-interests at the partner firm's (principal's) expense. Though both theories recognize that some firms (or agents) may indeed be trustworthy, the overriding assumption is that it is too difficult to identify a priori who is really trustworthy. Furthermore, the theories implicitly assume that trusting the partner firm (or the agent) is simply naïve and gullible.

Clearly, not all economic actors automatically behave opportunistically, even when given the chance. By adopting the assumption of opportunism, however, we do shield ourselves from potential damages from the relationship. Indeed, this is exactly what TCE prescribes. Ghoshal and Moran (1996) call TCE "bad for practice" because presuming opportunistic nature in the partner firm precludes developing meaningful relationships. Gilbert (1996) similarly calls this phenomenon the "prisoners of the prisoner's dilemma" (p. 165). Dees (1992) points out that attributing all human behavior to self-interest seeking is adopting a worst-case scenario, which could become selffulfilling, possibly because "distrust breeds further distrust” (Yamagishi 2001, p. 139). Similarly, referring to agency theory, Mitnick (1992, p. 76) notes the theory is "a study in Murphy's Law", or what can go wrong will go wrong, and hence we must always assume the worst. 
The relational exchange paradigm parallels this view (Dwyer, Schurr, Oh 1987; Morgan and Hunt 1994; Heide and John 1992). Studies have shown that relational norms effectively deter opportunism (cf. Brown, Dev, and Lee 2000). Assuming the worst in each other clearly is not the solution to opportunism, but research is still lacking in the area to address the issues.

Simon (1955) argues that, rather than focusing on normative decision-making (or how one should behave), economists (and/or statisticians) should instead focus on the discrepancies in decisions caused by perceptual, cognitive, and learning factors. It is interesting to note that both agency theory and TCE provide the frameworks for identifying the optimal contract or governance forms. Incidentally, both Dees (1992) and DeGeorge (1992) assert that agency theory has normative implications when it is used as an aid for decision-making.

Dees (1992, p. 35) describes that agency theory is inherently biased because it (1) treats obligations as one-way (agents to principal); (2) develops excessive distrust and disrespect for agents; (3) overlooks important issues of fairness; and (4) misses solution possibilities that include ethical/social norms. In addition, Kahneman, Knetsch, and Thaler (1986a, p. S299) criticize normative theories (e.g., agency theory, TCE) for their overly simplistic view of human decision making in complex societal contexts. More specifically, they call for the need to modify standard microeconomic models to incorporate norms of fairness. Their series of experiments indicate the prevalence of fairness-seeking behavior in our society despite the normative theories' treatment of fairness as irrelevant, instead favoring the pursuit of economic efficiency (see Kahneman et al. 1986a, 1986b) 
It is no small wonder that empirical studies of TCE and agency theory show discrepancies in their accounts of how firms and employees actually behave. As normative theories, neither TCE nor agency theory provides adequate insights as to when and why opportunism takes place. Moreover, some economic control mechanisms for managing opportunism (i.e., vertical integration and credible commitments in the form of transaction specific investments) have been found to actually increase opportunism in marketing channels (cf. Brown et al. 2000). The literature has also found monitoring to have inadvertent, negative effects (e.g., John 1984; Murry and Heide 1998). Following these normative theories, therefore, firms may inadvertently exacerbate the problem by employing too much control in their quest to avoid being victimized by opportunistic channel partners.

As effectiveness refers to the "degree to which a social system achieves its goals" (Price 1972, p. 101), I point out that control mechanisms are not effective unless they actually deter opportunism. While verifying the partner firm's ability and motivation during relationship initiation can be a proactive strategy (Stump and Heide 1996), what are apparently needed are more fine-grained mechanisms for effectively safeguarding against ex post opportunism, or "behaviors that unilaterally improve the party's term of trade" (Wathne and Heide 2000, p. 39).

\section{Research Significance}

The present research posits that using the dichotomy of trustworthy-untrustworthy to characterize the exchange partner is too simplistic. Rather than automatically assuming 
that channel firms are opportunistic, I argue that they exhibit differing levels of propensity for opportunism (PFO, hereafter).

I pay attention to both $\mathrm{PFO}$ and actual opportunistic behaviors (OB, hereafter). PFO is defined as the extent to which a marketing channel member is inclined to behave opportunistically. I distinguish propensity, or an "intense natural inclination or preference" (Merriam-Webster dictionary), from actual behaviors because (1) propensity reflects desires, which strongly influence intentions (Bagozzi and Edwards 1998), yet (2) individuals do not necessarily act on their desires. According to Vroom's (1964) expectancy theory, the linkage between the desirability of a particular outcome and actual behaviors is influenced by the feasibility of actions, while desires persist over time regardless of feasibility (cf. Perugini and Bagozzi 2004). That is to say, constraints such as economic or social costs may restrain a manager from acting opportunistically; however, s/he may well behave opportunistically if the constraints were to loosen or be removed.

As Koford and Penno (1992) note, while some people are more ethical than others, any individual will be ethical in some situations and not in others. Consider the following descriptions of alternative motives for ethical behaviors from Solomon (1999, p. 117):

1. Rule-bound - thinking and acting on the basis of rules and principles, with only secondary regard to circumstances or possible exceptions;

2. Utilitarian - weighing probable consequences, both to the company or the profession and to the public well-being;

3. Professional - evaluating all decisions first in terms of benefit to the profession, the institution, and the company and its reputation;

4. Loyalist - duties and obligations defined by way of identification with the company or the organization; 
5. Virtuous - every action is measured in terms of its reflection on one's character (or the profession, institution, or company reputation) without immediate regard to consequences and often without paying much attention to general principles;

6. Intuitive - making decisions on the basis of conscience, even without deliberation, argument, or reasons. Intuitive thinkers tend to be impatient with more deliberative deontological and utilitarian types; and

7. Empathetic - following one's feelings of sympathy and compassion. "Putting oneself in the other's place" is the modus operandi of the empathetic style, whether the "other" be a competitor ("How would we like it if he ...") or a client ("I can easily imagine how it would feel to be ...").

Two things can be said about Solomon's conceptualization. First, it highlights and supports the basic notion that social exchange, whether interfirm or interpersonal, is embedded deeply in social structures (Granovetter 1985; Shapiro 1987). Both TCE and agency theory largely ignore such embeddedness of exchange relationships. In recent years, researchers have explored relationalism (Macneil 1980) or relational norms (Heide and John 1992) as an alternative control mechanism that foster efficient exchanges. According to Brewer (1979), one effect of group identification may be that individuals attach greater weight to collective outcomes than they do to individual outcomes alone. Previous research has also shown that TCE's assumption of opportunism has received mixed support (see Rindfleisch and Heide 1997 for review). The importance of the relational norms of exchange has generated strong support, on the other hand (John 1984; Brown et al. 2000; Rokkan, Heide, and Wathne 2003).

Second, examining Solomon's seven alternative reasons more specifically, one can identify different categories by which individuals' ethical behaviors are determined. Rule-bound and utilitarian reasons may easily be described in terms of TCE and agency theory assumptions that individuals are opportunistic and calculative, and explicit contracts and/or monitoring must be exercised to prevent such behaviors. Professional 
and virtuous reasons are related to moral behaviors derived from the professional environment. A Loyalist reason is based on identification (or relationalism) with the exchange partner (or the principal). Intuitive and empathetic reasons are related to individual-specific moral sensitivity.

While the literature on rational economic actor models (i.e., TCE and agency theory) provides some guidance in predicting $\mathrm{OB}$, it is based on the self-interest assumption which has been under criticism for many years. To resolve this issue, this dissertation takes a holistic view and analyzes three levels of PFO and OB: individual, dyadic, and extra-dyadic.

The purpose of this dissertation is to investigate the determinants of PFO and OB at the three levels of embeddedness simultaneously. First, I explore the impact of individual differences in business conduct in terms of moral values and personality traits. Second, I examine the embeddedness of a dyadic relationship structure on a manager's decisions to behave opportunistically. Third, I explore the social embeddedness in the dyadic relationship and the role of the ethical environment and social network in which the dyadic relationship is embedded. After all, dyadic exchange relationships never exist in a vacuum. Directly or indirectly, there are other firms involved in the environment that may have influence over or be affected by the dyad.

Incorporating three levels of analysis of PFO allows the present research to extend the current marketing channel literature by considering both the "bad apples" argument as well as the "bad barrels" argument from the business ethics literature. The "bad apples" argument blames unethical behaviors on particular individuals who lack some personal quality such as moral character (Trevino and Youngblood 1990). The present research is 
the first to examine the individual-specific propensity of opportunistic behaviors within the marketing channel literature. The "bad barrels" argument attributes unethical conduct to the organizational environment that fails to reinforce ethical behavior, or even pressures individuals to behave unethically (Trevino and Youngblood 1990). Again, this dissertation provides a first look at the social environmental influence on dyadic opportunistic behaviors.

By investigating a partner firm's PFO and the feasibility (i.e., economic and social costs) of $\mathrm{OB}$, I intend to contribute to the marketing channel literature in the following ways:

(1) Extend the traditional level of analysis of opportunism from a dyadic focus to encompass individual and extra-dyadic levels;

(2) Offer an alternative, behavioral perspective that can meaningfully inform us as to when and why opportunistic behaviors actually take place in marketing channel relationships; and

(3) Distinguish between PFO and OB (and their determinants), so that we can advise managers as to how they can better safeguard their relationship investments by

(a) Effectively deterring opportunism,

(b) Avoiding unnecessary transaction costs involved with using inappropriate governance mechanisms (e.g., excessive surveillance, overly explicit contracts), and ultimately,

(c) Helping to develop collaborative, mutually beneficial relationships.

\section{Research Questions}

Given the limitations of extant research on opportunism, and to summarize the purpose of this dissertation, the following several important issues are to be investigated:

(1) How do individual differences impact the PFO and OB of an exchange partner? 
(2) How do the quality and the structure of the dyadic relationship influence PFO and OB?

(3) What role does social environment play in reducing or increasing PFO and OB?

(4) To what extent are the explicit control mechanisms (e.g., monitoring) necessary and/or efficient in preventing opportunism?

As noted by Milgrom and Roberts (1992), TCE's assumption of opportunism is "self-interest unconstrained by morality." Rather than uncritically assuming opportunism in the exchange partner, this research will investigate the role individual moral character plays in PFO in a business-to-business context. Consider the following comment of Niccolo Machiavelli over 500 years ago:

"Any person who decides in every situation to act as a good man is bound to be destroyed in the company of so many men who are not good. Wherefore, if the Prince desires to stay in power, he must learn how to be not good, and must avail himself of that ability, or not, as the occasion requires" (quoted in Stevens 1979, p. 49)

Machiavelli believed that personal ethics and professional requirements are simply irreconcilable. Do managers behave according to their moral character, or do they observe other conventions in their business dealings? The answer to this question, especially pertaining to marketing channel relationships, has not yet been uncovered.

This question also is tied to the second one, which considers the degree to which managers follow the rational, economic-man assumption independent of the context. As mentioned previously, the rational-actors are assumed to always take actions that maximize their wealth. The dissertation questions the validity of such an assumption. The marketing channels literature provides plenty of evidence that affect plays an important role in relationship management, such as satisfaction (see Geyskens, Steenkamp, and Kumar 1999 for review), affective commitment (Kim and Frazier 1997; Gilliland and Bello 2002), and perceived fairness (Dwyer et al. 1987; Kumar, Scheer, and Steenkamp 
1995b). While these emotions clearly exist in any social relationship, I question the extent to which they influence channel managers' PFO. If managers strictly follow the rational economic actor assumption, these emotions should play no role in managers' pursuit of their objectives.

Following the social embeddedness literature (Granovetter 1985; Uzzi 1997), it is also suspected that an extra-dyadic professional environment, which reflects the extent of socialization within a particular industry and is based upon membership in professional/industry associations, plays a significant role in PFO and OB. Social network studies have provided evidence that firms within a social network tend to hold shared values (or norms) that determine appropriate business conduct (Macauley 1963; Dore 1983; Asanuma 1985).

Lastly, the results of this research investigating the contributing factors for opportunism should provide an answer to an ultimate question: To what extent are the explicit control mechanisms necessary and/or efficient in preventing opportunism? These control mechanisms are designed and implemented with the assumption that channel managers are rational, guileful and self-interest seeking economic actors. By enhancing our understanding of why channel managers act opportunistically, we will effectively be able to determine efficient levels of safeguarding - both explicit and implicit control measures.

\section{Organization of the Dissertation}

This dissertation is structured as follows. Following this introductory chapter, Chapter Two provides the literature review and conceptual background for examining the 
three levels of analyses of PFO and OB. Chapter Three provides the overall conceptual model, followed by hypotheses that specify the impact of the three levels on PFO and OB. Both Chapter Four and Chapter Five are focused on research methodology: Chapter Four is devoted to the discussion of the research sample and data collection; while Chapter Five focuses on the survey instrument. Chapter Six provides the hypothesis testing results. Finally, Chapter Seven discusses overall contributions of the research, managerial implications and research implications, as well as future research directions. 


\section{CHAPTER II}

\section{LITERATURE REVIEW}

\section{Opportunism Management in Marketing Channels}

Opportunism is one of the most critical issues in marketing channels management. In Wathne and Heide's (2000) extensive review on the forms of opportunism, three are identified: (1) adverse selection, (2) active opportunism, and (3) moral hazard. The problem of adverse selection (Akerlof 1970) occurs when a channel member purposely fails to disclose his/her true attributes to the exchange partner firm before entering the relationship. As a result of a failure to select the most qualifying candidate, the principal likely incurs increased ex post transaction costs due to active opportunism and/or moral hazard. Active opportunism occurs when a party deliberately lies or "misrepresents material facts" (Shell 1991, p. 238). Active opportunism also takes place through an active breach of contract, such that expressly forbidden acts are committed (Rousseau 1995). Lastly, the moral hazard problem involves passive opportunism, that is, one of the exchange parties purposely withholds effort (Griesinger 1990; Masten 1988; Rousseau 1995), or somehow refrains from performing actions that they originally agreed to perform (Goetz and Scott 1981).

Adverse selection is an ex ante opportunism, while active opportunism and moral hazard are ex post opportunism, such that an exchange party "engages in behaviors that unilaterally improve the party's term of trade" (Wathne and Heide 2000, p. 39). More generally speaking, all types of opportunism share the nuance of a "lack of candor or 
honesty in transactions, to include self-interest seeking with guile" (Williamson 1975, p. 9).

Traditionally, marketing channel researchers have mainly focused on governance mechanisms in the dyadic relationship when determining the level of threats of opportunism. Governance mechanisms are those "tools that are used to establish and structure exchange relationships" (Brown et al. 2000, p. 52). The extant research suggests that there are several generic approaches to control potential opportunism; among these are (1) qualification procedures (Heide and John 1990; Stump and Heide 1996), (2) credible commitment (Anderson and Weitz 1992), (3) monitoring (Lal 1990; Stump and Heide 1996), (4) explicit formal contracts (Macneil 1978), and (5) ownership (vertical integration) (Williamson 1975). In addition, recent research also suggests the important role of socialization, or relational norms in managing opportunism (cf. Brown et al. 2000). Table 2.1 summarizes the previous literature investigating the determinants of opportunism. The following subsections discuss each in detail, with exceptions of ownership and formal contracts, which are covered in a later subsection within the framework of Transaction Cost Economics (TCE).

\section{Ex Ante Qualification Procedures}

Rigorous selection efforts, as in Xerox Corporation's supplier certification processes (so-called Xerox Multinational Supplier Quality Survey), represent proactive and effective control mechanisms to ex ante opportunism. A priori screening of high quality exchange partners is said to be the "most straightforward way of managing opportunism" (Wathne and Heide 2000, p. 45). Qualification procedures require 
Table 2.1: Previous Research on Determinants of Opportunism

\begin{tabular}{|c|c|c|c|c|}
\hline Study & Study Context & Predictor Variables & Control variables & $\begin{array}{c}\% \\
\text { variance } \\
\text { explained }\end{array}$ \\
\hline John (1984) & $\begin{array}{l}\text { Oil retail dealers reporting } \\
\text { their degree of opportunistic } \\
\text { behaviors against their } \\
\text { suppliers }\end{array}$ & $\begin{array}{l}\text { Non-contingent influence } \\
\text { attributions } \\
\text { Coercive influence } \\
\text { attributions } \\
\text { Reward influence attributions } \\
\text { Bureaucratic structure } \\
\text { Attitudinal orientation }\end{array}$ & $\mathrm{N} / \mathrm{A}$ & $34.1 \%$ \\
\hline $\begin{array}{l}\text { Provan and Skinner } \\
\text { (1989) }\end{array}$ & $\begin{array}{l}\text { Farm and power equipment } \\
\text { dealers reporting their degree } \\
\text { of opportunistic behaviors } \\
\text { against their primary supplier }\end{array}$ & $\begin{array}{l}\text { Three Dependence variables } \\
\text { (service dependence, number } \\
\text { of suppliers, and availability } \\
\text { of alternatives) } \\
\text { Formalization } \\
\text { Centralization }\end{array}$ & N/A & $16.0 \%$ \\
\hline $\begin{array}{l}\text { Gundlach, Achrol, and } \\
\text { Mentzer (1995) }\end{array}$ & $\begin{array}{l}\text { Experiment (simulation) - } \\
\text { subjects assumed either } \\
\text { manufacturer or distributor } \\
\text { responsibilities in negotiations }\end{array}$ & $\begin{array}{l}\text { Commitment Proportionality } \\
\text { (distributor's commitment to } \\
\text { the relationship minus that of } \\
\text { manufacturer, and vice versa) }\end{array}$ & & $3.2 \%{ }^{1}$ \\
\hline
\end{tabular}

${ }^{1} \mathrm{~F}=1.11(\mathrm{P}>.10) .3 \%$ is the mean across four measurements regression analyses. 


\begin{tabular}{|c|c|c|c|c|}
\hline \multicolumn{5}{|c|}{ Table 2.1 continued. } \\
\hline Ramaswami (1996) & $\begin{array}{l}\text { American Marketing } \\
\text { Association members } \\
\text { reporting their own degree of } \\
\text { opportunistic behaviors within } \\
\text { their firm }\end{array}$ & $\begin{array}{l}\text { Output controls } \\
\text { Process controls } \\
\text { Self control } \\
\text { Role ambiguity } \\
\text { Role conflict } \\
\text { Performance documentation } \\
\text { Procedural knowledge } \\
\text { Supervisory participation } \\
\text { Supervisory knowledge } \\
\text { Supervisory consideration }\end{array}$ & $\begin{array}{l}\text { Age } \\
\text { Gender } \\
\text { Management }\end{array}$ & $26.8 \%$ \\
\hline $\begin{array}{l}\text { Joshi and Arnold } \\
\text { (1997) }\end{array}$ & $\begin{array}{l}\text { Experimental design - } \\
\text { industrial purchasing agents } \\
\text { served as participants }\end{array}$ & Dependence & $\begin{array}{l}\text { Low and high relational } \\
\text { norms (multi-group } \\
\text { analysis) }\end{array}$ & Not reported \\
\hline $\begin{array}{l}\text { Brown, Dev, and Lee } \\
(2000)\end{array}$ & $\begin{array}{l}\text { Hotel general managers } \\
\text { reporting their degree of } \\
\text { opportunistic behaviors } \\
\text { against their brand } \\
\text { headquarter }\end{array}$ & $\begin{array}{l}\text { Transaction specific assets } \\
\text { Relational norms }\end{array}$ & $\begin{array}{l}\text { Hotel chains } \\
\text { Hotel size } \\
\text { Hotel ownership }\end{array}$ & $13.7 \%$ \\
\hline $\begin{array}{l}\text { Ramaswami and Singh } \\
\text { (2003) }\end{array}$ & $\begin{array}{l}\text { Salespeople from Fortune } 500 \\
\text { companies reporting their } \\
\text { degree of opportunistic } \\
\text { behaviors within their firm }\end{array}$ & $\begin{array}{l}\text { Supervisor trust } \\
\text { Job satisfaction } \\
\text { Distributive fairness }\end{array}$ & N/A & $17.0 \%$ \\
\hline $\begin{array}{l}\text { Rokkan, Heide, and } \\
\text { Wathne (2003) }\end{array}$ & $\begin{array}{l}\text { Building materials suppliers' } \\
\text { opportunistic behaviors } \\
\text { investigated. Dyadic data-- } \\
\text { buyer sample reported their } \\
\text { suppliers' opportunism, and } \\
\text { suppliers reported their own } \\
\text { opportunism. }\end{array}$ & $\begin{array}{l}\text { Buyer transaction specific } \\
\text { investments (TSIs) } \\
\text { Extendedness (analogous to } \\
\text { Economies of Continuation) } \\
\text { Solidarity } \\
\text { Buyer TSIs*Extendedness } \\
\text { Buyer TSIs*Solidarity } \\
\end{array}$ & $\begin{array}{l}\text { Relative size } \\
\text { Number of employees } \\
\text { Buyer concentration } \\
\text { Supplier TSIs }\end{array}$ & $\begin{array}{l}10 \% \\
\text { (suppliers' } \\
\text { own OB) } \\
36 \% \\
\text { (buyers' } \\
\text { perceptions of } \\
\text { supplier OB) } \\
\end{array}$ \\
\hline
\end{tabular}


management's ability to identify the best possible partner (Heide and John 1990; Spekman 1988).

In order to avoid being locked in with a problematic partner, Stump and Heide (1996) argue for verifying both ability and motivation during relationship initiation. In addition to evaluating the partner firm's abilities in areas such as product quality, customer service, and delivery performance, Stump and Heide point out that the partner firm's motivation may be assessed a priori on the basis of their willingness to undergo qualification processes as well as to make necessary investments.

While these ex ante control mechanisms represent a partial solution to opportunism, Wathne and Heide (p. 46) caution that opportunism may still prevail even after the screening processes.

\section{Credible Commitment}

Developing interfirm relationships often requires making investments that are specific to the exchange relationship and have little value outside the focal relationship (Williamson 1985, p. 55). These transaction-specific investments (TSIs, hereafter) are used as incentives for maintaining the relationship in order to achieve long-term gains. TSIs take the form of human assets, administrative procedures, tools, capital equipment and other physical assets, and so on. The development of relationship-specific capital results in benefits associated only with the continuation of the relationship (Klein, Crawford, and Alchian 1978). As such, TSIs are frequently referred to as hostages, as the investing firm would suffer a sizeable loss if the relationship terminated prematurely. In 
addition, TSIs are considered credible commitments because they signal the investing firm's commitment to a long-term relationship and because they improve coordination between the firms (Anderson and Weitz 1992; Jap and Ganesan 2000).

While TSIs appear to have a bonding effect on channel members, Ghosh and John 1999, p. 134) call TSIs "valuable but vulnerable" because of the possibility of being expropriated. Some contend that asymmetry in TSIs potentially allow the less invested firm to take advantage of its position in negotiations (Williamson 1985; 1996; Shell 1991; Muris 1981). Empirical studies, however, show weak support for the argument (Gundlach, Achrol, and Mentzer 1995; Rokkan, Heide and Wathne 2003). Joshi and Stump (1999) suggest that boundary conditions exist for the main effect between TSIs and cooperation such as levels of trust and decision uncertainty. Rokkan et al. (2003) show that TSIs can have both bonding and expropriation effects, depending on the levels of expected future transactions. They find that the receiving firm's opportunism increase for lower levels of extendedness (expropriation effect), while the receiving firm exhibit lower levels opportunism under higher levels of extendedness. The findings also included that the threat of expropriation can be mitigated by the presence of a norm of solidarity.

The clearer implication of TSIs is that when reciprocal investment occurs a “mutual reliance relation" may be created (Williamson 1985, p. 190). When transactions are supported by bilateral credible commitments (Anderson and Weitz 1992; Williamson 1985) in the form of TSIs, the threat of opportunism by either party may be mitigated for the other. Jap and Anderson (2003) also suggest that bilateral TSIs are key to achieving high levels of performance and future continuation of relationships. Ahmadjian and Oxley (2006) also observe Japanese automobile assemblers use partial equity stakes to 
make credible commitments to otherwise vulnerable suppliers, while maintaining a notable lack of detailed contracts or formal partnership agreements.

\section{Monitoring}

According to Williamson (1994), the third mechanism, monitoring, compensates for what selection and TSIs cannot cover. According to Ouchi (1979, p. 846), "People must either be able to trust each other or to closely monitor each other if they are to engage in cooperative enterprises." Monitoring is generally defined as any information collection by the principal to ensure contractual responsibilities (Jacobides and Croson 2001; Fama and Jensen 1983). Adler and Borys (1996), focusing on organizational control (i.e., bureaucracy), review two schools of monitoring research: a positive and a negative view. Adler and Borys (1996) posit that enabling (i.e., positive) and coercive (i.e., negative) bureaucratic controls are continuous variables representing two opposite ends of a spectrum, rather than a dichotomy. The negative view sees bureaucratic control as coercive and entailing an abrogation of individual autonomy. Furthermore, as Adler and Borys (1996, p. 62) note, "the centrality of bureaucracy's coercive function is further emphasized by the economists' standard assumption that work is disutility" [Italics

added], and as a consequence, the employees exhibit dissatisfaction and lack motivation. On the other hand, according to the positive view, bureaucratic control can be fulfilling and gives "needed guidance and clarifies responsibilities" (Adler and Borys 1996, p. 61). Adler and Borys cite role stress theory (Kahn et al. 1964; Jackson and Schuler 1985) and reason that the positive consequences are because "formalization reduces role conflict and ambiguity, thereby increasing work satisfaction and reducing feelings of alienation 
and stress" (p. 64). The latter may be the case for Bello and Gilliland (2002), who find positive effects of close behavioral control with foreign distributors.

The predominant take of the marketing channel literature is the negative view, which is consistent with the frameworks of TCE and agency theory. Wathne and Heide's (2000, pp. 43-44) review describes two ways by which monitoring reduces opportunism. First, from a behavioral perspective, the monitoring process itself may place uncomfortable social pressure on a party and thereby increase compliance (Blau and Scott 1962; Murry and Heide 1998). Second, from an economic perspective, monitoring increases the ability to detect opportunism and ultimately the ability to match rewards and sanctions to the partner's behavior in an appropriate fashion.

Monitoring efforts may be undermined by such factors as measurement imperfection and low task programmability (Eisenhardt 1985). If the principal had access to perfect information about the agent's behaviors, then there would be no incidents of moral hazard (Holmstrom 1979, 1982; Holmstrom and Tirole 1989). Low task programmability can explain the inability to identify and specify a particular observable measure for monitoring (Baker 1992; Barzel 1982). Kidwell and Bennett (1993) suggest that the difficulty of monitoring a particular employee in a group setting may derive from several factors: (1) group size, (2) task interdependence, and (3) individual task invisibility.

Similarly, the extensive review by Jacobides and Croson (2001) narrows down four factors that impact the extent of monitoring efficiency: (1) measurement imperfection, (2) multiple tasks in agency relations, (3) ex ante causal ambiguity, and (4) latent economies of continuation. First, traditional agency theory suggests that 
measurement imperfection is due to "noise" in the gathered data. The recent literature suggests other aspects of measurement imperfection. For one thing, quantifiable measures are inherently imperfect indicators of the underlying value creation process (Kerr 1975; Meyer 2000). There is also the possibility of the agent manipulating the system, such that the agent may produce high scores on the indicators measured by the monitoring at the expense of other value-creating efforts that are not monitored. The political economy literature also suggests that agents face choices between self-serving efforts and cooperative ones (Lazear 1989; Milgrom and Roberts 1989). That is, the agent is free to disclose only the kind of information that serves his/her self-interests to the principal. The agent may, then, withhold other, vital information at the expense of the principal who could use the information to enhance the operations. Holmstrom and Milgrom (1987) show that tying pay to firm performance will make it more likely that executives will search for ways to smooth firm performance and thereby reduce the risk to their annual levels of pay.

Second, multiple tasks in agency relationships reflect the extent to which the agent's effort to create superior value for the relationship can be attributed to many tasks, yet only some of which can be measured quantitatively. Such ability to collect only partial crucial information leads to a distorted picture of the agent's total efforts. In industrial sales context, Anderson (1988) shows that such difficulty in evaluating performance by limitedly available information can increase salespeople's opportunistic behaviors.

The third factor contributing to inefficiency in monitoring is ex ante causal ambiguity (Thompson 1967), which occurs as the principal is unaware of the specific 
agent actions that add value beforehand. In turn, ex ante causal ambiguity, or task programmability, may have the principal committed to a particular scheme of measuring performance before learning of a more appropriate measure.

The fourth factor, latent economies of continuation, or the "shadow of the future" (Heide and Miner 1992), refers to the agent's expectation of multi-period contracting. Unlike the preceding three factors which have negative impacts on monitoring efforts, economies of continuation are associated with improving agents' cooperation, and hence less need for monitoring. Klein and Leffler (1981) suggest that the agent's expected future benefits from continuing the relationship may be enough incentive to deter shirking. Multi-period exchange also allows for more incomplete contracting than transactional exchange (Williamson 1975).

Previous studies have shown that agents engage in cooperative behaviors when they anticipate extended future exchange (Heide and Miner 1992; Dyer 1996; Dal Bo 2005). Particularly, Heide and Miner (1992) suggest four specific domains of cooperative behaviors to reflect agents' cooperative behaviors under high expectation of future exchange: flexibility, information exchange, shared problem solving, and restraining the use of power. Jacobides and Croson (2001) summarize that such cooperation offsets problematic measures in monitoring, in turn substituting for strict monitoring (Barney and Hansen 1994; Kreps 1990). Because monitoring is less needed under high expectations of continuing exchange, it can be said that more monitoring does not improve principals' payoffs.

In addition to these studies identifying monitoring efficiency, the overall literature concerning monitoring is extensive. A majority of researchers have paid attention to the 
determinants of monitoring intensity (Van de Ven and Walker 1984; Lal 1990; Agrawal and Lal 1995; Zajac and Westphal 1994; McAlister 1995; Stump and Heide 1996; Dahlstrom and Nygaard 1999; O’Donnell 2000; Gomez-Mejia, Nunez-Nickel, and Gutierrez 2001). For example, in the franchising context, Agrawal and Lal (1995) and Lal (1990) find that increases in royalty rates positively affect monitoring frequency. According to Lal (1990), royalty rate and monitoring are highly correlated because of the potential "free-rider problem." Lal describes that for the agent, an increase in royalty rates means fewer payoffs and therefore less of an incentive to invest in service. A franchisee can then "free-ride" on other franchisees who invest in good services and enhance the franchise's brand name, which in turn creates demand even for the freeriding franchisees. The suspecting principal who wishes to maintain its brand equity, as a consequence, increases monitoring efforts. Agrawal and Lal (1995) extend Lal's model by incorporating heterogeneity in monitoring costs among franchisees. The results again show that the increased royalty rate and the agent's service level are negatively related.

The literature also shows that monitoring can exacerbate the problem of opportunism (John 1984; Murry and Heide 1998). According to John (1984), bureaucratic structuring leads to "an erosion of positive attitudes" (p. 287). Perrow (1986) describes monitoring as an inescapably obtrusive management approach in nature. Following Perrow (1986), Murry and Heide (1998) empirically support this idea and show that monitoring efforts discourage retailers from participating in display programs. Provan and Skinner (1989) also show that suppliers' control over their dealers' decisions, centralization in particular, induces dealer opportunism. Deci and Ryan (1987) suggest 
that monitoring produces feelings of increased pressure and tension, decreased productivity, decreased positive emotions, and lower self-esteem in employees.

In the context of executives-boards relationships, Zajac and Westpal (1994) caution that maximizing monitoring efforts may have adverse effects due to motivational considerations such as lack of autonomy. Similarly, Cowen and Glazer (1996) caution that increased monitoring can inadvertently induce less effort when the monitored party places too much emphasis on monitored behaviors and neglects other valuable efforts that can significantly enhance dyadic wealth. Jacobides and Croson (2001) argue that increased efforts in monitoring may "destroy social welfare even as they add to principal welfare" (p. 206).

These negative consequences of monitoring can be explained from several theoretical perspectives. Reactance theory (Brehm 1966) can, for example, directly explain the motivation behind the negative reactions to monitoring. As a consequence of a party's authoritarian behaviors (e.g., monitoring) on another, according to reactance theory, the other party's perceived threat of constraints on autonomy increases, which could lead to motivation to engage in behaviors that undermine these constraints. Previous studies are generally in agreement with the negative reactions to authoritarian behaviors, such that the use of power by less dependent party on more dependent party is positively related to non-functional conflicts and dissatisfaction (Frazier, Gill, and Kale 1989; Anderson and Narus 1990). However, the literature lacks empirical evidence showing the direct link between perceived threats on autonomy and reactance, opportunistic behaviors. 
The concept of "zone of indifference" (Barnard 1938) ${ }^{2}$ also directly relates to the negative effects of monitoring. Zone of indifference refers to the amount of authority the agent is willing to grant to the principal. Wathne and Heide (2000), from their extensive review, note that monitoring may require that a certain "zone of indifference" exist within which monitoring is accepted. Barnard (1938) proposes that the principal is successful in gaining the agent's cooperation when the agent's zone of indifference operates in such a way that "many orders are accepted by the individual without conscious questioning" (p. 167) of them. Barnard notes that a person will accept a communication as authoritative when the following conditions simultaneously exist:

1) The agent can and does understand the communication;

2) The agent believes that it is not inconsistent with the purpose of the agency relationship;

3) The agent believes it to be compatible with his personal interest as a whole; and

4) The agent is able mentally and physically to comply with it

Simon (1947), extending Barnard's notion of zone of indifference, renames it "zone of acceptance." The key idea of Simon's take on the revised conceptualization is that the agent may "accept" an order coming from the principal as the agent internalizes the objectives of the agency relationship and realizes that the order is consistent with his/her objectives. Simon explicitly discusses the internalization with the concept of loyalty. In the organizational context, once internalization takes place, the agent thinks in terms of "what is good for the firm," rather than "what is good for him/her." If monitoring is conducted within the zone of acceptance, it seems likely that negative

\footnotetext{
${ }^{2}$ The book, The Functions of the Executive, is one of the most influential management book of the $20^{\text {th }}$ century (Bedeian and Wren 2001)
} 
consequences of monitoring may be avoided altogether, and it may even have positive outcomes.

More specifically and descriptively, Frey (1993) suggests that monitoring can either successfully preempt and/or prevent opportunistic behaviors (“disciplining effects") or negative effects ("crowding out effects"). Crowding out effects highlight the role of an implicit psychological contract (Robinson 1996) which is broken by monitoring and hence reduces agents' overall work effort. Frey notes (pp. 664-665):

“...the agent may perceive more intensive monitoring by the principal as an indication of distrust, or as a unilateral break of the contract built on mutual trust. As a consequence, the agent affected sees no reason why he or she should not behave in an opportunistic way ... this will maximize his or her utility by exploiting all possibilities for profitable shirking to the full ... increased monitoring raises the marginal utility from shirking as the agent's "bad conscience" is absolved by the breakdown of trust with the principal."

Furthermore, from his review in the social psychology literature (e.g., Deci and Ryan 1985), Frey (1993) points out that the following two conditions crowd out work effort (Frey 1993, p. 665):

1. When an agent affected feels that the extent of self-determination is unduly restricted by the principal. In that case, the agent rationally substitutes intrinsic for extrinsic control.

2. When the principal's control reduces the agent's self-evaluation. Monitoring which indicates that the principal is convinced that the agent is unable or unwilling to fulfill the assigned task to the principal's satisfaction tends to reduce the agent's intrinsic motivation.

In sum, crowding out effect refers to "how far the agent's self-determination and self-evaluation are affected by the principal's monitoring activities" (Frey 1993, p. 665). This effect is supported by cognitive psychology research. "Hidden costs of reward" 
(McGraw 1978; Deci and Ryan 1985), for example, describes that the intrinsic reason (or motivation) for doing the right thing is crowded out when individuals are extrinsically rewarded for a task that they are ready to undertake for its own sake. Similarly, following social exchange theory (Homans 1961; Blau 1964), the violation of the norm of reciprocity (Gouldner 1960) reduces perceived benefits from a given exchange, such that their marginal benefit from work efforts decreases.

\section{Relational Norms}

A recent development of relational norms perspective emphasizes the importance of "socialization" (Wathne and Heide 2000) and relationalism (Macneil 1980) or relational norms (Heide and John 1992). The role of relational norms, as Heide and John (1992) describe, is "[to prescribe] behaviors directed toward maintaining the system or relationship as a whole and curtailing behavior promoting the goals of the individual parties" (p. 35), thereby safeguarding against opportunism. The results in Aulakh, Kotabe, and Sahay's (2006) study suggest such form of trust derives from the use of social control, whereby shared beliefs in the focal firm's management philosophy is instilled in the relationship.

Barney and Hansen (1994) call it "strong-form trust," by which trustworthy behavior emerges in response to sets of principles and standards that guide the behavior

of exchange partners. Cost-benefit analyses of behaving or not behaving opportunistically (i.e., "semi-strong trust" by Barney and Hansen 1994) have little significance because channel managers value solidarity of the relationship with mutual respect. 
Empirical investigations have been supportive of this mechanism. For example, John's (1984) study, while based on the TCE framework, highlights the importance of "social contract" in maintaining efficient exchange in long-term relationships that are vulnerable to opportunism. The results of his study find that franchisee opportunism is positively related to their perceptions that the franchisor employs a bureaucratic mode of governance. More recently, Rokkan et al. (2003) examine the extent to which the opportunism potential manifests itself in the form of actual opportunism. They find that a strong norm of solidarity decreased the TSI receiver's opportunism, while a relationship characterized by a weak solidarity norm promoted opportunism. Brown et al. (2007) also show that mutual perceptions of relational norms effectively control opportunism.

In addition, efforts have been made to examine the relative effectiveness of various control mechanisms to limit opportunism. For example, Brown et al. (2000) investigate simultaneously the impact of (1) ownership, (2) TSIs, and (3) relational norms on opportunism. The results show support for relational exchange, while ownership and investments, when used alone, did not effectively limit opportunism. Brown et al. (2007) also found that TSIs were actually positively related to opportunism. In hotel brand headquarter-hotel relationships, they also showed that ownership restricted hotel managers' opportunism under two conditions: (1) when the brand headquarters could easily monitor the hotel's activities and outcomes and (2) when opportunism was reciprocated by the brand headquarter.

Other studies have further provided support for the notion that control mechanisms' effectiveness are complex and contingent on other factors. Jap and Anderson (2003) have shown that, under higher levels of opportunism, goal congruence 
becomes a more powerful safeguard than interpersonal trust. In Cavusgil, Deligonul, and Zhang's (2004) study, which compared the roles of trust (both partner credibility and benevolence) and formal contracts on opportunism under low and high legal hostility conditions in the environment. When legal hostility was high, trust was negatively related to opportunism under both low and high legal hostility. Formal contracts had a negative relationship with opportunism only under low legal hostility, while it was positively related to opportunism under high legal hostility. Carson, Madhok, and Wu (2006) also show that cooperative relationships manifested in mutual trust effectively deterred opportunism with or without formal contracts.

\section{$\underline{\text { Summary and Implications for Opportunism }}$}

Even though the literature suggests that relational norms are a powerful and effective control mechanism against opportunism, they must be developed over time with mutually cooperative behaviors requiring high levels of trust and commitment from both firms. In other words, partnering firms that are relatively new in the relationship cannot immediately employ relational norms as a chief control mechanism. Firms must therefore employ other control mechanisms, such as monitoring and credible commitment (TSIs).

These explicit control mechanisms are employed based on the assumption of selfinterest seeking, opportunistic individuals. They operate under the assumption of "semistrong trust" (Barney and Hansen 1994), which emerges when rational actors find it in their best interest not to behave opportunistically or in other words, when the benefits of not behaving opportunistically outweigh the benefits of behaving opportunistically.

As reviewed in this section, the extant literature generally suggests that monitoring has inadvertent consequences. Even though the intent of monitoring is to 
discourage opportunistic behaviors, it can also exacerbate the problem. If monitoring is unnecessarily and excessively used, it can have unintended adverse effects, such as reduced trust and increases in negative attitudes toward the principal. The literature seems scattered and lacks consensus about the role of monitoring in interfirm relationships and guidance as to the appropriate use of monitoring.

In addition, it seems clear that the traditional notion of "economic actors" is too naïve. In long-term, highly committed relationships, managers are often willing to sacrifice short-term costs in hopes of gaining uncertain benefits from cooperative relationships in the future (Ganesan 1994). As a result of repetitive cooperative behaviors, relationships gain more efficiency beyond what would be possible with transactional exchange. Relational norms, once established, allow exchange partners to share proprietary information (Heide and John 1992; Anderson and Weitz 1992; Cannon and Perrault 1999; Day 2000), share burdens of exchange (Macneil 1980; Dwyer, Schurr, and Oh 1987), and make more flexible adjustments to future contingencies (Macneil 1980) and environmental uncertainty (Noordewier, John, and Nevin 1990; Buchanan 1992; Jap 1999; Eisenhardt and Schoonhoven 1996), all because channel members are not preoccupied with the threat of opportunism.

\section{Theoretical Frameworks for Opportunism}

As mentioned previously, traditional opportunism studies have utilized TCE and agency theory frameworks. The following sections review these research frameworks. Also reviewed is the organizational justice literature, which takes a significantly different perspective from the economic theories. Organizational justice studies have not explicitly 
been used in interfirm opportunism research. Nonetheless, I believe that they have tremendous implications for the present research.

\section{Agency Theory}

Agency theory has been used for several decades by scholars in many fields, including accounting, economics, finance, marketing, and organizational behavior. The theory is concerned with an agency relationship in which one party (the principal) depends on another party (the agent) to perform some action on the principal's behalf (Bergen, Dutta, and Walker 1992). The aim of the theory is to determine the most efficient contract governing the principal-agent relationship (Eisenhardt 1989). The theory is based on the assumptions as follow:

- Human assumptions (i.e., self-interest, risk aversion);

- Information asymmetry due to incomplete information obtained by the principal; and

- Information as a purchasable commodity.

First, agency theory assumes individuals are utility-seeking in nature, and they look for ways to minimize costs while maximizing gains. For agents, "effort is a disutility. . . but it has a value to the principal in the sense that increases the likelihood of a favorable outcome" (Arrow 1985, p. 38). The theory posits that an agent chooses an action from a number of alternatives that can maximize his/her own wealth.

Second, the theory also posits that people are risk averse and the principal and agent differ in their degrees of risk preferences. Eisenhardt (1989, p. 61) describes that the issue of risk arises with outcome uncertainty arising from external influences such as government policies, economic climate, competitor actions, and customer preferences; all 
of which influence uncontrollable variations in the agent's outcome performance. Such risk is borne by the agent, and as the uncertainty increases, more risk is shifted to the agent. Such risk-minimizing tendency of agents is observed by Sarin and Mahajan (2001).

In addition to these human assumptions, agency theory assumes information asymmetry between the principal and the agent. First, the principal does not have perfect information ex ante about whether a particular agent has desired qualifications. Second, the theory assumes that the agent has informational advantage over the principal because the principal does not have perfect information about the agent's activities. However, the theory also suggests that the principal may purchase information as to the extent of the agent's adherence to the contractual obligations by means of monitoring.

Collectively, these assumptions in turn give rise to two essential agency problems: adverse selection and moral hazard. First, adverse selection (Akerloff 1970; Spence 1973; Kreps 1990), or "hidden information" (Arrow 1985) is a pre-contractual agency problem. This problem occurs when the agent misrepresents their true abilities and the principal is unable to verify the true character of the agent to perform the desired action due to unavailability of perfect information. Second, the post-contractual agency problem is termed moral hazard (Hart and Holstrom 1987), or "hidden action" (Arrow 1985). The problems arise when the agent does not perform actions the principal desires due to goal incongruence, differences in risk preferences, or environmental uncertainty.

For hidden information problems, agency theory provides solutions such as screening and "signal" (Spence 1973) detections (see Bergen et al. 1992). Extensive screening processes include an information gathering strategy to determine the nature of 
the agent's character. At the same time, the agent may present signals to the principal that $\mathrm{s} /$ he possess desirable attributes such as a high level of motivation and commitment, as well as capabilities to perform well. Cowen and Glazer (1996) caution, however, that some agents may abuse signaling to their advantage to mask their true nature.

For hidden action problems, agency theory presents two solutions: monitoring and providing incentives. Monitoring provides the principal with performance-related information (i.e., agents' inputs) in addition to the outcomes, and it allows the principal to better understand the input-output relation (Anderson and Oliver 1987). It is designed to reduce information asymmetry in principal-agent dyads to limit the aberrant activities of the agent, thereby constraining the agent's opportunity to "shirk" (Fama 1980; Fama and Jensen 1983). As Cowen and Glazer (1996, p. 113) put it, "Common wisdom in the economics literature suggests that the less the principal knows about the activities of his agents, the more agents will shirk."

However, agency theory recognizes that monitoring as a sole solution to opportunism is limited because of the imperfect nature of information available to the principal. The main problem arises as task programmability (Ouchi 1979; Eisenhardt 1985), or the extent to which the agent's appropriate behavior can be specified in advance. Eisenhardt (1989, p. 62) gives an example of a retail sales cashier, whose job can relatively easily be programmed. Agents engaged in more programmed jobs are easier to observe and evaluate; hence, behavior-based contracts (e.g., hourly wages) become more attractive than outcome-based ones (e.g., commission pay). For jobs that are low in task programmability, behavior-based information becomes too costly (i.e., too difficult to measure) to adopt. In addition, environmental uncertainty increases the 
complexity of the agent's tasks. Celly and Frazier (1996) show that suppliers are more likely to use behavior-based control when environmental uncertainty is high.

Besides monitoring, another solution to opportunism is providing agents with incentives to perform according to the desire of the principal (Ross 1973; Jensen and Meckling 1976; Holstrom 1979; Grossman and Hart 1983). Based on the assumption of self-interest seeking nature of agents, the theory posits an agent refrains from opportunistic behaviors as long as s/he receives incentives to do so. Telser (1980) notes, “... one of the strongest incentives for honesty of a seller is his desire to obtain the continued patronage of his customer" (p. 28) and that "someone is honest only if honesty, or the appearance of honesty, pays more than dishonesty" (p. 29). The extant research offers strong support for economic incentive alignment as a self-enforcing mechanism (Jeuland and Shugan 1983; Kleindorfer and Sertel 1979; Tosi, Katz, and Gomez-Mejia 1997; Wong, Tjosvold, and Yu 2005). Barthélemy and Quélin's (2006) study also suggest, to deter opportunism, contracts must provide incentives and penalties, as well as monitoring clauses. Recent studies also indicate that the positive effects are contingent on the external environment, such as intensity of competition (Banker et al. 1996). Zajac and Westpal (1994) note that firm- and industry-specific contingencies interact with the effectiveness of incentives.

The extant research also suggests that the two forms of control (behavior- and outcome-based) are substitutes for each other (Conlon and Parks 1990; Eisenhardt 1985). More specifically, the potential for output improvement from implementing outcomebased incentives is lower when there already is a high level of behavior-based control in place. Empirical studies seem to support this idea (e.g., Banker et al. 1996). Milgrom and 
Roberts (1992) also suggest that, behavior- and outcome-based control complement each other because "undertaking either activity makes the other more [effective]" (p. 227). At the same time, some studies suggest that both behavior- and outcome-based controls cause employees to behave dysfunctionally, in terms of manipulating and reporting invalid data, and working against the organizational goals (Jaworski 1988; Jaworski and MacInnis 1989; Ramaswami 1996).

\section{$\underline{\text { Summary and Implications for Opportunism }}$}

Agency theory predicts that monitoring inefficiency and lack of incentives are the two main reasons for moral hazard. As for the adverse selection problem, the theory recognizes that some firms are more trustworthy than others (i.e., low propensity for opportunism, or PFO), and there are some practical solutions such as screening and certification processes (see Bergen et al. 1992). The theory does not, however, tell us about why different levels of PFO among agents exist. The overriding assumption of agency theory is that principals must automatically assume self-interest seeking nature in agents, and that only monitoring and outcome incentives can induce desired behaviors. I question the assumption as it can lead to detrimental effects.

\section{Transaction Cost Economics (TCE)}

While agency theory emphasizes contractual designs to promote cooperative behavior (on behalf of the principal), as Masten (1988) notes, TCE "focuses on the frictions that prevent cooperation from being achieved in the first place" (p. 181). 
Transaction costs analysis derives from Coase's (1937) observation that coordinating and costs must be considered explicitly to understand why some transactions occur within a firm and others occur between firms, thereby giving rise to the conceptualization of governance structures and transaction costs. The elaborated framework of Transaction Cost Economics (TCE) was developed by Williamson (1975).

Based on Coase's (1937) work, Williamson (1975) asserted that firms organize their exchange relationships to minimize transaction costs that arise when it is difficult to value the goods or services exchanged. He originally conceived of two mechanisms: markets (transactions are governed through competitive pressures that assure that the qualitative and quantitative value of a good or service being exchanged is accurately reflected in its price) and hierarchies (i.e., vertical integration). A decade later he added intermediate forms of organization, or hybrids, which include "various forms of longterm contracting, reciprocal trading, regulation, franchising, and the like" (Williamson, 1996, p. 104) that are more elastic than hierarchy and more legalistic than market.

Traditionally, TCE has provided a theoretical framework for determining the level of risk of opportunism by analyzing asset specificity, as well as environmental and behavioral uncertainty. Asset specificity concerns the level of transaction-specific investments, or the financial and/or human investments made specifically for the relationship. A high level of asset specificity represents "sunk costs that have little value outside of a particular exchange relationship" (Rindfleisch and Heide 1997, p. 41). The firm making relationship-specific investments that cannot be redeployed to alternative uses must safeguard their investments by assuring relationship continuity. 
Both environmental and behavioral (or the agent's performance) uncertainty lead to incomplete contracts which cannot specify ex ante all future contingencies due to the manager's limited capabilities in analyzing complex problems and measuring the agent's performance. Williamson refers to this problem as deriving from bounded rationality (Simon 1957), such that "all complex problems are unavoidably incomplete contracts" (Willliamson 1996, p. 37). Because of their incomplete nature, contracts serve as a safeguarding mechanism mitigating ex post opportunism only limitedly, such that asset specificity may expose the investing firm's TSIs to expropriation hazards by the exchange partner. As exchange hazards rise so must contractual safeguards (Williamson, 1985; Klein, Crawford, and Alchian, 1978). Williamson $(1985,1996)$ prescribes that the problem can be mitigated by reciprocations in TSIs; that is, bilateral hostage situations in which neither party benefits by leaving the exchange relationship prematurely. In addition to the incomplete nature of contracts, Klein (1996) also suggests detailing all potential contingencies and articulating clauses cost too much time and negotiation costs.

The extant literature offer mixed support for the TCE's take on formal contractual agreements, or explicit, written statements of obligations to perform particular actions in a business exchange. Some studies have shown formal contracts indeed reduce opportunism (e.g., Joskow 1988; Heide 1994), while others have shown their conditional effects. For example, Wuyts and Geyskens' (2005) study indicates that detailed contracts effectively deter opportunism when (1) involved with an exchange partner with no prior relationships and (2) when the exchange relationship is embedded in a network of close mutual contacts. At the same time, previous studies have also suggested that explicit contracts signal distrust to the exchange partner (e.g., Ring and Van de Ven 1994; Goshal 
and Moran 1996; Jap and Ganesan 2000). Brown et al. (2006) also show explicit contracts were related positively with conflict. Yet, Poppo and Zenger (2002) show that formal contracts compliments close, relational exchange in terms of their performance.

The TCE framework explicitly considers "efficiency" as the criterion for adopting alternative governance mechanisms. The theory posits that relationship outcomes are optimal when there is congruence between the governance structure and the underlying dimensions of exchange. Basically, if the costs of performance evaluation and safeguarding are absent or low, coupled with low levels of asset specificity, a market governance form is preferred over hierarchy. As these factors rise costs, firms adopt increasingly hierarchical forms of governance (i.e., vertical integration). Williamson (1996, p. 5) notes, “. . . the measurement of transaction costs poses formidable difficulties. These difficulties are significantly relieved by looking at the issue of governance comparatively, so the costs of one mode of governance are always examined in relation to alternative feasible modes." In hybrid governance form, White and Lui (2005) show empirical evidence for increased transaction costs of both cooperation and control as both task complexity and interpartner diversity increase. In market governance form, Anderson and Dekker (2005) similarly provide support for increased transaction costs, including extensive contracts, when the relationship characteristics are associated with hazards.

Bounded rationality and opportunism represent the two behavioral assumptions of TCE. On bounded rationality, TCE assumes that it is too difficult to identify a priori trustworthy firms from non-trustworthy. In addition, environmental and behavioral uncertainty makes it impossible to construct contracts that specify all contingencies that 
may give rise to opportunistic behaviors. As for opportunism, TCE assumes people are motivated only by their self-interests, and they will act in a "calculative effort to mislead, distort, disguise, obfuscate or otherwise confuse" (Williamson 1985, p. 47) whenever possible. In sum, based on these assumptions, the appropriate selection of governance forms is based on the presumed levels of potential for opportunism.

TCE has been widely used to investigate a broad range of marketing channel exchange issues. Specifically, these studies can be classified within one of four main contextual domains: (1) vertical integration, (2) vertical interorganizatioal relationships, (3) horizontal interorganizational relationship, and (4) tests of TCE's assumptions (see Rindfleisch and Heide 1997 for review).

Vertical integration studies most typically focus on a manufacturer's decision to backward integrate into the supply of materials or forward integrate into distribution and sales. TCE's claim that firms employ vertical integration as a means to counter performance measurement difficulty is broadly supported (e.g., Gatignon and Anderson 1988; John and Weitz 1988; Anderson 1985). Anderson and colleagues (Anderson 1985; Anderson and Schumittlein 1984; Weiss and Anderson 1992) use the TCE framework and support the tenet that high levels of behavioral and environmental uncertainty lead to the selection of in-house versus independent sales forces (manufacturer's representatives). John and Weitz (1988) also find that both environmental and behavioral uncertainty are positively related to manufacturer's use of vertically integrating distribution.

Asset specificity has also received wide support for vertical integration (e.g., Klein, Frazier, and Roth 1990; Levy 1985; Maltz 1994; Masten, Meehan, and Snyder 
1991; Monteverde and Teece 1982). As for environmental uncertainty, though in general, TCE has received mixed support (cf. Rindfleisch and Heide 1997). While a few studies do find that environmental uncertainty is positively associated with vertical integration (e.g., John and Weitz 1988; Levy 1985; Masten 1994), a greater number of studies have shown that environmental uncertainty either has no direct impact on vertical integration (e.g., Anderson and Schmittlein 1984; Maltz 1994) or even acts as a disincentive to integration (e.g., Klein et al. 1990). Others also conclude that environmental uncertainty's influence on vertical integration may only be significant through its interaction with other decision factors such as asset specificity (Anderson 1985).

Vertical interorganizational relationships studies focus on management of governance problems in market and hybrid modes of governance. The broad area of study includes dependence-balancing (Heide and John 1988), role of TSIs (Anderson and Weitz 1992; Rokkan, et al. 2003), control mechanisms (Stump and Heide 1996; Brown et al. 2000), and adaptation (Noordewier et al. 1990). These studies aim to investigate how various governance problems, such as safeguarding TSIs, can be managed without complete integration (see Rindfleisch and Heide 1997). These studies parallel the relational exchange research stream (Macneil 1981; Dwyer et al. 1987), which focuses on the development of close and enduring relationships whereby mutual benefits are sought.

Relatively speaking, there have been a limited number of studies focusing on horizontal interorganizational relationships (e.g., co-marketing, collaborative R\&D). Rindfleisch and Heide (1997) cite Gates' (1989) study as the first TCE study in the horizontal interorganizational relationship context. Other studies include Bucklin and Sengupta (1993), Osborn and Baughn (1990), Parkhe (1993), and Jap (2001). Similar to 
vertical interorganizational relationship studies, these studies also aim to investigate transaction costs issues such as asset specificity in developing processes of horizontal relationships

As for testing the assumptions of TCE, recent development of relational exchange research stream has highlighted the efficiency of a hybrid form governance. With longterm, norm-based relationships, firms can mitigate the threat of opportunism and protect their TSIs. While wide empirical support stands for firms utilizing vertical integration to protect their investments, an alternative way to accomplish the same is to establish relational exchange (see Brown et al. 2000; Wathne and Heide 2000; Barney and Hansen 1994). Relational exchange relationships can be characterized by relational norms (Heide and John 1992) in which role integrity, mutuality, solidarity, and flexibility, harmonious conflict resolution, and bilateral information exchange play a significant role in governing relationships (Macneil 1980; Dwyer et al. 1987; Ganesan 1994; Kaufmann and Stern 1988). Norms thus serve as a general protective device against deviant behavior (Stinchcombe 1986; Thibaut 1968), such that involved parties rely considerably less on explicit control mechanisms.

Finally, in terms of control mechanisms to deter opportunism, Williamson (1985; 1996) discusses monitoring as a control mechanism, but only to point out the imperfect nature of monitoring due to measurement problems. Williamson (1996, p. 14) suggests that measurement hazards in conjunction with multiple tasks (Holmstrom and Milgrom 1991) and/or over-searching (Barzel 1982; Kenny and Klein 1983) give rise to the use of hierarchy over market in terms of efficiency in obtaining control. TCE claims that firms, as opposed to markets, offer superior protections against opportunism due to: (1) more 
powerful control and monitoring mechanisms, (2) long-term, forward-looking orientation reduces attractiveness of short-term payoffs from opportunistic behaviors, and (3) socialization allows creation of convergent goals (cf. Rindfleisch and Heide 1997). Indeed, the TCE's claim that high levels of behavioral uncertainty (i.e., high costs of monitoring) and vertical integration are positively related has been empirically supported (Gatignon and Anderson 1988; John and Weitz 1988).

In addition, TCE-based research has mainly recognized TSIs and reward/coercion power as control mechanisms (see Collins and Burt 2003). TSIs as hostages have been widely discussed, and the review for TSIs is provided previously in this chapter (under Credible Commitment). The other, reward and/or coercive power, ${ }^{3}$ is said to be an alternative to monitoring (Klein et al. 1978; Klein and Murphy 1988). Together, these two control mechanisms are in line with self-enforcing contract (Telser 1980) mentioned in the previous section of the agency theory review, such that agents comply with the principal as long as they see merit in behaving that way and at the same time it is not in their best interest to cheat and incur loss. Morgan and Hunt (1994, p. 24) note, "Expected termination costs lead to an ongoing relationship being viewed as important, thus generating commitment to the relationship." Ping (2007) also shows that lack of attractive alternative exchange partners restrain opportunism, explaining nearly $60 \%$ of variance.

In the marketing channel literature, several studies have consistently suggested that power symmetry may have implications for opportunism. Studies have found that relationships that are asymmetric in power and dependence, which is considered the

\footnotetext{
${ }^{3}$ It is noteworthy, however, that Williamson (1996) concurs with March $(1988$, p. 70$)$ that power is a "disappointing concept. It tends to become tautological label for the unexplained variance." Dependency issues "can be addressed in efficiency terms" (Williamson 1996, p. 39).
} 
obverse of power (Emerson 1962), are more dysfunctional (Anderson and Weitz 1989) are associated with high levels of conflicts and low levels of trust and commitment (Kumar et al. 1995a). Kumar et al. (1998) suggest that this could be explained by relative power theory (Cook and Emerson 1978) that increasing asymmetry in punitive capabilities result in greater punitive acts by the firm which possesses the power. At the same time, Gundlach and Cadotte (1994) and Lusch and Brown (1996) suggest that increased mutual dependence is related to relational behaviors and refraining from opportunistic behaviors to avoid jeopardizing the relationship.

\section{$\underline{\text { Summary and Implications for Opportunism }}$}

Much like agency theory, the main premise of TCE is that individuals are selfinterest seeking and they will always choose the option that can unilaterally maximize outcomes. The main prescription for the selection of governance form (hierarchy, market, or hybrid) is based on the presumed levels of potential opportunism. High costs of safeguarding relationship-specific investments, for example, is one reason for choosing vertical integration (i.e., hierarchy) over market because the partner firm is assumed to be opportunistic and likely to take advantage of the other firm's vulnerability.

As with agency theory, difficulty in performance measurement is also an issue when monitoring the exchange partner. TCE also addresses incompleteness in contract, based on its "bounded rationality" assumption, that managers are unable to construct contracts that cover all future contingencies and safeguard their investments. Besides imperfect monitoring and incomplete contracts, credible commitment (i.e., mutual TSIs) and reward/coercive power are two alternative control mechanisms. 
Similar conclusions and implications can be made about TCE. By following TCE, firms may shield themselves with appropriate governance mechanisms. At the same time however, firms may preclude themselves from developing any meaningful relationships. In addition, following TCE, the principal may make excessive use of explicit control (e.g., formal contracts and monitoring) presuming an opportunistic nature in the exchange partner. In turn, the principal may signal distrust of the agent thereby undermining trust, even encouraging opportunistic behavior (Ghoshal and Moran 1996, Macaulay 1963). Enhanced knowledge of PFO should improve TCE prescriptions by determining the more realistic level of opportunism that the exchange partner really is exposed to.

\section{Organizational Justice Literature}

Unlike the normative economic theories (i.e., TCE and agency theory), the organizational justice literature pays particular attention to the role of fairness in the intra-firm settings. The premise of this research stream is that justice concerns play a significant role in agents' actions. In economic theories, agents' actions are based solely on maximizing their economic payoffs. Justice research posits that, on the other hand, agents' perceptions of justice in the exchange relationship dictate their behaviors regardless of economic payoff maximization. According to organizational justice theory, an individual is sensitive to fairness perceptions and behaves in ways that $\mathrm{s} / \mathrm{he}$ sees fit in a given exchange. The overall literature focuses on different types of justice: distributive justice (Homans 1961), procedural justice (Thibaut and Walker 1975), and interactional justice (Bies and Moag 1986; Tyler and Bies 1989) and their implications. 
Generally speaking, distributive justice (Homan 1961) focuses on outcomes among parties involved in a social or economic exchange. In marketing channel relationships, it "relates to the division of benefits and burdens" (Frazier, Spekman, and O’Neal 1988, p. 60). Distributive justice "plays an important role in shaping an overall pattern of both conflict sources and people's cognitions about conflict (Kabanoff 1991, p. 417).

Two of the main distributive rules are equity and equality (cf. Meindl 1989). Equity principles for sharing specify divisions of payoff that are equal to each party's contributions. Generally speaking, equality principles specify that each party receives an equal share (a 50/50 split) of the payoffs. Some scholars suggest that equity and equality distribution of payoffs are specific to the nature of social relationships. According to referential standards theory (Berger et al. 1972), equality perception is established when individuals compare self with similar generalized others, such that they expect the same reward level that is typically allocated to persons like themselves.

In the field of sociology, Deutsch (1975) proposes that equity rule should be the dominant principle in cooperative relations in which economic productivity is a primary goal so as to encourage the contributions of the most able, while equality rule is for cooperative relation in which the fostering or maintenance of enjoyable social relations is the common goal in order to promote mutual self-esteem. Building on Deutsch's conceptualization that equity emphasizes productivity and equality emphasizes cohesion, Kanbanoff (1991) more specifically proposes that the equity rule is dominant in an exchange relationship between allocator and recipient in which power differentiation is high, while equality rule applies to relationships between peers in which power is 
undifferentiated. Chen, Meindl, and Hui (1998) empirically support the proposition. However, the results drawing from student sample are questionable in terms of generalizeability. For example, the findings may not hold in the case of multi-unit franchisees who hold more symmetric power in franchisor-franchisee relationship as compared with other franchisees.

Classical equity theory (Adams 1963, 1965), from which much of distributive justice research derived, suggests that any perceived inequity leads first to distress and then to attempts to reduce distress by restoring equity, which is consistent with Festinger's (1957) cognitive dissonance theory. Adams (1965) specifies that the presence of inequity will motivate an individual "to achieve equity or to reduce inequity, and the strength of motivation to do so will vary directly with the magnitude of inequity experienced" (p. 283). When people think they are over-rewarded, they feel guilty and tend to increase their efforts. The opposite is true when they are under-rewarded. According to Adams, the individual may reduce productivity (i.e., inputs) to balance outcome-input ratios, while s/he may also attempt to establish equity by overtly expressing dissatisfactions in efforts to increase their outcomes. Alternatively, Adams suggests, the individuals may also make-believe their inputs and outputs cognitively; that is, they may alter the importance or relevance of their inputs and outcomes so as to reduce cognitive dissonance. Adams suggests that this solution may be more evident when altering neither inputs nor outcomes seems possible.

Subsequent research has demonstrated support for the validity of equity and equality concepts, as well as the distributive justice concept in general (see Greenberg 1982; Leventhal 1980; Sheppard, Lewicki, and Minton 1992; Mowday 1987). The 
common finding is that individuals will respond to unfair relationships "by displaying certain negative emotions, which they will be motivated to escape by acting so as to redress the experienced inequity" (Greenburg 1987, p. 11). In various experimental settings, underpaid workers have been found to be less satisfied and less productive than equitably paid workers, while overpaid workers are also less satisfied but more productive than equitable counterparts (see Greenberg 1982).

In field studies, a wide support also exists that perceived distributive unfairness is associated with job dissatisfaction (e.g., Brief 1998; Folger and Cropanzano 1998; McFarlin and Sweeney 1992). Generally, research has shown that distributive justice predicts specific personal outcomes (e.g., pay satisfaction) better than general organizational outcomes such as organizational commitment and turnover (which are better predicted by procedural justice) (Folger and Konovsky 1989; Greenberg 1990; Sweeney and McFarlin 1993). In marketing, Netemeyer et al.'s (1997) studies also indicate fairness in reward allocation is an important predictor of job satisfaction of salespeople. In a meta-analysis (Cohen-Charash and Spector, 2001), distributive justice has been found to be significantly and positively related to affective commitment and negatively related to turnover intentions. Pay dissatisfaction, in general, can result in job dissatisfaction, lower motivation, and even dysfunctional (or deviant) behavior (Cropanzano and Randall 1993).

Distributive justice has also been applied to interfirm relationships. Jap (2001) finds, in interfirm $R \& D$ collaborative relationships, that the use of complex equity sharing principles may be excessive (negative impact on relationship quality) when: (1) idiosyncratic investments exist and (2) the parties value mutual payoffs. Gassenheimer, 
Houston, and Davis (1998) suggest that distributive justice is a significant factor when making strategic decisions about retaining or terminating an interfirm relationship. Kumar, Scheer, and Steenkamp (1995b) also report that distributive fairness is an important indicator of relationship quality in interfirm relationships. Gundlach and Murphy (1993) propose that distributive justice is an important dimension of ethical interfirm exchange, and that lack of equity can stimulate retaliatory acts in addition to reduced satisfaction and trust in exchange relationships (Smith 1990). Ross, Anderson and Weitz (1997) questions, however, the relationship between overreward and guilty feelings. Counter to equity theory's suggestion that people feel guilty and work harder to try to even the balance in an overrewarded situation, Ross et al. (1997) did not find the positive correlation among distribution channel managers.

Procedural justice refers to the extent to which individuals, or agents, perceive fairness in terms of their principals' procedures used for allocating outcomes (Thibaut and Walker 1975). Although Thibaut and Walker (1975) recognized that there may be two forms of procedural justice (one regarding the formal procedures, and the other with interpersonal or social side), historically, justice researchers did not distinguish between the two (Bies and Moag 1986). In the present research, the fairness of formal procedures will be used as procedural justice, while the fairness of interpersonal relationship will be referred to as interactional justice (Bies and Moag 1986) to be discussed subsequently.

Thibaut and Walker (1975) developed their theory of procedural justice by examining people's reactions to five dissimilar legal dispute-resolution processes (bargaining, inquisitorial, single investigator, double investigator, and adversary). Their findings indicate that procedures that vest process control in those affected by the 
outcome of the procedure are viewed as more fair than are procedures that vest process control in the decision maker. Adversary procedures were perceived as more fair than inquisitorial procedures because they conform to the distribution of process control that disputants prefer (Lind and Tyler 1988, p. 35).

Applying this to more general contexts, Leventhal (1980) expanded the concept by proposing six procedural rules that people use for fairness evaluation: the firm's formal allocation procedures are fair to the extent that they demonstrate consistency, bias suppression, accuracy, correctability, representativeness, and ethicality:

- Consistency rule - allocative procedures should be similar across people and over time;

- Bias suppression rule - personal self-interest and blind allegiance to narrow preconceptions should be prevented;

- Accuracy rule - decisions must be based on as much good information and informed opinion as possible;

- Correctability rule - opportunities must exist to modify and reverse decisions;

- Represenativeness rule - the allocation process must represent the concerns of all important subgroups and individuals; and

- Ethicality rule - the allocation process must be compatible with prevailing moral and ethical standards.

The procedural justice concept expanded the research on organizational justice since the findings showed that the distribution of rewards was not always as important as the process by which they were arrived at (see Lind and Tyler 1988 for review). In the organizational literature, procedural justice generally refers to the degree of individual control over the reward (or pay) distribution decision process. Much like distributive 
justice, procedural justice concerns with the individuals' reactions to their perceived fairness. Empirical studies have shown that, distributive justice and procedural justice have different implications. Procedural justice has been shown to influence evaluations of systems and authorities (Greenberg 1990; Lind and Tyler 1988).

Studies have generally suggested that distributive justice predict well the personal outcomes such as pay and/or job satisfaction, whereas procedural justice is a more important predictor of organizational outcomes such as organizational commitment and supervisor evaluation (McFarlin and Sweeney 1992; Sweeney and McFarlin 1993; Folger and Konovsky 1989). Kumar et al. (1995b), in the supplier-reseller context, show that resellers' perceived procedural fairness has relatively stronger effects on relationship quality (trust, commitment, and conflict) than the distributive fairness counterpart. Moorman (1991) reports support for a relationship between procedural justice (fairness concerning formal procedures and interactions) and organizational citizenship behavior, while distributive justice had no effects. Although, Roberts, Coulson, and Chonko (1999) show that salespeople's commitment to the firm and intent to turnover was explained significantly by their perceived distributive fairness, more so than procedural justice. Ramaswami and Singh (2003) also show that perceptions of procedural fairness did not have significant effects on neither job satisfaction nor supervisor trust.

Also noteworthy is the extensive review by Brockner and Wiesenfeld (1996). Brockner and Wiesenfeld consolidated findings from 45 studies that the effects of procedural and distributive justice are contingent on the level of the one another. More specifically, they report that the effects of (1) procedural justice effects on individual's reactions are more positively related when outcome fairness is relative low and (2) 
distributive justice effects on individual reactions are more positively related when procedural justice is relatively low. That is to say, when individuals are satisfied with outcome distribution, they are somewhat unconcerned with the fairness of the procedures. Similarly, when the perceptions of procedural justice is high, they are less concerned with the outcome favorability.

In addition, some studies target specific aspects of procedural justice. For example, an American Management Association (AMA) survey in 1999 with 2,100 major U.S. firms reports that $73 \%$ of the firms engage in electronic monitoring, and $35 \%$ of them use video surveillance to prevent employee or customer theft, of which $15 \%$ use video recording as a way to monitor, appraise, and improve job performance. The concerned employers have legitimate reasons to prevent employee theft as a norm of theft is widespread (Traub 1996), the potential consequences may be damaging employment relationships. Ambros, Alder, and Noel (1998) point out that many employees feel such procedures violate their basic right (e.g., privacy) and dignity, while others suggest that monitoring inadvertently decrease work quality (Griffith 1993; Kulik and Ambrose 1993; Ottensmeyer and Heroux 1991). In Hovorka-Mead et al. (2002) studies, the fairness perceptions of employees who learned of secret monitoring predicted well their intention for re-employment, and whether the employer had strong or weak justifications also moderated the effect.

In terms of interactional justice, Bies and Moag (1986) and Tyler and Bies (1989) point out, perceptions of justice are influenced by interpersonal treatment. Bies and Moag (1986) argue that interactional justice is a separate dimension of justice that examines the quality of interpersonal treatment and the communication aspect of defining procedures. 
They suggest that researchers have "confounded concerns about procedural fairness with those dealing with interactional fairness" (p. 45). Treatment with respect and truthfulness of communication are two key characteristics of interactional justice (Bies and Moag 1986). As such, interactional justice is the extent of fairness of the communication between the management (or those controlling rewards and resources) and the recipient of rewards (Bies and Moag 1986; Tyler and Bies 1990).

Colquitt (2001) offers support for the construct validation of interactional justice, including predictive validity. The results indicated that interactional justice predicts (teammate) helping behavior. Yukl (2002) suggests that leadership figures' behaviors such as truthful communications, treating employees with courtesy and politeness create environment that enhance communication exchanges among employees. Masterson and Taylor (1996) report that employees' interactional justice perceptions predicted supervisor-related outcomes, while procedural justice perceptions predicted organizational commitment and intentions to leave the firm. Similarly, Masterson, Lewis, Goldman, and Tyler (2000) demonstrate that perceived interactional justice represent supervisor-subordinate exchange, whereas procedural justice represents perceived organizational support.

Studies by Ramaswami and Singh (2003) indicate that salespeople's perceived interactional fairness explains more variance in supervisor trust and job satisfaction than did both distributive justice and procedural justice. Similar results were obtained by Moorman (1991). Moorman conceptualized that procedural justice as consisting of fairness perceptions concerning formal procedures and interactions. Of the two, only 
interactional justice had significant effects on organizational citizenship behaviors (altruism, courtesy, sportsmanship, and conscientiousness).

Lastly, similar to Brockner and Wiesenfeld's (1996) findings, Skarlicki and Folger's (1997) study suggest that distributive, procedural, and interactional justice are "capable of functioning as substitutes for one another" (pp. 438-439) in the context of employees' retaliatory behaviors. Their results suggest that a high level of perceived procedural justice compensate for relatively low levels of both distributive and interactional justice. Similarly, employees treated with respect and dignity reportedly tolerated retaliatory tendencies even though perceived distributive and procedural justice levels were low.

\section{$\underline{\text { Summary and Implications for Opportunism }}$}

As Kahneman et al. (1986a, 1986b) call for the need to modify standard microeconomic models to incorporate norms of fairness, and their series of experiments indicate the prevalence of fairness-seeking behavior in our society despite the normative theories' treatment of fairness as irrelevant, instead favoring the pursuit of economic efficiency, it is clear that the role of fairness perceptions should be examined in interfirm relationships. Although an organizational justice framework has not been used explicitly in the interfirm relationships (with exceptions of Kumar et al.1995b and Jap 1999), there have long been studies that suggest negative relationship between the use of coercive power and the relationship quality (Lusch 1976; Gaski 1984; Brown, Lusch, and Nicholson 1995; Boyle et al. 1992; Simpson and Mayo 1997). Poor relationship quality generally manifests in increased conflicts between channel members. Although some 
conflicts are necessary and functional (cf. Anderson and Coughlan 2002),

overwhelmingly, data suggest that higher conflict accompanies declining satisfaction by marketing channel members (see Geyskens et al. 1999).

Building on this research stream, and following Gundlach and Murphy (1993)'s conceptualization that ethical principles such as fairness are the foundation of any meaningful exchange relationships, an interesting research question would be to examine the extent to which perceived fairness in interfirm exchange sets up the kind of norms that encourage or discourage opportunism.

\section{Individual-Specific Characteristics and Opportunism}

As the assumption of opportunism is questioned, it is important to note that the fundamental assumptions of human nature in theoretical frameworks do matter a great deal. As Simon (1985, p. 303) puts it:

"Nothing is more fundamental in setting our research agenda and informing our research methods than our view of the nature of the human beings whose behavior we are studying. It makes a difference, a very big difference..."

Agency theory also stresses the importance of screening and detecting "signals" to determine the quality of the exchange partner prior to forming the relationship. Both TCE and agency theory caution, however, that there are those who misrepresent their true nature by distorting material facts. Nevertheless, a clear implication is that treating all firms as having the same level of PFO can be misleading. Previous research has shown that firms (or managers) often demonstrate benevolence, or "extracontractual helping behavior" (Lee et al. 2004, p. 32), and such quality helps develop trust in exchange 
relationships (Doney and Canon 1997; Ganesan 1994). The premise of this dissertation is that channel managers exhibit different levels of PFO, which has not been previously examined in the extant literature dealing with opportunism management. I therefore turned to the ethics literature for insights into individual-specific characteristics that may contribute to dissimilar levels of PFO.

One of the most dominant schools of ethics is called utilitarianism (cf. Solomon 1992). Utilitarian theories judge ethicality of a behavior based on its outcomes or consequences. In other words, "unethical" behaviors are those decisions that: (1) create personal gain exceeds that of society's gain, and (2) result in relatively inefficient attainment of desired societal benefit when alternative decisions that could provide greater benefit are readily available (Fritzsche and Becker 1984, p. 167).

The ethical approach relates directly to the concept of opportunism, or selfinterest seeking, guileful behaviors. Indeed, opportunistic behaviors imply that an exchange party "engages in behaviors that unilaterally improve the party's term of trade" (Wathne and Heide 2000, p. 39) with no regards to the consequences on the partner firm. As Koford and Penno (1992, p. 131) note, "whether a person behaves ethically depends to some extent upon balancing self-interests against the interests of others or balancing self-interest against some sort of moral standard.” In addition, Macneil (1981, p. 1023) suggests that guileful behaviors are those "taking advantage of opportunities with little regard for principles or consequences." Hence, choosing to seek self-interest over the interests of others is the common conceptualization of both opportunistic and egoistic behaviors. If we consider a dyadic interfirm relationship to be a micro society, it can be 
said that a party is unethical to the extent that it fulfills individual gain at the expense of the dyadic gain.

The ethics field has long examined ethical behaviors by studying individual characteristics and the context in which they make ethical decisions. As far as the individual differences are concerned, they seem to be in agreement that there is a continuum of individual moral character (cf. Parks and Smith 1998). Accordingly, the main premise of this section (individual-specific propensity for opportunism) is that some individuals are simply more ethical than others, just as some are purely self-interested with guile. On one end, an individual can act exclusively out of egoistic interest disregarding consequences for others' welfare. On the other, an individual always chooses actions to promote societal gain (i.e., altruistic). According to Jencks (1990), altruistic individuals always behave "as if the long-term welfare of others is important independent of its effects on their own welfare" (p. 53), whereas "selfish" individuals may only take steps to help others if the behavior increases their own outcome.

From the literature review, I have identified three individual-specific characteristics to be potentially useful in analyzing PFO: Cognitive Moral Development (CMD), Machiavellianism, and locus of control. The following sections will review the each subsequently.

\section{Cognitive Moral Development (CMD)}

Drawing on Piaget's (1932/1965) seminal work examining children's moral decision-making development, Kohlberg (1969) developed through a longitudinal study the theory of moral development, which is based on the belief that people progress in 
their moral reasoning in their bases for ethical behavior from birth to adulthood.

Kohlberg extended Piaget's three-stage model to six stages, each reflecting a progression from the previous stage in increasing understanding of the nature of moral obligations in complex social systems (Rest 1979). Trevino (1986, p. 602) describes that "an individual's level of cognitive moral development strongly influences the person's decision regarding what is right and wrong; the rights, duties, and obligations involved in a particular ethical dilemma."

According to Kohlberg, stages one and two are characteristics of young children; while stages three and four are where most adults are. The remaining 20 to $25 \%$ of the adult population have reached the last two stages. The six specific stages of CMD are categorized into three broad stages: pre-conventional, conventional, and postconventional as shown in Table 2.2.

These stages reflect the ways of thinking about moral matters. The self-perception of the preconventional level is such that individuals see the value of interpersonal relationships only as a means to their own needs. At the conventional stages, individuals see themselves as part of their immediate society to which they belong to the extent that they seek conformity to stereotypical images of the conducts that are shared among the members. In other words, what these individuals consider to be the right behaviors are ones that are congruent with the values of the majority. At the highest postconventional level, individuals value social order above and beyond their immediate social group because they deeply respect rights of others.

Rest (1979, pp. 26-39) describes the characteristics of each stage as follows (in the order of stage one to stage six): obedience, instrumental egoism and simple exchange, 
interpersonal concordance, law and duty to the social order, social consensus, and nonarbitrary social cooperation. At Stage One, "being moral is being obedient" and "right and wrong are defined simply in terms of obedience to fixed rules" (pp. 24-25). Stage Two advances from the first stage. The right action is described in this stage as "if it does some good for the actor" (Rest 1979, p. 26). Morality serves a purpose in that a person is motivated to pursue his/her own interests, and s/he should obey the rules only if it is prudent to do so. Rest also notes (p. 27), "cooperative interactions are entered voluntarily, with each party understood as having something to gain - and that's what makes it fair."

Entering conventional level, stage three advances to "reciprocal role taking" (Flavell et al. 1968). Reciprocal role taking "makes possible a new kind of cooperative reciprocity among people: not favor-to-favor, as at Stage Two, but the reciprocity of enduring friendship" (Rest 1979, p. 27). Here, a good behavior is based on a pro-social motive, such that "each party in this cooperative system determines his rights and responsibilities by anticipating the feelings, needs, and expectations of the other" (p. 29). Whereas Stage Three views moral behavior based on social interaction and mutual understanding, it is still "limited to primary group relations based on sentiment" (p. 29). In other words, it does not constitute moral guidelines for strangers, people not of one's liking, or for outside one's circle of friends and immediate family members.

Stage Four advances this limitation by expanding norms of behavior to all members of society. Rather than personal consideration or circumstances, "a general social arrangement" must precede "in order to make a society-wide cooperative system work" (p. 30). In the end, individuals at Stage Four feel that it is their obligation to society. Advancing to postconventional level of CMD, the defining difference between 
TABLE 2.2: Cognitive Moral Development (CMD) ${ }^{4}$

\begin{tabular}{ccl}
\hline LEVEL & STAGE & \multicolumn{1}{c}{ MOTIVATION FOR MORAL BEHAVIOR } \\
\hline Pre-conventional & 1 & $\begin{array}{l}\text { Orientation to punishment, obedience, and } \\
\text { physical and material power. Rules are obeyed to } \\
\text { avoid punishment. }\end{array}$ \\
Naïve instrumental hedonistic orientation. The \\
individual conforms to obtain rewards. \\
"Good boy/girl" orientation designed to win \\
approval and maintain expectations of one's \\
immediate group. The individual conforms to \\
avoid disapproval. One earns approval by being \\
"nice." \\
Orientation to authority, law, and duty, to maintain \\
a fixed order, whether social or religious. Right \\
behavior consists of doing one's duty and abiding \\
by the social order.
\end{tabular}

\footnotetext{
${ }^{4}$ Adapted from Rich and Devitis (1985 p. 88)
} 
Stage Four and Stage Five is that "Stage 4 provides a rationale for supporting established social arrangements, but not to a rationale for choosing between different systems of law Or different sets of social arrangements" (Rest 1979, p. 32). That is, some social orders still distribute the benefits and burdens of social cooperation unequally and "do so on arbitrary grounds ... Stage Five anticipates that people can reach agreement about their laws if (1) the law-making process reflects the general will of the people, and (2) if certain minimal safeguards of people's welfare are guaranteed for everyone, i.e., certain basic rights like "life, liberty, and the pursuit of happiness" (pp. 32-33). Rest also notes (p. 36) that Stage Five attempts to neutralize inequities and lopsided reciprocity through procedural justice, or procedures for making laws, but it still is reflecting only majority will. That is, Stage Five still relies on social consensus. Rest provides an example of the acceptance of slavery in early America that "the collective judgment of the people at one time may be unfair as viewed by the people at a later time" (p. 36). Stage Six respects that "individuals each have an equal claim to benefit from the governing principles of cooperation" (p. 38). Hence, at Stage Six, individuals have clear rationale in anticipating "what principles a rational society would want to end up with for governing its system of cooperation" (p. 36).

It is noteworthy, however, that both Kohlberg (1970) and Rest (1979), through their series of empirical data, could not distinguish the two stages (Stage Five and Stage Six). Also note that Kohlberg (1970) abandoned stage Six by making it an advanced stage Five form.

To contrast with other trait or psychometric approaches that view people as aggregates of quantitative dimensions or traits, CMD places emphasis on patterning in 
behavior and its logical interconnectness (Kohlberg 1969, pp. 348-349). As Hunt and Vitell (1991, p. 781) put it, “. . . stages of cognitive moral development implies a high capacity to reason through complex ethical situations."

Over the past decade, CMD has generated an enormous research field studying different demographics (e.g., age, gender, and education) and professions which aid into ultimately understanding ethics-related behavioral tendencies in individuals. In summarizing the general empirical findings, CMD research provides overwhelming evidence that moral reasoning scores increase with age and formal education, and Rest and Deemer (1986, p. 57) suggested that moral judgment accompanies "a growing awareness of the social world and one's place in it." Rest (1986) reported that gender differences on the CMD are trivial, and that when they exist, females score higher. Gilligan (1977), though, criticized that Kohlherg developed his justice-based theory using an all-male longitudinal sample.

Researchers in recent years continue to investigate the relationship between CMD and: (1) country-specific culture (e.g., Kracher, Chatterjee, and Lundquist 2002; Tsui and Windsor 2001), (2) demographics (e.g., Elm, Kennedy, and Lawton 2001; Wimalasiri 2001; Weber and Wasieleski 2001), (3) occupation (e.g., White 2002; Bigel 2000), (4) ethical behavior and decision-making (e.g., Gul, Ng, and Tong 2003; Tsui 2001; Trevino and Youngblood 1990; Goolsby and Hunt 1992), and (5) ethical training (Izzo 2000).

The original contention of CMD is that the moral maturity predicts moral actions (Colby and Kohlberg 1984). Indeed, many studies have demonstrated the positive relationship between advances in CMD and ethical behaviors. An experiment by Kohlberg and Candee (1984) show that participants' CMD scores are positively related to 
their decision to help and the act of helping a drugged student. In Stratton, Flynn, and Johnson's (1981) study, management students' responses to an ethical dilemma involving padding an expense account revealed that those students who agreed to padding an expense account used a rationale categorized in the first three stages of CMD, while those who disagreed to padding expense account used a rationale based on the latter three CMD levels. Goolsby and Hunt (1992) report that marketing practitioners do not particularly score lower on $\mathrm{CMD}$, and those with higher CMD tend to have socially responsible attitudes and behaviors.

Though, researchers in recent years have abandoned the idea of a simple linear relationship between CMD and moral behaviors because many empirical studies have failed to demonstrate such one-to-one correspondence between the two (see Trevino and Youngblood 1990; Goolsby and Hunt 1992; Marnburg 2001). Today, the consensus remains that CMD is a necessary but not sufficient condition for ethical conduct, as postulated by Kohlberg (1969) and Rest (1979). In determining the actual ethical behaviors, consensus seems to be that CMD is not the sole predictor. In addition to examining the $\mathrm{CMD}$ as an independent variable explaining the impact on ethical behaviors, Rest (1986), as a leading figure of CMD research, also contends that people's CMD scores differ according to the environment and group dynamics.

In the business ethics literature, more comprehensive models such as the Hunt-Vitell Theory of Ethics (Hunt and Vitell 1986, 1991) incorporates CMD as a personal characteristic (besides age, gender, education, income, and religion, among others). The grand model posits that cultural, industrial, and organizational environments also greatly influence and shape the perceived ethical problems and perceived alternatives, as well as 
perceived consequences. Including the positive effects of CMD on ethical behaviors, some studies have found support for the Hunt-Vitell model (Mayo and Marks 1990; Hunt and Vasquez-Parraga 1993; Burns and Kiecker 1995; Menguc 1998).

\section{$\underline{\text { Summary and Implications for Opportunism }}$}

While the correlation between CMD and actual behaviors may not strongly be correlated, CMD still offers an interesting theory in determining individual differences in moral reasoning. The stages of CMD have implications for understanding the reasons behind channel managers' priorities in moral decision-making.

In applying CMD into interfirm relationships, it can be said that "moral" behaviors are ones that contribute to mutual gains for the involved parties, while a "selfish" party acts exclusively out of individual gains. Though CMD is an individuallevel construct, it provides useful guidance about underlying motivations behind behaving morally (e.g., keeping promises, fulfilling obligations) in interfirm relationships. A higher level of CMD, according to Hunt and Vitell (1991, p. 781), implies "a high capacity to reason through complex ethical situations ... [and considerations of] the interests of more stakeholders in their decision making." A marketing channel manager frequently faces a decision about whether to behave on behalf of the channel relationship as a whole (i.e., collective gain for all the stakeholders) or simply seek his/her own firm's benefits regardless of the decision's consequences on the members of the marketing channel.

Referring to each level of CMD, at the preconventional level of moral development, firms may obey the contract and fulfill its duty to avoid punishment. In the 
conventional level, however, firms may value what others in their social group think of them to the extent that they fulfill their obligations to conform. Finally, at the postconventional level, they may value the social contract that foster universally accepted principles in business conduct. At the very least, CMD can reflect the logical motivations behind why firms (or managers) would want to act ethically in the exchange relationships.

Furthermore, the main criticism of CMD is that research in moral reasoning has not focused on behaviors; rather they assume individuals' beliefs are highly correlated with their actions (Marnburg 2001; White 2003). One must wonder whether Kohlberg's CMD can be reflected in the manners by which firms conduct business. Do moral people act ethically in business exchanges? In other words, do business managers behave according to their levels CMD, or do they operate at different mentality in business conduct? To what extent does the proverbial "is business bluffing ethical" hold?

It is interesting to investigate whether managers, regardless of CMD, operate at preconventional level as in the assumptions of agency theory and TCE. Or, are they more in line with the conventional level of moral reasoning such that they allow the social context to alter their behaviors? It is plausible to assume that individuals differing in their levels of CMD would differ in their actions in the interfirm exchanges, nevertheless. Investigating CMD levels of business managers can potentially discriminate their levels of PFO. Extensive monitoring may be much needed and work well if the managers are in the preconventional stages of moral reasoning. On the other hand, those in the conventional stages may largely be influenced by environmental factors such as industry norms regarding ethical business conduct. 


\section{Machiavellianism and Opportunism}

Machiavellianism is a construct that has widely been discussed in the ethics literature. Machiavellian individuals are "egotistical in nature, [and] they will employ opportunistic, exploitative means to achieve personal objectives without any feelings of guilt or remorse" (Ferrell, Gresham, and Fraedrich 1989, p. 57). Though Machiavellians may not be totally lacking in morals, they may just operate under a set of ethical guidelines that are inconsistent with conventional morality (Christie and Geis, 1970). Christie and Geis (1970), the developers of the widely used Mach IV scale to measure Machiavellianism, after 38 studies using Mach IV scale conclude that "high Machs" (those who score high on the Machiavellianism scale) manipulate more, win more, are persuaded less, persuade others more, and otherwise differ significantly from "low Machs" (those who score low on the scale).

Studies have consistently demonstrated that Machiavellianism and unethical behaviors (e.g., lying, cheating, or manipulating) are positively related (e.g., Hegarty and Sims 1978, 1979; Singhapakdi and Vitell 1990; Granitz 2003). Using experimental settings, both Geis and Moon (1981) and Excline et al. (1970) demonstrated that the subjects with high Machiavellianism scores (high Machs) lie more plausibly (as rated by independent judges) than those with low Machiavellianism scores. Ross and Robertson (2000) show that high Mach employees are more likely to lie to the firm, and they are more likely to consider that lying to the firm is acceptable than those with low Machiavellianism scores.

According to Mudrack (1993), Machiavellians are more likely to perceive dubious workplace behaviors (e.g., making personal long-distance calls, stealing office 
supplies) to be acceptable. Hegarty and Sims $(1978,1979)$ show in laboratory

experiments that Machiavellians pay bribes significantly more than the low Machiavellian subjects. Similarly, Giacalone and Knouse (1990) show in experimental settings that high Machiavellian subjects tended to justify organizational sabotage differently than others.

However, there is no definitive evidence that Machiavellians are either immoral or amoral (cf. Learly, Knight, and Barnes 1986). Following Forsyth (1980), Learly et al. (1986) show that Machiavellians differ in moral judgment in two dimensions: relativism and idealism. Relativistic individuals believe that moral rules are relative rather than absolute and that absolute moral principles cannot be formulated. Idealism refers to the degree to which individuals believe that a moral behavior always leads to good outcomes. The result of their study demonstrates that individuals with high Machiavellianism scores endorse ethical beliefs that are more relativistic and less idealistic than the low Machiavellianism counterparts. Similarly, Erffmeyer, Keillor, and LeClair (1999) report that Machiavellian consumers' judgment of ethically questionable behaviors depended heavily on situational factors (i.e., relativistic), and these individuals would also be likely to initiate an illegal activity from which they would benefit. According to Singhapakdi and Vitell (1991), Machiavellian individuals tend to agree less with guidelines or rules as guiding principles in their behaviors.

In addition, according to Christie and Geis (1970), Machiavellians are more likely to exploit loosely structured elements of situations than others. Schepers (2003) shows that Machiavellianism is negatively related to contractualism, or the use of "tacit understandings between individuals or between the individual and society" (p. 340) as 
guiding behavior. The contractualism view of exchange goes "beyond a purely economic nature and include notions of fair play, truth telling, duty, and rights" (Reidenbach and Robin 1990, p. 647), which is in line with Social Contracts Theory (Rawls 1999). Under social contracts, individuals are committed to relationally justifiable standards of morality to which each will be held.

\section{$\underline{\text { Summary and Implications for Opportunism }}$}

From the literature review, it is clear that Machiavellianism has significant impact on ethical behaviors. While it is also clear that it is not the only factor explaining ethical behaviors, the literature seems to be in agreement that Machiavellianism is indeed one of the most powerful indicators because studies have consistently revealed that Machiavellians tend to be individualistic and self-interest seeking in nature (Morris, Davis, and Allen 1994).

According to Christie and Geis (1970), Machiavellian individuals possess a kind of cool detachment that makes them less emotionally involved with others. Such ability to detach oneself from guilt may have significant implications for the PFO in interfirm relationships. In marketing channel relationships, Machiavellianism may have a significant explanatory power in the extent to which channel managers are willing to conduct unethical behaviors in order to maximize gain while not feeling guilt.

As with CMD, Machiavellianism is also an individual-specific characteristic that can help us determine business managers' levels of PFO. By applying the construct to the interfirm business context, it may reflect the degree of willingness to behave in selfish 
ways; that is, a marketing channel manager's willingness to seek only the his/her firm's gain at the expense of the exchange partner firm.

Another interesting implication for PFO, as addressed by Schepers (2003), is the negative relationship between Machiavellianism and contractualism, or norm-based unwritten agreement. It can be said that Machiavellian individuals may more readily break relational norm-based agreements.

\section{Locus of Control and Opportunism}

The second individual trait of interest is the locus of control. Based on Jung's (1923) definition of two opposing tendencies in personality: introversion and extroversion, Rotter (1966) developed the locus of control construct, which refers to the internal or external causes to which individuals attribute their success and failures. The internal-external locus of control construct refers to an individual's perception of events as determined internally by his/her own behaviors (internal control) or as the result of forces beyond one's control, such as chance, fate, or powerful others (external control) (see Lefcourt 1981, p. 15). According to Ashford, Lee, and Bobko (1989), in comparison with locus externals, locus internals generally see environmental situations as being less important and believe that they have the power to counteract environmental threats.

Previous studies have found that individuals with an external locus of control perceive events to be influenced by outside forces or others' behavior, and they are more likely to behave unethically than those with internal locus of control (Hegarty and Sims 1978; Singhapakdi and Vitell 1991; Jones 1993). Hegarty and Sims (1978) find that locus internals engaged in bribe payments significantly less than locus externals in the 
laboratory experiment. Jones (1993) finds that individuals with an external locus of control were more likely to inflate expense reports than the internal locus counterpart. Cherry and Fraedrich (2000) suggest that sales managers with an internal locus of control judge bribery more harshly and exhibit less intension to pay a bribe than the external locus counterpart. Similarly, the experiment by Trevino and Youngblood (1990) finds that locus internals are more capable of making ethical decisions.

Forsyth, Pope, and McMillan (1985), Karabanick and Srull (1978), and Leming (1980) all report that students with an external locus of control are more likely to cheat. The studies by Donnelly, Quirin, and O'Bryan (2003) also show that auditors with an external locus of control are more likely to accept dysfunctional audit behavior (e.g., premature sign-off, underreporting of time, and altering/replacement of audit procedures). Jones (1993) and Deflumeri (1982) suggest that individuals with an external locus of control look at others to decide appropriate behavior. In addition, studies have found that individuals whose locus of control is internal exhibit more consistency between moral judgment and behavior than those whose locus of control is external (Trevino and Youngblood 1990). Locus of control has also been studied in conjunction with both CMD and Machiavellianism.

Some studies have shown a positive correlation between locus of control and Machiavellianism (Gable, Hollon, and Dangello 1990; Mudrack 1990), that is, the locus externals tend to score high on Machiavellianism. For example, Connolly and McCarrey (1978) suggest that ethical decisions made by the individuals with an internal locus of control moral judgments are guided by the intrinsic value of an act as measured by internalized standards of rightness. In general, studies that examined both locus of control 
and CMD report strong and significant positive relationships between internal locus of control and advanced moral reasoning (e.g., Connolly and McCarrey 1978; Dewolfe et al. 1988; Murk and Addleman 1992; Cherry and Fraedrich 2000). Trevino (1990) reports that individuals with an internal locus of control display higher levels of CMD, less unethical behavior, and greater inclination to do what they think is right regardless of contexts.

\section{$\underline{\text { Summary and Implications for Opportunism }}$}

Locus of control has been studied extensively in the ethics literature and has shown consistently its significance in ethical decision making. There also seems to be some overlap between the construct and Machiavellianism, though, the two personal traits are not the inverse of each other. As such, the extent of what each factor can explain in terms of ethical behaviors deserves further analyses. As Mudrack et al. (1999) point out, individuals with an external locus of control seem to lack the blatant self-interest characteristic of Machiavellians. Rather, external locus of control seems to imply ethical decision makings that are more easily swayed by others and are less willingness to endure social rejection or discomfort in doing what they feel is morally correct than the internal locus counterpart.

Also interesting to note is the positive relationship between CMD and the locus of control. In determining the channel manager's PFO, it would be interesting to compare the individual-specific characteristics simultaneously, including Machiavellianism. Previous empirical studies testing locus of control with other individual-specific variables (e.g., Machiavellianism) on unethical behaviors or moral judgment (Hegarty and Sims 
1978; Singhapakdi and Vitell 1991) do not make explicit comparisons of their relative impact on their dependent variables (e.g., ethical decision-making and ethical behaviors).

Taken together, these individual-level constructs have not been applied to the context of marketing channel relationships, and it would be interesting to investigate the potential role each of these characteristics may play in terms of levels of PFO.

\section{Extra-Dyadic Analysis of Opportunism}

In addition to individual differences in moral reasoning, the ethics literature suggests a "bad barrel" argument, which posits that individuals' attitude towards unethical behaviors are learned from their surrounding ethical climate. While most empirical studies have been conducted in intra-firm settings, my review extends to the extra-dyadic contexts, which are gaining increasing attention in marketing channels literature. In applying the "bad barrel" argument to inter-firm relationships, the premise here is that a dyadic relationship, the focal unit of analysis of this research, are embedded in a larger, social network which influence the attitudes and behaviors pertaining opportunism.

\section{Ethical Climates}

Individual ethical decision-making and the role of the environment have received a great deal of attention. According to Trevino and Youngblood (1990, p. 378), “bad barrels" refer to the argument that something in the environment poisons otherwise good apples. Some researchers suggest that often there is very little protection for those who bring "foreign" ethical standards into the corporate world with its own compromised 
ethics standards (Quinn et al. 1997). Quinn et al. (1997) add to the pervasiveness of badbarrel influence that, "Under constant and insistent pressure, employees simply give in and conform. They become good 'organizational people"” (p. 1426).

The shared norms within a workplace may well safeguard against opportunism. Using an ethnographic approach, Marshall (2003) depicts shared culture of cooperation in three service-sector organizations, in which individuals overcome the "paradoxes of rational selfishness by acting through symbols [of 'help'] and acting to be seen to be acting through symbols" (p. 566). Marshall (2003) explains that the symbol of 'help' acts as a component of governance allowing workers to refrain from free-riding, and it is "indisputably how these workers work and not something tacked on to their work patterns" (p. 567).

From experimental psychology research, famous experiments by Milgram (1974) and Zimbardo (1975) demonstrate how otherwise ethical individuals can act unethically even pathologically. Milgram's (1974) electric shock experiments at Yale in the 1960s find that, in extremely authoritarian conditions, subjects of lower status relinquish control to authority (i.e., experimenter) and no longer view themselves as responsible for their actions, and rather obey the instructions without questioning the moral nature of their tasks. Zimbardo's (1975) mock prison experiments also show people's capabilities to act out of their normal, everyday character to fit the forced role as "guards" or "prisoners," which eventually led them to act sadistic and submissive behaviors, respectively.

In business contexts, some researchers (e.g., Andrews 1989; Posner and Schmidt 1984) argue that organizational rules and examples set by supervisors overpower company or profession ethics policy. Employees in turn mimic such behaviors through 
"behavioral referencing" (Schneider 1990; Vidaver-Cohen 1997). Some studies such as D'Aquila (1997) and Lewin and Stephens (1994) have demonstrated that top managers set the tone of the organizational ethical climate. Corporate culture undoubtedly plays a substantial role for employees" ethical behavior as corporate ethical culture is "the shared values and beliefs about what works within an organization, and values about preferred end states and the ... approaches used to reach them" (Reidenbach and Robin 1991, p. 273). Verbeke, Ouwerkerk, and Peelen (1996), for example, show that perceptions of colleagues (i.e., opinions of colleagues concerning the ethicality of some behaviors) set an ethical climate that in turn becomes a significant contributor to an employees' decision making concerning the ethicality of some behaviors.

Ethical climate may be defined as prevailing perceptions of environmental signals regarding norms for making decisions with a moral component (see Victor and Cullen 1987, 1988; Vidaver-Cohen 1998). Basically, it is concerned with the ethical decisionmaker's perception of what is acceptable/unacceptable behavior judging from the social environment. The role of ethical climate has generally been studied in the intra-firm setting. These studies have examined external factors influencing unethical behaviors: peer behavior (Zey-Farrell and Ferrell 1982; Zey-Ferrell, Weaver, and Ferrell 1979) and supervisor or senior management influences (Chen, Sawyers, and Williams 1997; Chonko and Hunt 1985; Hegarty and Sims 1979; Nwachukwa and Vitell 1997; James 2000; Zey-Ferrell and Ferrell 1982). In the marketing literature, also, Ferrell and Gresham (1985) describe "significant others" (i.e., peers and management) as a contingent variable in marketers' decisions on ethicality of issues, because those disparate social groups bear distinct norms, values, and attitudes. 
Corporate codes of ethics are used to clarify formulated policy about what is expected of the employee (Weaver 1993). The review of empirical studies by Murphy (1995) shows that the effectiveness of codes of ethics is mixed. In laboratory settings, codes of ethics generally produced ethical behaviors (e.g., Laczniak and Inderrieden 1987). The study by McCabe, Trevino, and Butterfield (1996) shows that employees' self-reported behaviors are positively related to the codes of ethics. Ferrell and Skinner (1988) also report positive effects on employees' ethical behaviors. The mere existence of the codes is not sufficient, according to Trevino (1990), providing an enforcement structure, such as outlining a series of organizational supports is necessary for effective implementation. Indeed, Akaah and Riordan (1989) and Cleek and Leonard (1998) find no effects of codes of ethics. Ross and Robertson (2000) demonstrate that codes of ethics are effective when employees perceive that their firm provides guidelines about ethical behavior, considering the extent to which the codes effectively reduce "ethical ambiguity" (Spekman and Salmond 1992).

The literature also suggests that people do not always follow their personal moral values in business conducts. Rather, they seem to adapt to the business (or professional) environment. Fritzsche (2000) finds that the majority (58\%) of employees at a high tech firm subscribe to laws and professional codes of ethics for a variety of ethical dilemmas, followed by personal morality (17\%), company profit/self-interest (12\%), firm rules and procedures (8\%). Bone and Corey (2000) also demonstrate the prevalence of two types of values: pragmatic and moral values. Pragmatic values refer to business-relevant values such as profit maximization and organizational efficiency. Fritzsche (1995) also report 
that such instrumental values explained differences in managers' judgments on bribery, lying, and whistle-blowing (i.e., identifying and reporting of an unethical behavior).

Some researchers overtly suggest that ethical decision-making differs between work and non-work situations for the same individual (Fraedrich 1988; Ferrell et al. 1989). Zey-Ferrell, Weaver, and Ferrell (1979) report that both opportunities, or the "occurrence of the right combination of circumstances to permit ethical/unethical behavior" (Ferrell et al., p. 61), and differential associations with peers and top management predicted ethical behaviors in a marketing firm better than their personal beliefs about ethical behaviors.

Expanding the notion of environmental effects, Hunt and Vitell's (1991) ethical behavior model includes three forms of environment: professional, industry, and organizational. Each of these forms contain its own: (1) informal norms, (2) formal codes, and (3) code enforcement, such that "all industries, professional associations, and organizations have complex sets of norms, some of which are often formalized in codes, but most of which are informal norms communicated in the processes whereby individuals are socialized into their respective organizations, professions, and industries" (p. 782). Sethi (1994, p. 806) notes, there is a "systematic pattern of illegal and unethical behavior that persists in all industrial and corporate sectors," and that highly competitive industries may also promote greater opportunities and incentives for unethical business behaviors. 


\section{$\underline{\text { Summary and Implications for Opportunism }}$}

The stream of research is in line with social cognition research (see Folkes and Kiesler 1991 for review), which views that people's social perception greatly influences their behaviors. In a business-to-business context, I posit that the same is true. That is, buyer-seller transactions never occur in a vacuum isolated from all surrounding social influences of a complex business environment. Understanding the social context thus provides a dynamic, holistic view of the ethical behaviors within interfirm exchanges.

\section{The Social Network Mechanism}

The present research intends to broaden the scope of analysis by treating marketing channel relationships as residing within business networks. A business network is a set of connected relationships between firms (Astley and Fombrun 1983;

Miles and Snow 1992; Häkansson and Johanson 1993; Anderson et al. 1994). The extant marketing literature on networks focuses on the characteristics of such networks. For example, Achrol and Kotler (1997) categorize a variety of network forms, including internal network, vertical networks, intermarket networks, and opportunity networks. Iacobucci and Hopkins (1992) model dyadic relationships and interdependent relationships in the network in terms of coalition formation in buying centers, identification of opinion leaders, and so forth. Anderson et al. (1994) provide insights on the "connectedness" of firms. So far, very few studies have explicitly examined the impact of network on firms' behaviors.

Social network theory's basic premise is the interdependent nature of firms and how their positions in networks influence their opportunities, constraints, and economic 
behaviors (Wasserman and Galaskiewicz 1994). The most prominent view of social network is the concept of "embeddedness" (Granovetter 1985). The basic premise of the embeddedness perspective is that a firm's economic actions are shaped by the structure of its social relationships. Granovetter (1985) is critical of new institutional economics (i.e., TCE) because it fails to appreciate the extent to which the dyadic relations are embedded in broader systems of social relations. He also argues that "the anonymous market of neoclassical models is virtually nonexistent in economic life and that transactions of all kinds are rife with the social connections" (p. 495).

Antia and Frazier (2001) is an exception; they investigate network characteristics (viz., network density and network centrality) in interfirm relationships, in particular, franchising. Their results suggest that the franchisor may take less severe disciplinary response to an agent's violation of a contractual obligation when the franchisee network is dense. Network density (Burt 1992) refers to the strength of relationships within a network. Such strong within-network communication and close ties facilitate high levels of shared beliefs and consensus (Friedkin 1984; Galaskiewicz and Wasserman 1989; Meyer and Rowan 1977). They also suggest that the network centrality, or the strength of an individual agent's position in an agent network, also lead the principal to tone down enforcement response.

Similarly, so-called network closure argument suggests that obligations, information channels, and social norms develop within a network, which in turn reduce risks of uncertainty and facilitate trust (Coleman, 1988, 1990). Coleman (1988) argues that individuals in closed networks of personal relations often convey and reinforce norms of exchange and more easily able to monitor their observance and enforce 
sanctions. As such, social norms enforce sanctions because "mutual acquaintances

observing two people: (a) make behavior between two people public, which (b) increases the salience of reputation for entry to future relations with the mutual acquaintances, (c) making the two people more careful about the cooperative image they display, which (d) increases the confidence with which each can trust the other to cooperate" (Burt, 2000, p. $352)$.

Granovetter's (1985) embeddedness argument stresses "the role of concrete personal relations and structures (or "networks") of ... relations in generating trust and discouraging malfeasance" (p. 490). Providing a synthesis of TCE and social network theory, Jones, Hesterly, and Borgatti (1997) propose that there are two social mechanisms for safeguarding exchanges: collective sanctions and reputation. Though they are not legally binding, they are "socially-binding" (p. 914), such that collective sanctions "involve group members punishing other members who violate group norms, values, or goals and range from gossip and rumors to ostracism and sabotage" (p. 931). Collective sanctions "safeguard exchanges for they define and reinforce the parameters of acceptable behavior by demonstrating the consequences of violating norms and values" (Jones et al. 1997, pp. 931-932). Reputation "involves an estimation of one's character, skills, reliability, and other attributes important to exchanges and is important under exchange conditions of uncertainty and customization" (p. 932). The Maine lobster industry, for example, sanctions its "interlopers" who violate well-accepted norms of territorial fishing "through surreptitious destruction of their traps" (Acheson 1985, p. 386). Hagen and Choe (1998) and Yamagishi (1988) also support the existence of social 
sanctions and propose that Japanese cooperative interfirm relationships are made possible by such mechanisms.

Reputation, according to Jones et al. (1997), "reduces behavioral uncertainty by providing information about the reliability and goodwill of others" and "safeguards exchanges because it relays the detection of and serves to deter deceptive behavior, which enhances cooperation" (p. 933). In the entertainment film industry, for example, those "with successful track records move ahead in their careers, those with moderate reputation do not, [and] those with poor reputations experience employment difficulties" (Faulkner and Anderson 1987, p. 881). Both Dyer (1996) and Williamson (1991, 1996) also suggest the firm's need to maintain good reputation for efficiency reasons. Williamson (1991, pp. 290-291) also mentions that, "reputation, supported by structural embeddedness, allows specialized exchanges to occur under a wider range of governance mechanisms."

Furthermore, Uzzi (1997) conceptualizes the formulation of exchange as a continuum of exchange, such that a firm may belong to a network that ranges within the extremes of neoclassical (or transactional) to embeddedness. Empirical examples of embedded relationships include Japanese auto and Italian knitwear industries, which may be characterized by trust and personal ties, rather than explicit contracts, and these features make expectations more predictable and reduce monitoring costs (Dore 1983; Asanuma 1985; Smitka 1991; Gerlach 1992). 


\section{$\underline{\text { Summary and Implications for Opportunism }}$}

As Antia and Frazier (2001, p. 77) encourage marketing channels researchers to incorporate a network-level perspective because "Network characteristics are likely to influence most aspects of the interfirm coordination process," it is crucial to include extra-dyadic influences on interfirm opportunism. The present research develops a theoretical framework for analyzing the role of network as a control mechanism in marketing channel relationships, possibly moderating the linkage between PFO and OB. It is also noteworthy that the two control mechanisms, collective sanctions and reputation, proposed by Jones et al. (1997) have not explicitly been examined in combination with other, dyadic level control mechanisms, such as monitoring and TSIs. 


\section{CHAPTER III}

\section{CONCEPTUAL DEVELOPMENT}

The extant marketing channel literature has seldom examined the opportunism construct explicitly, with several exceptions (Brown et al. 2000; Gundlach et al. 1995; Rokkan et al. 2003; Achrol and Gundlach 1999; Joshi and Arnold 1997; Provan and Skinner 1989; Anderson 1988; John 1984). Following Kahneman et al. (1986a, 1986b) who criticize the widely used, normative theoretical frameworks (i.e., TCE and agency theory) for their overly simplistic view of human decision making in complex societal contexts, the dissertation aims to extend the extant literature by offering an alternative, behavioral perspective of opportunism by integrating a number of research streams which were reviewed in Chapter Two.

The literature reviews reveal that uncritically assuming opportunism and treating exchange partners with distrust can inadvertently exacerbate the problems of opportunism. Rather than automatically assuming opportunistic nature in exchange partners, I propose that the degree of PFO (propensity for opportunism) is contingent on individual, dyadic, and extra-dyadic factors. The reviews in Chapter Two support the idea that all three levels of analysis are needed to gain a more complete picture of the complex nature of opportunism in marketing channel relationships. Integrating the scattered literature streams is much needed not only to enhance our understandings of interfirm opportunism but also to investigate the boundaries of the traditionally used normative frameworks for opportunism, which are based on rational economic actor assumptions. 
Figure 3.1 depicts my conceptual model. In this chapter, hypotheses will be developed for each factor that is proposed to contribute to PFO or OB. By subjecting these hypotheses to empirical testing, this research aims to provide answers for (1) the extent to which individual differences impact the PFO of an exchange partner, (2) the extent to which relational structure influence PFO and OB, and (3) the role of extra-dyadic forces in opportunism. By answering these research questions, I also hope to understand better the appropriate levels of the explicit control mechanisms (e.g., monitoring) in preventing opportunism.

\section{Determinants of Propensity for Opportunism}

The following sections describe the hypotheses at the individual, dyadic, and extradyadic levels of analysis with regards to the determinants of PFO. As Figure 1 shows, the literature review from the previous chapter reveals factors at each level of analysis that may contribute to PFO in marketing channel relationships.

\section{Individual Level Analysis}

Agents' ethical behaviors such as keeping promises, meeting obligations, and even acting loyally without the presence of direct payoff go against the TCE's and agency theory's assumption of the norm of self-interested behavior. Such behaviors, however, pose potential benefits of reducing transaction costs, even from the economists' point of view. Using game theory solutions, Noreen (1987) demonstrates that ethical behaviors result in more productive outcome than competitive behaviors. Organizational theorists 
FIGURE 3.1: Conceptual Model

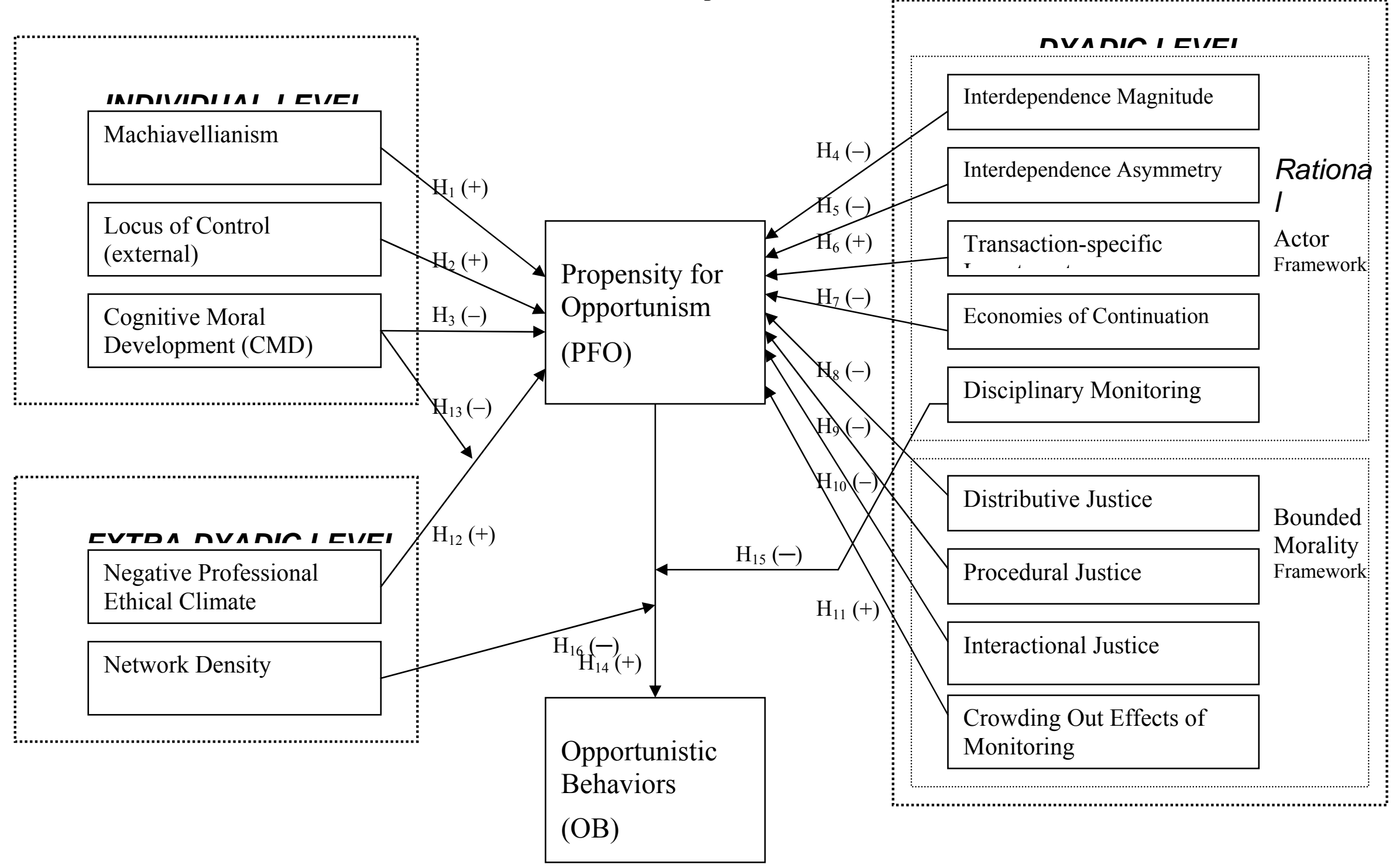


have argued for decades that acts of loyalty are productive and efficient (Ouchi 1980; Barnard 1938).

Regardless of whether ethical behaviors benefit or hurt the overall outcome of an exchange relationship, the present research's premise is that individuals differ significantly in terms of ethical behavior propensity. Some individuals may prioritize maximizing individual payoff and choose to act in a way that disregards subsequent consequences to others, while others may emphasize moral principles over personal gains. That is to say, some would engage in ethically-correct behaviors only if doing so were economically rewarding, while others would act ethically even if such acts did not promote personal gains.

The extant marketing channel literature, however, has neglected to investigate possibilities that individual-specific characteristics may explain differences in the levels of one's likelihood of behaving opportunistically. I argue that individual-specific traits have significant effects on PFO and deserve empirical examinations.

\section{Machiavellianism}

Machiavellianism is a personal trait construct based on the writings of Niccolo Machiavelli (1992/1513). Machiavellianism refers to the extent to which an individual detaches from considerations of ethics and perform actions that profit the self (Robinson and Shaver 1973). Such an ability to be calculative and to take advantage of other individuals to maximize his/her own wealth has long been considered to impact one's ethical behavior. 
Previous research has consistently shown a significantly positive correlation between Machiavellianism and unethical behavior (see Ford and Richardson 1994 and Loe, Ferrell, and Mansfield 2000 for review). Hegarty and Sims $(1978,1979)$ find Machiavellianism to be positively correlated with engaging in bribe payments in laboratory experiments. When it comes to ethical judgment, Vitell, Lumpkin, and Rawwas (1991) find that Machiavellians (i.e., those whose Machiavellianism scores are high) tend to regard questionable consumer practices as generally acceptable. Mudrack (1993) reports a similar finding that Machiavellians tend to regard questionable organizational behaviors as generally acceptable.

In addition, Machiavellians are more likely to exploit loosely structured elements of situations than others (Christie and Geis 1970; Schepers 2003). Schepers (2003) shows that Machiavellianism is negatively related to contractualism, or relational contracts, under which individuals are committed to relationally justifiable standards of morality to which each will be held. It is these fundamental characteristics of Machiavellianism that gives rise to opportunistic propensity. Both TCE and agency theory assume everyone has such a cold, calculating nature. Based on past research, I propose that only Machiavellian individuals have such natures, and they are more likely to have high levels of PFO because they mainly are concerned about maximizing their own gain rather than mutual gain and reciprocating good will:

$\mathbf{H}_{1}$ : Managers with higher Machiavellianism exhibit higher levels of PFO. 


\section{Locus of Control}

Locus of control is another personal construct of interest. Locus of control refers to the extent to which individuals attribute events as contingent upon themselves (Rotter 1966). A locus internal individual "perceives that the event is contingent upon his own behavior or his own relatively permanent characteristics," (Rotter 1966, p. 1). On the other hand, locus externals perceive events "as following some action of his own but not being entirely contingent upon his action" (Rotter 1966, p. 1) such that reinforcement is conceived as the result of forces beyond one's control, such as chance, fate, or powerful others (Lefcourt 1981).

Previous studies have found that individuals with an external locus of control are more likely to behave unethically than those with an internal locus of control (Hegarty and Sims 1978; Jones 1993; Forsyth et al. 1985; Karabanick and Srull 1978; Leming 1980). As for individuals with an internal locus of control, Trevino and Youngblood (1990) also report that they show more consistency between moral judgment and moral action than the external locus counterpart. In addition, some researchers suggest that they are generally more likely to engage in pro-social behavior (i.e., behavior concerning the well-being of others) (Lefcourt and Wine 1969; Spector 1982; Zahra 1989) than the external locus ones.

In summary, a substantial amount of empirical results seems to suggest that locus of control is an important indicator for PFO. Because the previous research shows that locus internals are more likely to behave in morally-correct ways, I hypothesize that they will also be less likely to behave in ways that jeopardize the development of a mutually beneficial relationship. Hence, 
$\mathbf{H}_{2}$ : Managers with an external locus of control are more likely to exhibit higher levels of PFO than their internal counterparts.

\section{Cognitive Moral Development}

$\mathrm{CMD}$, as reviewed in the previous chapter, is an individual-level construct that measures advances in moral reasoning and is based on Piaget (1965) and Kohlberg's (1969) findings that individuals develop the capacity for advanced logical reasoning through successive stages from childhood to adulthood. The original contention of CMD was that the moral maturity predicts moral actions (cf. Colby and Kohlberg 1984).

Today, the consensus remains that CMD is a necessary but not sufficient condition for ethical conduct, as postulated by Kohlberg (1969) and Rest (1979). Nevertheless, researchers have generally shown the positive association between CMD and ethical behaviors (cf. Rest 1986). Many studies continue to demonstrate such effects (e.g., Gooslby and Hunt 1992). It is also noteworthy that Arnold and Ponemon (1991) report that individuals with higher CMD identified and reported an unethical behavior (i.e., whistle-blowing) more often than those with a lower level of CMD. This may also be an indication that individuals with advanced CMD behave ethically more often than those with less advanced CMD.

As for marketing channel managers' PFO, I propose that those with more advanced CMD are more likely to adhere to their obligations and fulfill their duties because they (1) are more aware of behaviors that are morally correct and (2) place less emphasis on personal gains that are at the expense of others. Hence,

$\mathbf{H}_{3}$ : CMD and PFO are negatively related, such that as mangers exhibit more advanced CMD, the magnitude of PFO decreases. 


\section{Dyadic Level Analysis}

The following sections are categorized into two frameworks: (1) rational actor framework and (2) bounded morality framework. The rational actor framework is based on the assumptions of both TCE and agency theory, which have been the primary frameworks used in previous literature on opportunism (cf. Wathne and Heide 2000). The bounded morality framework primarily benefits from the organizational justice literature, which highlights employees' tendencies to react to perceived injustice within the organization in order to restore balance.

The term "bounded morality" was originally coined by Beitz (1979) and was intended to reflect the moral controversy about the Vietnam War and other international relations. Beitz refers to just war theory which is inherently complicated by the presence of many positions that can be taken to judge what is moral or immoral. That is, moral judgment is greatly influenced by the perspective one chooses to take. This is to be contrasted with the rational actor framework, which assumes a rational ability to select profit-maximizing strategies in any context. Bounded morality framework, therefore, is used to reflect the agent's judgment of moral behaviors (or what may be considered “acceptable" behaviors), which are influenced by the relationship context. In other words, the agent's perceptions of acceptable behaviors are bounded to the extent that they are distorted by the perceptions of the relationship characteristics.

\section{Rational Actor Framework}

The present research incorporates both normative, rational actor frameworks (i.e., TCE and agency theory) and descriptive, norm-based perspectives, as Kahneman et al. 
(1986a, 1986b) recommend. The premise of both TCE and agency theory is that firms or agents act exclusively out of self-interest. According to Moe (1984, p. 756), "The agent has his own interests at heart, and is induced to pursue the principal's objectives only to the extent that the incentive structure imposed in their contract renders such behavior advantageous."

Hypotheses developed in the following sections are based on these assumptions. Three factors uncovered in the literature review are likely to influence the extent to which the agent likely will act opportunistically: (1) interdependence, (2) transaction-specific investments (TSIs), and (3) economies of continuation.

\section{Interdependence}

The extant research suggests self-regulation (Eisenhardt 1989) or self-enforcing contract (Telser 1980) as a strong control mechanism. As reviewed by Wathne and Heide (2000), self-enforcing agreements can take a variety of forms, such as TSIs (i.e., hostages) (Williamson 1983) and price premiums (Dutta et al. 1994), both of which suggest that discontinuing the relationship would result in a significant loss, so that jeopardizing the relationship is not in a rational actor's best interest.

Lusch and Brown (1996) show that bilateral dependency is associated with relational behaviors because the interdependent parties are motivated to make the relationship work and endure (Buchanan 1992). Kumar et al. (1995a) also show that high levels of interdependence are related to high levels of trust and commitment. Gundlach and Cadotte (1994) also suggest that increased mutual dependence is related to relational 
behaviors and refraining from opportunistic behaviors to avoid jeopardizing the relationship.

Hence, it is expected that high levels of interdependence effectively deter PFO because the involved parties believe opportunistic behaviors would jeopardize the relationship and result in significant losses.

$\mathbf{H}_{4}$ : Managers exhibit lower levels of PFO as interdependence magnitude grows larger.

\section{$\underline{\text { Asymmetric Dependence }}$}

Morgan and Hunt (1994, p. 24) note that "expected termination costs lead to an ongoing relationship being viewed as important, thus generating commitment to the relationship." The dependent party, given the high costs of switching partners, should be motivated to avoid behaving opportunistically. Even without actual termination, the more powerful party can make credible threats (Keith, Jackson, and Crosby 1990). Firms, when interdependence asymmetry is to their advantage, have less incentive to continue such relationships should they fall short of expectations (Lusch and Brown 1996).

Provan and Skinner (1989) show that farm equipment dealers' service dependence on their suppliers was negatively related to dealer opportunism, and they suggest that dependence deters opportunism when the dependent party is concerned about retaliation by the other firm. Furthermore, the dependent party's reactions to the partner firm's destructive acts are likely to be passive and disengaging in order to avoid escalation (Hibbard, Kumar, and Stern 2001; Kumar, Scheer, and Steenkamp 1998). 
Assuming that marketing channel managers are calculating and self-interest seeking, then when they are unilaterally dependent on the partner firm, they should be less inclined to behave opportunistically:

H5: Managers exhibit lower levels of PFO as interdependence asymmetry favoring their partner firms grows larger.

\section{$\underline{\text { Transaction-Specific Investments }}$}

Continuing with the concept of self-regulation, TSIs also serve as an incentive not to behave opportunistically (Williamson 1983). Previous literature suggests that the nonsalvageable nature of transaction-specific investments deters opportunism. Closely related to the self-regulation approach of incentive alignment, the agent's TSIs serve as "hostages" such that "engaging in opportunistic behavior and risking the dissolution of the relationship is contrary to the self-interest of the channel member" (Anderson and Weitz 1992, p. 21). This is in line with the assumption about the agent's self-interest seeking behaviors. "Credible commitment" (Anderson and Weitz 1992; Klein and Leffler 1981; Telser 1981; Williamson 1983), or a high level of TSIs, is one indication of the agent's level of behavioral commitment. There is an underlying notion of switching costs (Jackson 1985), such that TSIs make them less likely to jeopardize the relationship by acting opportunistically (cf. Williamson 1996). Wathne and Heide (2000) describe the situation as agents being "locked-in" (p. 39) with a principal. Previous empirical studies, though, indicate no straight-forward effects of TSIs in reducing opportunistic behaviors. For example, Brown et al. (2000) show that TSIs actually exacerbate the problem of opportunism. One possible explanation, according to the authors, is that "opportunistic 
behavior is one way the hotel [the agent] can generate additional returns on these investments" (p. 63). That is to say, TSIs can actually motivate the agent to act opportunistically in order to maximize the return on their investments.

Agency theory, therefore, is in agreement with both arguments. Following Brown et al.'s (2000) post hoc discussion, it is proposed that the effects of TSIs may be contingent on the principal's monitoring effectiveness. Wathne and Heide (2000) suggest that a high level of information asymmetry facilitate a condition in which agents may pursue opportunistic actions without being caught. The results obtained by Brown et al. (2000) indicate that TSIs as a control mechanism, the first argument, may be true in the case of effectual monitoring. They also suggest that when the chance of being caught and sanctioned is slim, it may encourage the agent to try to maximize the return on investments. Under ineffectual monitoring, therefore, rational actors may find the cost of being caught and sanctioned to be sufficiently lower than the benefits of acting opportunistically.

Many empirical studies have shown the positive relationship between high levels of asset specificity (i.e., high levels of TSIs) and vertical integration (e.g., Klein, Frazier, and Roth 1990; Levy 1985; Maltz 1994; Masten, Meehan, and Snyder 1991; Monteverde and Teece 1982). However, little research has examined the direct relationship between TSIs and opportunism, with a notable exception of Brown et al. (2000). Despite several researchers' (e.g., Klein and Leffler 1981; Klein 1980; Williamson 1983) contention that TSIs serve as hostages which serve as a disincentive for opportunism, I expect that TSIs increase agents' willingness to act opportunistically (i.e., PFO) to gain return on investment following the findings of Brown et al. (2000). Hence, I hypothesize that, all 
else being equal, agents exhibit reduced levels of PFO when they have invested high levels of TSIs.

$\mathbf{H}_{6}$ : Managers exhibit higher levels of PFO when they have invested higher levels of TSIs.

\section{$\underline{\text { Economies of Continuation }}$}

Following the same line of thinking, economies of continuation (Jacobides and Croson 2001), or economic rewards for expected future exchange with the same partner (i.e., "shadow of the future" by Heide and Miner 1992), should have implications on agents' PFO simply because they have too much to lose if opportunistic behaviors are found that could jeopardize future exchanges.

Klein and Leffler (1981) suggest that the agent's expected future benefits from continuing the relationship may be enough incentive to deter shirking. Both Heide and Miner (1992) and Dyer (1996) show that agents engage in cooperative behaviors when they anticipate extended future exchange.

Agents' perceptions of economies of continuation should reduce PFO because the future exchange opportunities are contingent on the current performance, and rational economic actors would view sacrificing the future exchange opportunities with the principal as irrational.

Therefore, I hypothesize that economies of continuation are negatively related to PFO for economic reasons.

$\mathbf{H}_{7}$ : Managers exhibit lower levels of PFO when their perceptions of economies of continuation with the same exchange partners are higher. 


\section{Bounded Morality Framework}

The key distinction between the rational actor model and the bounded morality model is the assumption of economic rationality. Both agency theory and TCE assume that agents are rational actors who will always choose actions that maximize individual wealth. The bounded morality framework assumes individuals' perceptions of acceptable behaviors depends on how they are treated by the principal. The agents, rather than focusing on maximizing their own wealth whenever possible, instead are influenced by the degree of reciprocation and fairness in their relationship with the principal.

The descriptive, norm-based perspectives question these normative theories' assumptions, which have received mixed empirical support (see Rindfleisch and Heide's review 1997). John (1984) contends that the behavioral assumption is too simplistic:

"It appears that opportunism can be viewed usefully as an endogenous variable that is evoked by certain antecedents within a long-run relationship. In other words, individuals may not always behave opportunistically even if the conditions permit such behavior. Refusals to honor agreements and misrepresentation of intentions cannot be taken for granted. Rather, they are induced by certain other factors" (p. 287).

I concur that managers' behaviors may be largely influenced by the exchange context. The marketing channels literature provides plenty of evidence that affect play an important role in relationship management, such as satisfaction (see Geyskens et al. 1999 for review), affective commitment (Kim and Frazier 1997; Bello and Gilliland 2002), and perceived fairness (Dwyer et al. 1987; Kumar et al. 1995b). If managers strictly follow the rational actor assumption of TCE and agency theory, these emotions should play no role in managers' pursuit of unilateral outcome maximization. My aim here is to investigate the relative strength of rational actor and bounded morality frameworks. 
The extant literature has shown that relational norms at the dyadic level are developed through reciprocal exchange over time (Heide and John 1992; Noordewier et al. 1990). Once the relational norms are established in an exchange relationship, it is widely accepted that the threats of opportunism are deterred significantly (cf. Brown et al. 2000). As such norms develop over time with repeat collaborative transactions (Dwyer et al. 1987; Macneil 1980), I believe it is important that I examine the conditions that promote relational behavior. Instead of focusing on relational norms as a primary control mechanism, I conceptualize relational behaviors (i.e., information exchange, flexibility, shared problem solving) as the opposite of opportunism. That is, relational norms and OB are not in a causal relationship; rather, they represent different levels of cooperation as OB is a manifestation of unilateral gain seeking, while bilateral gain seeking is manifested relational norms.

The extant research shows that perceived fairness or justice in an exchange relationship is a necessary condition for the development of relational norms (cf. Gundlach and Murphy 1993). Gundlach and Murphy (1993) note that ethical principles such as fairness are the foundation of any meaningful exchange relationships. Hardin (2001) also suggests that reciprocity plays a central role in relationship development:

"The more I encounter people who reciprocate my cooperative gestures, the more I come to understand the nature of our potentially beneficial interaction, so that I become trustworthy in the sense that I begin to take others' interests into account in deciding what to do. When furthering their interests furthers mine and I recognize this fact, they have reason to judge me to be trustworthy" (p. 25).

Unlike explicit formal contracts, relational exchange relies heavily on psychological contracts, which are made up of beliefs about the reciprocal obligations 
between exchange partners. Such beliefs are developed through repeat transactions that support norms of equity (Ring and Van de Ven 1992). The development processes of cooperative interfirm relationships are, in Ring and Van de Ven's (1994) framework, cyclical and based on reciprocal fair dealings over time.

In addition, Gundlach and Murphy (1993) note that relational norms are grounded in honesty, fairness, and equity because an enlightened self-interest for the preservation of the relationship guides the exchange. According to Dwyer et al. (1987), perceived justice in interfirm exchanges is necessary for developing trust between firms. Studies by Kumar et al. (1995b) also show that perceived fairness significantly enhances relationship quality (trust, commitment, and conflict). Ganesan (1994) also demonstrates that a channel member's satisfaction with an equitable relationship is positively related to their perception of a vendor's benevolence and credibility.

The dissertation's take on the bounded morality framework reflects Trivers' (1971) notion of "reciprocal altruism." Trivers (1971) views each individual as possessing both altruistic and cheating tendencies. He demonstrates reciprocal altruism using the ecological system context, which he then applies to the human species. Reciprocal altruism is essentially analogous to the description of "an ongoing pattern of interaction in which I help you, then you help me" (Jencks 1990, p. 61). It is a learning process by which individuals determine the adaptiveness of reciprocal altruism. He also explains that variables such as friendship, dislike, moralistic aggression, gratitude, sympathy, trust, suspicion, trustworthiness, and guilt are the variables that contribute to the ultimate cost-benefit balancing of altruistic behaviors. Hence, Trivers' view is that 
agents' decisions to behave cooperatively is greatly influenced by the perception of relationship quality.

Based largely on the organizational justice literature, the bounded morality framework, or affect-driven rationality of appropriate behaviors, is different from the rational actor framework in that the bounded morality framework assumes that economic actors are sensitive to the exchange context. Here, agents, rather than focusing on maximizing their own wealth whenever possible, instead are carried away by emotions based on perceived relationship quality with the principal. To a large degree, the organizational justice literature is based on cognitive dissonance theory (Festinger 1957), which posits that individuals react to dissonance, or a negative drive state caused by holding two dissimilar cognitions. Individuals are then motivated to eliminate or reduce that dissonance even if such actions may be irrational and lead to suboptimal outcomes for themselves. The organizational justice literature argues that the presence of injustice creates tension that is proportional to the magnitude of perceived injustice, which in turn motivates individuals to act to regain balance (see Adams 1965).

Akerlof (1982) and Nagin, Rebitzer, Sanders, and Taylor (2002) also offer a remarkable perspective of psychological costs of bad behavior. Using Homans'(1954) observation of a small group of workers who neither desired nor expected rewards substantially exceeding the minimum work standards, Akerlof (1982) discusses in his model of "gift exchange" what the standard neoclassical economics theory cannot explain: norms of reciprocation. His model focuses on the utility a worker derives from work efforts, which s/he then uses to determine the level of effort which maximizes utility. Nagin et al. (2002) further elaborate on this idea and show that agents' positive 
attitudes toward employer reduce their opportunistic behaviors that maximize their wealth at the expense of their principals. Nagin et al. (2002) explain that these employees experience heightened disutility in engaging in opportunistic behavior, which "may be due to feelings of reciprocity for receiving fair treatment from the employer or may reflect a set of innate psychological traits (such as empathy) that make it easier to feel good about the employer and also raise the psychological costs of bad behavior" (p. 867).

Such tension may be caused by perceived distributive, procedural, or interpersonal injustice. In addition, I also expand the bounded morality framework to include the "crowding out effect of monitoring" (Frey 1993) as monitoring often signals mistrust (Ghoshal and Moran 1996). Monitoring is generally defined as any information collection by the principal to ensure contractual responsibilities (Jacobides and Croson 2001; Fama and Jensen 1983), and I argue that monitoring efforts may backfire unless carefully planned.

\section{Distributive Justice}

As reviewed in the previous chapter, equity theory (Adams 1963; 1965) posits that individuals are sensitive to equity relationships such that they evaluate their relationships with others by assessing the ratio of their outcomes from and inputs to the relationship. In addition, they feel distressed when inequity exists and individuals react to restore equity by distorting inputs or outputs.

The empirical studies in the organizational literature, using a wide variety of simulated work settings, have found support for these predictions (see Greenberg 1982 for review). In addition, equity theory research has examined the impact of perceived 
equity/inequity on a number of organizational outcome variables, such as quality of work (Andrews 1967; Goodman and Friedman 1968; Valenzi and Andrews 1971), turnover (Carrell and Dittrich 1978; Telly, French, and Scott 1971), and absenteeism (Carrell and Dittrich 1978). More recently, survey-based empirical studies in the organizational behavior literature have shown that the perceived distributive injustice influences employees' behaviors (Greenberg 1990). Janssen (2001) demonstrates that job performance and job demands have a negative relationship for the surveyed managers who believed they were underrewarded, while those whose perception of effort-reward fairness was high performed better and felt more satisfied as job demands increased to intermediate levels. Moorman (1991) empirically demonstrates that the perception of distributive justice greatly influences employee citizenship behaviors (e.g., courtesy, civic virtue).

In the context of marketing channels relationships, some studies have shown the effects of generally perceived unfairness on interfirm conflict and dissatisfaction (Frazier 1983; Frazier et al. 1988). Kumar et al. (1995b) demonstrate the negative relationship between distributive injustice and relationship quality. Ramaswami and Singh (2003), in the salesforce context, unexpectedly found that salespeople under perceived distributive injustice are more likely to behave opportunistically by engaging in activities that undermine organizational effectiveness. The authors also report that perceived distributive justice is a significant indicator for overall job performance (e.g., meeting sales/business/professional objectives).

Interestingly, I also point out that distributive justice may have implications for the findings of Agrawal and Lal (1995) and Lal (1990) that increases in royalty rates by 
franchisors are related positively with increases in their monitoring frequency. As reviewed in the previous chapter, royalty rates and monitoring are highly correlated because of the potential "free-rider problem," and as Lal (1990) describes, the suspecting principal who wishes to maintain its brand equity increases monitoring efforts as a consequence. However, it could be said that increases in royalty rates could be understood in terms of distributive injustice. That is to say, rather than concluding that franchisees are self-interest seekers, quality shirking could have been due to unjust feelings of franchisees who are then motivated to balance inequity.

Based on these findings, I predict that marketing channel managers' perceptions of distributive justice are negatively related to PFO because their efforts in the channel relationships are rewarded fairly, and therefore have no motivation to establish equity:

$\mathbf{H}_{8}$ : Managers exhibit lower levels of PFO when their perceptions of distributive justice are higher.

\section{Procedural Justice}

While the focus of distributive justice is on the perceived fairness of resource distributions, the concept of procedural justice focuses on the procedures by which the reward allocation decisions are made. Contrary to the assumption of the agency theory, procedural justice research suggests that individuals' reactions to authorities go beyond whether such behaviors directly benefit their interests. Rather, individuals are sensitive to notions of respect, dignity, and fairness in authoritarian treatments (Tyler 1990; Tyler and Lind 1992).

In organizational justice research, empirical studies have shown that procedural justice and distributive justice have dissimilar effects on the consequences. Moorman 
(1991) shows the positive relationship between perceived procedural justice and organizational citizenship behaviors. Additional studies also indicate procedural justice better predicts employees' level of citizenship behaviors than does distribute justice (Organ and Moorman 1993; Moorman, Niehoff, and Organ 1993; Konovsky and Pugh 1994). Similarly, Folger and Konovsky's (1989) studies conclude that procedural justice better explains supervisor trust and organizational commitment, while distributive justice better explains job satisfaction.

In marketing channel relationships, Kumar et al. (1995b) examine simultaneously the effects of both distributive and procedural fairness on relationship quality (levels of conflicts, trust, and commitment) and show relatively stronger effects of procedural justice. In general, Colquitt et al.'s (2001) meta analysis the effects of various justice perceptions indicates that procedural justice explains well job satisfaction, organizational commitment, and job performance more so than the distributive justice counterpart.

Collectively, studies generally suggest that procedural justice is a good predictor of relational qualities such as organizational commitment and supervisor evaluation (e.g., Moorman 1991; McFarlin and Sweeney 1992; Sweeney and McFarlin 1993; Folger and Konovsky 1989). Hence, I expect that when agents feel their principals use fair procedures (i.e., consistent, accurate, correctable, representative, and ethical) in determining their reward allocation, they are less likely to feel the need to engage in retaliation to "get even" (Skarlicki and Folger 1997). Therefore:

$\mathbf{H}_{9}$ : Managers exhibit lower levels of PFO when their perceptions of procedural justice are higher. 


\section{$\underline{\text { Interactional Justice }}$}

Interactional justice is related to the perceptions of fairness in communication between principal and agents. Respectful treatment and truthful communication are two key characteristics of interactional justice (Bies and Moag 1986). Colquitt (2001) and Colquitt et al. (2001) demonstrate that although different justice dimensions (i.e., distributive, procedural, and interactional justice) are moderately to highly correlated, interactional justice is a distinct construct of its own. As interactional justice is a relatively new construct, a limited number of empirical studies have been conducted to date.

Among the few empirical tests of the consequences of interactional fairness, Ramaswami and Singh (2003) show that perceived interactional fairness of the supervisor greatly influences salespersons' job satisfaction and supervisor trust, which in turn enhance their organizational commitment and reduce opportunistic behaviors, respectively. Similarly, Masterson et al. (2000) report that interactional justice explain a significantly large variance in employees' perceptions of the quality of their relationship with their supervisors, which in turn positively impact job satisfaction and citizenship behaviors (altruism, courtesy, and careful attention to their jobs). In addition, Moorman (1991) unexpectedly finds that interactive justice explains job satisfaction and organizational citizenship behaviors, such as altruism and sportsmanship, better than the distributive and procedural justice counterparts. These pieces of empirical evidence suggest that agents reciprocate when they feel that their principals treat them with respect, kindness, and truthfulness in communications. Therefore, I expect that agents' perceptions of interactional justice in their exchange relationships with their principals 
have significant impact on their willingness to engage in cooperative behaviors (i.e., PFO). Thus,

$\mathbf{H}_{10}$ : Managers exhibit lower levels of PFO when their perceptions of interactional justice are higher.

\section{Crowding Out Effects of Monitoring}

In addition to the concepts of organizational justice, the bounded morality framework includes the crowding out effects of monitoring, which essentially derives from criticism of TCE's assumption of opportunism. According to Williamson (1993, p. 102), opportunism is the ultimate cause for the failure of markets and for the existence of organizations. By assuming opportunism, interfirm exchange relationships necessarily require explicit control mechanisms such as monitoring. According to Ghoshal and Moran (1996), however, assuming opportunism is dangerous because it leads to mechanisms that may create more opportunism, and they call the phenomenon a "selffulfilling prophecy."

Gilbert (1996) argues that opportunism abounds "if we go looking for it" (p. 174), and comments that the more we assume opportunism or see the world in terms of the prisoner's dilemma, the more likely we are to think and act like the prisoners in the model and become "prisoners of the prisoner's dilemma."

Ishikawa, as "one of the world's foremost authorities on [total] quality control"

(Chen, Sawyers, and Williams 1997, p. 839) notes,

"If a person does not trust his ... subordinates and imposes strict control and frequent inspection, he cannot be a good manager. His control is based on the belief that people are by nature evil, and such a system simply does not work (Ishikawa 1985, p. 66).” 
Moschandreas (1997) also contends that TCE fails to account for the diversity of

human motivation and its asymmetric use of opportunism:

“. . . to exercise authority ... systems measuring productivity, monitoring performance, auditing, and intervening to resolve disputes in case of conflict must be in place. Such systems do not discriminate between opportunists and nonopportunists. The question then arises as to what is the likely impact of structures built on the assumption of opportunism on individuals who are not inclined to behave opportunistically? The answer must include the possibility that such structures may (1) have adverse motivational and productivity effects, and more importantly (2) may compromise an individual's proclivity to behave honestly. Individuals, treated with suspicion and on the expectation that given the opportunity they will cheat, may be induced to behave in the postulated manner" (p. 47)

Her notion of authority is that of hierarchy (in-house), and she points out that "the premise that internal markets always work well may be seriously misguided if the impact of hierarchical structures on human behavior were adverse and significantly strong” (p. 47). Considering the consequences of distrusting others, Yamagishi (2001) also adds that "distrust breeds further distrust since it prevents people from exposing themselves to opportunities to develop social intelligence" (p. 139).

In addition, John (1984), drawing from the frustration-aggression phenomenon (e.g., Child 1972; Dewar and Werbel 1979) notes that the lack of autonomy and selfcontrol creates frustration particularly for autonomy-oriented entrepreneurs in the wholesaling and retailing sectors of marketing channels. Similarly, based on Reactance Theory (Brehm 1966), if relatively dependent agents view monitoring as mere enforcement of power by the principal, they build resistance and engage in reactance behaviors to undermine the constraints threatening their freedom of action (Joshi 1998).

Closely related is the term "zone of acceptance" (Simon 1947), and it can be said that the principal's authoritarian actions (i.e., monitoring) could have "perverse effects" 
(Jacobides and Croson 2001) if they fall out of the zone of acceptance. As reviewed in the previous chapter, Frey (1993) conceptualizes the crowding out effects of monitoring as breaking mutual trust (i.e., psychological contract) and "the agent affected sees no reason why he or she should not behave in an opportunistic way" (p. 664). More specifically, the crowding out effect refers to "how far the agent's self-determination and self-evaluation are affected by the principal's monitoring activities" (Frey 1993, p. 665).

The literature generally supports the idea that monitoring actually increases channel member opportunism (John 1984; Murry and Heide 1998). According to John (1984), bureaucratic structuring leads to "an erosion of positive attitudes" (p. 287). Perrow (1986) describes that monitoring is inescapably an obtrusive management approach by nature. Jacobides and Croson (2001) argue that more monitoring is not always better as it may "destroy social welfare even as [it] add[s] to principal welfare" (p. 206). Murry and Heide (1998) empirically support the idea by showing that monitoring efforts discourage retailers to participate in display programs. Ramaswami (1996) also shows that both outcome- and behavior-based controls are positively related to employees' dysfunctional behaviors such as gaming (behaviors that look good on paper but are dysfunctional for the firm otherwise), smoothing (evening out performance over time), focusing (enhancing or degrading performance information through selective communication to supervisors), and invalid reporting (deliberately reporting inaccurate data to management).

Some monitoring efforts can successfully aid agents' performance (Bello and Gilliland 1997) and hence they have a "disciplining effect" (Frey 1993). On the other hand, though, monitoring activities may have crowding out effects when used 
inappropriately. Within the context of employment relationships, Jacobides and Croson (2001) suggest that monitoring leads astray when it interferes with coordination, and thus monitoring should only be used when it is designed to facilitate "efficient resource allocation within the firm and directing the effort of employees to the most efficient goals" (p. 211). If the agent views monitoring as obtrusive and an act of mistrust, rather than as well-coordinated attempts to attain optimal outcomes to benefit both firms, it may induce increased negative feelings, such as distrust and disrespect for the principal.

Hence, I hypothesize that managers exhibit higher levels of PFO when they observe monitoring as overly intruding upon their autonomy $\left(\mathrm{H}_{11}\right)$ :

$\mathbf{H}_{11}$ : Managers, as a result of higher levels of the crowding out effect of monitoring, exhibit higher levels of PFO.

\section{Extra-Dyadic Level Analysis}

While research on marketing channels builds predominantly on the political economy framework, Grewal and Dharwadkar (2002, p. 83) point out that researchers have focused primarily on internal economic structure and processes, which they refer to as "microdyadic issues," yet have paid little attention to the ubiquitous influence of the institutional environment.

Accordingly, in addition to investigating the influences of individual differences ("bad apples") and dyadic structures, the present research model simultaneously examines the "bad barrel" argument. According to Trevino and Youngblood (1990, p. 378), the "bad barrel" refers to the argument that something in the environment poisons 
otherwise good apples. In this dissertation, I argue that examining the role of social forces provides further insights about PFO.

More specifically, I examine the roles of (1) negative professional ethical climates and (2) social network mechanisms. The former deals broadly with the professional ethical climate within an industry, while the latter is mainly concerned with "network density" (Burt 1992).

\section{Professional Ethical Climate}

A professional environment is comprised of socialization within a particular industry as well as membership in professional/industry associations. Professional ethical climate is conceptualized as the extent to which extra-dyadic environment discourages opportunistic behaviors in a dyad. According to integrative social contract theory (ISCT) (Donaldson and Dunfee 1994), there exist two types of social contracts: (1) normative and hypothetical contract among economic participants and (2) an existing implicit contract that can occur among members of specific communities, including informal subgroups within departments, professional associations, industries, national economic organizations, and so on. In this section, my focus in on the latter, the extent to which extra-dyadic ethical climate influences marketing channel managers' PFO within a dyad.

It is conceptualized that ethical climate pertains to the prevalence of informal norms for disregarding collective welfare. Informal norms represent shared values within a professional environment. Such informal norms "are communicated in the processes whereby individuals are socialized into their respective organizations, professions, and industries" (Hunt and Vitell 1991, p. 782). Empirical studies have concentrated on intra- 
firm informal ethical norms and demonstrated substantial influence of supervisor or senior management on employee's perceptions of acceptable behaviors (Chen, Sawyers, and Williams 1997; Chonko and Hunt 1985; Ferrell and Gresham 1985; Hegarty and Sims 1979; Nwachukwa and Vitell 1997; James 2000; Zey-Ferrell and Ferrell 1982). In terms of industry-level informal ethical norms, Jackall (1988) describes proliferated effects:

"[One executive in the textile industry says] We lie all the time, but if everyone knows that we're lying, is it really a lie? ... [many customers in the textile business] will lie, cheat, and steal from you without blinking twice. " (Jackall 1988, p. 121)

Cote and Goodstein (1998) also describe the nature of the security industry as having informal norms of self-interest seeking activities (e.g., insider-trading) rather seeking the interest of the public to whom they have primary responsibility. Sethi and Sama (1998) argue that propensity to engage in ethical or unethical behavior is determined greatly by market-competitive factors. Although no empirical studies have been conducted to examine directly the influence of informal ethical norms outside of a firm on an employee's ethical decision making, research findings in intra-firm settings suggest that such norms play an influential role in marketing channel managers' ethical decision making. In addition, many studies have reported the prevailing role of culture in on one's ethical perception, attitude, and behavior (e.g., Singhapakdi et al. 1994; Kracher et al. 2002; Christie, Kwon, Stoeberl, and Baumhart 2003). Chen, Peng, and Separito (2002) argue that cultural conditioning of individualism-collectivism influences one's feelings of moral obligations toward different transaction. I conceptualize that informal 
norms within a particular professional environment may be used as a reference on determining acceptable behaviors.

Research suggests that formal company rules and professional ethics codes and code enforcement also influence an ethical decision maker's moral judgment. Kohlberg's (Kohlberg 1984; Power, Higgins, and Kohlberg 1989) Just Community experiments demonstrate the critical roles of the environment (organizational policies and procedures) in schools and prisons in creating positive moral judgments and actual behaviors such as stealing and cheating. Other empirical studies also show that formal codes of ethics are positively related to ethical behaviors (e.g., McCabe et al. 1996; Ferrell and Skinner 1988). While ethical codes seem to play a substantial role, Murphy's (1995) review shows mixed findings of the effectiveness of codes of ethics. Several researchers highlight the importance of the enforcement of codes of ethics (Trevino 1990; Spekman and Salmond 1992; Ross and Robertson 2000), as well as clarity of the codes in communicating specific guidelines about ethical behaviors (Ross and Robertson 2000).

Collectively, in terms of PFO, it is hypothesized that marketing managers' PFO is influenced by their professional ethical climate. Hence,

$\mathbf{H}_{12}$ : Managers exhibit higher levels of PFO under higher levels of negative professional ethical climate.

\section{Interaction between CMD and Professional Ethical Climate}

In addition to focusing on the main effects of social networks, I propose interaction effects between professional ethical climates and CMD.

In line with the "bad barrel" argument, studies suggest that an individual's ethical behaviors are greatly influenced by environmental forces. In determining acceptable 
ethical behaviors, it is plausible that those with conventional level CMD are most likely to be influenced by the environment because they derive moral judgment based on "general social arrangements" (Rest 1979, p. 30). At the same time, those in postconventional level CMD may be less deterred by social influences because they uphold the basic rights and wealth of others. Ferrell et al. (1989, p. 58) observe that "The 'principled' individual sees beyond the norms, laws, or authority of groups or individuals." Trevino and Youngblood (1990, p. 379) also note, "With each successive stage, the individual's moral judgment grows less and less dependent on outside influences."

The interaction between CMD and professional ethical climates may be significant because research shows that most adults operate at the conventional level, which indicates that they are susceptible to the influence of their social environments (Trevino 1986). Studies also demonstrate that employees' personal moral convictions interact with organizational value systems (Nwachukwu and Vitell 1997; Frederick and Weber 1987).

Meanwhile, those individuals at the postconventional level may value the environmental influences, such as norms, laws, or authority of groups or individuals less than their conventional counterparts (Ferrell et al. 1989). The original conceptualization of CMD also is in agreement that individuals become less and less deterred by environmental influences with each successive stage (cf. Rest 1979). Hunt and Vitell (1991, p. 781) write, "Since stages of cognitive moral development [CMD] implies a high capacity to reason through complex ethical situation, it would seem that individuals high in cognitive moral development would, among other things, bring in more deontological 
norms in any situation and would consider the interests of more stakeholders in their

decision making." Deontological views, dating back to Socrates, emphasize the "best" set of rules to live by, while teleological views are relativistic, consequence-dependent judgments of morality (Frankena 1963).

It is also noteworthy that Kohlberg (1965) followed up Milgram’s (1974) obedience experiments conducted at Yale in the 1960s (reviewed in the previous chapter), in which the experimenter ordered the participants to give increasingly severe electric shocks to an experiment confederate. He interviewed the subjects in Milgram's experiment and reported that $75 \%$ of the stage six participants quit during the experiment while only $13 \%$ of the lower stage participants quit (Kohlberg 1965, 1969).

It is my intention to investigate the environment-CMD interactions because the extant literature has not empirically treated CMD as a moderator. Instead, CMD remains an independent variable contributing to ethical decision-making and/or behaviors. I hypothesize that advances in CMD mean being less susceptible to environmental influences, such that:

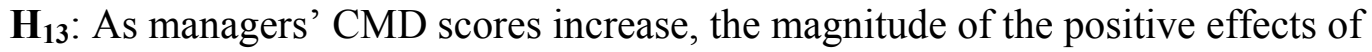
a negative professional ethical climate on $\mathrm{PFO}$ reduces.

\section{Determinants of Opportunistic Behaviors}

The premise of the conceptual model is that PFO and OB are positively related, and that the actual occurrence of $\mathrm{OB}$ is moderated by several factors (i.e., constraints) that reflect both social and economic costs of $\mathrm{OB}$.

$\mathbf{H}_{14}$ : Managers with higher levels of PFO exhibit higher levels of OB 
As shown in Figure 3.1, I have identified two moderating factors: (1) disciplinary monitoring and (2) network density.

\section{Disciplinary Monitoring}

At the dyadic level, disciplinary monitoring, or the principal's ability to detect and punish noncompliance (Eisenhardt 1985), is proposed to reduce the linkage between PFO and OB. Monitoring the agent's outputs can be ineffective when (1) the principal uncritically relies on measures that agents can "learn their way around" (Jacobides and Croson 2001) and manipulate information asymmetry to their advantage (e.g., Hunt 1986) and (2) high levels of ex ante causal ambiguity (Thompson 1967) exists, such that the principal employs inaccurate monitoring schemes that sacrifice relevance in the name of precision (Kaplan 1989). As such, measurement problems due to measurement imperfection and/or ex ante causal ambiguity can inhibit the principal's ability to catch agents' OB.

For monitoring to be disciplinary, it must be able to deter opportunism. That is, monitoring is ineffective when it does not involve adequate punishments. Following the rational actor framework, incurring little or no costs for opportunistic behaviors even after being caught would only encourage the agent to gain at the expense of the principal. In other words, the subsequent costs of being caught in opportunistic behaviors must be significantly greater than the benefit of the opportunistic behaviors. Wathne and Heide (2000) explain that monitoring is used to detect opportunism and ultimately the ability to match rewards and sanctions to the partner's behavior in an appropriate fashion. Hence, 
the concept of disciplinary monitoring is twofold: (1) ability to detect the agent's opportunistic behaviors and (2) employing adequate levels of punishment upon detection.

One domain needs not be correlated with the other. In fact, agents may opt to behave opportunistically if they see that they face little punishment should they be caught by the principals. At the same time, principals could impose serious punishment (e.g., sudden termination of exchange relationship) but which may be ineffective if they are unable to catch the agents behaving opportunistically. Hence, each of the two domains is necessary but not sufficient condition for disciplinary monitoring by itself. When both are in place, it can be an effective mechanism for curbing opportunism. Holmstrom and Roberts (1998), for example, show Japanese automakers actively monitor and adjust purchase volumes to reward suppliers for their good behavior (and punish bad behavior).

Following the rational actor framework, the agent must be calculative and weigh the costs and benefits of opportunistic behaviors. Given high levels of PFO, I expect that high levels of disciplinary monitoring should reduce the likelihood of actual OB. Hence,

$\mathbf{H}_{15}$ : Disciplinary monitoring reduces the magnitude of positive effects between PFO and $\mathrm{OB}$.

\section{Network Density}

In addition to the professional ethical climate, I also investigate the role of network density (Burt 1992), or the strength of social ties, within an "embedded" (Granovetter 1985) business network. The premise of a network perspective is that a firm exists within a business network, which is a set of connected relationships between firms (Astley and Fombrun 1983; Miles and Snow 1992; Häkansson and Johanson 1993; Anderson et al. 1994). Because of a network's embeddedness, a firm's actions are shaped by its social 
relationship within. Structurally embedded norms propel firms to be cooperative so as to reduce monitoring and coordination costs (Jones et al. 1997).

As reviewed in the previous chapter, network density (Burt 1992) represents the strength of relationships within a network. I propose that understanding the social ties of network relationships is critical in determining OB because strong ties facilitate high levels of shared beliefs and consensus (Friedkin 1984; Galaskiewicz and Wasserman 1989; Meyer and Rowan 1977), which lead to socially constructed norms and expectations of behavior (Oliver 1991; Myer and Rowan 1977; Coleman 1988; Rowley 1997; Walker, Kogut, and Shan 1997; Kreps 1990).

Network density seems to affect OB because of two social mechanisms: collective sanctions and reputation (Jones et al. 1997). Such socially binding mechanisms are important to those managers who have a strong involvement with other members of the network. Coleman (1988) argues that cohesive networks, due to the visibility of actions, effectively curb opportunistic behaviors. According to Jones et al. (1997), involved members can "punish other members who violate group norms, values, or goals and range from gossip and rumors to ostracism and sabotage" (p. 931). Hagen and Choe (1998) illustrate the powerful mechanism of social sanction in the context of the Japanese automotive industry. Antia and Frazier (2001) also find network density to have a significant effect on franchisors' decisions as to the extent of severity of contract enforcement on franchisees, because "potential costs of retaliation [by franchisee network] are likely to mitigate potential benefits of a more severe enforcement response" (p. 70). 
Keeping a good reputation within a network may be of concern to a firm, as Powell (1990) argues that social network arrangements represent the most efficient source of information for other firms both within and outside the network. In a similar vein, reputation plays an important role when searching for a potential exchange partner, as reputation helps identify a credible partner firm. Such a role of "trust transfer" (McEvily, Perrone, and Zaheer 2003) is well documented in the marketing channel literature (see Ganesan 1994; Kumar et al. 1995b; Weigelt and Camerer 1988; Anderson and Weitz 1992; Weiss, Anderson, and MacInnis 1999; Veugelers 1993).

In sum, network density is an important indicator of the two social mechanisms, collective sanctions and reputation, as "dense networks where closer relationships allow more communication, social sanctions can be more easily levied on individuals whose performance levels are below shared behavioral norms" (Senjem and Reed 2002, p. 142).

$\mathbf{H}_{16}$ : Network density reduces the magnitude of positive effects between PFO and $\mathrm{OB}$. 


\section{CHAPTER IV}

\section{METHODOLOGY - SAMPLE AND DATA COLLECTION}

This chapter outlines and details data collection procedures employed prior to the empirical test of research hypotheses. The three main areas covered are sampling, data collection, and description of the final sample. The development of scales is discussed in Chapter Five.

\section{The Sample}

\section{Study Population}

This dissertation's findings may be relevant to many business relationships, especially those in which opportunism is possible (i.e., in bilateral, monopolistic exchange). In terms of research methodology, an ideal sampling frame would consist of business-to-business relationships embedded in a broader social network.

Even though several researchers have called for marketing channel research to expand beyond its traditional focus on the dyadic relationship (see Anderson et al. 1994; Heide 1994; Achrol and Kotler 1997; Grewal and Dharwadkar 2002; Iacobucci and Hopkins 1992), few empirical examinations have been reported. Empirical studies of network density, one of my key research variables, have been especially limited with a few exceptions (Rowley, Behrens, and Krackhardt 2000; Senjem and Reed 2000; Antia and Frazier 2001). In particular, Antia and Frazier's (2001) research is the only research that has examined the role of network density in a dyadic exchange relationship.

Following Antia and Frazier (2001), I chose franchising as the study population. They find that interactions within a franchisee network play a significant part in a 
franchisor's decisions to enforce contracts on their franchisees. Indeed, franchising is frequently characterized by horizontal communication among franchisees, who often develop social relationships as a result. Such a degree of socialization is also crucial for the development of informal norms, which are "communicated in the processes whereby individuals are socialized into their respective organizations, professions, and industries" (Hunt and Vitell 1991, p. 782). In addition to informal norms, the franchising context should also provide an adequate context for two additional components of professional ethical climate: formal ethical codes and their enforcement (Hunt and Vitell 1991).

The sample population of franchising appears to vary sufficiently in these network-related constructs. The formative scale of Negative Professional Ethical Climate ranged from 1.00 to $7.00(\mathrm{M}=3.32, \mathrm{SD}=1.24)$ on a 7 -point scale ${ }^{5}$. Network Density ranged from 1.00 to $7.00(\mathrm{M}=4.60, \mathrm{SD}=1.53)$. The sample statistics suggesting that franchisee networks indeed offer sufficient variance in terms of network effects.

Franchising as the study population produced sufficient variance on other key constructs at the dyadic level as well. On the Interdependence construct, previous studies examining franchising relationships have shown that the costs of switching exist at different levels on both sides of the dyad (e.g., Antia and Frazier 2001). In addition, as Ingram (1996) describes, a franchisor's dependence on its franchisees exists to the extent that franchisees are accountable for maintaining and enhancing the reputation of the franchising brand. From a franchisee's perspective, levels of dependence on their franchisors may vary according to the levels of franchisor's support. Studies show that once franchisees become more experienced, they attribute their success to their own

\footnotetext{
${ }^{5}$ Unless noted otherwise, 7-point Likert-type scales (1="strongly disagree", 7="strongly agree") are used hereafter.
} 
efforts rather than to the efforts of the franchisor (Knight 1986), which may indicate lessened levels of dependence on franchisors. At the same time, franchisees who manage multiple locations may have more bargaining power than those who manage only one location. In the current study, Franchisor Dependence ranged from 1.00 to $7.00(\mathrm{M}=3.76$, $\mathrm{SD}=1.45)$, and Franchisee Dependence ranged from 1.00 to $7.00(\mathrm{M}=4.76, \mathrm{SD}=1.69)$, suggesting sufficient variance in both constructs.

Similarly, franchising as a study population provides sufficient variance in TSIs and Economies of Continuation. Franchisees incur a variety of franchise-specific investments from the start, such as initial investment, training, franchise brand-specific equipment, store-interior investments, and so on, which may not be recovered upon termination. Some industries, such as residential cleaning services and cosmetic and beauty care products typically incur much fewer TSIs as compared to hotels and restaurants. As for Economies of Continuation, the duration of franchise contracts vary greatly in length. As a franchisee owns a limited license, not a perpetual right, contract renewal frequency may be of a great concern to franchisees. In the sample, Franchisee TSIs ranged from 1.00 to $7.00(\mathrm{M}=4.96, \mathrm{SD}=1.63)$, and Economies of Continuation ranged from 1.00 to $7.00(\mathrm{M}=5.04, \mathrm{SD}=1.81)$.

Additionally, franchisors routinely monitor franchisees' operations to ensure compliance with pre-set standards. The frequency and depth of monitoring, as well as the severity of punishment for non-compliance should vary greatly across various industries and different franchises. As reviewed in previous chapters, the extent to which monitoring effectively detects opportunism should vary depending upon franchisees' task characteristics such as levels of task programmability. In the sample, Disciplinary 
Monitoring ${ }^{6}$ ranged from 1.00 to $49.00(M=23.01, S D=11.14)$, suggesting franchising offers sufficient variance in the extent of franchisors' ability to effectively monitor and discipline franchisees' non-compliance to agreed-upon terms.

Opportunistic Behaviors take a variety of forms in the franchising context as in other governance structures. The present research broadly defines opportunism as selfinterest seeking with guile, such that a franchisee engages in behaviors that unilaterally improve its term of trade. Breach of contracts, quality shirking, inaccurate reporting, violation of promotion agreements are examples of opportunistic franchisee behaviors that are prevalent in franchising. As franchising represents a hybrid form governance, it is impossible for franchisors to control franchisees' behaviors as they would in a hierarchy form of governance (Williamson 1985; 1996). To the extent that the interests of the principal and agent are imperfectly aligned, there exists room for opportunism in which franchisees may try to maximize unilateral gains at the expense of the franchisor. In the present sample, Opportunistic Behaviors ranged from 1.00 to $6.00(\mathrm{M}=2.43, \mathrm{SD}=1.26)$, which is somewhat negatively skewed. Though, previous studies using similar selfreporting opportunism scale share a common skewness. Table 4.1 summarizes a list of previous studies directly measuring opportunism (either self-reported or reporting on exchange partner) with reported means and standard deviations. It is apparent that skewness in response is common when a respondent reports his/her own deviant behaviors. In addition, other studies with exchange partners' degree of opportunism report similar negative skewness, with means ranging from 1.44 (Rokkan, Heide, and Wathne 2003) to 4.47 (Cavusgil, Deligonul, and Zhang 2004). It seems that the skewness

\footnotetext{
${ }^{6}$ It is a multiplicative scale between Franchisor's Ability to Detect Opportunism and Franchisor's Ability to Sanction Opportunism; both were measured using 7-point scale.
} 
Table 4.1: Previous Studies Measuring Opportunism

\begin{tabular}{|c|c|c|c|c|c|}
\hline Study & $\begin{array}{c}\text { Self- } \\
\text { reported? }\end{array}$ & $\begin{array}{c}\text { Reporting } \\
\text { on } \\
\text { partner? }\end{array}$ & Study Context & $\begin{array}{l}\text { Mean } \\
\text { (7-pointscale) }\end{array}$ & $\begin{array}{l}\text { Standard } \\
\text { Deviation }\end{array}$ \\
\hline John (1984) & $\sqrt{ }$ & & $\begin{array}{l}\text { Oil retail dealers reporting } \\
\text { their degree of } \\
\text { opportunistic behaviors } \\
\text { against their suppliers }\end{array}$ & $\begin{array}{l}\text { Not } \\
\text { reported }\end{array}$ & $\begin{array}{l}\text { Not } \\
\text { reported }\end{array}$ \\
\hline $\begin{array}{l}\text { Provan and } \\
\text { Skinner (1989) }\end{array}$ & $\sqrt{ }$ & & $\begin{array}{l}\text { Farm and power equipment } \\
\text { dealers reporting their } \\
\text { degree of opportunistic } \\
\text { behaviors against their } \\
\text { primary supplier }\end{array}$ & 2.95 & 1.05 \\
\hline Parkhe (1993) & & $\sqrt{ }$ & $\begin{array}{l}\text { Chemicals and non-electric } \\
\text { machinery manufacturers } \\
\text { reporting their partners' } \\
\text { opportunism }\end{array}$ & $\begin{array}{l}.38 \\
\text { (scale } \\
\text { unknown) }\end{array}$ & $\begin{array}{l}.12 \\
\text { (scale } \\
\text { unknown) }\end{array}$ \\
\hline $\begin{array}{l}\text { Gundlach, } \\
\text { Achrol, and } \\
\text { Mentzer (1995) }\end{array}$ & & $\sqrt{ }$ & $\begin{array}{l}\text { Experiment (simulation) - } \\
\text { subjects assumed either } \\
\text { manufacturer or distributor } \\
\text { responsibilities in } \\
\text { negotiations }\end{array}$ & $2.63^{8}$ & $1.23^{9}$ \\
\hline $\begin{array}{l}\text { Ramaswami } \\
\text { (1996) }\end{array}$ & $\sqrt{ }$ & & $\begin{array}{l}\text { American Marketing } \\
\text { Association members } \\
\text { reporting their own degree } \\
\text { of opportunistic behaviors } \\
\text { within their firm }\end{array}$ & 2.45 & .75 \\
\hline $\begin{array}{l}\text { Joshi and Arnold } \\
(1997)^{10}\end{array}$ & $\sqrt{ }$ & & $\begin{array}{l}\text { Experiment (simulation) - } \\
\text { subjects assume the role of } \\
\text { purchasing managers }\end{array}$ & 2.21 & $\begin{array}{l}\text { Not } \\
\text { reported }\end{array}$ \\
\hline $\begin{array}{l}\text { Dahlstrom and } \\
\text { Nyggard (1999) }\end{array}$ & & $\sqrt{ }$ & $\begin{array}{l}\text { Norwegian oil distributors } \\
\text { (franchisees) reporting their } \\
\text { suppliers' (franchisors') } \\
\text { degree of opportunism }\end{array}$ & 3.06 & 1.48 \\
\hline
\end{tabular}

\footnotetext{
${ }^{7}$ Mean and standard deviation are converted from their original a 9-item additive 6-point scale

${ }^{8}$ Mean value across (1) two time periods and (2) manufacturer and distributor sides; ranged between 2.38 and 2.93

${ }^{9}$ Mean value across (1) two time periods and (2) manufacturer and distributor sides

${ }^{10}$ Mean and standard deviation are converted from their original a 9-item additive 6-point scale
} 


\begin{tabular}{|c|c|c|c|c|c|}
\hline \multicolumn{6}{|c|}{ Table 4.1 Continued } \\
\hline $\begin{array}{l}\text { Brown, Dev, and } \\
\text { Lee }(2000)\end{array}$ & $\sqrt{ }$ & & $\begin{array}{l}\text { Hotel general managers } \\
\text { reporting their degree of } \\
\text { opportunistic behaviors } \\
\text { against their brand } \\
\text { headquarter }\end{array}$ & 2.23 & 1.05 \\
\hline $\begin{array}{l}\text { Rokkan, Heide, } \\
\text { and Wathne } \\
\text { (2003) }\end{array}$ & & $\sqrt{ }$ & $\begin{array}{l}\text { Dyadic measurement: } \\
\text { Managers of independent } \\
\text { manufactures of building } \\
\text { materials reporting their } \\
\text { suppliers' degree of } \\
\text { opportunism. The suppliers } \\
\text { also reported their own } \\
\text { opportunistic behaviors }\end{array}$ & $\begin{array}{c}1.44 \\
\text { (supplier) } \\
1.80 \\
\text { (buyer) }\end{array}$ & $\begin{array}{l}.98 \\
.68\end{array}$ \\
\hline $\begin{array}{l}\text { Jap and } \\
\text { Anderson (2003) }\end{array}$ & & $\sqrt{ }$ & $\begin{array}{l}\text { Fortune } 50 \text { manufacturers' } \\
\text { procurement managers and } \\
\text { their respective suppliers } \\
\text { reporting on each other's } \\
\text { opportunism }\end{array}$ & 2.15 & 1.03 \\
\hline $\begin{array}{l}\text { Cavusgil, } \\
\text { Deligonul, and } \\
\text { Zhang (2004) }\end{array}$ & & $\sqrt{ }$ & $\begin{array}{l}\text { US manufacturers } \\
\text { (industrial equipment, } \\
\text { medical, appliances) } \\
\text { reporting on their foreign } \\
\text { distributors' degree of } \\
\text { opportunism }\end{array}$ & 4.47 & 1.73 \\
\hline $\begin{array}{l}\text { Rawaswami and } \\
\text { Singh (2003) }\end{array}$ & $\sqrt{ }$ & & $\begin{array}{l}\text { Salespeople from Fortune } \\
500 \text { companies reporting } \\
\text { their degree of } \\
\text { opportunistic behaviors } \\
\text { within their firm }\end{array}$ & 2.83 & .83 \\
\hline $\begin{array}{l}\text { Wuyts and } \\
\text { Geyskens (2005) }\end{array}$ & & $\sqrt{ }$ & $\begin{array}{l}\text { Dutch industrial equipment } \\
\text { manufacturers reporting on } \\
\text { their suppliers' } \\
\text { opportunism }\end{array}$ & 1.99 & .95 \\
\hline $\begin{array}{l}\text { Wong, Tjosvold, } \\
\text { and Yu (2005) }\end{array}$ & & $\sqrt{ }$ & $\begin{array}{l}\text { Chinese consumer product } \\
\text { distributors reporting on } \\
\text { their suppliers' } \\
\text { opportunism }\end{array}$ & 2.62 & .63 \\
\hline $\begin{array}{l}\text { Carson, } \\
\text { Madhok, and } \\
\text { Wu (2006) }\end{array}$ & & $\sqrt{ }$ & $\begin{array}{l}\text { R\&D outsourcing managers } \\
\text { reporting their contractors' } \\
\text { degree of opportunism } \\
\text { (new product development) }\end{array}$ & 1.73 & .91 \\
\hline $\begin{array}{l}\text { Deligonul, et al. } \\
\text { (2006) }\end{array}$ & & $\sqrt{ }$ & $\begin{array}{l}\text { US manufacturers } \\
\text { (exporters) reporting on } \\
\text { their foreign distributors' } \\
\text { degree of opportunism }\end{array}$ & $\begin{array}{l}\text { Not } \\
\text { reported }\end{array}$ & $\begin{array}{l}\text { Not } \\
\text { reported }\end{array}$ \\
\hline
\end{tabular}


in the present sample is not unique to the current context; rather, it is a common feature in opportunism measurement.

Lastly, the three types of justice concerns vary sufficiently in franchising. Franchisors usually keep a close eye on franchisees in terms of supervision, service assistance, ways to communicate competitive strategies, etc. As they would frequently interact with their franchisors, franchisees were expected to have sufficient perceptions as to the fairness of their franchisors. At the same time, perceptions of distributive and procedural fairness were expected to have sufficient variance as franchisors vary in terms of royalty fees, profit sharing, and the procedures to determine them. In the sample, the means and standard deviations for Distributive, Procedural, and Interactional Justice are $3.57(\mathrm{SD}=1.84), 4.14(\mathrm{SD}=1.64)$, and $4.58(\mathrm{SD}=1.54)$, respectively, offering evidence for sufficient variance in the study population.

In summary, franchising as the study population appears to be adequate, providing sufficient variance in the key research variables. In addition, judging from the extra-dyadic level standpoint, franchising offers an easily identifiable social network in which high levels of socialization take place. This in turn significantly reduce the ambiguity of multiple and confounding social network effects, as it is frequently the case for other types of business.

\section{Generalizeability to Other Industries}

Lastly, the present research intends to contribute to the extant marketing literature by taking a closer look at socialization effects within a franchising community which represents a significant portion of our economy. According to International Franchise 
Association's (IFA's) study ${ }^{11}$ based on 2001 economic data shows that franchised businesses account for $\$ 1.53$ trillion in economic activity, which is $9.5 \%$ of the privatesector economic output. Over 75 industries now engage in franchising, and the economic contributions seem to continue to grow. The findings of this dissertation, therefore, should apply to many business relationships in which opportunism is possible (i.e., in bilateral, monopolistic exchange within supply chains).

\section{Survey Participants}

In survey research, respondents are those who provide "their personal feelings, opinions, and behaviors" (Seidler 1974, p. 817) while key informants are those who report "about patterns of behavior, after summarizing either observed (actual) or expected (prescribed) organizational relations" (Seidler 1974, p. 817). While this dissertation is interested in franchisees' subjective views of their exchange relationships with their franchisors, it also requires their observations of organizational phenomena (e.g., levels of TSIs, interdependence, etc.). Hence they will serve as both respondents and key informants for the survey.

It is important that survey participants qualify as both respondents and key informants. As key informants, they should be knowledgeable about the ongoing exchange relationships (Phillips 1981). As respondents, it is important that they have had enough ongoing interactions with their franchisors to have developed certain opinions about their relationships. Therefore, they should meet the following two criteria:

- They deal directly with the representatives of their franchisors on a regular basis

\footnotetext{
${ }^{11}$ Source: Policymakers Digest published by IFA on its website (www.franchise.org) in March, 2004.
} 
- They hold certain responsibilities in the outcome of the exchange (i.e., deciding whether and how they can act opportunistically against their franchisors)

I suspected that owners or co-owners of franchise outlets (i.e., unit franchisees) would be the most appropriate survey participants given the criteria described above. To ensure that unit franchisees actually meet the criteria, the survey posed relevant questions for qualification screening purposes. Specifically, a question was asked to report their knowledgeability in franchisor-franchisee relationship ("How knowledgeable are you about your franchise unit's relationship and dealings with your franchisor?"), and franchisees whose response was below five on the 7-point scale (1="Not at all knowledgeable", 7="Very knowledgeable") were deleted listwise and excluded from the final sample. In total, 20 franchisees (10.6\%) rated their knowledgeability below five. The length of being a franchisee was also checked by specifically asking a question of "How long have you managed this franchised unit?" I had no pre-specified cutoff for this, as franchising relationship can begin long before the actual starting date for managing the franchise unit. One franchisee reported less than six months of managing the franchise unit, but his/her knowledgeability was already below the cutoff, therefore, this case had already been excluded, and no other cases were deleted due to length of relationship. In all, the final sample only includes those franchisees with a high level of knowledgeability and experience in on-going relationship with his/her franchisor.

\section{Sampling Frame}

A mailing list of unit franchisees was purchased from FRANdata in Arlington, Virginia, a data supplier for franchisors, franchise attorneys, research and consulting, and 
industry vendors. The company's products and services include preparing reports such as competitive analysis, company and industry reports, as well as providing contact lists of franchisors and franchisees. The company was chosen to supply a mailing list because it had readily available a database containing over 100,000 single-unit franchisees. A list of 4,328 unit franchisees randomly-selected from its main database was purchased at a nominal 30 cents per contact with $20 \%$ educational discount. FRANdata was also determined to be a credible source for a mailing list because it has actively collaborated with IFA Education Foundation in research having published various reports on franchising business, including highly-regarded the Profile of Franchising series.

An advantage of purchasing single-unit-only franchisees allowed automatic exclusion of multiple-unit franchisees and master franchisees from the sampling frame. Master franchisees are those franchisees whose franchisors grant them the rights to subfranchise third parties to develop and operate the franchised business within their exclusive territories. While the degree of rights granted by their franchisors vary, it is important to screen out master franchisees because they are in many cases directly responsible for the supervision of the subfranchisees. In other words, they more or less perform the role of franchisors. The screening was performed using the available information provided by the mailing list provider.

\section{The Survey Instrument}

The detailed description of scale development and measure verification is provided in Chapter Five. A copy of final survey is found in Appendix A. The aim of this section is to provide a brief overview of the survey itself in terms of its length and format. 
The survey measures 31 constructs over twelve pages: 23 constructs come from the hypothesized research model, and the remaining constructs are additional constructs that were added for possible use in alternative models. The survey contains 220 questions, including 21 questions to tap research participants' demographic and franchise business-related information.

The survey's finished format was a folded and saddle-stitched booklet with a dimension measuring 5.50 inches by 8.5 inches. The cover page was titled "National Survey of Franchisees" featuring Virginia Tech official logo at the top. To further enhance credibility of survey, my name, title, and signature as well as those of my dissertation co-chairs were also printed on the cover page.

Following Dillman's (1978) recommendation, a careful attention was paid to the cover letter (printed directly on the first page) in an effort to increase response rate. It was important to communicate with the audience upfront that the survey aims to discover what makes franchising relationships work and that their help is needed to achieve the goal. Dillman (1978) emphasizes that the researcher is portrayed as a reasonable person who is making a reasonable request for help. In exchange for a complete survey, upon request, it was promised that a copy of survey results would be shared. It was also important the extent of anonymity and confidentiality in the study and my phone and email address were printed on the cover page in case a need for clarification for any parts of survey arose. A standard Business Reply barcode was printed (Permit no.10 from Virginia Tech Treasurer) with return address on the back cover. Participants were requested to mail back the completed survey by simply stapling the survey booklet and place in the mail. 
Each booklet was mailed in an envelop (six inches $\mathrm{X}$ nine inches) with the standard letterhead logo imprint of the Department of Marketing at Virginia Tech and the return address, and return service was requested. Each envelope had an address label affixed with a unit franchisee's name and address from the mailing list. The surveys were mailed pre-sorted (by Zip) First Class by U.S. Postal Service.

\section{Data Collection Procedures}

This section outlines pre-tests procedures and primary data collection.

\section{Pre-Test Procedures}

Three sets of pre-test were conducted to ensure the quality of the questionnaire. First pre-test involved the measurement scale of CMD aiming to (1) determine the best scale out of two alternatives (2) reduce the scale to a manageable size. The second pretest entailed exploratory field interviews to verify the face validity of hypothesized model as well as to explore additional variables that could possibly have impact on dependent variables. The third pre-test involved refining the preliminary questionnaire, and this was to ensure the relevance and understandability of each item in the survey.

\section{Pre-Test 1: Reduction of CMD scale}

Pre-tests were necessary in order to determine the best CMD scale for the current study, and additionally, possibly reduce the length of the scale to a more manageable one. It was critical that the most appropriate CMD scale be chosen first. 
CMD captures advances in moral reasoning and a progression to a higher stage that reflects an increased understanding of the nature of moral obligations in complex social systems (Rest 1979). Two CMD scales are widely used: Rest's (1979) Defining Issues Test (DIT) and Lind's (1978) scale called the Moral Judgment Test (MJT). The ease of administration of both the DIT and the MJT has resulted in numerous studies spanning various disciplines. Both instruments require that subjects read complex ethical dilemmas and subsequently analyze and respond to 12 statements that take dissimilar ethical viewpoints. Needless to say, both scales require a significant amount of time to complete (ranging usually 10 to 40 minutes).

A consideration was first given to the MJT, as this scale requires a shorter time to complete due to its use of only two ethical dilemmas as opposed to the DIT, which uses three. It was not, however, clear about whether the two scales are perfectly comparable to one another. After a literature review, it became clearer that the DIT and the MJT subscribe to two different interpretations of CMD: CMD stage preference (DIT) and CMD stage consistency (MJT). The ethical dilemmas given in these two scales are very similar, but the unique distinction is that the MJT requires subjects to respond to both supporting and opposing statements regarding each stage of CMD. The DIT only employs supporting arguments.

Previously, few studies have made direct empirical comparisons of the two scales, and none were given to the same subjects to see what their scores actually represent. Therefore, I implemented a direct comparison approach in which I gave the study participants both the DIT and the MJT and compared the two indices against the individual's ethical ideology classifications. Ethical ideology is a construct that deals 
TABLE 4.2: Taxonomy of Ethical Ideologies ${ }^{12}$

\begin{tabular}{|l|l|l|}
\hline Low Relativism & Low Idealism & High Idealism \\
\hline Exceptionists: & $\begin{array}{l}\text { Feel conformity to moral rules is } \\
\text { desirable, but believe that } \\
\text { exceptions to these rules are often } \\
\text { permissible. Morality of an action } \\
\text { depends on the consequences } \\
\text { produced by it. Rule-utilitarian }\end{array}$ & $\begin{array}{l}\text { Absolutists: } \\
\text { Assume that the best possible } \\
\text { autcomes can always be } \\
\text { moral rules. Deontologists. }\end{array}$ \\
\hline High Relativism & $\begin{array}{l}\text { Subjectivists: } \\
\text { Do not believe in absolute moral } \\
\text { rules. Moral evaluations based on } \\
\text { one's own personal perspective } \\
\text { rather than universal moral } \\
\text { principles. Ethical egoists }\end{array}$ & $\begin{array}{l}\text { Skeptical of absolute moral } \\
\text { rules to provide the best } \\
\text { possible outcomes and } \\
\text { advocate contextual } \\
\text { appropriateness of each act in } \\
\text { each situation. Idealistic } \\
\text { skeptic }\end{array}$ \\
\hline
\end{tabular}

${ }^{12}$ Adapted from Forsyth (1982, p. 219) 
with individual variations in approach to moral judgment (Schlenker and Forsyth 1977; Forsyth 1980); in other words, differences in judgment of what is moral (see Table 4.2). The pre-test study selected ethical ideology as a reference scale because it generates a unique taxonomy of individuals based on their personal ethical ideologies, which then allows for unique multi-group comparisons of the DIT scores and the MJT scores.

A total of 134 marketing undergraduate students at Virginia Tech participated in the pre-test survey. The final sample size was 117 after listwise deletions of participants with missing responses and/or a high M-score (proxy, built-in measure for reliability) in the DIT scale following Rest's (1990) recommendation. The final sample consisted of 55 males and 62 females. The MJT took less time to administer; the study average was 8.7 minutes as compared to 14.5 minutes for the DIT. To compare the mean differences in CMD score across groups of individuals who belong to different ethical ideology classification, survey participants were classified into four subgroups using median splits of low/high scorers: absolutists $(\mathrm{n}=27)$, situationists $(\mathrm{n}=36)$, subjectivists $(\mathrm{n}=28)$, and exceptionists $(n=26)$.

I first examined whether the two measures of CMD are related to each other. The correlation between DIT scores and MJT scores was significant and positive $(r=0.24)$. Though, the correlation coefficient indicates that the two scales share only about six percent of variance in common. Next, it was found that the absolutist (i.e., individuals who subscribe to deontological norms) subjects scored the lowest in the MJT scale, but the highest in the DIT scale. This was particularly surprising because both scales are designed to measure the degree of moral development (i.e., CMD), which seems to suggest the highest regards for deontological norms. The pre-test demonstrated that it is 
the case only for the DIT. For the MJT, the pre-test finding suggests that appreciation for a certain moral value shown by consistent rating (between pro and con statements) needs not be consistent with universal moral principles. This seems to be in line with Lind's emphasis that his MJT scale represents one's cognitive structure, not affects (i.e., attitudes).

Overall, the two dissimilar approaches of the DIT (CMD stage preference) and the MJT (CMD stage consistency) could be distinctly observed in one's ethical ideology. As shown in Figure 4.1, the pre-test findings indicate that those individuals who subscribe to moral absolutes (i.e., absolutists) are likely to score low on the MJT scale, while they may score higher on the DIT scale. The higher DIT scores indicate higher preferences for deontological principles, as "absolutists" in Ethical Ideology scored significantly higher than the "situationists" group of individuals. The findings also suggest that the MJT's stage-consistency approach focuses on consistency of moral reasoning, and it may be very difficult for the absolutists, who believe that the best outcomes can be attained by following universal moral rules, to view from an opposing argument and be able to consistently follow the same value. Based on these findings, it was determined that the DIT was the more appropriate scale of CMD because for the present study the MJT can only inform us the franchisees' level of consistency in CMD, which is less important than the degree to which they subscribe to higher level of moral reasoning.

Once the decision was made to use the DIT, the next step was to try to reduce the scale to a more manageable length. Inspired by the MJT's use of only two ethical dilemma stories with a high level of reliability (see Lind 2001), I computed two-story 
Figure 4.1: Mean Values across Ethical Ideology Types (Values with common superscripts are significantly different at $p<.05$ )

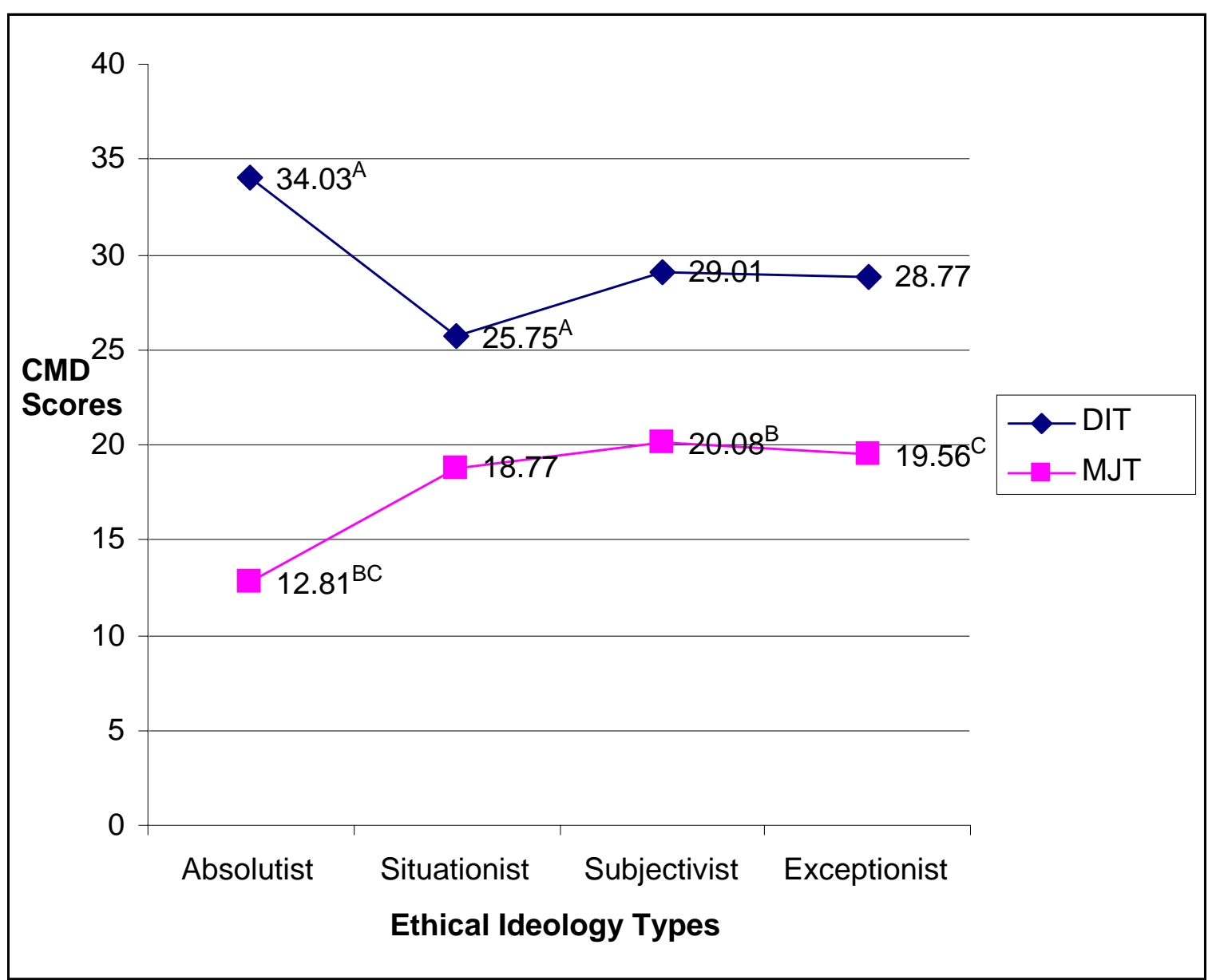


versions of the DIT scores, using the same algorithm. The only difference was that ratings from two ethical dilemmas were used, rather than three. The DIT scores were calculated for a total of three combinations of two ethical dilemmas. Table 4.3 shows the correlation among the three-story version and three two-story versions of the DIT.

The correlation coefficients were all significant at $p<.01$. The finding suggests that the 2-Story DIT Score 2 and 3 may be better candidates than the 2-Story DIT Score 1 , as their correlation with the 3-Story DIT Score are higher ( $\mathrm{r}=.84$ in both cases). The correlation between these two 2-Story DIT scores $(\mathrm{r}=.62)$ are also significantly higher than the other two combinations $(\mathrm{r}=.43$ and .45$)$. Assuming that the reduction from 3Story to 2-Story would lead to two thirds of time necessary to complete, the high correlation of .84 with 3-Story ethical dilemmas was encouraging. In the sample, the average time took was 14.5 minutes (ranging 7 to 48 minutes) for 3-Story DIT, and such reduction seemed worthwhile without sacrificing reliability too much.

In hopes to replicate the results of a high correlation between 2-Story and 3-Story DIT, and also to gauge the external validity of such a finding, another study was conducted. This time, executive MBA students at West Virginia University were recruited. Unlike the convenience sampling at Virginia Tech, older participants who are more similar to the study population were sought. In total 32 executive MBA students participated in the study. The final sample size was 29 after listwise deletions of participants with missing variables and/or a high M-score (i.e., low reliability). The resulting correlation matrix is shown in Table 4.4. 
Table 4.3: Correlation among 3-Story and 2-Story Versions of the DIT based on 117 Undergraduate Students at Virginia Tech ${ }^{1314}$

\begin{tabular}{|l|c|c|l|l|}
\hline & $\begin{array}{l}\text { 3-story DIT } \\
\text { Score }\end{array}$ & $\begin{array}{l}\text { 2-story DIT } \\
\text { Score 1 }\end{array}$ & $\begin{array}{l}\text { 2-story DIT } \\
\text { Score 2 }\end{array}$ & $\begin{array}{l}\text { 2-story DIT } \\
\text { Score 3 }\end{array}$ \\
\hline $\begin{array}{l}\text { 3-story DIT } \\
\text { Score }\end{array}$ & 1.00 & & & \\
\hline $\begin{array}{l}\text { 2-story DIT } \\
\text { Score 1 }\end{array}$ & $.77^{*}$ & 1.00 & & \\
\hline $\begin{array}{l}\text { 2-story DIT } \\
\text { Score 2 }\end{array}$ & $.84^{*}$ & $.43^{*}$ & 1.00 & \\
\hline $\begin{array}{l}\text { 2-story DIT } \\
\text { Score 3 }\end{array}$ & $.84^{*}$ & $.45^{*}$ & $.62^{*}$ & 1.00 \\
\hline
\end{tabular}

${ }^{13}$ Ethical dilemmas are titled "Heinz and the Drug," "Escaped Prisoner," and "Newspaper." 2-Story DIT Score 1 uses Heinz and Newspaper. 2-Story Score 2 uses Escaped Prisoner and Newspaper. 2-Story Score 3 uses Heinz and Escaped Prisoner.

${ }^{14}$ significant at $\mathrm{p}<.01$ 
Table 4.4: Correlation among 3-Story and 2-Story Versions of the DIT based on 29 Executive MBA Students at West Virginia University

\begin{tabular}{|l|c|c|l|l|}
\hline & $\begin{array}{l}\text { 3-story DIT } \\
\text { Score }\end{array}$ & $\begin{array}{l}\text { 2-story DIT } \\
\text { Score 1 }\end{array}$ & $\begin{array}{l}\text { 2-story DIT } \\
\text { Score 2 }\end{array}$ & $\begin{array}{l}\text { 2-story DIT } \\
\text { Score 3 }\end{array}$ \\
\hline $\begin{array}{l}\text { 3-story DIT } \\
\text { Score }\end{array}$ & 1.00 & & & \\
\hline $\begin{array}{l}\text { 2-story DIT } \\
\text { Score 1 }\end{array}$ & $.59^{*}$ & 1.00 & 1.00 & \\
\hline $\begin{array}{l}\text { 2-story DIT } \\
\text { Score 2 }\end{array}$ & $.81^{*}$ & $.49^{*}$ & $.50^{*}$ & 1.00 \\
\hline $\begin{array}{l}\text { 2-story DIT } \\
\text { Score 3 }\end{array}$ & $.76^{*}$ & .27 & & \\
\hline
\end{tabular}


The correlation coefficients observed in this study were very similar to those from the previous one. The correlation between 3-Story DIT Score and 2-Story 2 and 3 were again very high ( $\mathrm{r}=.81$ and .76 , respectively). 2-Story DIT Score 1 again had a much lower correlation with the three-story counterpart.

In summary, 2-Story DIT 2 (Newspaper and Escaped Prisoner) was determined to be the best alternative to 3-Story version of the DIT based on the two studies using two dissimilar samples. The correlation coefficients obtained for 2-Story DIT 3 (Heinz and Escaped Prisoner) was the next best candidate with $r=.84$ and .76 . However, 2-Story DIT 2 offered a slightly better advantage in that at least $60 \%$ reliability can be expected based on the correlation coefficients with the 3-Story scores $(r=.84$ and .81). Overall, the results suggest a two-thirds reduction in time to take 2-Story DIT is worthwhile in an already a long questionnaire required for the primary data collection.

\section{Pre-Test 2: Exploratory Fieldwork}

The next step was to conduct exploratory field work soliciting the assistance of

local unit franchisees. Exploratory interviews were necessary to (1) verify that the owners or co-owners of a franchise unit would be the most appropriate survey participants and (2) gain valuable insights from the individuals who have extensive experience and handson knowledge in franchising business to improve the research model. On-site interviews are frequently used by marketing channel researchers (e.g., Morgan and Hunt 1994; Bello and Gilliland 1997; Antia and Frazier 2001) prior to data collection for gaining insights to help clarify research questions and improve survey instruments. 
A total of 26 unit franchisees were contacted in Blacksburg, VA and the surrounding area, and twelve of them agreed to interviews. Interviews typically took 20 to 90 minutes, with an average of approximately 45 minutes. After a greeting and a brief introduction, each interview started with an open-ended question "What can you tell me about your relationship with your franchisor?" Key findings from the interviews are listed as follow:

Interactions with other unit franchisees do exist with a seemingly sufficient variance. Some franchises offer more opportunities than others with online message boards, periodic regional meetings, mentoring programs, etc. Annual/semi-annual conventions for franchisees offered for the vast majority.

Some franchisees felt that their voices are not heard (or have say in how the franchise organization is run). Several other franchisees mentioned that whenever they encounter problems or have suggestions for improving business for the franchise, there exists an outlet in the form of (1) a discussion session at a convention in which franchisees sit down with corporate managers to discuss these issues, (2) a franchisee board (elected members of franchisees) who takes these issues to consideration as they arise, or (3) a direct communication with the corporate manager whose responsibility and job functions entail managing franchisorfranchisee relationships.

The amount of interactions with franchisors and monitoring differed significantly among the franchisees interviewed. Some franchisors employed extensive hands-on supervision, while others mentioned a distant relationship with only a periodic, minor check-up.

$>$ The amount of support from franchisors also differed greatly. Some franchises offer extensive support in terms of marketing and purchasing raw materials, while a few others reported that they have not received any support since purchasing the franchise unit.

$>$ The total investments in purchasing and running a franchise unit varied significantly.

A high degree of satisfaction with franchisors was evident in a majority of cases, while more than a few were experiencing a more or less onesided relationship in which they felt their franchisors are not on their side. 
These insights from real-life franchisees were invaluable to the present research as I gained a renewed understanding of franchising business from the perspective of franchisees. The interviewees were also shown the current research model and asked whether they agree or disagree with any of the independent variables. They unanimously agreed. Overall, the findings confirmed (1) the appropriateness of franchising as the study context and (2) various issues and unexamined theories that I raised in this research are in line with the real-life phenomena.

\section{Pre-Test 3: Measurement Development}

Once the preliminary survey instrument was complete, it was necessary to determine the questionnaire quality. Fortunately, many of the constructs embedded in the hypotheses already have established measures which have been rigorously tested for their psychometric properties. Table 4.5 summarizes these established measures, the developers, and reliability references for each of the constructs.

Those without established measures or ones that require significant modifications (PFO, Negative Professional Ethical Climate, Disciplinary Monitoring, and Crowding Out Effects of Monitoring, Distributive justice, and Procedural Justice) were developed through a five-step process. The procedures closely follow other survey research in the marketing channels field, especially Johnson, Sohi, and Grewal (2003) and Brown, Dev, and Lee (2000). This pre-test approach relying extensively on in-depth interviews with representative franchisees and a panel of academic researchers was appropriate given that relatively few constructs in the questionnaire were new, and this approach could also 
TABLE 4.5: Measurement Scales, Developer, and Reliability References

\begin{tabular}{|c|c|c|}
\hline Construct & Developer(s) & $\begin{array}{l}\text { Construct Reliability References } \\
\text { (technique) }\end{array}$ \\
\hline Machiavellianism & $\begin{array}{l}\text { Christie and Geis } \\
\text { (1970) }\end{array}$ & Christie and Geis (1970): 0.79 (Split-half) \\
\hline Locus of Control & $\begin{array}{l}\text { Valecha (1972): a short } \\
\text { form of Rotter's (1964) } \\
\text { scale }\end{array}$ & $\begin{array}{l}\text { Burrough and Mick (2004): } 0.71 \text { (KR-20) } \\
\text { Phillips and Bedian (1994): } 0.72 \text { (Split-half) }\end{array}$ \\
\hline $\begin{array}{l}\text { Cognitive Moral } \\
\text { Development }\end{array}$ & Rest (1979) & Rest (1990): 0.76 (Cronbach's $\alpha$ ) \\
\hline Interdependence & $\begin{array}{l}\text { Antia and Frazier } \\
(2001)\end{array}$ & Formative measure \\
\hline $\begin{array}{l}\text { Transaction- } \\
\text { specific } \\
\text { investments }\end{array}$ & $\begin{array}{l}\text { Antia and Frazier } \\
(2001)\end{array}$ & $\begin{array}{l}\text { Antia and Frazier (2001): } 0.77 \text { (Cronbach's } \\
\text { a) }\end{array}$ \\
\hline $\begin{array}{l}\text { Economies of } \\
\text { Continuation }\end{array}$ & Heide and Miner (1992) & $\begin{array}{l}\text { Heide and Miner (1992): } 0.88 \text { (Cronbach's } \\
\text { a) }\end{array}$ \\
\hline $\begin{array}{l}\text { Distributive } \\
\text { Justice }\end{array}$ & $\begin{array}{l}\text { Price and Mueller } \\
\text { (1986) }\end{array}$ & $\begin{array}{l}\text { Moorman (1991) 0.94 (Cronbach’s } \alpha \text { ) } \\
\text { Aryee, Budwar, and Chen (2002): } 0.95 \\
\text { (Cronbach's } \alpha \text { ) }\end{array}$ \\
\hline $\begin{array}{l}\text { Procedural } \\
\text { Justice }\end{array}$ & Moorman (1991) & Moorman (1991): 0.94 (Cronbach's $\alpha$ ) \\
\hline $\begin{array}{l}\text { Interactional } \\
\text { Justice }\end{array}$ & Moorman (1991) & $\begin{array}{l}\text { Moorman (1991): } 0.93 \text { (Cronbach's } \alpha \text { ) } \\
\text { Shapiro (2002): } 0.95 \text { (Cronbach's } \alpha \text { ) }\end{array}$ \\
\hline Network Density & $\begin{array}{l}\text { Antia and Frazier } \\
(2001)\end{array}$ & $\begin{array}{l}\text { Antia and Frazier (2001): } 0.91 \text { (Cronbach's } \\
\alpha)\end{array}$ \\
\hline $\begin{array}{l}\text { Opportunistic } \\
\text { Behaviors }\end{array}$ & Rokkan et al. (2003) & $\begin{array}{l}\text { Rokkan et al. (2003): } 0.90 \text { (Composite } \\
\text { reliability) }\end{array}$ \\
\hline $\begin{array}{l}\text { Performance } \\
\text { Ambiguity }\end{array}$ & $\begin{array}{l}\text { Stump and Heide } \\
\text { (1996) adapted from } \\
\text { Anderson (1985) }\end{array}$ & $\begin{array}{l}\text { Stump and Heide (1996): } 0.67 \text { (Cronbach's } \\
\alpha)\end{array}$ \\
\hline
\end{tabular}




\begin{tabular}{|c|c|c|}
\hline \multicolumn{3}{|c|}{ Table 4.5 Continued } \\
\hline $\begin{array}{l}\text { Ethical climate } \\
\text { (consists of } 5 \\
\text { factors) }\end{array}$ & $\begin{array}{l}\text { Victor and Cullen } \\
\text { (1988) }\end{array}$ & 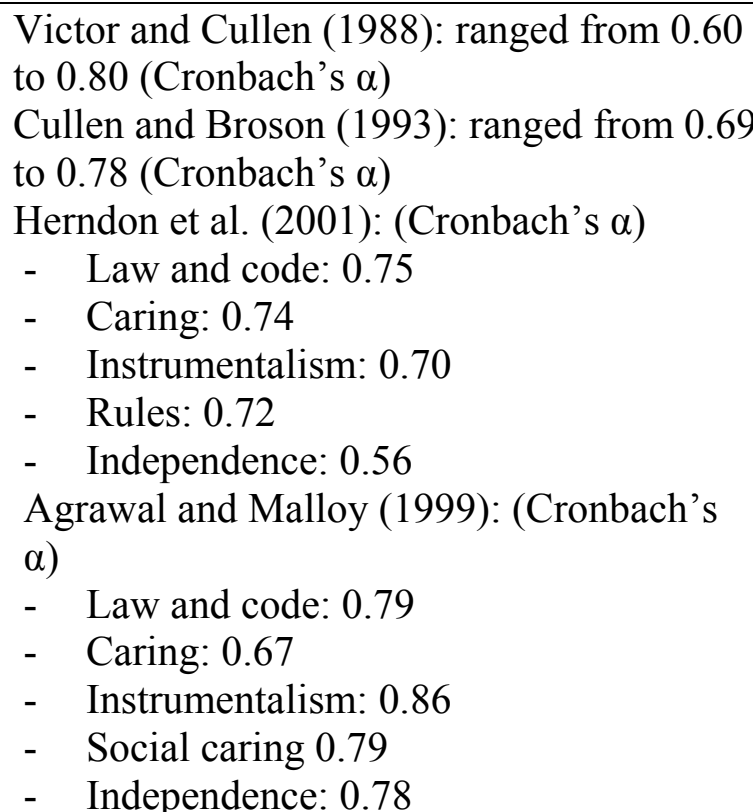 \\
\hline
\end{tabular}


isolate measurement and questionnaire format problems more effectively with in-depth interviews solely on those constructs (Johnson, Sohi, and Grewal 2003).

First, as suggested by Churchill (1979), scale development began with the relevant literature search and the identification of domain of construct. Second, sample of items were developed based on the operationalizations of the newly developed/modified constructs. Efforts were made to make the questionnaire items with the real-life franchising business, and the insights gained from the exploratory field interviews were very helpful. Measurement items were carefully developed so that each item was reflective of, or theoretically linked to the intended construct (Anderson and Gerbing 1991).

Third, a list of constructs and corresponding measurement items was submitted to a panel of two academic experts in the fields of marketing research and marketing channels. They were asked to evaluate each item for clarity, specificity, and representativeness. Next, I pre-tested the questionnaire through in-depth interviews with eight of the interviewees from the exploratory field interviews (Pre-test 2). In the interviews, franchisees were given a hard copy of the newly developed and modified scales along with operationalizations of the scale. They were then asked to evaluate each scale to ensure their relevance in the franchising context.

Most measurement items needed no modifications, and the exceptions to these were Distributive Justice and Procedural Justice scales. These two constructs had already well-established scales as seen in Table 4.5. However, they required extensive modifications as they had not been studied in the franchising context. In the literature, the construct of Distributive Justice is typically used in an organizational setting and it 
generally refers to the extent to which employees perceive rewards received from its employer to be fairly related to their inputs. Procedural Justice is a closely related construct, and it typically refers to the extent to which employees feel that the general procedures used by the employer in making reward-related decisions are fair. Franchising holds a unique marketing channel environment in that antitrust laws limit franchisor discretion on franchisee compensations, and furthermore, once set, usually remain fixed. Unlike other, more traditional study contexts, there exists little variance (at least shouldn't) among franchisees in terms of compensation schedules. Due to such discrepancies, operationalizations of the two constructs needed modifications to adapt specifically to the franchising context, and a new set of measurement items were developed subsequently to reflect the modified operationalizations.

Lastly, after a satisfactory conclusion on the item pools, the completed research instrument was again peer reviewed with format, appearance, and flow as the major focus. This was an iterative process, and many minor changes in question wording were made. The questionnaire format and cover letter were also refined at this phase to make it appear more user-friendly.

\section{Primary Data Collection}

Data collection through mail survey took place from the time the surveys were mailed (June $5^{\text {th }}, 2006$ ) until the last survey was returned (August $8^{\text {th }}, 2006$ ). The follow-

up post card was placed in the mail on July $3^{\text {rd }}$, and due to a concern for poor mailing list quality as well as limited budget, the postcards were mailed to 1,000 franchisees randomly selected from the original mailing list. Follow-up phone calls were also made 
between June 26 and July $21^{\text {st }}$. Efforts were made to reach as many franchisees as possible; however, being able to get the franchise owner/manager on the phone was a very difficult task. Understandably, franchise owners perform many tasks (e.g., payrolls, scheduling, purchasing, etc.) in and outside of the franchise location. Of the approximately 1,500 phone calls, only about 200 franchisees could actually be reached. Of the 200 who were reached, 27 claimed that they had not received the survey, and they were subsequently mailed another survey. Also, 41 of them mentioned of being extremely busy and that they would take a look at the survey when they had a chance. The remaining franchisees simply declined participation.

The second wave of data collection involved person-administered surveys. Because a very low response rate resulted from mail survey, it was determined helpful or even necessary to establish a credible and trusting relationship with unit franchisees prior to requesting their participation. Three groups of undergraduate students were offered an extra credit in exchange for administering the in-person survey. These were 14 marketing research students at Illinois State University (Normal, IL), 29 marketing research students at University of St. Thomas (Minneapolis, MN), and 35 marketing channels students at West Virginia University (Morgantown, WV). Some of the students submitted two completed surveys. There were 22 such students at West Virginia University and six at University of St. Thomas.

The instructions given to them entailed (1) reaching a franchisee on the phone and scheduled an appointment with him/her, (2) explaining the purpose of the study and the extent of confidentiality and anonymity, (3) conduct a survey in person. The same survey format used in mail survey was used for the in-person surveys. The list of unit franchisees 
was given to the students in their respective area, mostly in the vicinity of university. As the original mailing list was short on the list of franchisees in these areas, additional mailing list of 800 concentrating in these geographic areas was purchased.

\section{Quality of the Mailing List}

The mailing list purchased from FRANdata was not free of error. The original list contained 4,328 unit franchisees all around the U.S. Prior to actual mailing, an effort was made to eliminate undeliverable addresses by verifying each one on U.S. Postal Service website's (http://www.usps.gov) 9-digit Zip code look-up. Of these, 130 addresses were determined invalid (i.e., unable to find proper 9-digit Zip) and deleted from the list as a result.

After mailing 4,198 surveys on June $5^{\text {th }}, 2006$, a number of surveys were returned from the postal service as either undeliverable or no longer present at the location. In total 472 such mailings were returned by the postal service by the end of July (11.24\%). There is no way of determining the exact number of surveys received by the intended franchisee, as many more could have been delivered to unintended recipients. One reason for the poor quality of the mailing list may be due to the fact that small businesses including franchises have a high business failure rate. Although traditional statistics such as those from Dun \& Bradstreet claim only about $4 \%$ of franchises fail and report losses to creditor each year, according to Julian (1993), the majority of franchise failures do not involve losses hence the number actual failure rate may be much higher. 


\section{Treatment of Missing Data}

The final sample excludes returned surveys with excessive (20\% or more) missing values. Eighteen of the returned surveys were determined to be unusable due to significant amounts of missing data. The most common area in which most respondents neglected was the CMD scale (33 questions total or $15 \%$ of total questions). The scale requires that a respondent read two complex ethical dilemmas (approximately 200 words each) and make ethical judgments by responding to each of twelve statements that are based on various ethical standpoints. This is a difficult task that requires deep thinking and the ability to process complex information. It is assumed that some participants felt that it was too much to handle, rather than a refusal that is systematically linked to specific positions on topics covered in the survey (Kuechler 1998).

Other than the CMD scale, the most of the remaining question items seemed to have been missed rather unintentionally as they appeared sporadically. Because listwise deletions would have resulted in too many cases being removed even though only small percentage of responses was missing, I employed a simple data-imputation method (Finkbeiner 1979, Downey and King 1995). Specifically, I substituted item means for missing responses if a respondent omitted one item on a short scale (three- and fouritems) and two items on a longer scale (five or more items). If more items were missed, they were simply left alone as missing values.

\section{Response Rate Calculation}

Data collection through mail survey took place from the time the surveys were mailed (June $5^{\text {th }}, 2006$ ) until the last survey was returned (August $8^{\text {th }}, 2006$ ). The first 
batch of returned surveys was received on June $12^{\text {th }}$. In the first week (June $12^{\text {th }}-16^{\text {th }}$ ), in total 43 surveys was received, which was the highest number of return per week. In the following week I received thirteen surveys, and the number continued to fall.

Although there was a small increase in response rate shortly after sending reminder postcards and successful follow-up phone calls, by the conclusion of the mail survey only 88 were returned. Of the 88 surveys, eight returns had to be excluded as they had substantial missing data and/or lack sufficient knowledge in the subject matter. In the end, I received 80 usable surveys, which correspond to a response rate of $2.2 \%$. Given the poor quality of the original mailing list, it is still substantially lower than anticipated. Prior research studying franchising relationships have reported, for example, $11.2 \%$ (Grunhagen, Dorsch, and Gentry 2002) to 18\% (Parsa 1999; Manolis, Gassenheimer, and Winsor 2004).

In addition to the poor quality of the mailing list, the length of the survey itself may have contributed to the low response rate. The survey includes 220 questions spanning over 12 pages. It is highly possible that many more unit franchisees would have participated in the survey had the survey been shorter. Though, Kanuk and Berenson (1975) report that studies comparing response rates between short versus long versions of mail surveys have resulted in mixed results; therefore, it is not clear whether the shorter survey instrument could have induced much higher participation.

Another reason for the low response rate may be due to the fact that many of the questions dealt with sensitive, socially undesirable behaviors, such as opportunistic behaviors against franchisors, propensity for such behaviors, as well as Machiavellian tendencies. Research suggests that studies addressing sensitive issues often have reduced 
numbers of participation (Kanuk and Berenson 1975, Kuechler 1998), citing a human nature's increased tendency to avoid responses deemed socially undesirable. Even though steps were taken to ensure prospective respondents the nature of strict confidentiality, it is possible that unit franchisees who received the survey felt uneasy trusting the researcher in an impersonal mail survey.

In addition, previous studies in marketing channels reporting a higher response rate took more rigorous steps to enhance participation by pre-screening of a mailing list by telephone calls prior to administering the mail survey and only sending the questionnaires to those who agreed to participate in the study (e.g., Kumar, Stern, and Anderson 1993; Stump and Heide 1996; Mishra, Heide and Cort 1998; Jap 2001; Rindfleisch and Moorman 2001; White, Varadarajan, and Dacin 2003; Wathne and Heide 2004). However in retrospect, due to the extreme difficulty in reaching unit franchise owner experienced during pre-tests, it was determined that trying to reach all individuals on the list by telephone would have been virtually impossible without incurring a huge expense in already tight budget. Furthermore, telephone pre-screening process could have resulted in a convenience sample of pre-screened individuals who were more or less easier to reach, which could have limited external validity of this research itself.

Lastly, mail survey studies with cooperation from professional(s) or other business network contacts in encouraging the members to participate report higher response rates (e.g., Heide and Weiss 1995; Brown, Dev, and Lee 2000; Atuahene-Gima and Li 2002; Rokkan, Heide, and Wathne 2003). For example, Dahlstrom and Nygaard (1999) report response rates of 50-96\% among multiple studies and explain that mail surveys were sent to prospective participants along with appeals for participation from 
the supplier, retail managers' (key informants for the study) union, and their superiors. Because the present study involved a sampling frame that entails various industries, the only way of enhancing participation this way would have been to contact a professional association for a broader franchising industry, such as American Franchisee Association (AFA). However, to some degree, it can also introduce unwanted bias in a study. In franchising industry, it is not uncommon for franchisors to pressure their franchisees not to join a trade association with other franchisees. Its members, therefore, are necessary those who are (1) allowed to join AFA, (2) already members of independent associations of franchisees which also belong to AFA \{e.g., the Association of Kentucky Fried Chicken Franchisees (AKFCF) \}, or (3) actively seeking avenues to resolve conflicts with their franchisors. As the present study aims to achieve external validity, such limited membership led to the decision not to contact AFA (or alike) to seek support.

The second wave of data collection in which undergraduate marketing students from three universities collected data in-person resulted in seemingly better cooperation. Once a unit franchisee agreed to participate in the study, according to the students, the franchisee usually completed the survey. Instead of inherently impersonal mail surveys, this personal approach to data collection led to a total of 100 completed surveys. The same criteria from the mail survey were used in excluding surveys: surveys with significant ( $20 \%$ or more) missing values and/or knowledgeability self-rating of less than five on a 7-point scale. Eighteen of the surveys were excluded as they had substantial missing data and/or lack sufficient knowledge in the subject matter. 
In sum, the final sample size is 162 , which includes 80 mail surveys and 82 inperson surveys. The detailed information of the final sample is given in the last section of this chapter.

\section{Response Bias Estimation Procedures}

While one of the key advantages of mail survey is that it can reach many individuals who otherwise couldn't be reached by other media (Burns and Bush 2005), it also presents a potential for self-selection bias. Kuechler (1998, p. 191) comments that "Refusals and, consequently, low response rates are not a real problem as long as one is willing to assume that non-cooperation is not systematically linked to specific positions on topics covered in the survey." Accordingly, I took steps to estimate the possibility of response bias in order to establish the final sample's generalizeability.

Non-response bias was estimated using Armstrong and Overton's (1977) extrapolation procedures. The followings are the extrapolation methods I employed in the present research:

1. Time trends - Based on the assumption that participants who respond "less readily" by responding late are more similar to non-respondents (Pace 1939), early and late respondents are compared based on their responses to key research variables.

2. The method of concurrent waves - This procedure involves employing dissimilar methods to induce participation, and it allows for an extrapolation across the subsamples resulted from different stimuli.

For the mail survey respondents, the time trends method seemed adequate. There are variations in postal times as surveys were sent to franchisees across the U.S., and I considered the possibility that early versus late response could be due to differences in 
regions. However, when the respondents' locations were checked, I noticed that the first half of the mailed surveys had been postmarked in a wide span of regions across the country, and the difference between the first and second halves in terms of their geographical locations seemed minimal.

Statistically, the early mail survey respondents are in 28 different states, and no more than three franchisees are from the same state. The location was widespread from east coast states such as Virginia $(n=2)$, North Carolina $(n=3)$, Pennsylvania $(n=2)$ to west coast states such as California $(n=2)$ and Colorado $(n=2)$, and gulf coast states such as Texas $(\mathrm{n}=2)$ and Louisiana $(\mathrm{n}=2)$. The late mail respondents are in 23 different states, and no more than four franchisees are from the same state. The location was also widespread in a similar manner as in the early mail sample. A Pearson Chi-square test also reveals that the difference in locations was not statistically significant $(\mathrm{p}<.49)$.

Another concern with possible inadequacy in employing the time trends method was that some of the late responses could have been a result of reminder postcards and follow-up phone calls. However, the second half of the total mail survey sample (i.e., late respondents") only involved eight such franchisees, and the number seems too small to contribute to a potential bias in comparison. In addition, because the number is so small $(\mathrm{n}=8)$, subjecting these respondents to statistical comparison against those who were not induced by follow-up attempts was not possible.

Using two-tailed t-tests, early and late respondents $(\mathrm{n}=40$ each) were compared on the constructs that appear in hypothesized model. As shown in Table 4.6, only one construct had significant differences $(\mathrm{p}<.05)$ between early and late respondents. 
Table 4.6: Non-Response Bias Results Using Time Trends T-Tests

\begin{tabular}{|c|c|c|c|c|}
\hline Construct & Time Trend & Mean & T (df) & p-value \\
\hline \multirow[t]{2}{*}{ Franchisor TSIs } & Early & 2.58 & $.30(76)$ & .77 \\
\hline & Late & 2.49 & & \\
\hline \multirow[t]{2}{*}{ Franchisor Dependence } & Early & 3.56 & $.02(78)$ & .99 \\
\hline & Late & 3.55 & & \\
\hline \multirow[t]{2}{*}{ Distributive Justice } & Early & 2.91 & $-.42(75)$ & .68 \\
\hline & Late & 3.08 & & \\
\hline \multirow[t]{2}{*}{ Procedural Justice } & Early & 3.74 & $.04(78)$ & .97 \\
\hline & Late & 3.73 & & \\
\hline \multirow[t]{2}{*}{ Interactional Justice } & Early & 4.34 & $.77(77)$ & .44 \\
\hline & Late & 4.07 & & \\
\hline \multirow[t]{2}{*}{ Franchisee Dependence } & Early & 4.60 & $-1.07(77)$ & .29 \\
\hline & Late & 5.00 & & \\
\hline \multirow[t]{2}{*}{ Disciplinary Monitoring } & Early & 22.41 & $.68(78)$ & .50 \\
\hline & Late & 22.75 & & \\
\hline Economies of & Early & 4.73 & $-.03(78)$ & .98 \\
\hline Continuation & Late & 4.74 & & \\
\hline Crowding Out Effects of & Early & 2.95 & $-.14(77)$ & .89 \\
\hline Monitoring & Late & 2.99 & & \\
\hline \multirow[t]{2}{*}{$\mathrm{OB}$} & Early & 2.34 & $-.33(77)$ & .74 \\
\hline & Late & 2.49 & & \\
\hline Negative Professional & Early & 3.46 & $-2.25(77)$ & .03 \\
\hline Ethical Climate & Late & 4.00 & & \\
\hline \multirow[t]{2}{*}{ Network Density } & Early & 4.12 & $-.75(77)$ & .46 \\
\hline & Late & 4.39 & & \\
\hline \multirow[t]{2}{*}{ PFO } & Early & 2.72 & $-.61(69)$ & .56 \\
\hline & Late & 2.97 & & \\
\hline \multirow[t]{2}{*}{ CMD } & Early & 30.86 & $.13(57)$ & .90 \\
\hline & Late & 30.33 & & \\
\hline External Locus of & Early & 1.95 & $-.83(77)$ & .41 \\
\hline Control & Late & 2.25 & & \\
\hline \multirow[t]{2}{*}{ Machiavellianism } & Early & 23.70 & $.15(76)$ & .88 \\
\hline & Late & 23.26 & & \\
\hline \multirow[t]{2}{*}{ Social Desirability } & Early & 5.85 & $-.50(72)$ & .65 \\
\hline & Late & 6.11 & & \\
\hline
\end{tabular}


The early respondent group rated significantly lower on Negative Professional Ethical Climate scale $(\mathrm{p}=.03)$. No significant mean difference was observed in Network Density, the other network-level scale, which suggests this was not a systematic difference in franchisee networks. Therefore, the difference in Negative Professional Ethical Climate may not raise a concern. In addition, because no mean differences were reported in theoretically related variables such as Franchisor TSIs and three justice scales, it is likely that the difference in Negative Professional Ethical Climate was nonsystematic.

Demographic information (nominal variables) was also compared using Pearson Chi-square tests. Age $(\mathrm{p}=.48)$, Gender $(\mathrm{p}=.11)$, Annual Sales $(\mathrm{p}=.59)$, and Industry Sector (.21) all indicated non-significant differences between early and late respondents.

Overall, the results from the time trends extrapolation method indicate minimal nonresponse bias, assuming that late respondents are very similar to non-respondents (Armstrong and Overton 1977).

Next, the method of concurrent waves was employed to further examine the possibility of non-response bias. Armstrong and Overton (1977) use the term "concurrent" as in simultaneous administration of different stimuli to induce participation, in the current research, the two waves took place at two different points in time. The aim of this additional analysis is to gain insights about whether the difference in stimuli (mail survey sent without prior contact versus surveys administered in-person) could have led to systematic differences in response.

The main concern for employing different stimuli for recruiting participants was the fact that anonymity could not be established for surveys that were administered in 
person. Because the questionnaire includes sensitive items that involve socially undesirable behaviors, in-person surveys could have led to positively-skewed response for those questions (i.e. answering more negatively to undesirable behaviors). This concern is in line with Guilford's (1954) "Leniency Biases," referring the propensity for respondents "to rate those whom they know well, or whom they are ego involved, higher than they should" (p. 278). In particular, PFO and OB were the two constructs that seemed prone to such skewed response. The results (see Table 4.7) show, however, there is non-significant difference between mail survey and in-person survey in terms of responses to these two key constructs. In addition, non-significant difference $(p=.13)$ in Disciplinary Monitoring suggest that lack of response should not be attributed to fear of potential retaliation by franchisor (if response confidentiality was somehow violated).

A closer examination revealed that seven constructs had significant $(\mathrm{p}<.05)$ mean differences between mail survey and in-person survey respondents. As shown in Table 4.7, these seven constructs are:

Franchisor TSIs (+1.19 for in-person survey)

Distributive Justice (+1.12 for in-person survey)

Procedural Justice (+.81 for in-person survey)

Interactional Justice (+.73 for in-person survey)

Economy of Continuation (+.61 for in-person survey)

Crowding Out Effects of Monitoring (-.67 for in-person survey)

Negative Professional Ethical Climate (-.82 for in-person survey) 
Table 4.7: Non-Response Bias Results Using Concurrent Waves T-Tests

\begin{tabular}{|c|c|c|c|c|}
\hline Construct & Waves & Mean & T (df) & p-value \\
\hline Franchisor TSIs & $\begin{array}{l}\text { Mail } \\
\text { In-person }\end{array}$ & $\begin{array}{l}2.53 \\
3.72\end{array}$ & $-5.23(158)$ & .00 \\
\hline Franchisor Dependence & $\begin{array}{l}\text { Mail } \\
\text { In-person }\end{array}$ & $\begin{array}{l}3.56 \\
3.95\end{array}$ & $-1.75(158)$ & .08 \\
\hline Distributive Justice & $\begin{array}{l}\text { Mail } \\
\text { In-person }\end{array}$ & $\begin{array}{l}3.00 \\
4.12\end{array}$ & $-4.02(154)$ & .00 \\
\hline Procedural Justice & $\begin{array}{l}\text { Mail } \\
\text { In-person }\end{array}$ & $\begin{array}{l}3.73 \\
4.54\end{array}$ & $-3.21(160)$ & .00 \\
\hline Interactional Justice & $\begin{array}{l}\text { Mail } \\
\text { In-person }\end{array}$ & $\begin{array}{l}4.21 \\
4.94\end{array}$ & $-3.10(159)$ & .00 \\
\hline Franchisee Dependence & $\begin{array}{l}\text { Mail } \\
\text { In-person }\end{array}$ & $\begin{array}{l}4.81 \\
4.71\end{array}$ & $.39(159)$ & .70 \\
\hline Disciplinary Monitoring & $\begin{array}{l}\text { Mail } \\
\text { In-person }\end{array}$ & $\begin{array}{l}21.58 \\
24.41\end{array}$ & $-1.63(159)$ & .11 \\
\hline $\begin{array}{l}\text { Economies of } \\
\text { Continuation }\end{array}$ & $\begin{array}{l}\text { Mail } \\
\text { In-person }\end{array}$ & $\begin{array}{l}4.73 \\
5.34\end{array}$ & $-2.15(159)$ & .04 \\
\hline $\begin{array}{l}\text { Crowding Out Effects of } \\
\text { Monitoring }\end{array}$ & $\begin{array}{l}\text { Mail } \\
\text { In-person }\end{array}$ & $\begin{array}{l}2.97 \\
2.30\end{array}$ & $3.23(159)$ & .00 \\
\hline $\mathrm{OB}$ & $\begin{array}{l}\text { Mail } \\
\text { In-person }\end{array}$ & $\begin{array}{l}2.45 \\
2.42\end{array}$ & $.15(158)$ & .88 \\
\hline $\begin{array}{l}\text { Negative Professional } \\
\text { Ethical Climate }\end{array}$ & $\begin{array}{l}\text { Mail } \\
\text { In-person }\end{array}$ & $\begin{array}{l}3.73 \\
2.91\end{array}$ & $4.42(157)$ & .00 \\
\hline Network Density & $\begin{array}{l}\text { Mail } \\
\text { In-person }\end{array}$ & $\begin{array}{l}4.26 \\
4.92\end{array}$ & $-2.78(159)$ & .01 \\
\hline PFO & $\begin{array}{l}\text { Mail } \\
\text { In-person }\end{array}$ & $\begin{array}{l}2.84 \\
3.16\end{array}$ & $-1.05(149)$ & .29 \\
\hline CMD & $\begin{array}{l}\text { Mail } \\
\text { In-person }\end{array}$ & $\begin{array}{l}30.59 \\
31.27\end{array}$ & $-.22(128)$ & .82 \\
\hline $\begin{array}{l}\text { External Locus of } \\
\text { Control }\end{array}$ & $\begin{array}{l}\text { Mail } \\
\text { In-person }\end{array}$ & $\begin{array}{l}2.10 \\
2.17\end{array}$ & $-.27(159)$ & .79 \\
\hline Machiavellianism & $\begin{array}{l}\text { Mail } \\
\text { In-person }\end{array}$ & $\begin{array}{l}23.48 \\
21.06\end{array}$ & $1.04(158)$ & .30 \\
\hline Social Desirability & $\begin{array}{l}\text { Mail } \\
\text { In-person }\end{array}$ & $\begin{array}{l}5.97 \\
6.57\end{array}$ & $-1.43(152)$ & .15 \\
\hline
\end{tabular}


No mean difference exceeded one standard deviation. Examination of these eight constructs also indicated that standard deviations between the two groups were very similar. The mean differences in three constructs that deal with just treatment by franchisor (Distributive, Procedural, and Interactional Justice) suggest that the in-person survey participants have slightly fairer relationships with their franchisors. The result does not seem to suggest clear underlying motivation for self-selecting, nonetheless. The difference in responses for Crowding Out Effects of Monitoring similarly suggest that the respondents who participated in in-person survey may feel less negative about being monitored by their franchisors. Assuming that the in-person survey respondents were less readily self-selected to study participation, the significantly higher ratings on several constructs that deal with fair treatment by franchisor and network cohesiveness may seem to suggest that dissatisfied franchisees (i.e., mail survey participants) exhibited higher motivation to participate in the study. However, when attitude-toward-franchisors (i.e., PFO) in two groups were compared, no significant differences were observed. The key difference between mail survey and in-person survey was the extent of anonymity, and because none of the seven constructs deal with sensitive issues, a concern for response bias should be minimal.

Furthermore, a demographic information comparison between the two groups shed light on a possible source of mean differences in these seven constructs. Pearson Chi-square tests were conducted to determine whether the difference in stimulus had any impact on demographics of the respondents. The difference in Industry Sector was significant $(\mathrm{p}=.00)$, as shown in Table 4.8 , and the significant difference in Industry Sector perhaps pinpoints the source of the two groups' differences in Franchisor TSIs, 
Table 4.8: Industry Sector Differences between Mail and In-Person Surveys

\begin{tabular}{|l|r|r|}
\hline \multicolumn{1}{|c|}{ Industry } & \multicolumn{1}{c|}{ Mail } & \multicolumn{1}{c|}{ In-Person } \\
\hline Food & $28(35.0 \%)$ & $29(35.4 \%)$ \\
General Printing & $19(23.8 \%)$ & $2(2.4 \%)$ \\
Auto Repair/Maintenance & $12(15.0 \%)$ & $8(9.8 \%)$ \\
Personal Services & $11(13.8 \%)$ & $7(8.5 \%)$ \\
Residential/Commercial Services & $2(2.5 \%)$ & $13(15.9 \%)$ \\
Professional Services & $5(6.3 \%)$ & $9(11.0 \%)$ \\
Retailing & $1(1.3 \%)$ & $11(13.4 \%)$ \\
Lodging & $2(2.5 \%)$ & $3(3.7 \%)$ \\
& $80(100.0 \%)$ & $82(100.0 \%)$ \\
\hline
\end{tabular}


three Justice scales, Economies of Continuation, Crowding Out Effects of Monitoring, and Negative Professional Ethical Climate.

Considerably more franchisees from the mail survey are in the General Printing industry, and significantly more franchisees from the in-person survey are in the Residential/Commercial Industries and Retailing. Such differences in participants' industry could easily explain differences in terms of Franchisor TSIs and Economies of Continuation. The difference in response for Crowding Out Effects of Monitoring also may be due to the differences in the amount of monitoring activities across industry sectors. As for the three Justice constructs and Negative Professional Ethical Climate, it is possible that franchising industry subsectors entail systematic differences in terms of franchisee-franchisor interactions and ethical climate in franchisee networks. The results from field interviews in pre-tests also support this notion. Overall, the significant differences in seven of the key constructs seem minor in terms of their implications on non-respondent bias.

As for the remaining demographic data comparisons, no significant differences were observed in Age $(p=.21)$ or Gender $(p=.29)$. There was a slight difference in terms of Annual Sales $(\mathrm{p}=.02)$. A sufficiently larger number of respondents in mail survey reported annual sales of $\$ 500-\$ 999,000$ than did in in-person survey $(32.5 \%$ and $13.4 \%$, respectively). At the same time, a notably larger number of in-person survey respondents reported annual sales of $\$ 1-\$ 2.99$ million than did in mail survey $(23.2 \%$ and $11.3 \%$, respectively). The difference here could also easily be explained by the differences respondents' industry sectors. 
Lastly, additional analysis (MANOVA) was conducted comparing the possible bias due to in-person survey location differences. The location difference also suggests possible differences in skills in survey administrators (undergraduate students enrolled in marketing classes). As shown in Table 4.9, the only significant $(\mathrm{p}<.05)$ difference were observed in Machiavellianism scores and OB. A post hoc test revealed that the respondents between Illinois and West Virginia scored significantly different $(p=.00)$ in Machiavellianism scale. The difference between Illinois and Minnesota was marginal $(p=.10)$. Similarly, the main difference in OB scores was between Illinois and the other two states ( $\mathrm{p}<.05$ for both pairs). In both cases a caution should be given to the small sample size in Illinois $(\mathrm{n}=12)$.

When demographic information was checked by Pearson Chi-square tests, nonsignificant differences were found in Age $(p=.88)$, Gender $(p=.93)$, Industry $(p=.744)$, and Annual Sales $(\mathrm{p}=.52)$. Overall, it appears that no meaningful response bias in terms of location of in-person survey exists.

In summary, the three sets of analyses aimed to identify the possibility of nonresponse bias suggest any differences observed were non-critical in terms of their potential effects on research outcome. Comparisons between early and late mail survey respondents show significant difference in mean values of Negative Professional Ethical Climate only. The difference in the extent of anonymity between mail survey and inperson survey did not lead to significant differences in response to sensitive questions.

Furthermore, no meaningful differences in location for in-person surveys were observed. Although responses in several constructs were significantly different between mail and in-person survey participants, no clear bias could be implied. Rather, the 
Table 4.9: Non-Response Bias Results Using Concurrent Waves by Location

\begin{tabular}{|c|c|c|c|c|}
\hline Construct & Location & Mean & $F\left(\mathbf{d f}_{1}, \mathbf{d f _ { 2 }}\right)$ & p-value \\
\hline Franchisor TSIs & $\begin{array}{l}\text { Illinois } \\
\text { Minnesota } \\
\text { West Virginia }\end{array}$ & $\begin{array}{l}3.23 \\
3.76 \\
3.82\end{array}$ & $.66(2,78)$ & .52 \\
\hline Franchisor Dependence & $\begin{array}{l}\text { Illinois } \\
\text { Minnesota } \\
\text { West Virginia }\end{array}$ & $\begin{array}{l}3.93 \\
3.87 \\
4.02\end{array}$ & $.09(2,79)$ & .91 \\
\hline Distributive Justice & $\begin{array}{l}\text { Illinois } \\
\text { Minnesota } \\
\text { West Virginia }\end{array}$ & $\begin{array}{l}4.60 \\
3.53 \\
4.43\end{array}$ & $2.67(2,76)$ & .08 \\
\hline Procedural Justice & $\begin{array}{l}\text { Illinois } \\
\text { Minnesota } \\
\text { West Virginia }\end{array}$ & $\begin{array}{l}5.46 \\
4.21 \\
4.52\end{array}$ & $3.00(2,79)$ & .06 \\
\hline Interactional Justice & $\begin{array}{l}\text { Illinois } \\
\text { Minnesota } \\
\text { West Virginia }\end{array}$ & $\begin{array}{l}5.71 \\
4.75 \\
4.87\end{array}$ & $1.94(2,79)$ & .15 \\
\hline Franchisee Dependence & $\begin{array}{l}\text { Illinois } \\
\text { Minnesota } \\
\text { West Virginia }\end{array}$ & $\begin{array}{l}4.76 \\
4.66 \\
4.73\end{array}$ & $.02(2,79)$ & .98 \\
\hline Disciplinary Monitoring & $\begin{array}{l}\text { Illinois } \\
\text { Minnesota } \\
\text { West Virginia }\end{array}$ & $\begin{array}{l}18.88 \\
23.21 \\
26.78\end{array}$ & $2.47(2,79)$ & .09 \\
\hline $\begin{array}{l}\text { Economies of } \\
\text { Continuation }\end{array}$ & $\begin{array}{l}\text { Illinois } \\
\text { Minnesota } \\
\text { West Virginia }\end{array}$ & $\begin{array}{l}4.91 \\
5.68 \\
5.20\end{array}$ & $1.24(2,78)$ & .30 \\
\hline $\begin{array}{l}\text { Crowding Out Effects of } \\
\text { Monitoring }\end{array}$ & $\begin{array}{l}\text { Illinois } \\
\text { Minnesota } \\
\text { West Virginia }\end{array}$ & $\begin{array}{l}1.73 \\
2.30 \\
2.45\end{array}$ & $1.28(2,79)$ & .29 \\
\hline OB & $\begin{array}{l}\text { Illinois } \\
\text { Minnesota } \\
\text { West Virginia }\end{array}$ & $\begin{array}{l}1.59 \\
2.47 \\
2.61\end{array}$ & $3.08(2,78)$ & .05 \\
\hline $\begin{array}{l}\text { Negative Professional } \\
\text { Ethical Climate }\end{array}$ & $\begin{array}{l}\text { Illinois } \\
\text { Minnesota } \\
\text { West Virginia }\end{array}$ & $\begin{array}{l}2.38 \\
2.99 \\
3.00\end{array}$ & $1.13(2,78)$ & .33 \\
\hline Network Density & $\begin{array}{l}\text { Illinois } \\
\text { Minnesota } \\
\text { West Virginia }\end{array}$ & $\begin{array}{l}5.67 \\
5.05 \\
4.62\end{array}$ & $2.68(2,79)$ & .08 \\
\hline PFO & $\begin{array}{l}\text { Illinois } \\
\text { Minnesota } \\
\text { West Virginia }\end{array}$ & $\begin{array}{l}1.75 \\
1.78 \\
2.03\end{array}$ & $1.74(2,77)$ & .18 \\
\hline CMD & $\begin{array}{l}\text { Illinois } \\
\text { Minnesota } \\
\text { West Virginia }\end{array}$ & $\begin{array}{l}27.73 \\
33.04 \\
30.94\end{array}$ & $.34(2,68)$ & .71 \\
\hline
\end{tabular}




\begin{tabular}{|c|c|c|c|c|}
\hline \multicolumn{5}{|c|}{ Table 4.9 Continued } \\
\hline External Locus of & Illinois & 1.28 & $2.83(2,79)$ & .07 \\
\hline \multirow[t]{2}{*}{ Control } & Minnesota & 2.00 & & \\
\hline & West Virginia & 2.54 & & \\
\hline \multirow[t]{3}{*}{ Machiavellianism } & Illinois & 9.00 & $6.94(2,79)$ & .00 \\
\hline & Minnesota & 17.93 & & \\
\hline & West Virginia & 26.59 & & \\
\hline \multirow[t]{3}{*}{ Social Desirability } & Illinois & 6.63 & $.26(2,77)$ & .77 \\
\hline & Minnesota & 6.83 & & \\
\hline & West Virginia & 6.36 & & \\
\hline
\end{tabular}


differences seem to simply arise from the differences in franchisees' industry sectors between the two subsamples. Taken together, a reasonable conclusion can be made that respondents and non-respondents are not critically different from each other.

\section{Final Sample Characteristics}

This section describes the demographic characteristics of unit franchisees in the final sample, as well as the characteristics of their franchise units. Table 4.10 lists a complete list of the questions that were asked. The following variables are used to describe the sample and its degree of representativeness for the study population:

Subject knowledgeability about the franchisor-franchisee exchange

$>$ The length managing the franchise unit in years

$>$ Geographic location of the franchise

Total annual sales of the franchise

$>$ The total number of employees

$>$ Industry Sector

The franchisees in the final sample reported that they are highly knowledgeable about the franchise unit's dealings with its franchisor $(\mathrm{M}=6.43, \mathrm{SD}=.74)$ on a seven-point scale (1= "not at all knowledgeable", 7= "very knowledgeable"). A listwise deletion was done to eliminate the respondents who reported their knowledgeability as being less than five, and hence the final sample only includes those with a minimum rating of five in knowledgeability. The mean length managing the franchise unit was 8.97 years 
Table 4.10: Operational Measures: Franchise Unit and Subject Information

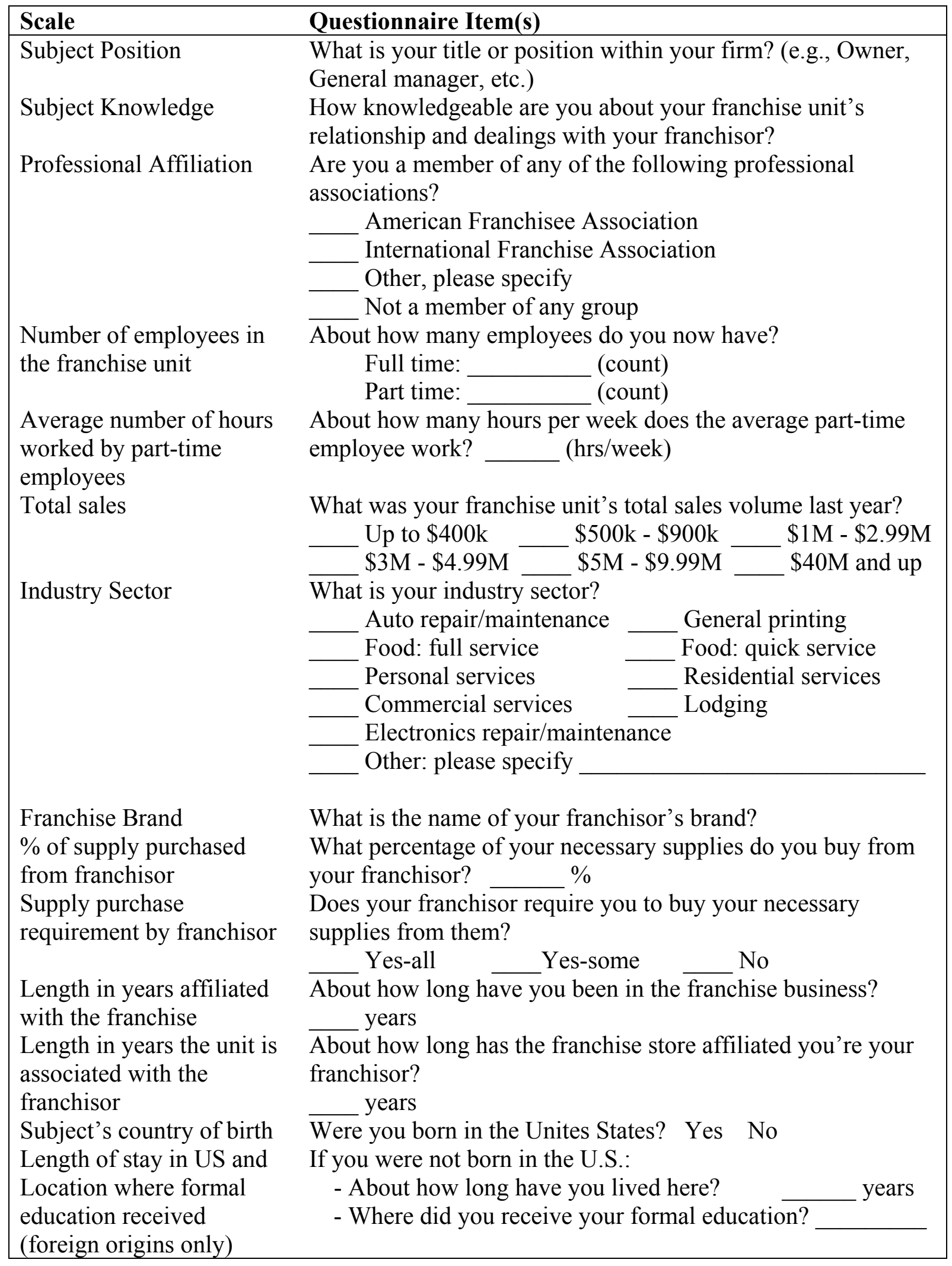




\section{Table 4.2 Continued}

Subject's gender What is your gender? Male Female

Subject's age

How old are you?

18-24yrs

25-34yrs

35-44yrs

$45-54 \mathrm{rs}$

$55-64$ yrs

65 or older 
$(\mathrm{SD}=7.89)$, ranging from six months to 39 years. In addition, $68.8 \%$ has managed the unit for at least five years, and $93.5 \%$ have managed the unit for at least two years. Taken together, the franchisees in the final sample qualify as both key informants and respondents as they have been highly involved in the franchisor-franchisee relationship for a considerable length of time.

The sample mean for the total number of employees was 19.23 $(\mathrm{SD}=24.76)$, of which the means for full-time and part-time employees were 8.48 and 10.53, respectively. $49.2 \%$ of the sample reported having at least ten total employees, and $90.0 \%$ reported having at least three employees. While 20 franchisees $(12.3 \%$ of total sample) did not report their annual sales, $43.2 \%$ of the sample indicated that their annual sales volume is less than $\$ 500,000.22 .8 \%$ of the sample indicated sales volume ranging from $\$ 500,000$ to $\$ 999,000.17 .3 \%$ reported $\$ 1$ million to $\$ 2.99$ million dollars in sales.

The location of franchisees was also diverse. Table 4.11 shows the number of respondents in each of 37 states from which I received data. The most concentrated states are Illinois, West Virginia, Pennsylvania, and Minnesota, and these four states represent $50.6 \%$ of all the respondents. The primary reason for the discrepancies is that these are the states in which in-person surveys were administered.

The franchisees in the final sample are involved in a diverse business sectors. As Depicted in Figure 4.2, almost one half of the franchisees are in either food or general printing industry. The Food industry represented the highest number of franchisees with $36 \%$ of the total sample, followed by General Printing (13\%), Auto Repair/Maintenance (12\%), Personal Services (11\%), Residential/Commercial Services (9\%), Professional Services (9\%), Retails (7\%), and Lodging (3\%). 
Table 4.11: Primary Data Collection by State

\begin{tabular}{|c|c|c|}
\hline State & No. of Participants & \% Participants \\
\hline AL & 1 & $0.62 \%$ \\
AZ & 1 & $0.62 \%$ \\
CA & 5 & $3.09 \%$ \\
CO & 4 & $2.47 \%$ \\
FL & 5 & $3.09 \%$ \\
GA & 4 & $2.47 \%$ \\
IA & 1 & $0.62 \%$ \\
ID & 1 & $0.62 \%$ \\
IL & 14 & $8.64 \%$ \\
IN & 1 & $0.62 \%$ \\
KS & 1 & $0.62 \%$ \\
KY & 1 & $0.62 \%$ \\
LA & 2 & $1.23 \%$ \\
MA & 4 & $2.47 \%$ \\
MD & 4 & $2.47 \%$ \\
ME & 1 & $0.62 \%$ \\
MI & 2 & $1.23 \%$ \\
MN & 32 & $19.75 \%$ \\
MO & 1 & $0.62 \%$ \\
NC & 4 & $2.47 \%$ \\
NE & 1 & $0.62 \%$ \\
NH & 1 & $0.62 \%$ \\
NJ & 4 & $2.47 \%$ \\
NM & 1 & $0.62 \%$ \\
NY & 4 & $2.47 \%$ \\
OH & 1 & $0.62 \%$ \\
OK & 1 & $0.62 \%$ \\
OR & 3 & $1.85 \%$ \\
PA & 11 & $6.79 \%$ \\
SD & 1 & $0.62 \%$ \\
TN & 1 & $0.62 \%$ \\
TX & 5 & $3.09 \%$ \\
UT & 1 & $0.62 \%$ \\
VA & 6 & $3.70 \%$ \\
WI & $15.43 \%$ \\
WV & 25 & $1.23 \%$ \\
WY & 2 & \\
& & 1 \\
\hline
\end{tabular}


Figure 4.2: The Final Sample by Industry Sector

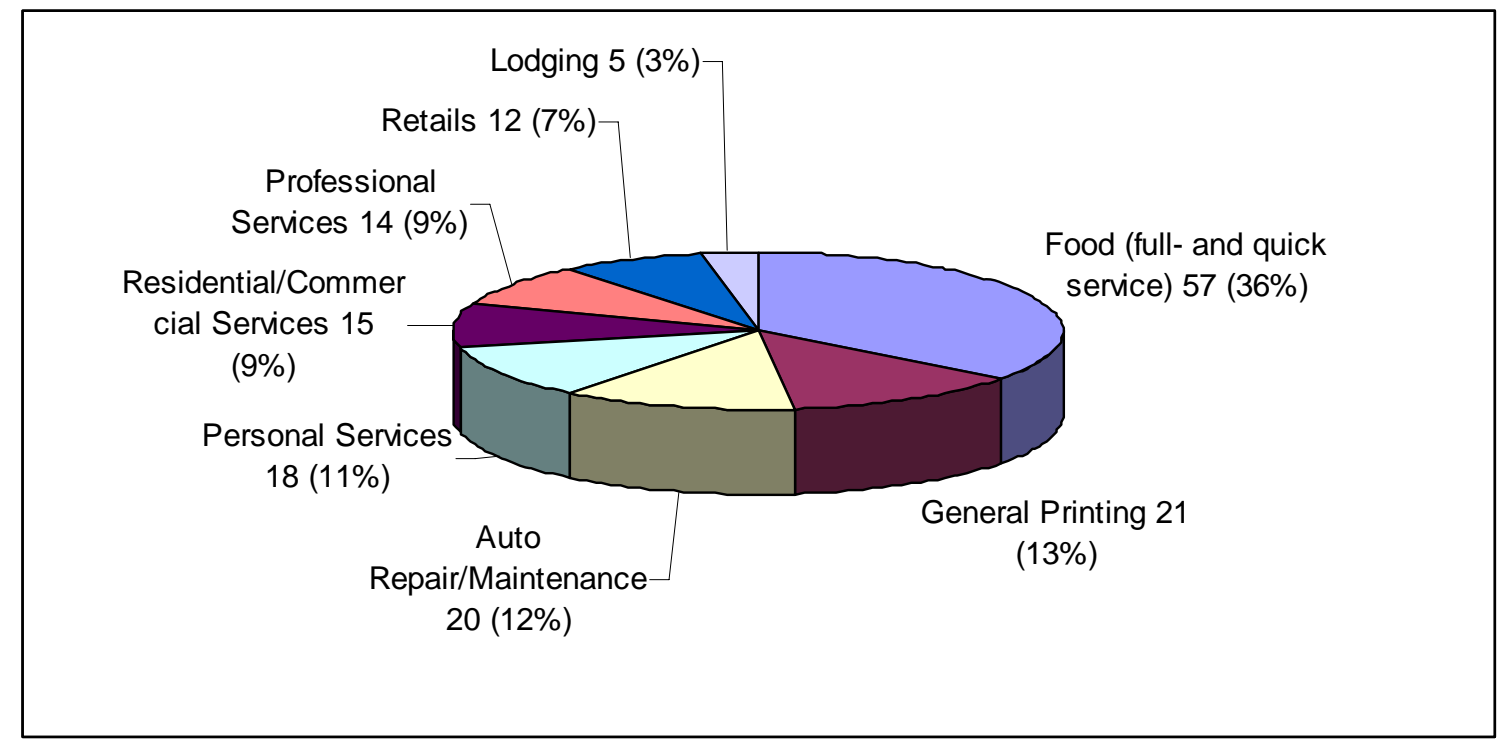




\section{Sample Representativeness}

In total, 188 individuals voluntarily participated in this study. After a listwise deletion of those responses with (1) significantly missing data (20\% or more responses missing) and/or (2) insufficient knowledge in franchisor-franchisee dealings (selfreported knowledgeability of less than five on a 7-point scale), the final sample was 162 . These participants are unit franchisees from 37 states. Their industry sectors vary greatly: Food (36\%), General Printing (13\%), Auto Repair/Maintenance (12\%), Personal Services (11\%), Residential/Commercial Services (9\%), Professional Services (9\%), Retailing (7\%), and Lodging (3\%). Of those who reported annual sales volume, approximately one half $(49.3 \%)$ indicated their annual sales volume being less than $\$ 500,000$, and $26.1 \%$ reported between $\$ 500,000$ and $\$ 999,000$.

To establish generalizeability of the research findings, the final sample must be representative of the population of franchisees in the U.S. The economic census data from the Census Bureau of the Department of Commerce may be most helpful in making such comparison. Unfortunately, such data on franchising as a whole do not exist yet. According to Franchising World (2006), with collaboration with IFA, the Census Bureau plans to include franchise-related questions on the census forms for approximately 80 industry categories that have franchised business starting the year 2007. Alternatively, The Profile of Franchising: Series V (2006) and Economic Impact of Franchised Business (2004) by IFA Educational Foundation were used to assess the generalizeability of the sample.

Three sets of analysis were done to estimate the generalizeability of the sample. First, because the original mailing list was randomly selected from a master list of 
100,000 single-unit franchisees, I compared the final sample against the original mailing list. If the master list is a fair representation of all single-unit franchisees in the U.S., this should make an effective judgment for the sample's generalizeability. Second, a comparison was made between nation-wide data on franchised industry from The Profile of Franchising in 2006 and the sample data. This was done to compare the final sample's representativeness with national franchisees as a whole. Third, state-by-state distribution of franchisees in the final sample was compared against that of the original mailing list.

The first analysis indicated that the final sample in the current research is likely to be generalizeable. Provided that the FRANdata's master list of unit franchisees is a good representation of the total single-unit franchisees in the nation, as shown in Table 4.12, the percentages of different industry sectors in the final sample are very similar to those of the original mailing list. The numbers are almost identical in General Printing, Auto Repair/Maintenance, Personal Services, Professional Services, and Lodging. Somewhat large discrepancies come from the Food, Residential/Commercial Services, Professional Services and Retailing sectors $(-14 \%,+6 \%,+4 \%$, and $+6 \%$ for the final sample, respectively). Indeed, the differences in proportion are statistically significant at $\mathrm{p}<.05$ using Fisher's Z-test for two proportions. Though, the differences are not exactly alarming, as the overall proportions appear rather similar (i.e., order of magnitudes remained the same; food being the largest, followed by General Printing, Auto Repair/Maintenance, and so forth). Overall, no meaningful conclusion could be derived even the statistically significant differences in four categories. A contingency effect such as the season (i.e., summer time) in which the data collection took place could have 
Table 4.12: Industry Comparison between the Final Sample and the Original Mailing List

\begin{tabular}{lcc}
\hline \multicolumn{1}{c}{ Industry Sector } & $\begin{array}{c}\text { The final } \\
\text { Sample }\end{array}$ & $\begin{array}{c}\text { Original } \\
\text { Mailing List }\end{array}$ \\
\hline Food (full- and quick service) & $35 \%$ & $49 \%$ \\
General Printing & $13 \%$ & $14 \%$ \\
Auto Repair/Maintenance & $12 \%$ & $13 \%$ \\
Personal Services & $11 \%$ & $12 \%$ \\
Residential/Commercial Services & $9 \%$ & $3 \%$ \\
Professional Services & $9 \%$ & $5 \%$ \\
Retailing & $7 \%$ & $1 \%$ \\
Lodging & $3 \%$ & $3 \%$ \\
\hline
\end{tabular}


attributed to the relatively minor differences. In addition, as described previously, the quality of mailing list was far from perfect, and it is possible that I had better quality list of franchisees in Professional Services, Residential/Commercial Services, and Retailing than the rest, which could have led to seemingly better response rate in these three categories of industry.

Next, another comparison was made between the final sample and the nation-wide data of franchisees by industries. Table 4.13 shows this comparison, and clearly there are some discrepancies in proportions. A caution must be made when making a comparison, however. The present study's sample only consists of unit-franchisees, while the nationwide data from IFA contain all businesses that are characterized as using the method of franchising, which include unit franchisees and multiple-unit franchisees (actually proportions not reported).

The proportions of Food industry (both full- and quick-service combined), Personal Services, Professional Services, Residential/Commercial Services, and Lodging were fairly represented in the final sample. General Printing, Auto Repair/Maintenance, and Personal Services had much higher percentages shown in the final sample compared to the nation-wide data $(+12 \%,+6 \%$, and $+4 \%$ in the final sample, respectively). Retailing was much more prevalent in the nation-wide data $(+9 \%)$ than in the final sample. Fisher's Z-test for two proportions revealed that these differences were indeed statistically significant $(\mathrm{p}<.05)$.

Such differences could be due to many factors, though, the possibility that General Printing and Auto Repair/Maintenance are more likely be owned by single-unit franchisees is high. This was more or less evident in the original mailing list, which was 
Table 4.13: Industry Comparison between the Final Sample and Nation-Wide Data on Franchisees (single- and multiple-unit combined)

\begin{tabular}{lcc}
\hline \multicolumn{1}{c}{ Industry Sector } & $\begin{array}{c}\text { The final } \\
\text { Sample }\end{array}$ & $\begin{array}{c}\text { Nation-wide } \\
\text { Data* }\end{array}$ \\
\hline Food (full- and quick service) & $35 \%$ & $35 \%$ \\
General Printing & $13 \%$ & $1 \%$ \\
Auto Repair/Maintenance & $12 \%$ & $6 \%$ \\
Personal Services & $11 \%$ & $7 \%$ \\
Residential/Commercial & & \\
Services & $9 \%$ & $13 \%$ \\
Professional Services & $9 \%$ & $13 \%$ \\
Retailing & $7 \%$ & $16 \%$ \\
Lodging & $3 \%$ & $3 \%$ \\
\hline *Source: Economic Impact of Franchises Businesses (2004) \\
\hline
\end{tabular}


randomly selected from FRANdata's master mailing list. 14\% of the franchisees in the original mailing list were in General Printing.

Lastly, a state-by-state comparison was made between the final sample and the original mailing list. Assuming that the original mailing list is a good representation of single-unit franchisees in the nation, similar distribution of franchisees in each state would be desirable. As seen in Table 4.14, there are some discrepancies in states of California, Minnesota, and West Virginia. This is primarily due to the in-person survey method I employed.

While the number of unit franchisees in California in the original list seemed unusually high and perhaps be ignored, the discrepancies for Minnesota and West Virginia would be a concern for external validity if the franchise environment in these states is significantly different from that in the other states. To investigate the possibility, Economic Impact of Franchised Business (2004) was used as it lists economic impact of franchisees (single- and multi-unit franchisees combined) by state. According to the statistics, the U.S. average of economic impact in terms of payroll caused by franchising was $11.1 \%$, while the numbers for Minnesota and West Virginia were $11.7 \%$ and $12.5 \%$, respectively. The comparison enables to establish a commonality in franchising environment for Minnesota and West Virginia with the rest of the nation, and therefore, the higher response rate in these two states should be considered minor. 
Table 4.14: State-by-State Comparison between the Final Sample and the Original Mailing List

\begin{tabular}{|c|c|c|}
\hline State & $\begin{array}{c}\text { \% Participants in the } \\
\text { Final Sample }\end{array}$ & $\begin{array}{c}\text { \% Participants in the } \\
\text { Original Mailing List }\end{array}$ \\
\hline AL & $0.62 \%$ & $1.41 \%$ \\
AZ & $0.62 \%$ & $1.79 \%$ \\
CA & $3.09 \%$ & $12.03 \%$ \\
CO & $2.47 \%$ & $2.86 \%$ \\
FL & $3.09 \%$ & $7.27 \%$ \\
GA & $2.47 \%$ & $4.22 \%$ \\
IA & $0.62 \%$ & $1.02 \%$ \\
ID & $0.62 \%$ & $0.55 \%$ \\
IL & $8.64 \%$ & $4.41 \%$ \\
IN & $0.62 \%$ & $2.07 \%$ \\
KS & $0.62 \%$ & $0.91 \%$ \\
KY & $0.62 \%$ & $1.41 \%$ \\
LA & $1.23 \%$ & $1.14 \%$ \\
MA & $2.47 \%$ & $2.17 \%$ \\
MD & $2.47 \%$ & $2.14 \%$ \\
ME & $0.62 \%$ & $0.29 \%$ \\
MI & $1.23 \%$ & $3.53 \%$ \\
MN & $19.75 \%$ & $2.50 \%$ \\
MO & $0.62 \%$ & $1.52 \%$ \\
NC & $2.47 \%$ & $3.00 \%$ \\
NE & $0.62 \%$ & $0.45 \%$ \\
NH & $0.62 \%$ & $0.40 \%$ \\
NJ & $2.47 \%$ & $3.26 \%$ \\
NM & $0.62 \%$ & $0.52 \%$ \\
NY & $2.47 \%$ & $4.03 \%$ \\
OH & $0.62 \%$ & $3.72 \%$ \\
OK & $0.62 \%$ & $0.76 \%$ \\
OR & $1.85 \%$ & $1.48 \%$ \\
PA & $6.79 \%$ & $4.57 \%$ \\
SD & $0.62 \%$ & $0.43 \%$ \\
TN & $0.62 \%$ & $1.86 \%$ \\
TX & $3.09 \%$ & $5.69 \%$ \\
UT & $0.62 \%$ & $0.91 \%$ \\
VA & $3.70 \%$ & $2.60 \%$ \\
WI & $1.95 \%$ \\
WV & & $0.17 \%$ \\
WY & \\
\hline & & \\
\hline
\end{tabular}




\section{Summary}

This chapter described in detail sampling and data collection procedures, as well as the final sample characteristics. First, sampling sections assessed the appropriateness of franchising as the study population. The study context of franchising offers an ideal sampling frame that consists of business-to-business relationships embedded in a broader social network that can clearly be defined. In addition, empirically, franchising presented sufficient variance on all key variables, just as expected prior to data collection. Sampling frame was also discussed.

Second, the chapter also included a discussion of three pre-tests procedures and results. These pre-tests aided us in refining the questionnaire. Primary data collection procedures, including first-wave (mail survey) and second-wave (in-person) were also described. Upon primary data collection, quality of mailing list was assessed, as well as an analysis of response rate using the extant literature as a reference. I also discussed a treatment of missing data and possibilities of response bias. The analyses of missing data and response bias led to a conclusion that no substantive bias was introduced during data collection.

Lastly, the degree of external validity was considered by analyzing the final sample characteristics. The sample's representativeness to the study population was considered carefully. The final sample was compared with the original mailing list in terms of industries and state-by-state distribution. The final sample was also compared with nation-wide data on franchised industry. Overall, a reasonable conclusion was drawn that the sample represents the study's target population well. 


\section{CHAPTER V \\ SURVEY INSTRUMENT}

The objective of this chapter is to describe in detail the scale operationalizations, scale development, and measure validation procedures. Many of the constructs embedded in the hypotheses already have established measures which have been rigorously tested for their psychometric properties. Those without established measures or ones that require significant modifications (PFO, Negative Professional Ethical Climate, Disciplinary Monitoring, Crowding Out Effects of Monitoring, Distributive Justice, and Procedural Justice) first went through domain sampling (Churchill 1979). This involved establishing an operationalization of construct and generating sample of measurement items that tap the domain. Several steps of pre-tests followed, some of which were described in Chapter Four.

Unless otherwise noted, the default construct model specification uses reflective indicators. The distinction between the two types of scales deserves scrutiny as the traditionally used methods for assessing construct reliability, which are based on the assumption of inter-item correlations (cf. Bagozzi 1994; Cohen et al. 1990) should not be used for formative variation (Bollen and Lennox 1991). The indicators of a reflective scale should be correlated highly (i.e., should be internally consistent). In contrast, there are no reasons to expect that the indicators of formative scales are correlated, and hence internal consistency is not implied because the direction of causality is from measure to construct. As Jarvis, Mackenzie, and Podsakoff (2003, p. 201) puts it, "Unlike the reflective model, this [formative] model does not assume that the measures are all caused by a single underlying construct. . . rather, it assumes that the measures all have impact 
on (or cause) a single construct." Formative constructs' content validity may be assessed based on the construct operationalization and whether the measurement items precisely and thoroughly tap it (Howell 1987). The guideline suggested by Jarvis, et al. (2003, p. 203 Table 1) was used to determine whether each construct had formative or reflective indicators:

1. Direction of causality from construct to measure

- Causality from indicators to construct (formative)

- Causality from construct to indicators (reflective)

2. Interchangeability of the indicators

- Indicators need not share a common theme (formative)

- Indicators should share a common theme (reflective)

3. Covariation among the indicators

- Not necessary for indicators to covary with each other (formative)

- Indicators are expected to covary with each other (reflective)

4. Nomological net of the construct indicators

- Indicators are not required to have the same antecedents and consequences (formative)

- Indicators are required to have the same antecedents and consequences (reflective)

The following sections are organized into two: (1) operationalization and development of constructs and (2) measure validation for dyadic and extra-dyadic scales. For operationalization and measure development sections, they are further organized along each level of analysis (individual, dyadic, and extra-dyadic), followed by control variables. The complete item pool for each variable along with their descriptive statistics such as means, standard deviations, and range can be found in Appendix B. With exceptions of Locus of Control, CMD, and PFO, all items used a 7-point Likert-type response format. Measure validation procedures are discussed afterwards. 


\section{Individual Level Constructs}

No changes were necessary for the individual-specific constructs (Machiavellianism, locus of control, and CMD) as research contexts are irrelevant to these personal-trait scales. These three constructs already have established measures that have been rigorously tested for their psychometric properties.

\section{Machiavellianism}

Machiavellianism is a personality trait that is generally defined as the extent to which an individual detaches from considerations of ethics and perform actions that profit the self (Robinson and Shaver 1973). Christie and Geis (1970) developed the scale, referred to as Mach IV, based on the statements of Niccolo Machiavelli in The Prince. The scale has total of 20 items and is designed to minimize response bias by ten of the items endorsing Machiavellian statements and the other ten items in the opposite direction. More specifically, the scale can be categorized into three groups (see Christie and Geis 1970). One group (nine items) deals with "Machiavellians tactics," such as, "never tell anyone the real reason you did something unless it is useful to do so." Another group (nine items) pertains to "views of human nature," for example, "it is safest to assume that all people have a vicious streak." The last two items belong to the third group: "abstract morality," such as "all in all, it is better to be humble and honest than to be important and dishonest." In the questionnaire, the scale used 7-point Likert-type scale (1 = "strongly disagree" to $7=$ "strongly agree"). 
The development of Mach IV was primarily in accordance with the principles of content validity (Christie and Geis 1970), which implies it makes no assumptions about the internal structure (Cronbach 1971). Through the use of confirmatory factor analysis and path analysis aimed to establish predictive validity, Hunter, Gerbing, and Boster (1982) make it clear that Mach IV is a formative scale by noting that “...Machiavellianism... is an arbitrary composite score formed by summing over Machiavellian beliefs that do have construct validity" (p.1304). As such, the present study treats Mach IV scale as a formative scale, and it was not included in measurement model. Mach IV scores ranged from -14.00 to $60.00(\mathrm{M}=22.24, \mathrm{SD}=14.70)$.

\section{External Locus of Control}

Locus of control refers to the extent to which individuals believe that they can control events that affect them (Rotter 1966). Rotter's (1966) internal-external locus of control scale (I-E scale) measures the tendency of the individual to perceive events as contingent on his/her own behavior or independent of it. Although Rotter's 29-item forced-choice scale of generalized feelings of locus of control has widely been used (e.g., Spector 1982; Singhapakdi and Vitell 1991), I chose to adopt a shorter, abbreviated version (11-items) of Rotter's scale developed and verified by Valecha (1972) and Valecha and Ostrom (1974) out of the concern about the length of my already-long questionnaire. The scale reportedly has very similar psychometric properties to Rotter's original 29-item I-E scale (Valecha and Ostrom 1974). In addition, this abbreviated I-E scale has been used in leading marketing and management journal research (e.g., Burroughs and Mick 2004; Phillips and Bedian 1994), and they report acceptable 
reliability (above $>.70$ ). The 11-item forced choice question pairs with an "internal" statement with and an "external" one. The possible scores ranges from zero (most “internal") to ten (most "external") with one filler item that is not counted.

The scale uses a forced-choice format, by which respondents are shown two statements by question item and is asked to select one that $\mathrm{s} /$ he more strongly agrees. Due to this dichotomous response format, Kuder-Richardson 20 (KR-20) test (the equivalent for Cronbach's $\alpha$ ) was used to determine the scale's reliability. Though this scale's reliability coefficient of .61 is slightly below recommended internal consistency of .70 (Nunnaly 1978), it compares favorably to the reliability found in other applications of short form Marlowe-Crowne scales (see Ballard 1992). The response ranged from .00 to $7.00(\mathrm{M}=1.78, \mathrm{SD}=1.67)$.

\section{Cognitive Moral Development (CMD)}

CMD measures advances in moral reasoning, and it captures advances in moral reasoning and a progression to a higher stage that reflects an increased understanding of the nature of moral obligations in complex social systems (Rest 1979). According to Kohlberg (1976), individuals progress through three levels of moral reasoning: preconventional, conventional, and post-conventional. CMD is operationalized as the extent to which an individual subscribes to post-conventional stages of moral reasoning.

Based on the pre-test result (see Chapter Four), the CMD scale chosen for the present study was the 2-Story DIT, by which a study participant reviews two moral dilemma scenarios and their respective twelve statements pertaining to stages of CMD. For each moral dilemma given, the respondents are asked to rate the relative importance 
of twelve pertinent items in helping them make the decision on a 5-point scale $\{1=$ "no importance (to my judgment)" to 5 = "great importance (to my judgment)" $\}$. The respondents are then asked to rank the four most important items from the twelve items. The reliability and validity of the DIT are well established through hundreds of academic studies over two decades (cf. Rest et al. 1999).

For each dilemma scenario, the DIT presents a scoring chart to determine which stage each of the twelve items exemplifies. Weighted scores are then computed and added, which is then converted to percentages by dividing the raw scores by 0.2 . The score indicates percentage of moral reasoning at the post-conventional level. The score can be interpreted as the relative importance a subject gives to principled moral considerations in making a decision about moral dilemmas (Rest 1979). The specific procedures for scoring are laid out in DIT Manual (1986), which includes internal checks on subject reliability using an "M-score." M-items are meaningless statements in terms of moral maturity and do not represent any stage of moral thinking. Rest (1986) explains that rating high on these statements represents "a subject's tendency to endorse statements for their pretentiousness rather than their meaning” (pp. 4-5).

In the study sample, I could not identify CMD scores for a total of 31 participants: ten did not fill out the DIT scale items, and the remaining 21 were determined as nonreliable (i.e., M percentage of 14 or more). The mean CMD score for the remaining 131 participants was 30.78 ( $\mathrm{SD}=17.06)$, with scores ranging from zero to 75 . 


\section{Dyadic Level Constructs}

This section of dyadic level constructs is organized in the order in which they were addressed in Chapter Three (Hypothesis).

\section{Interdependence Magnitude and Asymmetry}

Dependence reflects the extent to which firm A needs firm B to provide important resources, of which there are few alternative sources (Emerson 1962; Cadotte and Stern 1979). Following Emerson's (1962) power-dependence theory, the extent of dependence is determined by its exchange partner's motivational investment and its availability of alternatives.

Motivational investment refers to the value of resources or outcomes (e.g., sales and profits) mediated by the partner firm, and the availability of alternatives refers to the difficulty in replacing the exchange partner in fulfilling the desirable outcome.

Dependence is conceptualized as a first-order reflective, second-order formative scale as the two components (motivational investment in goals and replaceability) (1) need not be highly correlated and (2) each contributes separately to overall construct of dependence (cf. Antia and Frazier 2003). I operationalize Replaceability as the extent to which a franchisor (franchisee) finds it difficult to find a replacement partner. Motivational investment is operationalized as the extent to which a franchisor (or franchisee) needs to maintain the relationship to achieve profits.

Both Interdependence Magnitude and Interdependence Asymmetry were computed as products of Dependence measures. Dependence was measured from each side of the dyad: franchisor dependence on franchisee and franchisee dependence on 
franchisor, as reported by the key informants (i.e., franchisees). Interdependence Magnitude refers to the sum of the dependence in an exchange (Gundlach and Cadotte 1994), and following Antia and Frazier (2001), Interdependence Magnitude was measured as the sum of the dependence scores from each side of the dyad. Similarly, Interdependence Asymmetry was computed as the difference between the two dependence scores (i.e., franchisee dependence on franchisor minus franchisor dependence on franchisee). A positive interdependence asymmetry value indicates power advantage favoring the franchisor.

The scale for dependence was adapted from Antia and Frazier's (2001) 12-item measurement scales of interdependence structure (six each for franchisor and franchisee points of view). They developed their scale based on prior measures developed by Gundlach and Cadotte (1994) and Kumar et al. (1995a). They use a combination of semantic differentials (five items) and one Likert-type scale item for their measure of "franchisee dependence on franchisor," and six semantic differential items on "franchisor dependence on franchisee." For simplicity, I modified the response format to Likert-type for all the items. For example, the original item of "Easy to replace this franchisee - Very difficult to replace this franchisee" using semantic differential was modified to "For our franchisor, it would be difficult to replace us" with 7-point Likert-type response. No other changes were needed as the study population of Antia and Frazier's (2001) study was also franchising. As this was second-order formative scale, the lower-order factors are separately included in measurement analysis. 


\section{Franchisee TSIs}

Franchisee TSIs are operationalized as the non-salvageable investments that franchisees have made specifically in the relationship with their franchisor. I developed the scale based on Antia and Frazier's (2001) scale for TSIs at the dyadic relationship level, which had been developed from Anderson (1985) and John and Weitz (1988). Because the scale was designed to capture the extent of franchisors' investments made for the franchisees, for the present research I modified the measurement items to reflect the investments that franchisees made instead. I also relied on Shane's (2001) insights on various franchisee investments. Up-front cash investment, system-specific training, and system maintenance are among the TSIs typical franchisees incur, and incidentally, these costs seem to be well reflected in Antia and Frazier's (2001) items. Overall, the measurement scale for franchisee TSIs consisted of four items measured on 7-point scale, anchored by "strongly disagree" and "strongly agree" that is a slightly modified version of Antia and Frazier (2001). Specifically, modifications were made to some of the items by re-wording from "this franchisee" to "this franchisor."

\section{Economies of Continuation}

Economies of Continuation generally refer to the open-endedness of exchange relationships, or the degree to which exchange partners expect the relationship to continue indefinitely (Heide and Miner 1992). In the current research context, however, franchise relationships are intended to be non-transactional, and the length of contract is determined a priori. Typically, duration of franchise agreements range from four to 20 years. For example, many fast-food restaurant franchise systems use a 20-year contract, 
while fashion merchandise retail franchises tend to use shorter, three to five year contracts. In both cases renewal of contracts is open-ended. The total terms of agreement may also be broken into renewal periods at which the agreement is up for review.

Therefore, franchisees who have signed a ten-year agreement with their franchisors expect the relationships to last at least ten years unless the conditions for termination specified on the franchise agreement are broken and end up in early termination. Franchisees usually incur sizable early termination fees with voluntary early termination. Given that a franchise relationship operates in a pre-specified duration, my conceptualization of economies of continuation is specific to contract renewal. Hence, the operationalization of Economies of Continuation is the extent to which an extended relationship (i.e., renewal of contract) is contingent upon the franchisee's ongoing performance.

I adapted Heide and Miner's (1992) measurement scale for “extendedness of relationship" to fit the research context. Two of the items only required slight modification, for example, "renewal of agreements" was modified to "renewal of our franchise contract," as well as "the terms of individual purchases" was modified to "the current contract term." The other two items required more extensive modifications due to unique nature of franchise contract and its renewal procedure. "The parties expect this relationship to last a lifetime" was modified to "Our relationship length with the franchisor depends on the franchisor's evaluation of our current performance." "It is assumed that renewal of agreements in this relationship will generally occur" was modified to "The franchisor's decision to renew our contract is highly contingent on our 
current performance.” The measurement items are scored on a 7-point scale using anchors $1=$ "strongly disagree" and 7= "strongly agree."

\section{Distributive Justice}

Distributive Justice is concerned with the division of benefits and burdens. In the present research context it is operationalized as the extent to which franchisees perceive they are fairly compensated for their inputs to the job. There have been many measurement scales for the construct of distributive justice, and I have identified the scale developed by Price and Mueller's (1986) to be most consistent with franchising relationships. Their scale taps the degree to which individuals feel rewarded fairly considering (1) their responsibilities, (2) the amount of experience they have, (3) the amount of effort they put forth, (4) the work they have done well, (5) the stresses and strains of their job, and (6) their education and training. The scale was modified through an iterative refining process in pre-tests. The word "rewarded" was particularly problematic for a reason that antitrust laws limit franchisor discretion on franchisee compensations, and furthermore, once set, usually remain fixed. During pre-test interviews, a few franchisees asked if I meant "awards" instead, and some others commented that are no rewards per se. Therefore, I replaced the word rewards with compensates so as to stress the give-and-take aspect of the relationship, which is in line with classical equity theory (Adams 1963, 1965).

The original scale by Price and Mueller (1986) uses 5-point scale, with anchors ranging from $1=$ "very unfair" to $5=$ "very fair." In the present research, for consistency, 
the scale was modified to a 7-point Likert-type scale (1= "strongly disagree," $7=$ "strongly agree").

\section{Procedural Justice}

While the focus of distributive justice is on the perceived fairness in terms of division of benefits and burdens (i.e., outcomes), the concept of procedural justice focuses on the procedures by which the allocation decisions are made. Procedural Justice generally refers to the perceived fairness in procedures used to make outcome-allocation decisions in employment relationships. As with Distributive Justice, franchising context offers no discrepancy in rewards, and pre-tests made it clear that the use of "reward allocation decisions" phrase was inappropriate. After pre-tests, therefore, Procedural Justice was re-operationalized as the extent to which franchisees feel that the franchisor's general procedures in decisions affecting their business are fair. Of many measurement scales for procedural justice, I identified Moorman's (1991) measure to be consistent with the operationalization in that it can reflect all aspects of procedures that franchisors may use in making important business decisions for the franchisee. Moorman (1991) developed the measure using the rules of procedural justice developed by Levanthal (1980), such that the items focus on fairness perceptions in promoting consistency, bias suppression, accuracy, correctability, representativeness, and ethicality.

Moorman's (1991) measurement items were modified to adapt to the current research context and to provide a frame of reference. The original scale had seven items, and during a pre-test I excluded one of the items that dealt with “(franchisor's) providing useful feedback," as in-depth interviews revealed this did not apply well in the 
franchising context. In addition, my modified scale elaborated on franchisor's general policies by adding a phrase "In making decisions affecting our business, our franchisor's general policies..." to give a frame of reference. The original scale used a 5-point scale ( $1=$ "strongly disagree" to $5=$ "strongly agree"), which was modified to a 7 -point scale to be consistent with the remaining questionnaire.

\section{Interactional Justice}

Interactional Justice is operationalized as the extent to which franchisees feel that their interpersonal treatment by franchisors is with respect, kindness, and truthfulness (Bies and Moag 1986). Moorman's (1991) 6-item scale was slightly modified for the present research. More specifically, "your supervisor" was replaced with "our franchisor," as well as "an employee" was replaced with "a franchisee." In addition, a frame of reference was added to the first three items to ensure that survey participants provide their perceptions of fairness in the context of communication with their franchisors. For example, "Your supervisor considered your viewpoint" was changed to "our franchisor considers our viewpoint whenever s/he is communicating with us." Past

tense in the original measures was also modified to present tense. The scale uses a 7-point scale ranging from "strongly agree" to "strongly disagree," which was modified from the original 5-point scale.

\section{Crowding Out Effects of Monitoring}

Crowding Out Effects of Monitoring, as reviewed in Chapter Three, refers to "how far the agent's self-determination and self-evaluation are affected by the principal's 
monitoring activities" (Frey 1993, p. 665). Frey (1993) describes the following two conditions for such effects:

1. An agent feels that the extent of self-determination is unduly restricted by the principal.

2. The agent's self-evaluation is reduced as $\mathrm{s} / \mathrm{he}$ is convinced that the principle believes $\mathrm{s} / \mathrm{he}$ is unable or unwilling to fulfill the assigned task to the principal's satisfaction.

Following these two statements, I operationalized the crowding out effects as the extent to which franchisees feel that being monitored the franchisor produces the feelings of (1) self-determination restriction and (2) distrust by the franchisor on the basis of lack of trust in their ability and willingness to perform specified tasks as a franchisee.

As I was not aware of any measures specifically targeting these effects, I developed a pool of five measure items for the crowding out effects based on the operationalization. They were then subjected to pre-tests for content validity. The results indicated that the items are clear and in line with the operationalization. The only minor changes made were in the grouping of three of the items to begin with the same "By being monitored by my franchisor I feel...” to minimize wordiness. This newly developed reflective scale uses a 7-point Likert-type response anchored by 1 ("strongly disagree") and 7 ("strongly agree").

\section{Disciplinary Monitoring}

Disciplinary Monitoring refers to the extent to which the franchisor is able to detect and sanction the franchisees for opportunistic behaviors. As I conceptualized in Chapter Three, the two domains (ability to detect and ability to sanction) need not be 
highly correlated with each another. Yet, for monitoring to be effective, both factors must be present. For example, even if a franchisor possesses a high level of detecting opportunistic behaviors, it cannot properly discipline the franchisee if it is unable to take tough measures to deter opportunism.

Prior to pre-test in-depth interviews, Disciplinary Monitoring was conceptualized as a second-order formative, first order reflective scale composed of Ability to Detect and Sanction. It was determined that such additive, composite formulation cannot distinguish the effectiveness of monitoring. A multiplicative operationalization approach instead allows the construct to be rated higher when the two reflective scales (detecting and sanctioning) are closer in their ratings. For example, scores of 3 and 3 lead to a multiplicative score of 9 , while scores of 1 and 5 lead to a multiplicative score of 5. If additive formulation was to be used, scores of 3 and 3 would be rated the same as 1 and 5 (i.e., six), yet, in reality scores of 3 and 3 would be allowing the franchisor to better discipline its franchisee. The same line of thinking is used in Heide (1994) and Lusch and Brown (1996) in their measure of bilateral dependency between firms. The multiplicative approach allows the measure to be higher when both firms are dependent on one another, and lower when only one side is highly dependent on the other.

Hence, I posit that the construct of disciplinary monitoring as a multiplicative cross-product term between Franchisor's Ability to Detect Opportunism and Franchisor's Ability to Sanction Opportunism. Scale development for each construct is discussed separately in the following sections.

As a first-order scale for Disciplinary Monitoring, Franchisor's Ability to Detect Opportunism refers to the extent to which franchisor is able to detect the franchisee's 
opportunistic behaviors. The ability may be influenced by breadth and depth (i.e., frequency) of information collection. According to Jacobides and Croson (2001), however, the efficacy of each is contingent on ex ante causal ambiguity. In other words, ex ante causal ambiguity may lead to inappropriate choice of monitoring measures that may be too narrow or even irrelevant, such that the "'more monitoring is better' prescription will mislead" (Jacobides and Croson 2001, p. 210). Hence, the construct is closely related to an agent's ability to "learn their way around" (Jacobides and Croson 2001) and manipulate information asymmetry to their advantage (e.g., Hunt 1986). The notion also parallels "perceived behavioral control" in the theory of planned behavior (Ajzen 1985). The theory of planned behavior extends the theory of reasoned action (Fishbein and Ajzen 1975) by incorporating perceived behavioral control, or the beliefs regarding ease or difficulty to perform a given behavior.

To measure franchisees' perceptions of their franchisors' ability to detect their opportunistic behaviors, I adapted Stump and Heide's (1996) scale for performance ambiguity, which pertains to the inherent difficulty faced by the exchange partner in accurately evaluating the other's true performance (Ouchi 1979). I modified Stump and Heide's (1996) measures to reflect franchisees' perceptions of their franchisors' ability to detect opportunism. Besides minor changes such as replacing "this supplier" and "this supplier's" with "we" and "our," I also expanded each item to reflect each facet of opportunism. For example, I modified Stump and Heide's (1996) original item of "Evaluating this supplier's performance is a highly subjective process" was changed to "Our franchisor can easily catch franchisees using unfounded excuses for unfulfilled obligations." 
Three more measures were constructed to cover all facets of opportunism (see Appendix B for specific items). Pre-tests allowed for minor modifications in wording to make the items clearer and precise to the operationalization. All the items were measured using 7-point Likert-type scale anchored by "strongly disagree" to "strongly agree." Franchisor's Ability to Sanction Opportunism, another lower-order scale for Disciplinary Monitoring construct, is operationalized as the franchisees' perceptions regarding the level of sanction their franchisors would impose if their opportunistic behaviors were found. Respondents were asked to provide response given our definition of opportunism. I adapted Antia and Frazier's (2001) scale for "contract enforcement" to reflect the current research context. As with Franchisor's Ability to Detect Opportunism, I added each item with a particular aspect of opportunism, for example, "We took tough measures when this particular clause was violated" was modified to "Our franchisor would take tough measures against us if we were discovered withholding certain critical information for them."

Other minor changes to fit the current research context include modifying from "we" and "our response" to "our franchisor" and "this franchisor's response," respectively. Minor refinement of wording was done during pre-tests. I also modified the response format of Antia and Frazier's (2001) scale (four Likert-type scale items and three semantic differential scale items,) to be all 7-point Likert-type scale anchored by "strongly disagree" to "strongly agree" to be more consistent with the remaining questionnaire. 


\section{Propensity for Opportunism (PFO)}

PFO is operationalized as the extent to which franchisees are inclined to behave opportunistically against their franchisors. As reviewed in Chapter Three, PFO reflects desires, and it persists over time regardless of feasibility (Perugini and Bagozzi 2001). As noted by Perugini and Bagozzi (2004, pp. 80-81), desires are to be distinguished from intentions for the following reasons:

- Desires are less connected to actions and framed over longer time horizons than intentions.

- Feasibility is less important for desires than for goals.

- Desires are important predictors of intentions.

In addition, I posited that the feasibility of opportunistic behaviors (i.e., constraints such as economic or social costs) moderate the relationship between PFO and OB. Therefore, PFO exists independent of feasibility, while intentions would be influenced greatly by it.

I originally adapted Perugini and Bagozzi's $(2001,2004)$ scale for desire in construction of the PFO scale. Perugini and Bagozzi's scale reflects the respondents' degree of desire for exercising for health. I modified the scale to add each facet of opportunism in each item to reflect the franchisees' desire for opportunistic behaviors in a similar manner. However, during pre-tests I noticed that I had three other scales that use the same tactic, and they appeared very closely to one another: Opportunistic Behaviors, Franchisor's Ability to Detect Opportunism, and Franchisor's Ability to Sanction Opportunism all have their multiple items reflecting each facet of opportunism. It was determined that such redundancy in item format could invite unwanted response bias 
such as item priming effect (Salancik and Pfeffer 1977; Podsakoff et al. 2003), in which the predictor variables are more salient to the respondent to imply a causal relationship with other variables.

There was also a control variable (Economic Benefits of $\mathrm{OB}$ ) that pertained to opportunistic behaviors, and therefore I grouped the scales for these two constructs in a dissimilar response format as the other three constructs pertaining to opportunism. The revised scale lists examples of opportunistic behaviors, followed by question items asking research participants to indicate how they feel about these behaviors using semantic differential scale of willing-unwilling, motivated-unmotivated, tempted-reluctant, provoked-unprovoked, and compelled-not compelled. Pre-tests results were positive in terms of clarity and its ability to separate the PFO scale from the other three opportunism-related scales. The PFO scale was measured using 7-point $(-3$ to +3$)$ format, which was later transformed into 1 to 7 format for measurement analysis for simplicity.

\section{Opportunistic Behaviors (OB)}

OB is operationalized as franchisees' guileful behaviors that unilaterally improve the party’s term of trade. Many scales are available (John 1984; Anderson 1988; Dwyer and Oh 1988; Provan and Skinner 1989; Brown et al. 2000; Rokkan et al. 2003) tapping guileful self-interesting behaviors. I found the scale developed by Rokkan et al. (2003) to capture breach of both explicit and implicit agreements under various circumstances. The 6-item scale measures capture all aspects of opportunism as the several measures were complied from the previous research with an addition of two new measures. I made a few, minor changes to fit to the current context by replacing the wording from "this 
supplier" to "we," as well as "from our firm" to "from the franchisor." As with the original scale, the OB scale used a 7-point Likert-type scale ranging from 1 ("strongly disagree") to 7 (“strongly agree").

\section{Extra-dyadic Level Constructs}

Two constructs are discussed in this section: Network Density and Negative Professional Ethical Climate. Both scales deal with characteristics of franchisee network in which a franchisor-franchisee relationship is embedded.

\section{Network Density}

Network density generally refers to the average strength of relations in a franchise network. As reviewed in previous chapters, a dense network can be characterized as having close interactions among the members of the network and formed two mechanisms: (1) the establishment of informal norms and expectations; and (2) reputation effects (Jones et al. 1997). The only suitable measure was found in Antia and Frazier (2001). The scale needed only minor changes as the study context was the same. The only difference was that in Antia and Frazier's study the franchisee network was from that of the franchisor's perspective (i.e., franchisor was the key informant) and in the current study Network Density is measured form the perspective franchisees. More specifically, the phrase "franchisees of our system" was changed to "members of our franchise network." Antia and Frazier's (2001) scale used six items (three Likert-type scales and three semantic differential scales), and for survey all items were measured using 7-point Likert-type scale anchored by "strongly disagree" to "strongly agree." 


\section{Negative Professional Ethical Climate}

Negative Professional Ethical Climate refers to the degree to which the climate surrounding the franchisor-franchisee dyad is unethical, and it broadly refers to the extent to which the extra-dyadic environment encourages opportunistic behaviors between franchisor-franchisee dyads. Hunt and Vitell (1991) suggest that individuals adapt to external environment's norms as they are socialized into their respective organizations, professions, and industries.

The ethical climate literature typically focuses on identifying elements of work climate within an organization that serve as shared norms of behavior (e.g. VidaverCohen 1998; Victor and Cullen 1988; Weaver 1993; Murphy 1995). Such a climate is different from the mere existence of organizational rules or codes of ethics. Rather, it refers to institutionalized norms of conduct, which in turn influence how employees behave.

In a franchising context, I conceptualize that ethical climate pertains to the prevalence of norms for disregarding the collective welfare of the franchise network. More specifically, I posit that informal norms of self-interest seeking, norms for disobeying both company rules and professional ethical standards are the aspects of the franchisee network that impact overall ethical climate. That is, a negative ethical climate exists to the extent that the members of the franchise network act individualistically and/or disregard company policies and rules, and/or ethical standards.

I operationalize Negative Professional Ethical Climate as the extent to which a franchisee observes others in the franchisees to (1) share the norms of individualism, (2) 
disobey the corporate policies and procedures set for franchisees, and (3) disregard professional ethical standards. Individualistic norms refer to the extent to which the collective welfare of the franchise network is not valued as important, and therefore each franchisee pursues his or her own interest above all else. Corporate policies and procedures are those explicit guidelines set for franchisees as delegates for carrying out franchise business operations. Take Kentucky Fried Chicken for example. Company policies include cleaning the sink every 30 minutes and discarding food left unsold after 15 minutes. Professional ethical standards (codes) generally refer to a profession's enunciation of its professional norms, its moral dimension, and its collective conscience (Frankel 1989). In franchising, the codes set by the franchise broadly communicate ideal conduct in areas of (1) maintaining integrity and the reputation of franchising concept/system, (2) avoiding deception, such as misleading advertising, (3) providing a high quality product or service, and (4) complying with applicable laws pertaining to the specific industry (Preble and Hoffman 1999). Additional professional codes of ethics may be provided by an association to which a franchisee may be affiliated. For example, IFA has its own codes of conduct emphasizing trust and honest upon which the franchising relationship is founded, as well as collective, team spirit within a franchise network.

I posit that these three bases of ethical climate (Individualism, Corporate Rules, and Professional Codes of Ethics) need not be highly correlated. First, norms of individualism do not necessarily determine how much franchisees are able to disobey company policies and rules because the latter is largely dependent on monitoring and other enforcement activities by the franchisor. Second, professional ethical standards are a broader guideline of how one should behave to protect the wealth of franchise as a 
whole, which are independent of the franchise's policies on obligations delegated to the franchisees. Negative Professional Ethical Climate, therefore, is a lower-order reflective, higher-order formative scale, and each of the three elements individually contributes to the overall ethical climate.

The extant literature has examined ethical climate effects at the individual level, not in a business-to-business context, therefore requiring a significant modification to the current research context. In developing the ethical climate scale, I used Victor and Cullen's (1988) Ethical Climate Questionnaire (ECQ) as guideline. ECQ is based on nine ethical climate types based upon three major classes of philosophy (principle, benevolence, and egoism) and three loci of analysis (individual, local, and cosmopolitan). The 3 X 3 matrix is shown in Table 5.1. Based on Kohlberg (1981), Victor and Cullen (1987, p. 54) propose that, individual, benevolence, and principle "may be distinguished in terms of their basic motives, i.e., maximizing one's own interests, maximizing joint interests, or adherence to universal principles." As for loci of analysis, "local" refers to the important reference groups or sources of role definitions and expectations (Merton 1957). "Cosmopolitan" represents a larger social entity external to the system in which the individual is embedded.

Empirical analyses revealed that five key factors (reduced from nine) emerged characterizing ethical climate, and Victor and Cullen (1987) labeled them (1) Caring, (2) Law and Code, (3) Rules, (4) Instrumental, and (5) Independence. The caring dimension was comprised of a mixture of items from all three levels in the benevolence criterion, each concerned with caring for other members of organization. "Law and code" represents the original principle-cosmopolitan dimension (i.e., PC), while "rules" 
represents the original principle-local dimension (i.e., PL). The former deals with implicit expectations about following explicit company rules, while the latter deals with norms for obeying professional codes of ethics. "Instrumental" represents egoistic values (i.e., EI, EL, and EC) in the organization. "Independence" was comprised of items representing the original principle-individual dimension (i.e., PI), which emphasizes exercising personal morals rather than collective. The end product is ECQ that consists of 26 items. This scale has been used widely since then (e.g., Weber 1995; Upchurch 1998; Herndon, Fraedrich, and Yeh 2001), and the studies have shown reliability (Cronbach $\alpha$ ) ranging from .69 to a high of .85 .

In developing a pool of measurement items for the professional ethical climate, necessary changes had to be made to switch the study contexts from an employment relationship to franchising. Minor changes were made throughout to adapt the ECQ items to the present context. For example, "this company" was changed to "this business" or "this franchise."

In addition, some of the items in ECQ were designed to deal with socially ethical behaviors (with consumers as the beneficiary), while my main concern is the welfare of the franchisee network. ECQ's "Independence" factor was also excluded from my scale as the scale of ethical climate for franchise network does not concern the degree of how much each franchisee exercise his/her own moral values.

The items for "Law and Code" were modified slightly for the dimension of Professional Ethics Codes. I made changes from "people" to "people in this business" to modify the context from intrafirm in ECQ to interfirm context in the current research. Of the four items in ECQ, one of the items "In this company, the first consideration is 
TABLE 5.1: Victor and Cullen's $(1987,1988)$ Ethical Climate Typology

\begin{tabular}{|c|c|c|c|c|}
\hline & & \multicolumn{3}{|c|}{ Level of Analysis } \\
\hline & & $\begin{array}{l}\text { Individual } \\
\text { (I) }\end{array}$ & $\begin{array}{c}\text { Local } \\
(\mathrm{L})\end{array}$ & $\begin{array}{c}\text { Cosmopolitan } \\
\text { (C) }\end{array}$ \\
\hline \multirow[t]{3}{*}{$\begin{array}{l}\text { Type of } \\
\text { Criteria }\end{array}$} & $\begin{array}{l}\text { Egoistic } \\
\text { (E) }\end{array}$ & $\begin{array}{l}\text { Self-Interest } \\
\text { (EI) }\end{array}$ & $\begin{array}{l}\text { Company Profit } \\
\text { (EL) }\end{array}$ & $\begin{array}{l}\text { Efficiency } \\
\text { (EC) }\end{array}$ \\
\hline & $\begin{array}{c}\text { Benevolence } \\
\text { (B) }\end{array}$ & $\begin{array}{c}\text { Friendship } \\
\text { (BI) } \\
\end{array}$ & $\begin{array}{c}\text { Team Interest } \\
(\mathrm{BL}) \\
\end{array}$ & $\begin{array}{c}\text { Social } \\
\text { Responsibility } \\
\text { (BC) }\end{array}$ \\
\hline & $\begin{array}{l}\text { Principle } \\
\text { (P) }\end{array}$ & $\begin{array}{l}\text { Personal } \\
\text { Morality } \\
\text { (PI) }\end{array}$ & $\begin{array}{l}\text { Company Rules } \\
\text { and Procedures } \\
\text { (PL) }\end{array}$ & $\begin{array}{l}\text { Laws and } \\
\text { Professional } \\
\text { Codes } \\
(\mathrm{PC})\end{array}$ \\
\hline
\end{tabular}


whether a decision violates any law" was not used for the scale, because "a decision" does not reference to anything specific. All four items of the ECQ's "Rules" were used for the dimension of Corporate Rules. Again I switched the items' tone from positive to negative in order to reflect the construct of negative professional ethical climate. For example, "People in this company strictly obey the company policies" was changed to "People in this business don't strictly obey the company policies."

For Individualism, the last dimension of Negative Professional Ethical Climate, ECQ's "Caring" and "Instrumental" were carefully combined for two reasons. First, both "Caring" and "Instrumental" carried several items that dealt with consumer and public concerns. Second, the conceptualization of Individualism mainly involves instrumental pursuit of individual wealth; however, it also assumes duality between collective (i.e., caring for others) and individual good. Although the items for "Instrumental" are more in line with the scale, I also borrowed three items from "Caring" dimensions. For these three items, I changed the tone from positive to negative, for example, "What is best for everyone in the company is the major consideration here" was modified to "What is best for the franchise network is not the major consideration in this business."

In all, thirteen items were developed for the three facets of Negative Professional Ethical Climate: Individualism, Corporate Rules, and Professional Codes of Ethics. Each item is measured by a 7-point Likert-type scale with anchors "strongly disagree" and "strongly agree." Pre-tests results were favorable in that in-depth interviewees clearly understood the content and indicated that they are in line with the franchise environment. 


\section{Control Variables}

In any empirical research, efforts to identify and eliminate the possibility of extraneous variables confounding hypothesized effects are crucial part of establishing internal validity. Here, I have identified five variables to be used as control variables: age of relationship, and franchisor's TSIs, industry, economic benefits of $\mathrm{OB}$, and social desirability. The rationale for inclusion of each control variable is discussed below.

Age of relationship is an important element that needs to be controlled in order to partial out the quality of interactions between franchisors and franchisees solely based on the length of their relationships. One possibility is what Deeds and Hill (1998) call a "honeymoon period" in which the relationship is shielded from negative outcomes. Biased responses by franchisees may also be possible simply because they are unaware of any wrongdoing by their franchisors in an early stage of their relationships. Age of relationship was measured simply by asking the question of "About how long have you managed this franchise unit?"

Franchisor's TSIs was also measured and controlled based on the rationale given by Rokkan et al. (2003). Although their research's primary focus was the TSIs made by one side of the dyad (as is ours), the other party's levels of TSIs were controlled because they may influence behaviors of that party. As with their study, I should determine the effects of franchisees' levels of TSIs on opportunism controlling for the levels of TSIs made by the franchisors. This way, it is possible to: (1) determine the extent to which TSIs influence franchisees' behaviors irrespective of reciprocal investments made by franchisors; and (2) create a difference score that accounts for the degree of symmetry in TSIs and formally examine in post-hoc analyses whether the asymmetry has confounding 
effects on the hypothesized relationship (i.e., franchisee TSIs $\rightarrow$ PFO). I adopted the scale used in Antia and Frazier (2001) for measurement with minor modifications in wording. Specifically, "for us" was modified to "for them." The scale used a 7-point Likert-type scale (1= "strongly disagree," $7=$ "strongly agree").

Industry effects were also controlled as I was not interested in the effects of specific franchise industries. Industry differences can also account for much of franchisee outlet size (i.e., sales volume), which could also confound the nature of relationship between franchisors and franchisees. Pre-tests also revealed a high level of difference in relationship structure and quality, which are idiosyncratic to specific industries. For example, arms-length relationship was observed in the personal services industry, and hands-on, highly interactive relationship was observed the in food industry. I measured the industry variable by asking study participants to indicate their industry using the categorization of (1) auto repair/maintenance, (2) electronics repair/maintenance, (3) food - full service, (4) food - quick service, (5) financial services, (6) general printing, (7) personal services, (8) commercial/residential services, and (9) other.

The categorization was created based on the original mailing list which listed FRANdata's categorization of industry, and I chose to list ones that were dominant in the list. After primary data collection, these industries were narrowed down to a parsimonious and meaningful eight categories: Food, General Printing, Auto Repair/Maintenance, Personal Services, Residential/Commercial Services, Professional Services, Retailing, and Lodging.

Economic Benefits of $O B$ was included as a control variable in the present study out of suspicion that not all franchisees may actually benefit from opportunistic 
behaviors. I broadly define opportunistic behaviors as those that benefit the self at the expense of the exchange partner, and the transaction cost economics perspective would suggest that an agent would pursue these behaviors as long as they are feasible and profitable (cf. Williamson 1975, 1985). My position is that agents exhibit differing levels of propensity for opportunism, such that not all agents would engage in opportunistic behaviors even when they are given chance. The implicit assumption, then, is that economic benefits of opportunistic behaviors are held constant. Otherwise, differing levels of PFO and the effects of their antecedent factors could simply be due to differing levels of economic benefits of OB. During pre-test in-depth interviews this issue was raised as well. For some franchisees, opportunism as I define it could be a tool to greatly benefit themselves, and for others these behaviors produce little or no benefits. One without a high level of economic benefits of OB should not be considered more relationally-oriented, and this possibility of confounding effects must be controlled.

No previous measures existed for the new construct I termed Economic Benefits of Opportunism, and I developed three items that tap the degree of profitability of opportunism. I conceptualized that economic benefits are multi-faceted, such that it can simply mean increased profits, or it can derive from decreased operating costs as well reduced hours necessary to perform required tasks. These three facets of economic benefits were taken into consideration in the scale development. Pre-tests results were favorable, as the interviewees indicated that the items made sense, and it is in line with their business structure.

Lastly, Social Desirability was also controlled in the current study. The MarlowCrowne Social Desirability Scales measures an individual's need to present him/herself 
in a favorable light. With studies of this type, there is an issue of social desirability response bias (Randall and Fernandes 1991). The concept of social desirability has attracted research attention as it has the potential to distort survey responses by faking them to enhance self-image. Those individuals with strong social desirability tend to have strong needs to make a positive impression, and social desirability has been characterized as a well-known problem (Levin and Montag 1987; Podsakoff et al. 2003). Field studies using self-report methodology are said to be susceptible to social desirability response bias, particularly when the questions are direct and subjective, as opposed to more indirect, inferred objective questions (Arnold and Feldman 1981). According to Podsakoff et al. (2003), two variables frequently assumed to cause common method variance are the respondents' affective state and social desirability. They also report that partial correlation procedures designed to control for social desirability bias is effective.

Social desirability was measured using a short-form version of MarloweCrowne's (1960) social desirability index. Ballard's (1992)11-item short-form was used instead of the original 33 items due to survey length constraints. The use of the shortform should not compromise the internal validity as Ballard (1991) reports a reliability of .70 , only .05 less than that for the full scale. Other studies that have used this short-form have reported good reliability of the scale (e.g., Rindfleisch and Crockett 1999; Burroughs and Rindfleisch 2002). The scale uses true/false responses, and four of the 11 items represent positive behaviors which most people are not likely to exhibit (socially desirable answer is true) and the remaining seven items represented negative behaviors which are likely true of the general population (socially desirable answer is false). Due to the dichotomous nature of the response format, KR-20 was used to assess the scale's 
reliability. The resulted KR-20 coefficient was .70, and it was determined that the shortform social desirability scale exhibited acceptable level of reliability. In the sample, the response ranged between .00 and 11.00 , with mean=6.29 and standard deviation=2.62.

\section{Additional Construct Included in the Questionnaire}

A newly developed construct I term Individual PFO was also included in the questionnaire to pursue an alternative theoretical model. The suggestion for the inclusion of this construct came about during the dissertation proposal defense. With the original model, the antecedents of PFO include individual-specific traits (i.e., Machiavellianism, Locus of Control, and CMD) and relationship-specific attitudes toward franchisors (i.e.,

three justice scales and Crowding Out Effects of Monitoring). The concern expressed was that some of the factors are individual-specific propensity that is irrespective of context, while other antecedent factors only apply in the context of franchisor-franchisee relationship.

After additional literature reviews, it was further determined that, the distinction between individual-specific PFO and relationship-specific PFO could offer an alternative model in which Theory of Planned Behavior (Ajzen and Madden 1986) could be incorporated. Fishbein $(1967,1975)$ developed a model (Theory of Reasoned Action, or TRA) of the relationship between attitude and behavior (note it is different from theory of reasoned behavior), emphasizing that in order to predict behavior, one must know the individual's attitude toward that behavior and the subjective norm (social influence). Ajzen and Madden's (1986) model is an extension of TRA in that it adds perceptions of behavioral control (i.e., perceived ability in carrying out the behavior) as a predictor of 
both intention and behavior. According to the Theory of Planned Behavior (TPB), people act in accordance with their intentions and perceptions of control over the behavior, while intentions in turn are influenced by attitudes toward the behavior, subjective norms, and perceptions of behavioral control.

Here, Individual PFO could be a distinct, general attitude toward opportunistic behaviors, and the original PFO could be the franchisee's relationship-specific attitude toward opportunistic behaviors against his/her franchisor (hence may be termed Relational PFO). In sum, inclusion of Individual PFO seemed appropriate as it would allow us to model the specific roles of two distinct attitudes, as well as subjective norms, economic and social costs efficiently.

Individual PFO, therefore, was included in my questionnaire to pursue the possibility of additional benefits of distinguishing individual- and relationship-specific PFO. The scale was first operationalized as the degree to which a franchisee holds general attitudes that opportunistic behaviors are acceptable and prevalent in a business context. The items were then developed tapping the franchisee's general perception of opportunism as the general norms in business world. Such attitudes were conceptualized to include perceived prevalence, acceptance, and justifiability. The measurement items went through an iterative revision process in pre-tests. The final three measurement items use a 7-point Likert-type scale (1= "strongly disagree," 7= "strongly agree").

\section{Measure Validation}

This section focuses on measure validation, which entailed processes of confirmatory factor analysis (CFA) and exploratory factor analysis (EFA). CFA was 
conducted to purify the measurement, followed by a series of EFA to verify unidimensionality of constructs that are closely related.

\section{Confirmatory Factor Analysis}

The measurement properties of the data were further evaluated through the usual methods of item analysis and CFA. CFA evaluates the internal and external consistency of the multi-item reflective measures (Anderson, Gerbing, and Hunter 1987). Data normality was also checked during measurement validation by inspecting univariate frequency distributions (see Table 5.2). Normal distributions are symmetrical about their means, while non-normal distributions are either skewed or show kurtosis (i.e., negative kurtosis indicates flatter distributions).

This step is critical in estimation procedures, as both measurement and structural analyses assume normal distributions for continuous variables. It has long been established that moderate violations of parametric assumptions have little or no effect on substantive conclusions in most instances (e.g., Cohen 1969, pp. 266-267). Nonetheless, this check is still critical in the measurement purification stage because each measurement item is scrutinized. Hutcheson and Sofroniou (1999) recommend that both skewness and kurtosis be within the +2 to -2 range. Although some researchers use +1 to -1 as a more stringent criterion, the range seemed too narrow given my sample size. The items of scales with one or more non-normally distributed items were log-transformed.

I conducted measure validation using AMOS 7.0 in order to ensure the construct validity, which in CFA includes estimation of reliability, convergent and discriminant validity (Campbell and Fiske 1959), as well as measurement models fit analysis to check 
Table 5.2: Univariate Descriptive Statistics for All Measurement Items

\begin{tabular}{|c|c|c|c|c|}
\hline & Mean & Std. Deviation & Skewness & Kurtosis \\
\hline \multicolumn{5}{|c|}{ Franchiser Dependence - Replaceability } \\
\hline RDR111 & 3.83 & 2.03 & .03 & -1.24 \\
\hline RDR109 & 4.37 & 1.99 & .20 & -1.25 \\
\hline RDR114 & 4.43 & 2.05 & -.37 & -1.11 \\
\hline \multicolumn{5}{|c|}{ Franchiser Dependence - Motivational Investment } \\
\hline RMI112 & 3.42 & 2.00 & .30 & -1.17 \\
\hline RMI106 & 3.41 & 2.02 & .39 & -1.08 \\
\hline RMI113 & 2.79 & 1.82 & .87 & -.25 \\
\hline \multicolumn{5}{|c|}{ Distributive Justice } \\
\hline DJ115 & 3.76 & 1.89 & .02 & -1.00 \\
\hline DJ116 & 3.57 & 1.96 & .17 & -1.17 \\
\hline DJ117 & 3.54 & 1.90 & .21 & -1.04 \\
\hline DJ118 & 3.63 & 1.94 & .11 & -1.17 \\
\hline DJ119 & 3.33 & 1.91 & .32 & -1.06 \\
\hline \multicolumn{5}{|c|}{ Procedural Justice } \\
\hline PJ120 & 4.51 & 1.83 & -.39 & -.79 \\
\hline PJ121 & 3.92 & 1.91 & -.03 & -1.10 \\
\hline PJ122 & 4.31 & 1.84 & -.29 & -.92 \\
\hline PJ123 & 3.77 & 1.85 & .08 & -1.04 \\
\hline PJ124 & 3.96 & 1.86 & .04 & -1.05 \\
\hline PJ125 & 4.36 & 1.78 & -.28 & -.79 \\
\hline \multicolumn{5}{|c|}{ Interactional Justice } \\
\hline IJ126 & 4.15 & 1.77 & -.09 & -.79 \\
\hline IJ127 & 4.45 & 1.53 & -.41 & -.20 \\
\hline IJ128 & 4.46 & 1.84 & -.42 & -.83 \\
\hline IJ129 & 4.91 & 1.74 & -.76 & -.18 \\
\hline IJ130 & 4.60 & 1.89 & -.52 & -.79 \\
\hline IJ131 & 4.88 & 1.83 & -.75 & -.38 \\
\hline \multicolumn{5}{|c|}{ Franchisor's Ability to Detect Opportunism } \\
\hline FADO133 & 4.59 & 1.70 & -.35 & -.72 \\
\hline FADO135 & 4.73 & 1.68 & -.43 & -.67 \\
\hline FADO137 & 4.14 & 1.69 & -.01 & -.80 \\
\hline FADO139 & 4.38 & 1.75 & -.18 & -.81 \\
\hline FADO140 & 4.43 & 1.52 & -.20 & -.43 \\
\hline \multicolumn{5}{|c|}{ Franchisor's Ability to Sanction Opportunism } \\
\hline FASO132 & 5.57 & 1.58 & -1.13 & .38 \\
\hline FASO134 & 4.62 & 1.70 & -.33 & -.76 \\
\hline FASO136 & 5.16 & 1.66 & -.68 & -.46 \\
\hline FASO138 & 4.48 & 1.87 & -.28 & -.96 \\
\hline
\end{tabular}


Table 5.2 continued

\begin{tabular}{|c|c|c|c|c|}
\hline \multicolumn{5}{|c|}{ Franchisee Dependence - Replaceability } \\
\hline EDR201 & 5.98 & 1.61 & -1.72 & 2.13 \\
\hline EDR204 & 4.06 & 2.04 & -.01 & -1.24 \\
\hline EDR207 & 4.20 & 2.23 & -.10 & -1.42 \\
\hline \multicolumn{5}{|c|}{ Franchisee Dependence - Motivational Investment } \\
\hline EMI208 & 4.89 & 2.07 & -.63 & -.94 \\
\hline EMI211 & 5.19 & 1.90 & -.86 & -.39 \\
\hline \multicolumn{5}{|c|}{ Franchisee TSIs } \\
\hline ETSI219 & 4.91 & 1.98 & -.62 & -.87 \\
\hline ETSI218 & 4.99 & 1.99 & -.69 & -.81 \\
\hline ETSI210 & 6.31 & 1.13 & -2.00 & 4.15 \\
\hline ETSI217 & 4.98 & 2.04 & -.68 & -.87 \\
\hline \multicolumn{5}{|c|}{ Economies of Continuation } \\
\hline EC202 & 3.95 & 2.22 & -.05 & -1.49 \\
\hline EC206 & 3.74 & 2.12 & .14 & -1.23 \\
\hline EC209 & 4.82 & 2.01 & -.66 & -.75 \\
\hline EC213 & 5.25 & 2.06 & -1.07 & -.19 \\
\hline \multicolumn{5}{|c|}{ Crowding Out Effects of Monitoring } \\
\hline COEM501 & 2.77 & 1.74 & 1.02 & .25 \\
\hline COEM502 & 1.81 & 1.39 & 2.25 & 4.76 \\
\hline COEM503 & 3.14 & 1.87 & .63 & -.69 \\
\hline COEM504 & 2.29 & 1.26 & .92 & .59 \\
\hline COEM505 & 2.45 & 1.79 & 1.67 & 3.21 \\
\hline \multicolumn{5}{|c|}{ Propensity for Opportunism } \\
\hline PFO516 & 2.87 & 2.10 & .71 & -.96 \\
\hline PFO517 & 3.24 & 2.17 & .40 & -1.26 \\
\hline PFO518 & 2.88 & 1.92 & .57 & -.94 \\
\hline PFO519 & 2.97 & 1.92 & .39 & -1.19 \\
\hline PFO520 & 3.07 & 2.04 & .45 & -1.12 \\
\hline \multicolumn{5}{|c|}{ Opportunistic Behaviors } \\
\hline OB203 & 1.77 & 1.46 & 2.19 & 4.13 \\
\hline OB205 & 2.34 & 1.67 & 1.20 & .48 \\
\hline OB212 & 3.19 & 1.84 & .44 & -.89 \\
\hline OB214 & 2.31 & 1.59 & 1.22 & .69 \\
\hline OB215 & 1.89 & 1.44 & 2.03 & 3.57 \\
\hline \multicolumn{5}{|c|}{ Negative Professional Ethical Climate - Individualism } \\
\hline IN412 & 3.68 & 1.74 & .25 & -.77 \\
\hline IN411 & 3.77 & 1.76 & .32 & -.69 \\
\hline IN413 & 3.20 & 1.63 & .54 & -.49 \\
\hline IN414 & 4.25 & 1.77 & -.23 & -.95 \\
\hline IN415 & 3.94 & 1.86 & -.12 & -1.13 \\
\hline IN416 & 2.09 & 1.45 & 1.72 & 2.60 \\
\hline
\end{tabular}


Table 5.2 continued

\begin{tabular}{|c|c|c|c|c|}
\hline \multicolumn{5}{|c|}{ Negative Professional Ethical Climate - Corporate Rules } \\
\hline CR402 & 2.30 & 1.66 & 1.56 & 1.75 \\
\hline CR406 & 3.89 & 1.79 & .02 & -1.06 \\
\hline CR403 & 2.70 & 1.76 & .89 & -.21 \\
\hline CR407 & 3.35 & 1.74 & .35 & -.91 \\
\hline \multicolumn{5}{|c|}{ Negative Professional Ethical Climate - Professional Codes of Ethics } \\
\hline PCE401 & 2.39 & 1.66 & 1.24 & 67 \\
\hline PCE409 & 2.32 & 1.61 & 1.28 & .72 \\
\hline PCE405 & 2.07 & 1.42 & 1.73 & 2.65 \\
\hline \multicolumn{5}{|c|}{ Network Density } \\
\hline ND404 & 4.59 & 1.80 & -.49 & -.67 \\
\hline ND410 & 4.39 & 1.90 & -.33 & -1.01 \\
\hline ND419 & 4.45 & 1.83 & -.44 & -.82 \\
\hline ND417 & 4.91 & 1.65 & -.62 & -.31 \\
\hline ND418 & 5.08 & 1.67 & -.77 & -.28 \\
\hline ND408 & 4.15 & 1.74 & -.09 & -.87 \\
\hline \multicolumn{5}{|c|}{ Franchisor TSIs } \\
\hline RTSI105 & 3.21 & 2.09 & .46 & -1.11 \\
\hline RTSI107 & 3.42 & 2.01 & .39 & -1.12 \\
\hline RTSI108 & 3.19 & 1.90 & .45 & -.98 \\
\hline RTSI110 & 2.71 & 1.85 & .80 & -.65 \\
\hline \multicolumn{5}{|c|}{ Economic Benefits of $O B$} \\
\hline EBOB513 & 3.36 & 1.94 & .30 & -1.08 \\
\hline EBOB514 & 3.54 & 1.97 & .22 & -1.15 \\
\hline EBOB515 & 2.91 & 1.81 & .41 & -.08 \\
\hline \multicolumn{5}{|c|}{ Individual PFO } \\
\hline IPFO601 & 3.28 & 1.85 & .36 & -.94 \\
\hline IPFO602 & 1.99 & 1.23 & 1.42 & 1.65 \\
\hline IPFO603 & 2.81 & 1.64 & .57 & -.58 \\
\hline
\end{tabular}


for misspecifications of measurement properties. Table 5.3 summarizes the evaluation criteria.

According to Anderson and Gerbing (1988), convergent validity can be assessed by determining whether each indicator's factor loading is greater than twice its standard error, and the average variance extracted (AVE) is greater than .50, which indicates that the variance due to measurement error is no larger than the variance captured by the construct. Assessments of construct reliability followed using the guidelines suggested by Fornell and Larcker (1981), such that composite reliability (the shared variance among a set of observed variables measuring an underlying construct) exceeds .60 (Bagozzi and Yi 1988). Anderson and Gerbing (1988) recommend that discriminant validity be assessed two latent factors at a time by constraining the estimated correlation parameter between them to 1.0. Discriminant validity is said to be established when the chi-square value is significantly reduced for the unconstrained estimates. Fornell and Larcker (1981) also recommend another discriminant validity assessment, which requires that the squared correlation between two constructs be smaller than the average variance extracted for each construct. Both types of discriminant validity test were employed for a pair of constructs that had a significant correlation coefficient.

As for measurement model fit, various fit indices were adopted as criteria for assessing measurement models. The cutoffs shown in Table 5.3 are not meant to be absolute; as Bollen (1989) observes, cutoffs are rather arbitrary. Therefore, these multiple fit indices are taken into consideration and evaluated as a whole. All measurement items passed Bagozzi and Yi's (1988) criteria for error variances. Items with standardized 
Table 5.3: Evaluation Criteria Summary

\begin{tabular}{|c|c|c|}
\hline Criterion & Recommendation & Source \\
\hline \multicolumn{3}{|l|}{ Internal Structure } \\
\hline Factor Loadings & .60 or higher & Bagozzi and Yi (1988) \\
\hline \multirow[t]{2}{*}{ Composite Reliability } & .60 or higher & $\begin{array}{l}\text { Fornell and Larcker } \\
\text { (1981) }\end{array}$ \\
\hline & & Bagozzi and Yi (1988) \\
\hline \multirow[t]{2}{*}{ AVE } & .50 or higher & $\begin{array}{l}\text { Fornell and Larcker } \\
\text { (1981) }\end{array}$ \\
\hline & & Bagozzi and Yi (1988) \\
\hline \multicolumn{3}{|l|}{ Discriminant Validity } \\
\hline $\begin{array}{l}\text { 2-factor constrained }(\mathrm{r}=1) \\
\text { model versus unconstrained }\end{array}$ & $\begin{array}{l}\text { Chi-square reduction should } \\
\text { be significant for } \\
\text { unconstrained model }\end{array}$ & $\begin{array}{l}\text { Anderson and Gerbing } \\
\text { (1988) }\end{array}$ \\
\hline $\begin{array}{l}\text { Squared correlation between } \\
\text { two factors }\end{array}$ & $\begin{array}{l}\text { Smaller than the AVE for } \\
\text { each construct }\end{array}$ & $\begin{array}{l}\text { Fornell and Larcker } \\
\text { (1981) }\end{array}$ \\
\hline \multicolumn{3}{|l|}{ Measurement Model Fit } \\
\hline Negative error variance & None & Bagozzi and Yi (1988) \\
\hline Error variances & $\begin{array}{l}\text { All significantly different } \\
\text { from zero }\end{array}$ & Bagozzi and Yi (1988) \\
\hline Standardized factor loadings & .60 or above & Bagozzi and Yi (1988) \\
\hline Model Chi-square $\left(\chi^{2}\right)$ & p-value .05 or above & Bagozzi and Yi (1988) \\
\hline $\begin{array}{l}\text { Relative Chi-square } \\
\text { (CMIN/DF) }\end{array}$ & 3 or less & Klein (1998) \\
\hline Incremental Fit Index (IFI) & .90 or above & Bagozzi and Yi (1988) \\
\hline \multirow[t]{2}{*}{ Normed Fit Index (NFI) } & .90 or above & Bagozzi and Yi (1988) \\
\hline & $\begin{array}{l}.80 \text { or above (for small } \\
\text { sample) }\end{array}$ & Ullman (2001) \\
\hline Non-Normed Fit Index (NNFI) & .90 or above & Hu and Bentler (1995) \\
\hline Comparative Fit Index (CFI) & .95 or above & $\mathrm{Hu}$ and Bentler (1995) \\
\hline RMSEA & $\begin{array}{l}.05 \text { or less: excellent } \\
.05 \text { to } .08: \text { good } \\
.08 \text { to } .10: \text { fair }\end{array}$ & Bollen and Long (1993) \\
\hline $\begin{array}{l}\mathrm{p} \text { (close fit): probability that } \\
\text { RMSEA }<.05\end{array}$ & .05 or above & Bollen and Long (1993) \\
\hline
\end{tabular}


factor loadings below .60 were immediately removed. As shown in Tables 5.4 through 5.7, these items were dropped and excluded from further measurement analyses.

The list of criteria in Table 5.3 is not exhaustive, and I have selected representative criteria that seemed appropriate in the present study. Both model chisquare and relative chi-square assess whether the given model's covariance structure is significantly different from the observed covariance matrix, and it is essentially a measure for badness of fit. Using both indices seem redundant; however, unlike model chi-square, which can be misleading due to its dependence on sample size, relative chisquare attempts to overcome the sample size bias (Klein 1998). For the present study's small sample size, examining both indices make sense. Similarly, both NFI and NNFI (also known as Tucker-Lewis Index, TLI) were included in my analysis because of consideration of sample size. NFI values should be above .90 by convention, though, some authors have argued for more liberal cutoff of .80 citing that NFI underestimate fit for small samples (Ullman 2001).

Lastly, Goodness-of-fit (GFI) was not included in the analysis for two reasons: (1) upward bias as degree of freedom and sample size increases, and the consensus is not to use these measures (cf. Bollen and Long 1993) and (2) missing values in the dataset prevent calculation of GFI. For the latter, as discussed in Chapter Four, I avoided listwise deletions unless $20 \%$ or more responses were missing, and as a result, there were two to ten cases with missing values per measurement model. The calculation of GFI statistics requires a sample covariance matrix, and with missing data, a sample covariance matrix would not be a sufficient statistic to describe the sample (Arbuckle 2006). Therefore, it 
was determined that it would not be worthwhile to conduct additional measurement model analysis with listwise deletions just to obtain GFI values.

Before discussing the CFA results further, it is worth noting that I ran measurement models of small groups of constructs at a time. This is due to the small sample size in the study. With a final sample size of 162, it was not possible to run CFA on all measures in the study simultaneously. The ratio of sample size to the number of free parameters should approach the minimum 5:1 requirement (see Bagozzi and Baumgartner 1994; Jöreskog and Sörbom 1995), and the best alternative was to divide the scales into smaller groups and run CFA separately (Bentler and Chou 1987). This is a common practice among studies with relatively small sample size (e.g., Doney and Cannon 1997; Sivadas and Dwyer 2000; Wathne and Heide 2004). The following sections represent each group of constructs that were analyzed together in CFA.

\section{CFA Results- Dyadic Scales Group 1}

Dyadic scales that appear in my hypothesized model were split into two groups. The first group consisted of Franchisee Dependence, Distributive Justice, Procedural Justice, Interactional Justice, and two lower-order constructs for Disciplinary Monitoring (Franchisor's Ability to Detect Opportunism and Franchisor's Ability to Sanction Opportunism). Table 5.4 summarizes the CFA results. All indicators exhibited a standard loading above .60 significant at $\mathrm{p}<.001$, with the exception of FADO133, which was then dropped. Both composite reliability $\left(\rho_{\eta}\right)$ and Average Variance Extracted (AVE) were well above the recommended values, therefore establishing convergent validity for all the constructs. 
Table 5.4: Measurement Analysis - Dyadic Scales Group 1 (franchisees reporting on franchisors)

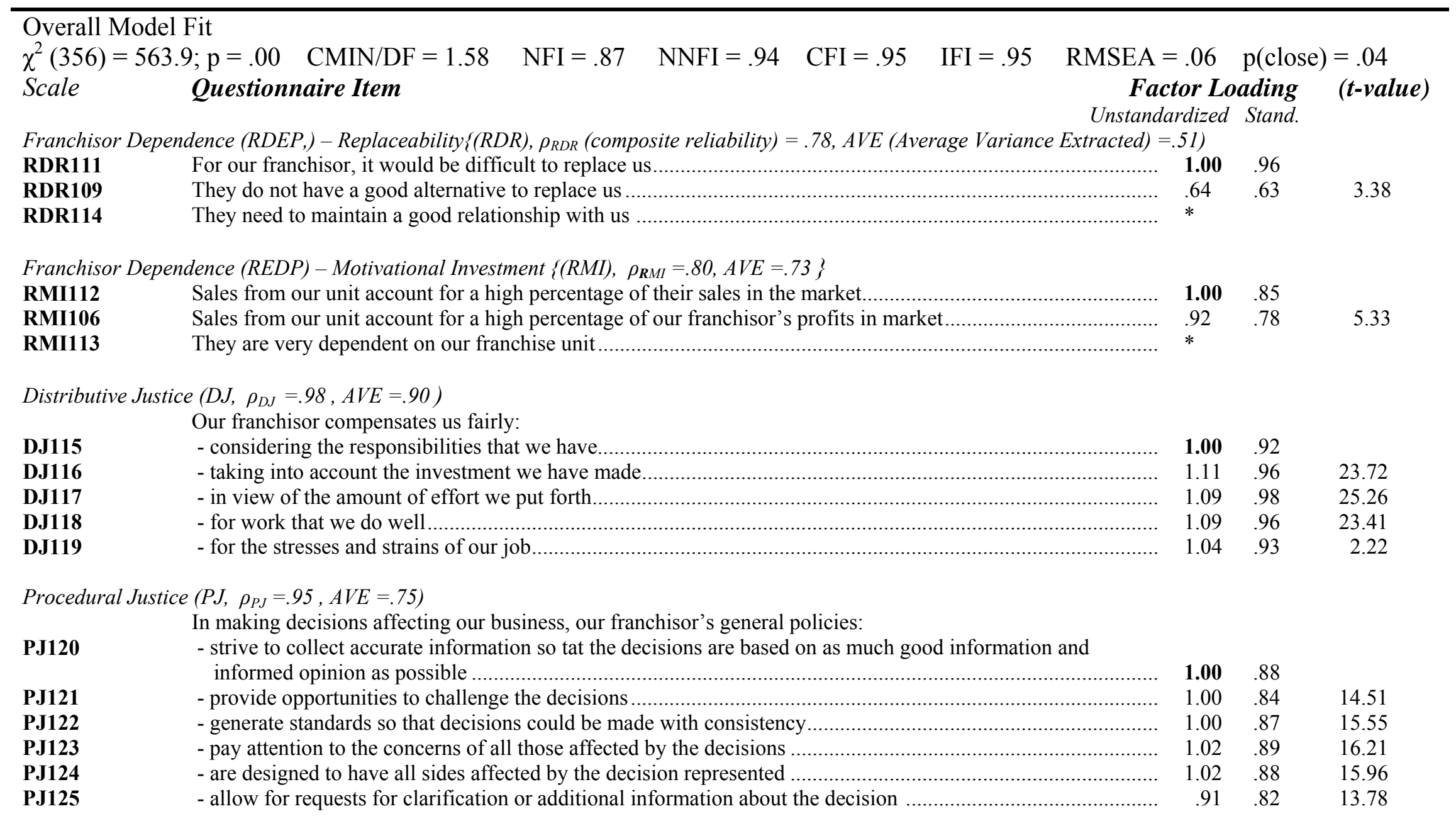


Interactional Justice (IJ, $\left.\rho_{I J}=.93, A V E=.70\right)$

Our franchisor:

IJ126 - considers our viewpoint whenever s/he is communicating with us ............................................................

IJ127

$\begin{array}{rrr}.74 & .76 & 12.31\end{array}$

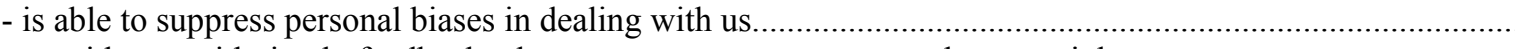

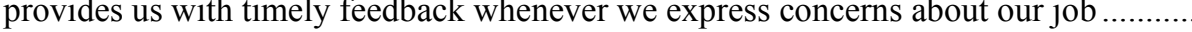

12.69

- treats us with kindness and consideration

13.34

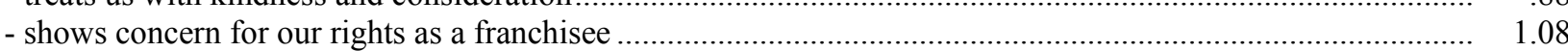

- takes steps to deal with us in a truthful manner

Wetect Opportunism (FADO, $\rho_{F A D O}=.79$, AVE $=.50$

Franchisor's Ability to Detect Opportunism $\left(F A D O, \rho_{F A D O}=.79, A V E=.50\right)$
$\begin{array}{ll}\text { FADO133 } & \text { We perform so many different tasks that this franchisor finds it difficult to determine whether we are }\end{array}$

FADO133 We perform so many different tasks that this franchisor finds it difficult to determine whether we are

FADO135 It is easy for our franchisor to determine whether we adhere to agreed upon quality standards and

FADO137

specification

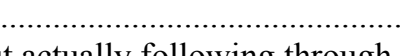

FADO139

Our franchisor easily detects when we promise to do something without actually following through

FADO140

It is difficult for us to breach informal agreements between our companies without being caught

Our franchisor can easily catch franchisees using unfound excuses for unfulfilled obligations.

Franchisor's Ability to Sanction Opportunism (FASO, $\rho_{F A S O}=.80$, AVE $=.50$ )

FASO132 Our franchisor would take tough measures against us if we were discovered withholding certain critical

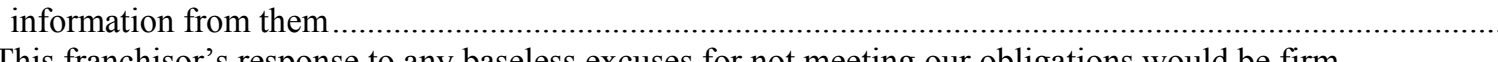

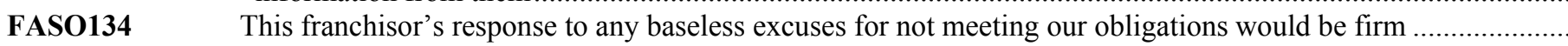

Our franchisor would take strict disciplinary action against us if we don't act in accordance with our

FASO136

contracts

If we don't adhere to our informally agreed upon terms, this franchisor would take severe action against us......

FASO138

Correlations $(\mathbf{p}<.05$ in boldface $)$

\begin{tabular}{|c|c|c|c|c|c|c|c|c|c|c|}
\hline$\Phi_{\mathrm{RDR}, \mathrm{RMI}}$ & .34 & $\Phi_{\mathrm{RMI}, \mathrm{DJ}}$ & .22 & $\Phi_{\text {DJ, PJ }}$ & .65 & $\Phi_{\mathrm{PJ}, \mathrm{IJ}}$ & .83 & $\Phi_{\mathrm{IJ}, \mathrm{FADO}}$ & .10 & $\Phi_{\text {FADO, FASO }}$ \\
\hline$\Phi_{\mathrm{RDR}, \mathrm{DJ}}$ & .09 & $\Phi_{\mathrm{RMI}, \mathrm{PJ}}$ & .04 & $\Phi_{\mathrm{DJ}, \mathrm{IJ}}$ & .66 & $\Phi_{\mathrm{PJ}, \mathrm{FADO}}$ & .30 & $\Phi_{\mathrm{IJ}, \text { FASO }}$ & -.15 & \\
\hline$\Phi_{\mathrm{RDR}, \mathrm{PJ}}$ & .04 & $\Phi_{\mathrm{RMI}, \mathrm{IJ}}$ & .11 & $\Phi_{\mathrm{DJ}, \text { FADO }}$ & .28 & $\Phi_{\mathrm{PJ}, \text { FASO }}$ & .08 & & & \\
\hline$\Phi_{\mathrm{RDR}, \mathrm{IJ}}$ & .01 & $\Phi_{\mathrm{RMI}, \mathrm{FADO}}$ & .21 & $\Phi_{\text {DJ, FASO }}$ & .13 & & & & & \\
\hline$\Phi_{\mathrm{RDR}, \mathrm{FADO}}$ & .21 & $\Phi_{\text {RMI, FASO }}$ & .16 & & & & & & & \\
\hline$\Phi_{\mathrm{RDR}, \mathrm{FASO}}$ & .17 & & & & & & & & & \\
\hline
\end{tabular}

Note: All scales used a 7-point Likert-type scale anchored by 1= "strongly disagree" and 7= "strongly agree."

Note: Items with asterisk (*) are items with standard loading well below .60 and subsequently dropped.

Note: boldfaced items were fixed to 1.00 . 
As for discriminant validity, as shown in Table 5.5, Procedural Justice and Interactional Justice exhibited a high correlation $(\mathrm{r}=.83)$ between them, as well as between Franchisor's Ability to Sanction and Franchisor's Ability to Detect Opportunism $(\mathrm{r}=.78)$. The former passed Fornell and Larcker's (1981) discriminant validity test, but the latter did not.

That is, squared correlation between the two constructs (.61) exceeded AVE's for each construct (.50 for both). Because the pair that did not pass Fornell and Larcker's test belongs to the same higher-order construct of Disciplinary Monitoring, it is only reasonable that they are highly correlated. Besides, Anderson and Gerbing's (1988) demonstrated unidimensionality for all the constructs as they passed the chi-square difference tests.

The overall model fit indices indicate good fit of the measurement model. NFI of .89 is slightly below the recommended .90; however, NNFI (more appropriate for small sample size) is well above .90 . Model chi-square resulted in $p=.00$, though, relative chisquare was well below the recommended value. The other indices were well within the recommended criteria.

\section{CFA Results- Dyadic Scales Group 2}

This group includes Franchisee Dependence, Franchisee TSIs, Economies of Continuation, Crowding Out Effects of Monitoring, Propensity for Opportunism, Crowding Out Effects of Opportunism, and Opportunistic Behaviors. Of these constructs, Franchisee TSIs and Opportunistic Behaviors were transformed using logarithmic transformation due to the non-normality data structure, and they were included in the 
Table 5.5: Discriminant Validity Test Results for Dyadic Group 1

\begin{tabular}{|c|c|c|c|}
\hline & $\begin{array}{l}\text { Correlation } \\
\text { Coefficient }\end{array}$ & $\begin{array}{l}\text { Fornell and } \\
\text { Larcker Test } \\
\text { Passed? }\end{array}$ & Anderson and Gerbing Test \\
\hline$\Phi_{\mathrm{RDR}, \mathrm{RMI}}$ & .34 & Yes & $\Delta \chi^{2}=94.4(\mathrm{p}<.001)$ \\
\hline$\Phi_{\mathrm{RDR}, \mathrm{FADO}}$ & .21 & Yes & $\Delta \chi^{2}=85.0(\mathrm{p}<.001)$ \\
\hline$\Phi_{\mathrm{RMI}, \mathrm{DJ}}$ & .22 & Yes & $\Delta \chi^{2}=148.4(\mathrm{p}<.001)$ \\
\hline$\Phi_{\mathrm{RMI}, \mathrm{FADO}}$ & .21 & Yes & $\Delta \chi^{2}=130.1(\mathrm{p}<.001)$ \\
\hline$\Phi_{\mathrm{DJ}, \mathrm{PJ}}$ & .65 & Yes & $\Delta \chi^{2}=560.1(\mathrm{p}<.001)$ \\
\hline$\Phi_{\mathrm{DJ}, \mathrm{IJ}}$ & .66 & Yes & $\Delta \chi^{2}=508.4(\mathrm{p}<.001)$ \\
\hline$\Phi_{\text {DJ, FADO }}$ & .28 & Yes & $\Delta \chi^{2}=232.7(\mathrm{p}<.001)$ \\
\hline$\Phi_{\mathrm{PJ}, \mathrm{IJ}}$ & .83 & Yes & $\Delta \chi^{2}=195.2(\mathrm{p}<.001)$ \\
\hline$\Phi_{\text {PJ, FADO }}$ & .30 & Yes & $\Delta \chi^{2}=218.2(\mathrm{p}<.001)$ \\
\hline$\Phi_{\mathrm{FADO}, \text { FASO }}$ & .78 & No & $\Delta \chi^{2}=36.3(\mathrm{p}<.001)$ \\
\hline \multicolumn{4}{|c|}{$\begin{array}{l}\text { Note 1: Correlation coefficients are significant }(\mathrm{p}<.05) \text { for all of these pairs of constructs. } \\
\text { Note 2: A pair of constructs is said to pass Anderson and Gerbing's }(1988) \text { test of } \\
\text { discriminant validity if Chi-square difference is significant (cut off } \chi^{2} \text { value is } 3.84 \text { with } \\
\text { one degree of freedom at } \mathrm{p}<05)\end{array}$} \\
\hline
\end{tabular}


measurement model only after ensuring normality. Franchisee TSIs were heavily skewed positively, while Opportunistic Behaviors were highly skewed negatively (see Table 5.2).

The CFA results are shown in Table 5.6. Several items did not reach the recommended standardized loading of .60. These were ETSI210, EC209, EC213, COEM501, COEM503, and OB203. Once they were removed, the constructs all had an acceptable levels of composite reliability and AVE. Some pairs of constructs were high in correlation: Franchisee Dependence-Replaceability and Franchise DependenceMotivational Investment ( $\mathrm{r}=.87)$, Franchisee Dependence-Replaceability and Economies of Continuation ( $r=.75)$, Franchise Dependence-Motivational Investment and Economies of Continuation $(\mathrm{r}=.92)$.

As shown in Table 5.7, these pairs did not pass Fornell and Larcker's (1981) discriminant validity tests, but they passed Anderson and Gerbing's (1988) tests. These pairs most likely failed Fornell and Larcker's test simply because they are theoretically highly related. Franchisee Dependence-Relaceability and Franchisee DependenceMotivational Investment are two dimensions of the higher-order construct Dependence. Economies of Continuation, or "shadow of the future" and Franchisee DependenceMotivational Investment and -Replaceability imply the importance of the relationship to achieving long-term profits.

The overall model fit was very similar to that of the previous group of constructs. NFI was slightly below the recommended .90 , but the NNFI value was acceptable. Model chi-square resulted in $\mathrm{p}=.00$, though, relative chi-square was well below the recommended value. The other indices were well within the recommended criteria. Overall, the measurement model exhibited a good fit. 
Table 5.6: Measurement Analysis - Dyadic Scales Group 2 (franchisees reporting on themselves)

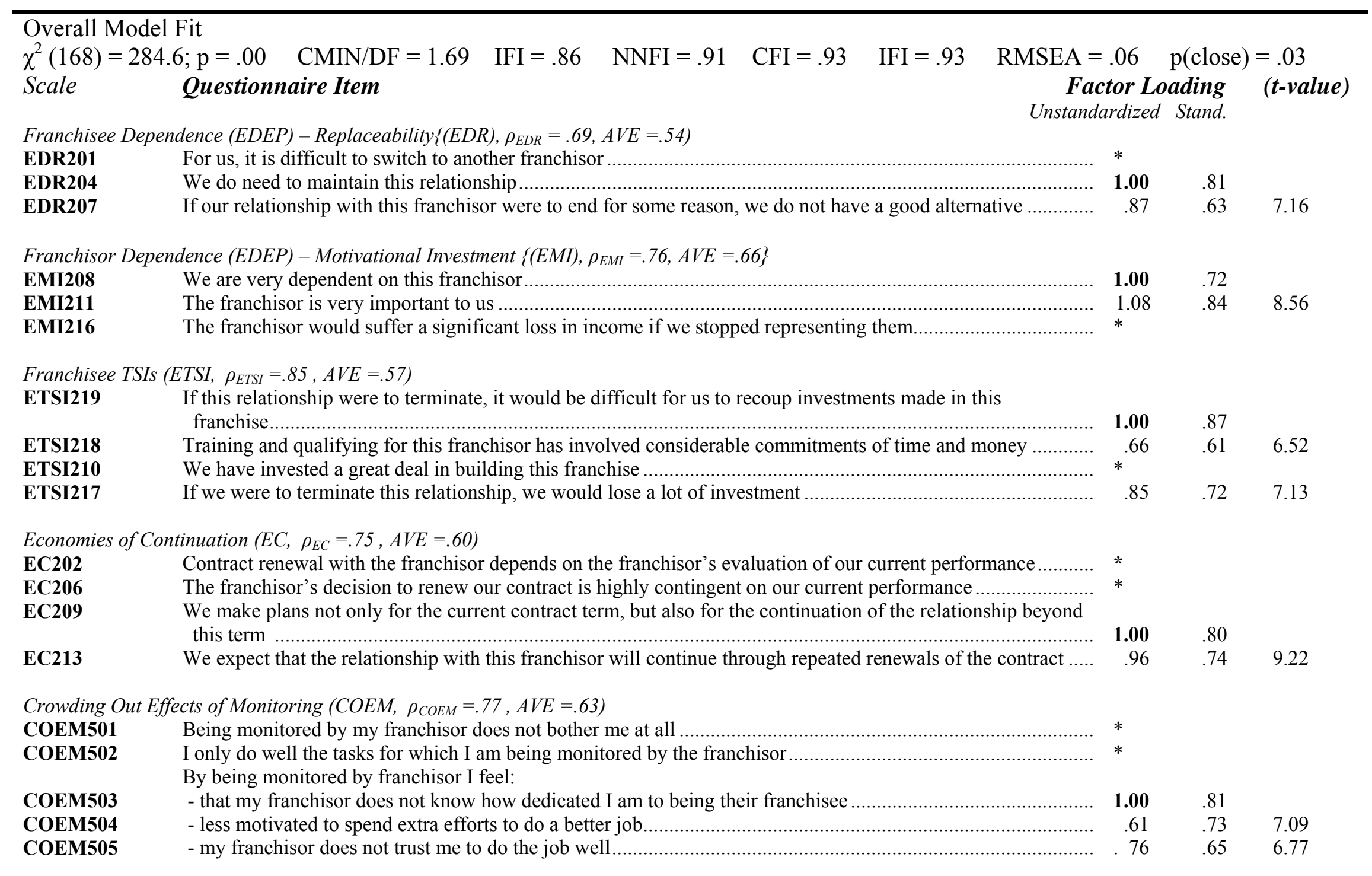


Propensity for Opportunism (PFO, $\rho_{P F O}=.95, A V E=.78$ )

In any given business relationship, a party may engage in certain actions to improve their terms of trade such as:

- Giving empty promises

- Breaching formal and/or informal agreements to maximize gains

- Taking advantage of "holes" in the contract

- Using excuses to re-negotiate terms of trade at the partner's expense

- Withholding important information from the partner

Specific to your franchisor, please circle the number below that indicates how you feel about using this

type of behavior:

PFO516

PFO517

Unwilling - Willing

Unmotivated - Motivated $\quad 1.12$

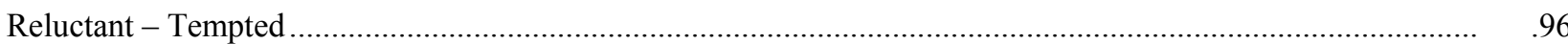

PFO518

PFO519

Unprovoked-Provoked.

Not compelled - Compelled

Opportunistic Behaviors $\left(O B, \rho_{O B}=.80, A V E=.50\right)$

OB203 On occasion, we lie or simply withhold critical information to advance our own interests.

OB205

We do not always act in accordance with our contract

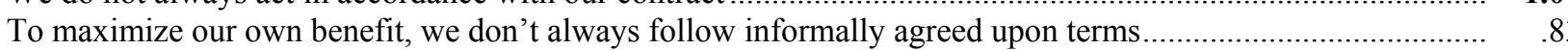

Occasionally we just don't adhere to our agreed upon quality standards and specifications......

\section{Correlations $(\mathbf{p}<.05$ in boldface $)$}

$\begin{array}{lclllllllll}\Phi_{\mathrm{EDR}, \mathrm{EMI}} & \mathbf{. 8 7} & \Phi_{\mathrm{EMI}, \mathrm{ETSI}} & \mathbf{. 4 0} & \Phi_{\mathrm{ETSI}, \mathrm{EC}} & \mathbf{. 3 9} & \Phi_{\mathrm{EC}, \mathrm{CO} \mathrm{EM}} & \mathbf{- . 4 2} & \Phi_{\mathrm{COEM}, \mathrm{PFO}} & .17 & \Phi_{\mathrm{PFO}, \mathrm{OB}} \\ \Phi_{\mathrm{EDR}, \mathrm{ETSI}} & \mathbf{. 4 8} & \Phi_{\mathrm{EMI}, \mathrm{EC}} & \mathbf{. 9 2} & \Phi_{\mathrm{ETSI}, \mathrm{COEM}} & -.05 & \Phi_{\mathrm{EC}, \mathrm{PFO}} & -.06 & \Phi_{\mathrm{COEM}, \mathrm{OB}} & \mathbf{. 2 1} & \\ \Phi_{\mathrm{EDR}, \mathrm{EC}} & \mathbf{. 7 5} & \Phi_{\mathrm{EMI}, \mathrm{COEM}} & \mathbf{- . 3 1} & \Phi_{\mathrm{ETSI}, \mathrm{PFO}} & .12 & \Phi_{\mathrm{EC}, \mathrm{OB}} & \mathbf{- . 2 2} & & & \\ \Phi_{\mathrm{EDR}, \mathrm{COEM}} & \mathbf{- . 2 0} & \Phi_{\mathrm{EMI}, \mathrm{PFO}} & -.03 & \Phi_{\mathrm{ETSI}, \mathrm{OB}} & -.02 & & & & \\ \Phi_{\mathrm{EDR}, \mathrm{PFO}} & .15 & \Phi_{\mathrm{EMI}, \mathrm{OB}} & -.07 & & & & & & \\ \Phi_{\mathrm{EDR}, \mathrm{OB}} & -.03 & & & & & & & & \end{array}$


Table 5.7: Discriminant Validity Test Results for Dyadic Group 2

\begin{tabular}{|c|c|c|c|}
\hline & $\begin{array}{l}\text { Correlation } \\
\text { Coefficient }\end{array}$ & $\begin{array}{c}\text { Fornell and Larcker } \\
\text { Test Passed? }\end{array}$ & Anderson and Gerbing Test \\
\hline$\Phi_{\text {EDR, EMI }}$ & .87 & No & $\Delta \chi^{2}=5.3(\mathrm{p}<.05)$ \\
\hline$\Phi_{\mathrm{EDR}, \mathrm{ETSI}}$ & .48 & Yes & $\Delta \chi^{2}=58.4(\mathrm{p}<.001)$ \\
\hline$\Phi_{\mathrm{EDR}, \mathrm{EC}}$ & .75 & No & $\Delta \chi^{2}=17.2(\mathrm{p}<.001)$ \\
\hline$\Phi_{\mathrm{EDR}, \mathrm{COEM}}$ & -.20 & Yes & $\Delta \chi^{2}=150.1(\mathrm{p}<.001)$ \\
\hline$\Phi_{\text {EMI, ETSI }}$ & .40 & Yes & $\Delta \chi^{2}=90.8(\mathrm{p}<.001)$ \\
\hline$\Phi_{\mathrm{EMI}, \mathrm{EC}}$ & .92 & No & $\Delta \chi^{2}=3.9(\mathrm{p}<.05)$ \\
\hline$\Phi_{\text {EMI, COEM }}$ & -.31 & Yes & $\Delta \chi^{2}=205.8(\mathrm{p}<.001)$ \\
\hline$\Phi_{\text {ETSI, EC }}$ & .39 & Yes & $\Delta \chi^{2}=80.1(\mathrm{p}<.001)$ \\
\hline$\Phi_{\mathrm{EC}, \mathrm{COEM}}$ & -.42 & Yes & $\Delta \chi^{2}=201.4(\mathrm{p}<.001)$ \\
\hline$\Phi_{\mathrm{EC}, \mathrm{OB}}$ & -.22 & Yes & $\Delta \chi^{2}=168.8(\mathrm{p}<.001)$ \\
\hline$\Phi_{\mathrm{COEM}, \mathrm{OB}}$ & .21 & Yes & $\Delta \chi^{2}=150.6(\mathrm{p}<.001)$ \\
\hline$\Phi_{\mathrm{PFO}, \mathrm{OB}}$ & .24 & Yes & $\Delta \chi^{2}=201.4(\mathrm{p}<.001)$ \\
\hline \multicolumn{4}{|c|}{$\begin{array}{l}\text { Note 1: Correlation coefficients are significant }(\mathrm{p}<.05) \text { for all of these pairs of constructs. } \\
\text { Note 2: A pair of constructs is said to pass Anderson and Gerbing's }(1988) \text { test of } \\
\text { discriminant validity if Chi-square difference is significant (cut off } \chi^{2} \text { value is } 3.84 \text { with one } \\
\text { degree of freedom at } \mathrm{p}<05 \text { ) }\end{array}$} \\
\hline
\end{tabular}


The only concern from the measurement analysis was that two of the four items of Economies of Continuation had to be removed. Usually, two-item scales exhibit lower reliability values (Nunnally 1978), and it is generally desirable that a greater number items be used to reflect different nuances of a construct (Churchill 1979). Nonetheless, the scale seemed stable with fewer than three items and still met the convergent validity criteria.

\section{CFA Results - Extra-Dyadic Scales}

Four constructs were included in the measurement model: three lower-order factors for Negative Professional Ethical Climate (Individualism, Corporate Rules, and Professional Codes of Ethics) and Network Density. The first three constructs also exhibited non-normal data, and hence a log-transformation was used. Table 5.8 summarizes the results of CFA.

Several measurement items had to be dropped due to insufficient (.60 or less) factor loadings: IN411, IN412, IN413, IN416, CE402, CE403, and CEE409. The results meant that each of the lower-factor constructs for Negative Professional Ethical Climate consist of only two items each. This was rather surprising because the pre-tests exhibited high level of content validity. Individualism, in particular, seemed problematic as four out of the six items had to be dropped. One possible explanation for the outcome is that the items had both positive and negative words within the measurement of an alreadynegative construct, which could have introduced "positive and negative item wording" item characteristic effects (Podsakoff et al. 2003). For example, while a statement of "In this franchise system, people protect their own interests above all else" is simply negative 
Table 5.8: Measurement Analysis - Extra-Dyadic Scales

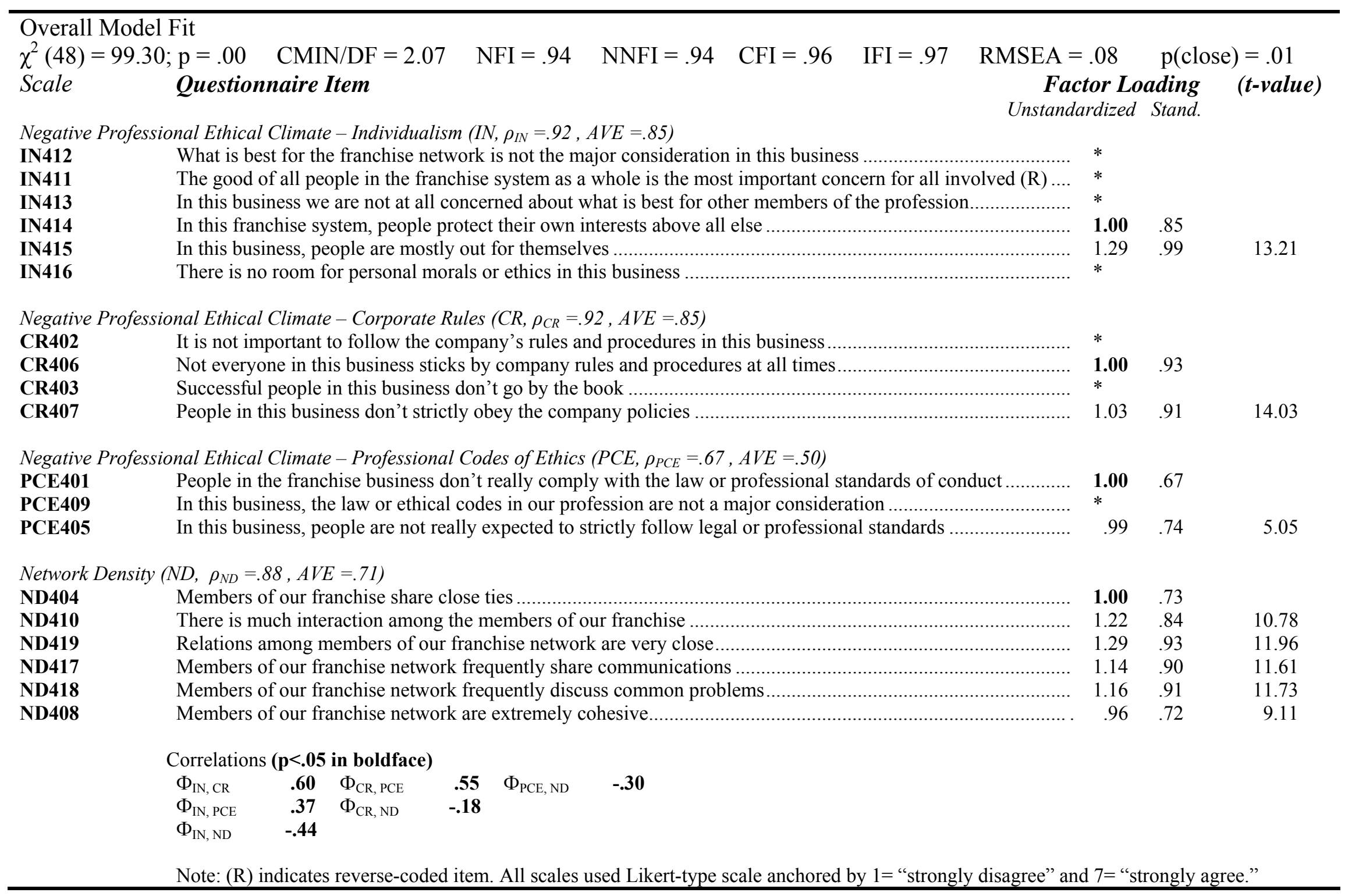


and straightforward, another item "In this business I am not at all concerned about what is best for other members of the profession" has both positive and negative nuances, which may be confusing. A statistical pre-test with a small sample of individuals could have prevented us from spotting this problem. Overall, even with two-item scales, the overall construct of Negative Professional Ethical Climate exhibited a high level of internal consistency. The CFA results also indicated that Network Density has convergent validity. All the items exhibited sufficient factor loadings and a high level of AVE (.71). As for unidimensionality, as expected, these constructs shared low correlation among them. Negative Professional Ethical Climate was developed as a formative scale consisting of three lower-order reflective factors of Individualism, Corporate Rules, and Professional Codes of Ethics. The highest correlation was .60 between Corporate Rules and Individualism, and Fornell and Larcker (1981) tests for discriminant validity determined that these two constructs are significantly different from each other. Table 5.9 summarizes the discriminant validity test results.

The second-order measurement model for Negative Professional Ethical Climate was subsequently analyzed. Figure 5.1 depicts the model, and Table 5.10 shows the results. The overall model fit indices are all within recommended cutoffs, displaying adequate fit. Although the scale only utilizes two items per lower-order scale, the overall higher-order scale exhibited acceptable measurement properties. 
Table 5.9: Discriminant Validity Test Results for Extra-Dyadic Scales

\begin{tabular}{|c|c|c|c|}
\hline & $\begin{array}{l}\text { Correlation } \\
\text { Coefficient }\end{array}$ & $\begin{array}{c}\text { Fornell and } \\
\text { Larcker Test } \\
\text { Passed? }\end{array}$ & Anderson and Gerbing Test \\
\hline$\Phi_{\mathrm{IN}, \mathrm{CR}}$ & .60 & Yes & $\Delta \chi^{2}=75.3(\mathrm{p}<.001)$ \\
\hline$\Phi_{\mathrm{IN}, \mathrm{PCE}}$ & .37 & Yes & $\Delta \chi^{2}=162.0(\mathrm{p}<.001)$ \\
\hline$\Phi_{\mathrm{IN}, \mathrm{ND}}$ & -.44 & Yes & $\Delta \chi^{2}=360.5(\mathrm{p}<.001)$ \\
\hline$\Phi_{\mathrm{CR}, \mathrm{PCE}}$ & .55 & Yes & $\Delta \chi^{2}=55.0(\mathrm{p}<.001)$ \\
\hline$\Phi_{\mathrm{CR}, \mathrm{ND}}$ & -.18 & Yes & $\Delta \chi^{2}=165.0(\mathrm{p}<.001)$ \\
\hline$\Phi_{\mathrm{PCE}, \mathrm{ND}}$ & -.30 & Yes & $\Delta \chi^{2}=285.9(\mathrm{p}<.05)$ \\
\hline
\end{tabular}




\section{CFA Results - Control and Extra Variable}

Our last group of measurement model included two control variables (Franchisor TSIs and Economic Benefits of $\mathrm{OB}$ ) and Individual PFO, which was not part of the original hypothesized model. The CFA results are shown in Table 5.11.

All the measurement items here displayed adequate factor loadings (above .60), significant at $\mathrm{p}<.001$. Evidence for convergent validity was observed in both composite reliability and AVE. Correlations among constructs were also very low (well below .50), and Fornell and Larcker (1981) test indicated that discriminant validity can be established. The overall model fit was adequate

An additional test of discriminant validity was done between Individual PFO and the original PFO, in order to validate the theoretical dissimilarity. As conceptualized, these two constructs exhibited a very low correlation coefficient $(r=.26, p<.05)$, and both Fornell and Larcker's (1981) and Anderson and Gerbing's (1988) tests also resulted in solid discriminant validity of the two scales.

\section{Exploratory Factor Analysis}

After we purified measurement items, I conducted a series of EFAs. This sequence follows that of Churchill (1979), who recommends checking dimensionality of closely related factors after the measure purification steps. If EFA is done before the purification steps, According to Churchill, EFA will likely produce many more dimensions than conceptually identified "partly due to 'garbage items' which do not have the common core but which do produce additional dimensions in the factor analysis" (p. 69). 
The CFA results discussed in the previous section indeed provide evidence for unidimensionality for all of the constructs in the research model, however, the discriminant validity tests were conducted at the construct level, not the item level. The premise of CFA is that measurement items are pre-specified to load on specific factor based on a priori conceptualization, while EFA enables the researcher to see which item statistically belongs to which factor. The purpose of EFA here is to detect any crossloadings of items. Item-level analyses of unidimensionality using EFA further provide confidence in the measures.

A series of EFA were conducted in groups of constructs. The groups were selected based on the basis of similarity in their operationalizations. The specific groups of the constructs are listed below:

Group 1: Distributive Justice, Procedural Justice, and Interactional Justice

Group 2: Franchisor's Ability to Detect Opportunism and Franchisor's Ability to Sanction Opportunism

Group 3: Individual PFO, Relational PFO, and OB

Group 4: Three dimensions of Negative Professional Ethical Climate (Individualism, Corporate Rules, and Professional Codes of Ethics) and Network Density

Principal component analysis with Varimax rotation was used for EFA. Varimax rotation, an orthogonal method, was used because it calculates loadings on the basis of assumed uncorrelated factors, which has the effect of differentiating the original variables by extracted factor (Stevens 1992). The analysis used two widely-used criteria to determine the number of factors. Kaiser criterion (K1 rule) drops all components with eigenvalues under 1.0. The scree plots were also examined to identify the elbow at which 
Figure 5.1: Measurement Model for Negative Professional Ethical Climate

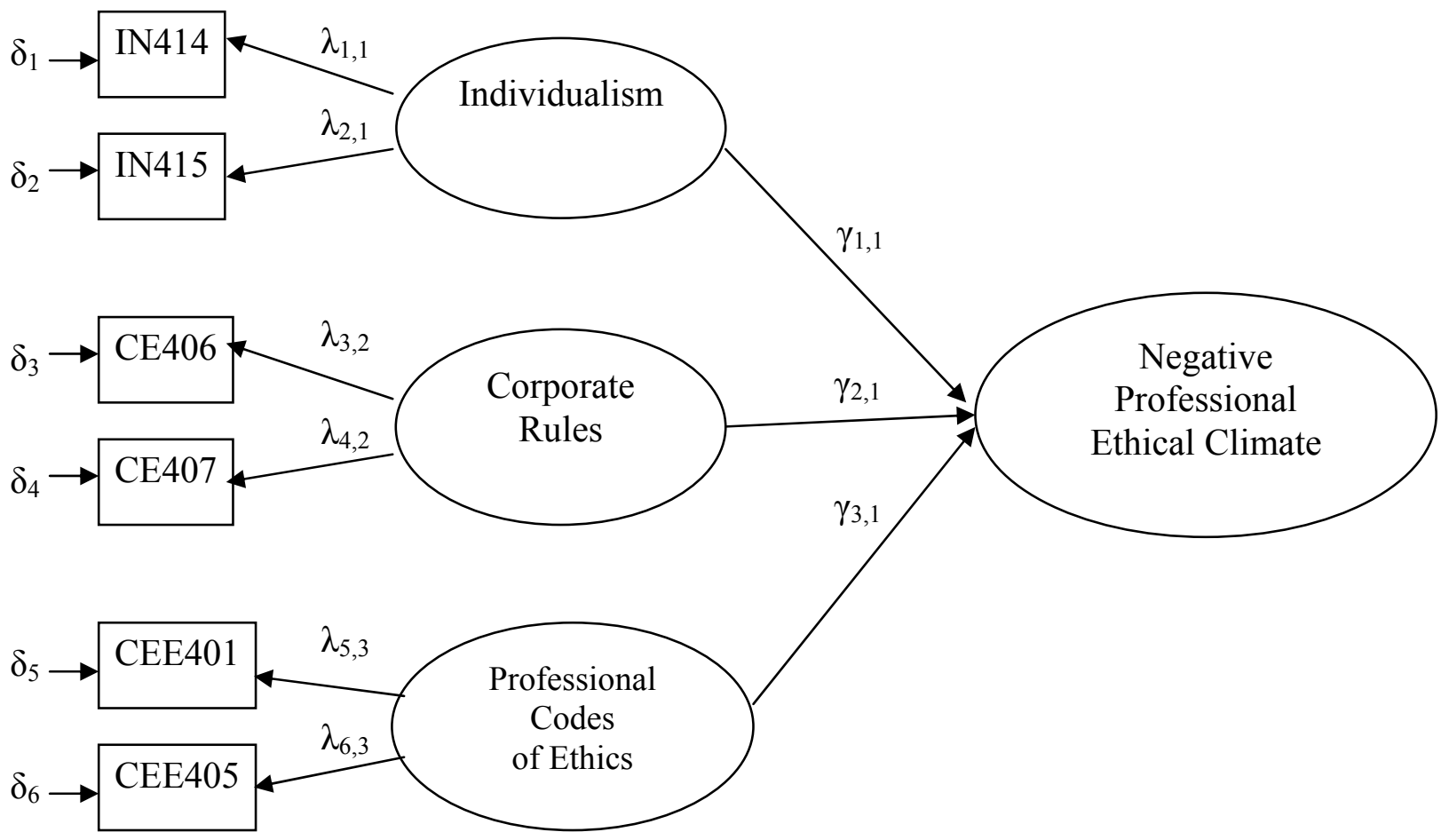


Table 5.10: Second-Order Factor Analysis for Negative Professional Ethical Climate

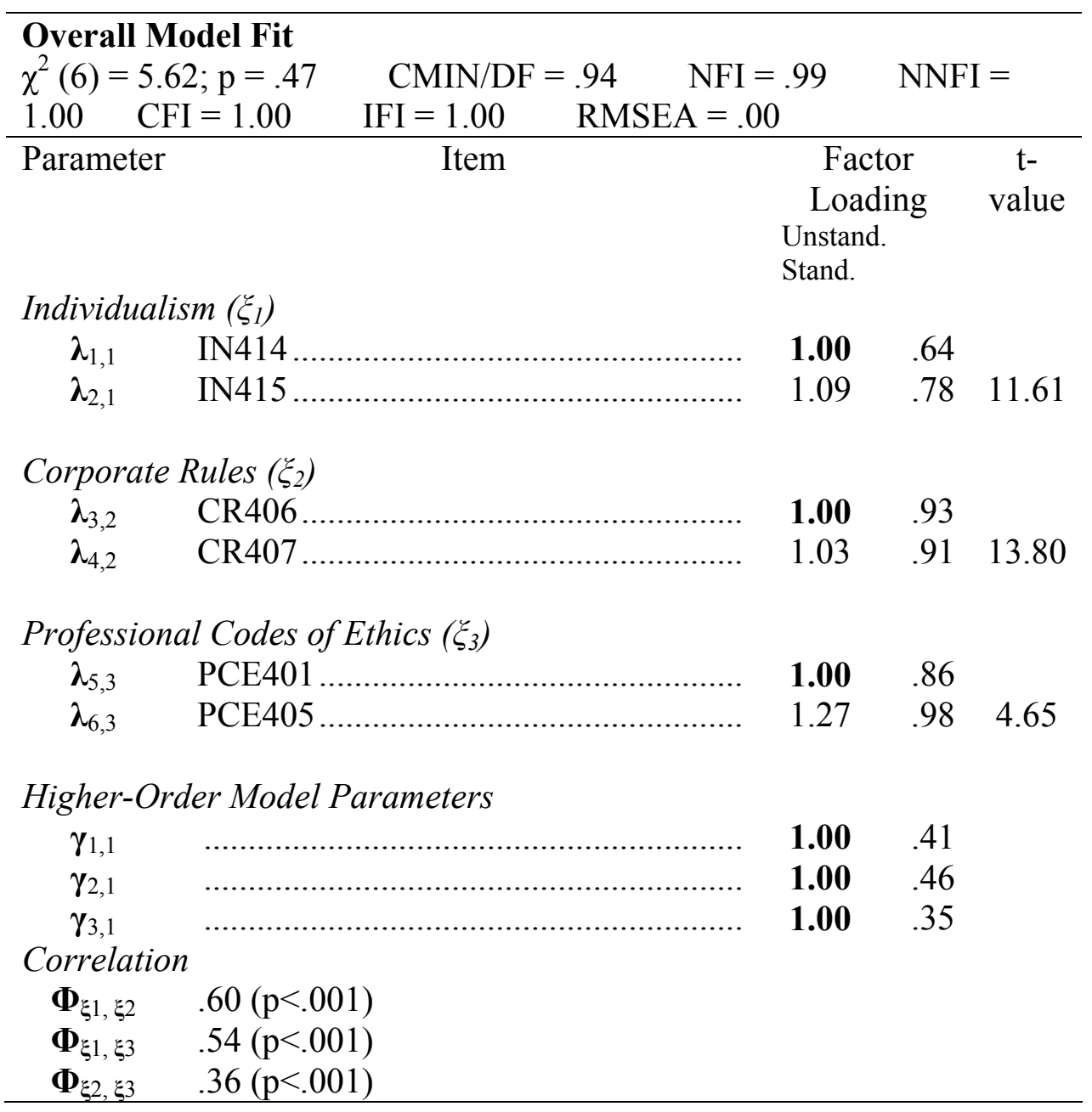


Table 5.11: Measurement Analysis - Control Variables and Extra Variable (IPFO)

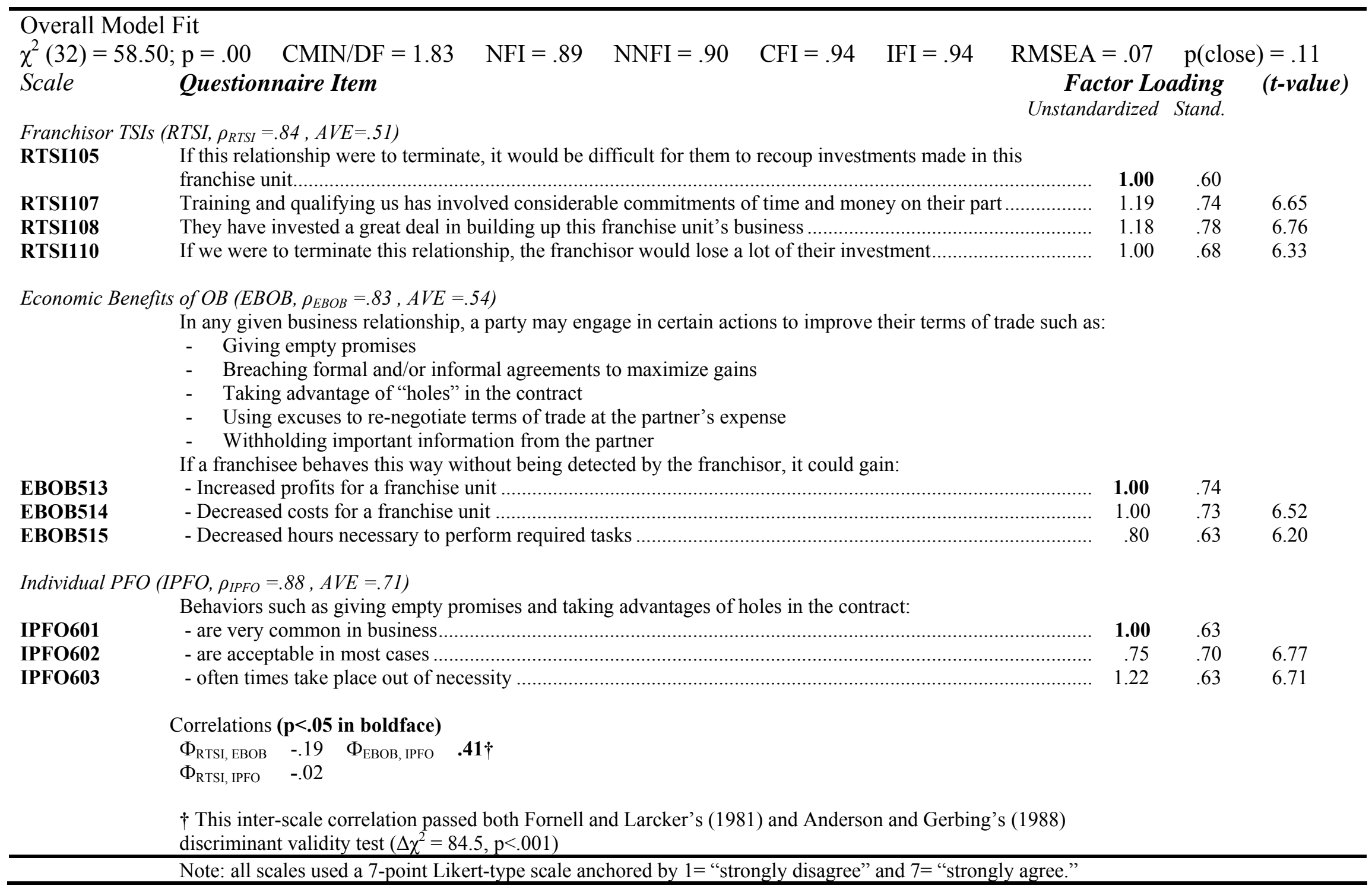


a flatter line begins between the number of factors (X-axis) and corresponding eigenvalues (Y-axis). In addition, factor loadings were examined for each factor. A common social science practice uses a cut-off of .3 or .35 (e.g., Singh 1998; Buvik and John 2000).

In addition, in order to test for possible common method bias, I ran a common factor EFA in which single-item construct measures (i.e., composites) were included. More than one factor should have strong loadings; otherwise a common method factor (e.g., item characteristics effects or context effects; see Podsakoff et al. 2003) can be said to bias the responses. Due to the large number of items and small sample size, I could not employ more traditional common method bias tests, such as those suggested by Cote and Buckley (1987), which would require all items be included in one confirmatory factor analysis. Nonetheless, I took steps in minimizing social desirability bias, one of the largest sources of common method bias, by directly measuring and including it in my hypothesis testing. Although this method does not tap the whole common methods variance domain, it is still an effective way to partial out a general method factor.

\section{EFA Results for Group 1}

Distributive Justice, Procedural Justice, and Interactional Justice are included in Group 1 . These are separate, yet arguably similar constructs as they all share the nuance of perceived fairness. The EFA results corroborate the extant literature which has shown the distinct characteristics of each construct. The eigenvalues and scree tests suggested a three-factor solution. The results show that $81.98 \%$ of variance is explained by three 
factors. Factor loadings (see Table 5.12) also indicate a three factor solution by which the three theoretically-distinct indictors load on their respective factor.

Distributive Justice items (DJ115 through DJ120) clearly load on Factor 1.

Procedural Justice items (PJ120 through PJ125) load on Factor 2, though, two items from Interactional Justice (IJ126 and IJ130) had loadings slightly above .40. Garson (2007) suggests that .6 may be required for Likert-scaled items to be considered "high." It is also clear that loadings are much stronger for Procedural Justice items (.65 to .85$)$. Therefore, these two items need not be considered as cross-loading. Interactional Justice items load on Factor 3. Similarly, although one of the Procedural Justice item (PJ126) load slightly on the factor (.43), this should not be a concern.

\section{EFA Results for Group 2}

Group 2 consists of two lower-order factors of Disciplinary Monitoring: Franchisor's Ability to Detect Opportunism and Franchisor's Ability to Sanction Opportunism. These two constructs have been newly developed for the present study. Although conceptually different, they still share the common concept of franchisor's monitoring activities. The EFA results suggest that they are also different statistically. Both eigenvalues and scree plot suggest that two factors are present. Cumulatively these two factors explain $63.4 \%$ of total variance.

As shown in Table 5.13, Franchisor's Ability to Detect Opportunism (FADO135 through FADO 140) items clearly load on Factor 1. For Factor 2, FASO136 and FASO138 had loadings of slightly below .60 (.58 and .53), and they also cross-load highly on Factor 2 (.55 and .53 , respectively). Statistically, the results indicate that both 
FASO136 and FASO138 cannot be distinguished between two factors. Though, a careful examination of the measurement items also suggest that FASO132 and FASO134 deal with withholding of critical information and giving baseless excuses, while FASO136 and FASO138 specifically deal with the acts of non-compliance to agreed-upon terms. Assuming that franchisees' perceptions of their franchisors' ability to sanction opportunism reflect the previous history of relationships, then, it is highly possible that withholding information or giving excuses (i.e., FASO132 and FASO134) are less likely to be sanctioned than the more obvious opportunistic behaviors (i.e., FASO136 and FASO138).

The two-dimensional plot depicts FASO136 and FASP138 being located in the midrange between Factor 1 and Factor 2, while the remaining items were located high on only one factor. When another CFA (Dyadic Scales Group 1) was run with the two items (FASO136 and FASO138) cross-loading on both Ability to Sanction and Detect Opportunism, these items' factor loadings dropped significantly (below .50 for all). I decided to keep FASO136 and FASO138 even with high cross-loadings for the following reasons:

(1) It is reasonable to expect franchisors' ability to detect and sanction opportunism are related to one another (though theoretically they need not be),

(2) They are essential items dealing with overt opportunism behaviors which FASO132 and FASO134 alone cannot entail,

(3) The FADO items do not at all load on Factor 2, and

(4) In a CFA where FASO136 and FASO138 load on Ability to Detect Opportunism along with the FADO items, FADO135 and FADO139 loadings dropped to below .60, which indicates that FASO136 and FASO138 are more suited to load on Ability to Sanction as originally proposed. 
Table 5.12: Factor Loadings for EFA Group 1

\begin{tabular}{lccc}
\hline & \multicolumn{3}{c}{ Factor } \\
& \multicolumn{2}{c}{$(\%$ of Variance } & Explained $)$ \\
\cline { 2 - 4 } & $(28.68 \%)$ & $(27.19 \%)$ & $(26.11 \%)$ \\
\hline DJ115 & .88 & .24 & .23 \\
DJ116 & .90 & .27 & .23 \\
DJ117 & .89 & .30 & .24 \\
DJ118 & $\mathbf{. 8 9}$ & .27 & .26 \\
DJ119 & $\mathbf{. 8 8}$ & .21 & .38 \\
PJ120 & .20 & .79 & .28 \\
PJ121 & .25 & $\mathbf{. 8 0}$ & .28 \\
PJ122 & .25 & $\mathbf{. 8 5}$ & .24 \\
PJ123 & .32 & .74 & .39 \\
PJ124 & .35 & .72 & .39 \\
PJ125 & .27 & .68 & .43 \\
IJ126 & .29 & .41 &. $\mathbf{7 5}$ \\
IJ127 & .20 & .23 & $\mathbf{. 8 0}$ \\
IJ128 & .22 & .43 & $\mathbf{. 6 6}$ \\
IJ129 & .20 & .28 & $\mathbf{. 8 0}$ \\
IJ130 & .33 & .42 & $\mathbf{. 7 2}$ \\
IJ131 & .37 & .34 &. $\mathbf{7 6}$ \\
\hline Note: Factor solutions are suggested in boldface \\
\hline
\end{tabular}


Table 5.13: Factor Loadings for EFA Group 2

\begin{tabular}{lcc}
\hline & \multicolumn{2}{c}{ Factor } \\
& $(\%$ of Variance & Explained $)$ \\
\cline { 2 - 3 } & $(50.77 \%)$ & $(27.44 \%)$ \\
\hline FADO135 & .68 & .17 \\
FADO137 & .79 & .25 \\
FADO139 & .66 & .24 \\
FAD0140 &. $\mathbf{8 4}$ & .15 \\
FASO132 & .16 &. $\mathbf{8 3}$ \\
FASO134 & .18 & $\mathbf{. 8 4}$ \\
FASO136 & .55 & $\mathbf{. 5 8}$ \\
FASO138 &. $\mathbf{5 3}$ & $\mathbf{. 5 3}$ \\
\hline Note: Factor solutions are suggested in boldface.
\end{tabular}




\section{EFA Results for Group 3}

Group 3 consists of three opportunism-related constructs: Individual PFO, Relational PFO, and OB. The first two scales have been newly developed for the present study. Though each deals with propensity for opportunism, Individual PFO strictly deals with individual-specific attitudes, while Relational PFO is propensity specifically in the context of franchisor-franchisee relationship. Both PFO scales are also arguably related to OB, though, OB refers to the actual behavior. As discussed in Chapter Three, a franchisee may exhibit a high level of propensity for opportunism, yet s/he may be unable or unwilling to do so. In all, these three constructs possess distinct characteristics and they are expected to correlate low.

Both eigenvalues and scree plot suggest that three factors are present. Together cumulatively they explain $71.6 \%$ of total variance. Without any borderline loadings, Group 3 led to a clear-cut three factor solution, as shown in Table 5.14. All the items that were expected to load together did so on the same factor.

\section{EFA Results for Group 4}

All four extra-dyadic scales are included in Group 4. Three of them are lowerorder factors for Negative Professional Ethical Climate (Individualism, Corporate Rules, and Professional Codes of Ethics) and the other is Network Density. Conceptually, the first three constructs deal with franchisee network's ethical climate and are necessarily related. Though, the operationalization of the construct clearly suggests each has its own nuance of ethical climate and need not be correlated. Network Density is another extra- 
dyadic construct, and it relates to closeness of franchisee network. All four constructs are similar in that they all measure aspects of franchisee network that are essentially products of interactions among franchisees.

As shown in Table 5.15, the items for Network Density and Professional Codes of Ethics appeared to exhibit high levels of discriminant validity. They clearly converge on a distinct factor and do not at all load on another factor. At the same time, Individualism items (IN414 and IN415) belong to the same factor as Corporate Rules items (Factor 2). Item-total correlation coefficients were also varied from .69 and .74. A closer look at Table 5.15 reveals that Corporate Policy items do load moderately high on Factor 3 (.35 and .39), which suggest the two constructs are not completely identical. As shown in Table 5.16, item correlation coefficients were also much lower between items that are conceptually different (between Individualism items and Corporate Rules). That is, convergent correlations (.84 and .85) are much greater than discriminant correlations $(.47, .48, .54$, and .55$)$.

Finally, the correlation coefficient between these two scales is .51, and the results of Anderson and Gerbing's (1988) test of discriminant validity from the original CFA suggested that the scales should be treated as separate. Taken together, it is easy to see how norms of individualism may be highly related to prevalence of disobeying corporate rules, and one may argue that Individualism reflect the attitudes, while disobeying Corporate Rules are manifestations of the attitudes. After all, disobeying corporate rules can be said to be individualistic behaviors. Theoretically, these are two distinct constructs as Individualism deals with lack of cohesiveness within franchisee network, while the Corporate Rules construct strictly regards to patterns of behaviors among franchisees. 
Table 5.14: Factor Loadings for EFA Group 3

\begin{tabular}{|c|c|c|c|}
\hline & \multicolumn{3}{|c|}{$\begin{array}{c}\text { Factor } \\
\text { (\% of Variance Explained })\end{array}$} \\
\hline & $\begin{array}{c}1 \\
(34.07 \%)\end{array}$ & $\begin{array}{c}2 \\
(19.63 \%)\end{array}$ & $\begin{array}{c}3 \\
(17.88 \%)\end{array}$ \\
\hline PF0516 & .87 & .15 & .06 \\
\hline PF0517 & .93 & .12 & .08 \\
\hline PFO518 & .91 & .05 & .12 \\
\hline PFO519 & .84 & -.02 & .19 \\
\hline PF0520 & .93 & .10 & .06 \\
\hline IPFO601 & .14 & .02 & .78 \\
\hline IPFO602 & .05 & .18 & .81 \\
\hline IPFO603 & .15 & .09 & .85 \\
\hline OB205 & .11 & .76 & .23 \\
\hline OB212 & .10 & .71 & .10 \\
\hline OB214 & .02 & .78 & -.15 \\
\hline OB215 & .06 & .76 & .16 \\
\hline
\end{tabular}


In all, although statistically Individualism and Corporate Rules are indistinguishable, the issue is trivial for my subsequent hypothesis testing because these two scales, along with Professional Code of Ethics, are lower-order scales for higher-order formative scale.

\section{EFA Results for Common Factor (Harman's One-Factor Test)}

Finally, all first-order constructs were included in one exploratory factor analysis as composites in an effort to identify a possibility of the presence of general factor (i.e., common method). Harman's one-factor test examines the results of unrotated factor solution, and a substantial amount of common method variance is present if (1) a single factor solution emerges or (2) multiple-factor solutions but only one account for the majority of the covariances (Podsakoff and Organ 1986).

The results of unrotated principal components factor analysis revealed six factors with eigenvalues greater than one, which accounted for only $59.2 \%$ of total variance. The first factor also accounted for $22.5 \%$ of variance. As shown in Table 5.17, commonmethod variance does not appear to be a problem as several factors were identified. Each factor also has strong loadings, not just one factor.

\section{Summary}

This chapter described in detail the scale operationalizations, scale development, and measure validation procedures. The chapter was primarily organized into two: (1) operationalization and development of constructs and (2) measure validation for dyadic and extra-dyadic scales. 
Table 5.15: Factor Loadings for EFA Group 1

\begin{tabular}{lccc}
\hline & \multicolumn{3}{c}{ Factor } \\
& \multicolumn{3}{c}{$(\%$ of Variance Explained $)$} \\
\cline { 2 - 4 } & $(38.37 \%)$ & $(23.13 \%)$ & $(13.57 \%)$ \\
\hline IN414 & -.28 & .82 & .00 \\
IN415 & -.33 & .85 & .00 \\
CR406 & .01 & .78 & .39 \\
CR407 & .02 & .80 & .35 \\
PCE401 & -.17 & .14 &. $\mathbf{8 1}$ \\
PCE405 & -.09 & .21 & .82 \\
ND404 & .80 & .04 & -.10 \\
ND410 & .74 & -.28 & -.13 \\
ND419 & .86 & -.18 & -.02 \\
ND417 & .90 & -.13 & -.07 \\
ND418 & .90 & -.12 & -.11 \\
ND408 & .93 & -.13 & -.08 \\
\hline Note: Factor solutions are suggested in boldface. \\
\hline
\end{tabular}


Table 5.16: Inter-Item Correlation between Individualism and Corporate

\begin{tabular}{|c|c|c|c|c|}
\hline \multicolumn{5}{|c|}{ Rules } \\
\hline & IN414 & IN415 & CR406 & CR407 \\
\hline IN414 & 1.00 & & & \\
\hline IN415 & $.84 * *$ & 1.00 & & \\
\hline CR406 & $.47 * *$ & $.54 * *$ & 1.00 & \\
\hline CR407 & $.48 * *$ & $.55 * *$ & $.85 * *$ & 1.00 \\
\hline Note: $* *=$ & & & & \\
\hline
\end{tabular}


Table 5.17: Harman's One Factor Test Results

\begin{tabular}{|c|c|c|c|c|c|c|}
\hline & & & & OR & & \\
\hline & 1 & 2 & 3 & 4 & 5 & 6 \\
\hline RDR & .07 & .25 & -.05 & .71 & -.05 & -.07 \\
\hline RMI & .19 & .29 & -.13 & .53 & .03 & .27 \\
\hline DJ & .70 & .18 & .35 & .08 & .06 & .01 \\
\hline PJ & .79 & .02 & .38 & -.05 & .04 & -.10 \\
\hline IJ & .77 & -.17 & .37 & -.01 & .08 & -.02 \\
\hline FADO & .33 & .55 & -.12 & .11 & -.29 & -.46 \\
\hline FASO & .13 & .63 & -.24 & .08 & -.41 & -.36 \\
\hline EDR & .41 & .52 & -.35 & -.15 & .21 & .15 \\
\hline EMI & .54 & .47 & -.25 & -.32 & .19 & .08 \\
\hline ETSI & .26 & .35 & -.31 & -.27 & -.13 & .42 \\
\hline $\mathrm{EC}$ & .67 & .31 & -.30 & -.20 & .17 & .07 \\
\hline COEM & -.69 & .34 & -.10 & .05 & -.15 & -.04 \\
\hline PFO & -.23 & .42 & .05 & .13 & .04 & .35 \\
\hline $\mathrm{OB}$ & -.25 & .30 & .42 & .03 & .32 & .10 \\
\hline IN & -.68 & .25 & -.11 & -.04 & .16 & .11 \\
\hline $\mathrm{CR}$ & -.56 & .31 & .04 & -.04 & .39 & .06 \\
\hline PCE & -.47 & .20 & .06 & .30 & .40 & -.08 \\
\hline ND & .64 & .13 & .21 & -.03 & .19 & .09 \\
\hline RTSI & .59 & .31 & .24 & .38 & .02 & .04 \\
\hline EBOB & -.43 & .53 & .05 & -.07 & -.03 & -.06 \\
\hline IPFO & -.31 & .31 & .56 & -.01 & -.21 & .08 \\
\hline CMD & .04 & -.09 & .06 & -.06 & -.59 & .45 \\
\hline $\begin{array}{l}\text { External Locus of } \\
\text { Control }\end{array}$ & -.15 & .31 & .34 & -.16 & -.20 & .33 \\
\hline Machiavellianism & -.32 & .39 & .49 & -.24 & -.14 & -.04 \\
\hline Social Desirability & .14 & -.30 & -.20 & .44 & -.08 & .44 \\
\hline
\end{tabular}


In scale development, although many of the factors had already had wellestablished scales, most went through rigorous steps of scale development. Modifying and developing scales first involved domain sampling (Churchill 1979), establishing an operationalization of construct and generating sample of measurement items that tap the domain. Several steps of pre-tests followed, some of which were described in Chapter Four.

After data normality check, measure validation involved both Confirmatory Factor Analysis (CFA) and Exploratory Factor Analysis (EFA). CFA was done at the scale-level, while EFA involved item-level analyses to give a full picture of my data's psychometric properties. Due to small sample size, both CFA and EFA were done in groups of constructs, which is a common practice in leading marketing journals. To maximize the benefit of analyses, the groups were created in a meaningful manner: dyadic, extra-dyadic groups, which were further divided into franchisee's reporting on themselves and reporting on their franchisors. The results from CFA led to deletion of several measurement items for their insufficient factor loadings and/or convergent validity to their respective factor. After deletions of these items, all factors exhibited acceptable composite reliability and AVE. Discriminant validity was also checked using both Fornell and Larcker's (1981) and Anderson and Gerbing's (1988) tests. Although some scales did not pass Fornell and Larcker's test, all scales passed those of Anderson and Gerbing's. Overall model fit was also examined for each group of constructs exhibited acceptable model fit. Table 5.18 shows correlation matrix for all first-order factor. Scales with very high correlation $(\mathrm{p}>.60)$ were already included in CFA together to test for discriminant validity tests. 
The EFA results suggest that all the measurement items do not cross-load sufficiently to be alarming. These items with moderate cross-loadings belonged to the same higher-order formative scale, which minimize the concern for lack of discriminant validity. Lastly, Harman's one factor test revealed a common method bias should not be an issue as several factors were identified, and each factor had strong loadings. Due to my large number of items and small sample size, I could not employ more traditional common method bias tests, such as those suggested by Cote and Buckley (1987); nonetheless, I took steps in minimizing social desirability bias, one of the largest sources of common method bias, by directly measuring it and including it in my hypothesis testing. Although this method does not tap the whole common methods variance domain, it is still an effective way to partial out a general method factor.

In all, the rigorous steps taken to operationalize, develop, and purify scales led to a dataset sufficiently adequate to test our hypotheses. 
Table 5.18: Correlation Matrix for All First-Order Scales

\begin{tabular}{|c|c|c|c|c|c|c|c|c|c|c|c|c|c|c|c|c|c|c|c|c|c|}
\hline & 1 & 2 & 3 & 4 & 5 & 6 & 7 & 8 & 9 & 10 & 11 & 12 & 13 & 14 & 15 & 16 & 17 & 18 & 19 & 20 & 21 \\
\hline 1. RDR & 1.00 & & & & & & & & & & & & & & & & & & & & \\
\hline 2. RMI & .27 & 1.00 & & & & & & & & & & & & & & & & & & & \\
\hline 3. DJ & .05 & .22 & 1.00 & & & & & & & & & & & & & & & & & & \\
\hline 4. $\mathrm{PJ}$ & .03 & .04 & .62 & 1.00 & & & & & & & & & & & & & & & & & \\
\hline $5 . \mathrm{IJ}$ & .01 & .10 & .62 & .78 & 1.00 & & & & & & & & & & & & & & & & \\
\hline 6. FADO & .16 & .17 & .25 & .26 & .14 & 1.00 & & & & & & & & & & & & & & & \\
\hline 7. FASO & .19 & .15 & .12 & .06 & -.13 & .63 & 1.00 & & & & & & & & & & & & & & \\
\hline 8. EDR & .10 & .21 & .26 & .17 & .12 & .27 & .30 & 1.00 & & & & & & & & & & & & & \\
\hline 9. EMI & -.03 & .13 & .33 & .34 & .25 & .33 & .25 & .64 & 1.00 & & & & & & & & & & & & \\
\hline 10. ETSI & -.03 & .09 & .05 & .13 & .06 & .16 & .22 & .35 & .33 & 1.00 & & & & & & & & & & & \\
\hline 11. EC & .01 & .17 & .43 & .40 & .38 & .30 & .20 & .50 & .69 & .34 & 1.00 & & & & & & & & & & \\
\hline 12.COEM & .09 & -.03 & -.42 & -.52 & -.62 & .03 & .16 & -.11 & -.22 & -.02 & -.32 & 1.00 & & & & & & & & & \\
\hline 13. PFO & .07 & .11 & -.06 & -.20 & -.27 & .05 & .11 & .13 & -.03 & .12 & -.05 & .16 & 1.00 & & & & & & & & \\
\hline 14. OB & -.05 & .04 & .03 & -.09 & -.12 & -.05 & -.01 & .01 & -.04 & -.07 & -.17 & .20 & .20 & 1.00 & & & & & & & \\
\hline 15. IN & -.02 & .05 & -.41 & -.50 & -.49 & -.13 & -.01 & -.12 & -.22 & -.03 & -.22 & .52 & .25 & .18 & 1.00 & & & & & & \\
\hline 16. CR & .02 & .01 & -.31 & -.33 & -.39 & -.16 & -.02 & -.08 & -.07 & .00 & -.23 & .39 & .17 & .21 & .51 & 1.00 & & & & & \\
\hline 17. PCE & .12 & -.03 & -.20 & -.28 & -.35 & -.03 & -.01 & -.08 & -.13 & -.21 & -.31 & .31 & .20 & .29 & .30 & .43 & 1.00 & & & & \\
\hline 18. ND & .11 & .06 & .47 & .59 & .46 & .14 & .03 & .27 & .35 & .21 & .42 & -.40 & .00 & -.06 & -.44 & -.19 & -.24 & 1.00 & & & \\
\hline 19. RTSI & .31 & .30 & .52 & .51 & .41 & .32 & .20 & .22 & .29 & .15 & .37 & -.29 & .06 & .07 & -.35 & .20 & -.11 & .37 & 1.00 & & \\
\hline 20.EBOB & .10 & -.03 & -.13 & -.33 & -.40 & .09 & .25 & -.01 & .03 & .02 & -.08 & .37 & .28 & .20 & .30 & .42 & .25 & -.14 & -.14 & 1.00 & \\
\hline 21. IPFO & .05 & -.06 & -.04 & -.08 & -.09 & .02 & .06 & -.16 & -.14 & -.08 & -.23 & .29 & .25 & .22 & .21 & .25 & .10 & -.02 & .00 & .29 & 1.00 \\
\hline
\end{tabular}




\section{CHAPTER VI}

\section{STRUCTURAL MODEL TEST}

This chapter primarily focuses on a discussion of empirical results of the hypothesized model described in Chapter Three. The results for an alternative model (discussed in Chapter Five), which arose during the time between dissertation proposal and data collection, are also discussed in this chapter. The variable acronyms and abbreviations are listed in Table 6.1. The correlation and descriptive statistics (mean and standard deviation) are shown in Table 6.2.

\section{Hypothesized Model}

\section{Model Specification}

The hypothesized model depicted in Figure 6.1 was tested using maximum likelihood estimation structural path analysis with AMOS 7.0. In the model, there were seventeen exogenous variables, including two moderator variables and two interaction (multiplicative) variables and six control variables. Structural path analyses are superior to traditional multiple regression analyses as (1) multiple dependent variables may be analyzed simultaneously and (2) exogenous variables may be allowed to correlate among themselves. Structural path analysis was chosen because in this research model there are two dependent variables (PFO and $\mathrm{OB}$ ), and many of the exogenous variables do correlate moderately. I hypothesized Network Density (ND) and Disciplinary Monitoring (DM) to be moderators, while CMD was hypothesized to be both predictor of PFO and a moderator (moderating the effects of Negative Professional Ethical Climate, NPEC on 
TABLE 6.1: Variable Acronyms and Abbreviations

\begin{tabular}{|l|l|}
\hline AGE & Age of Relationship \\
\hline CMD & Cognitive Moral Development \\
\hline COEM & Crowding Out Effects of Monitoring \\
\hline DJ & Distributive Justice \\
\hline DM & Disciplinary Monitoring \\
\hline EBOB & Economic Benefits of OB \\
\hline EC & Economies of Continuation \\
\hline ELC & External Locus of Control \\
\hline ETSI & Franchisee TSIs \\
\hline FOOD & Food Industry (dummy-coded) \\
\hline GAR & $\begin{array}{l}\text { General Printing, Auto Repair, or } \\
\text { Residential/Commercial Services Industries } \\
\text { (dummy-coded) }\end{array}$ \\
\hline IDM & Interdependence Magnitude \\
\hline IDA & Interdependence Asymmetry \\
\hline IJ & Interactional Justice \\
\hline IPFO & Individual PFO \\
\hline MACH & Machiavellianism \\
\hline ND & Network Density \\
\hline NPEC & Negative Professional Ethical Climate \\
\hline PJ & Procedural Justice \\
\hline RPFO & Relational PFO \\
\hline RTSI & Franchisor TSIs \\
\hline SD & Social Desirability \\
\hline
\end{tabular}


Figure 6.1: Structural Model

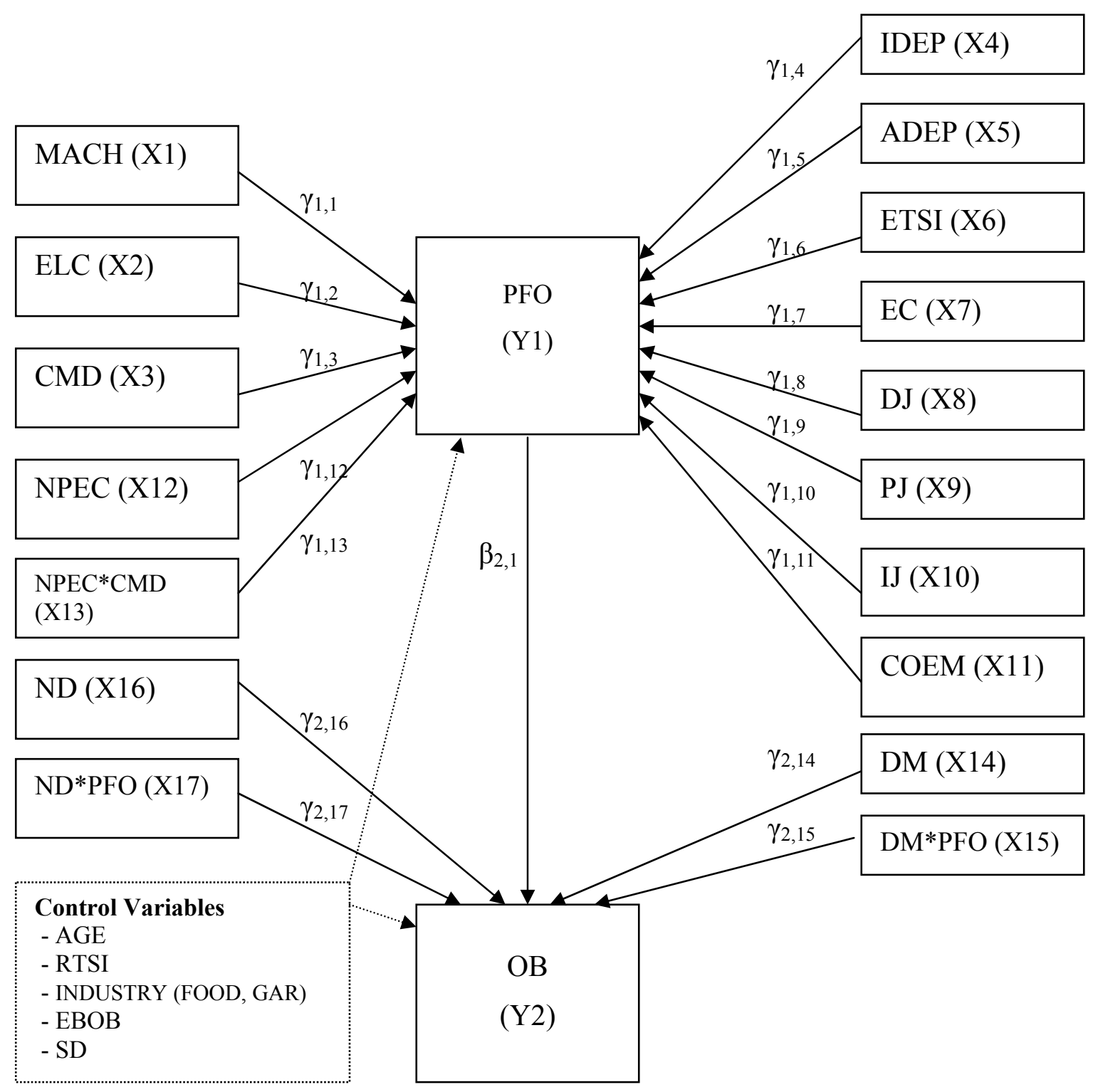


PFO). We note that all interaction terms of the moderator variables have been meancentered in order to control for biased estimations due to multicollinearity (Aiken and West 1991). The procedure requires subtracting the overall variable mean from each observation, then multiplying the values of the predictor variables by the values for the hypothesized moderators. The process resulted in three such variables: CMD*NPEC, $\mathrm{ND} * \mathrm{PFO}$, and $\mathrm{DM} * \mathrm{PFO}$. To determine whether there is a significant interaction, the criterion variables in this study (i.e., OB and PFO) were simultaneously regressed on the predictor variables and the interaction terms.

To run structural path analyses, composite variables were created for each construct that was measured by multiple items. They were then first subjected to normality checks, and as necessary non-normally distributed data were log-transformed to alleviate the normality assumption of ML estimation. These variables were OB, NPEC, Crowding Out Effects of Monitoring (COEM), AGE, and PFO. The interaction terms tend to be non-normally distributed, and a data normality check revealed that CMD*NPEC interaction term non-normality. Because the mean-centered interaction terms involve negative values, log-transformation was not possible. I further addressed the issue of non-normally distributed items by applying and comparing bootstrap estimation results. The detailed procedure is discussed at the end of this section.

The model includes age of relationships (AGE), Economic Benefits of OB (EBOB), Franchisor TSIs (RTSI), and Social Desirability (SD) as control variables. The eight franchising industry categories described in Chapter Four were further narrowed down to three groups: (1) FOOD, (2) GAR (General Printing, Auto repair/Maintenance, and Residential/Commercial Services), and (3) PPRL (Personal Services, Professional 
Table 6.2: Descriptive Statistics and Correlations

\begin{tabular}{|c|c|c|c|c|c|c|c|c|c|c|c|c|c|c|c|c|c|c|c|c|c|}
\hline & 1 & 2 & 3 & 4 & 5 & 6 & 7 & 8 & 9 & 10 & 11 & 12 & 13 & 14 & 15 & 16 & 17 & 18 & 19 & 20 & 21 \\
\hline 1. MACH & 1.00 & & & & & & & & & & & & & & & & & & & & \\
\hline 2. ELC & .29 & 1.00 & & & & & & & & & & & & & & & & & & & \\
\hline 3. CMD & -.04 & .12 & 1.00 & & & & & & & & & & & & & & & & & & \\
\hline 4. NPEC & .24 & .16 & -.17 & 1.00 & & & & & & & & & & & & & & & & & \\
\hline 5. DJ & -.07 & .05 & .04 & -.41 & 1.00 & & & & & & & & & & & & & & & & \\
\hline 6. PJ & -.05 & -.03 & .02 & -.48 & .62 & 1.00 & & & & & & & & & & & & & & & \\
\hline 7. IJ & -.16 & -.06 & .01 & -.52 & .62 & .78 & 1.00 & & & & & & & & & & & & & & \\
\hline 8. COEM & .31 & .20 & -.04 & .53 & -.42 & -.52 & -.62 & 1.00 & & & & & & & & & & & & & \\
\hline 9. IDEP & -.07 & .01 & -.03 & -.10 & .33 & .23 & .18 & -.11 & 1.00 & & & & & & & & & & & & \\
\hline 10. ADEP & -.01 & .06 & -.04 & -.16 & .14 & .19 & .12 & -.17 & .12 & 1.00 & & & & & & & & & & & \\
\hline 11. ETSI & -.02 & .08 & .10 & -.08 & .05 & .13 & .06 & -.02 & .29 & .28 & 1.00 & & & & & & & & & & \\
\hline 12. EC & -.21 & -.10 & -.06 & -.32 & .43 & .40 & .38 & -.32 & .53 & .45 & .34 & 1.00 & & & & & & & & & \\
\hline 13. DM & .08 & .04 & -.05 & -.09 & .19 & .16 & -.02 & .13 & .36 & .11 & .21 & .26 & 1.00 & & & & & & & & \\
\hline 14. ND & -.10 & -.04 & -.06 & -.37 & .47 & .59 & .46 & -.40 & .31 & .20 & .21 & .42 & .06 & 1.00 & & & & & & & \\
\hline 15. IPFO & .43 & .24 & .06 & .24 & -.04 & -.08 & -.09 & .29 & -.12 & -.13 & -.08 & -.23 & .01 & -.02 & 1.00 & & & & & & \\
\hline 16. RPFO & .14 & .10 & .04 & .26 & -.06 & -.20 & -.27 & .16 & .11 & -.04 & .12 & -.05 & .06 & -.00 & .25 & 1.00 & & & & & \\
\hline 17. OB & .29 & .16 & -.08 & .28 & .03 & -.09 & -.12 & .20 & -.02 & -.01 & -.07 & -.17 & -.06 & -.06 & .22 & .20 & 1.00 & & & & \\
\hline 18. AGE & -.04 & -.06 & -.06 & -.05 & -.08 & -.02 & -.06 & -.01 & -.20 & -.05 & -.15 & -.07 & .01 & .01 & -.06 & -.17 & -.01 & 1.00 & & & \\
\hline 19. RTSI & -.04 & .04 & -.01 & -.29 & .52 & .51 & .41 & -.29 & .43 & -.05 & .15 & .37 & .25 & .37 & .00 & .06 & .07 & -.08 & 1.00 & & \\
\hline 20. EBOB & .32 & .19 & -.02 & .42 & -.13 & -.33 & -.40 & .37 & .04 & -.02 & .02 & -.08 & .16 & -.14 & .29 & .28 & .20 & -.10 & -.14 & 1.00 & \\
\hline 21. SD & -.27 & -.04 & .06 & -.17 & .00 & -.02 & .08 & -.10 & .05 & -.19 & .06 & .03 & -.14 & .05 & -.12 & -.06 & -.14 & -.05 & .07 & -.22 & 1.00 \\
\hline Mean & 22.24 & 1.69 & 30.79 & 3.32 & 3.57 & 4.14 & 4.58 & 2.63 & 4.17 & 1.66 & 4.96 & 5.04 & 23.01 & 4.60 & 2.69 & 3.01 & 2.43 & 8.98 & 3.13 & 3.27 & 6.29 \\
\hline Std. Dev. & 14.70 & 1.67 & 17.06 & 1.24 & 1.84 & 1.64 & 1.54 & 1.36 & 1.17 & 4.04 & 1.63 & 1.81 & 11.14 & 1.53 & 1.31 & 1.84 & 1.26 & 7.89 & 1.55 & 1.55 & 2.62 \\
\hline
\end{tabular}


Services, Retailing, and Lodging). The grouping decision was based on prior knowledge of similarities and differences in the nature of franchisor-franchisee relationships, such as the knowledge gained from the pretest interviews. These three groups seemed to differ greatly in terms of the amount of supervisions by franchisors, the nature of contracts, the nature of investment, and overall relationship characteristics. These are relationship characteristics that are not explicitly measured in this research, and their systematic differences should be controlled. Together, these control variables were included in the analysis in order to partial out any effects of these variables on structural paths in the model. The theoretical justifications for the inclusions of these variables were provided in Chapter Five.

Lastly, as I noted in Chapter Four, I employed the simple data-imputation method in which I substituted item means for missing responses if a respondent omitted one item on a short scale (three- and four-items) and two items on a longer scale (five or more items). If more items were missed, they were simply left alone as missing values. After mean-substitution, there were still a few missing cases in the dataset, with PFO being the highest ten missing cases. With CMD, there were 31 missing values, and meansubstitution could not be employed. This was particularly troubling, as list-wise deletions would result in dropping too many cases from an already small sample size.

Rather than list-wise deletion, I employed the Expectation Maximization (EM) algorithm (Little 1983; Jamshidian and Jenrich 1994; Jamshidian and Bentler 1999) to estimate and fill in expectations of missing values of CMD using EQS. The estimated missing values are not to be taken for face value (or used in descriptive statistics); in other words, they are only filled in order to facilitate data program to handle incomplete 
data just as if there were no missing data. Hence, this case-wise ML estimation allows a statistical package (such as AMOS and EQS) to handle incomplete data without list-wise deletions.

The mathematical treatment of EM imputation is provided by Little (1983).

Studies have shown the EM missing data handling procedure to be a robust approach to handling missing data, providing less biased estimates than list-wise deletion (Graham and Donaldson 1993), and more accurate estimates than mean-substitution (Azen, Van Guilder, and Hill 1989). Jamshidian and Bentler (1999) also support the use of EM by directly comparing the estimates using three artificial datasets (i.e., three types of missing data) that are missing completely at random (MCAR), missing at random (MAR), and neither MCAR nor MAR.

\section{Structural Path Equations}

The overall structural path model is shown in Figure 6.1. The hypothesized paths in the model can be summarized in the following regression equations. Gammas $(\gamma)$ refer to the paths or structural coefficients in the regression of endogeneous on exogenous variables, and betas $(\beta)$ are the structural coefficients in the regression of endogenous on other endogenous variables.

The hypothesized model implies the following regression equations, and with a structural path analysis I estimate these equations simultaneously using maximum likelihood estimation: 


$$
\left.\begin{array}{rl}
\mathbf{P F O}= & \alpha_{1}+\gamma \mathrm{MACH}+\gamma \mathrm{ELC}+\gamma \mathrm{CMD}+\gamma \mathrm{IDEP}+\gamma \mathrm{ADEP}+\gamma \mathrm{ETSI}+\gamma \mathrm{EC}+\gamma \mathrm{DJ} \\
& +\gamma \mathrm{PJ}+\gamma \mathrm{COEM}+\gamma \mathrm{NPEC}+\gamma \mathrm{CMD} * \mathrm{NPEC} \\
& +\gamma \mathrm{AGE}+\gamma \mathrm{RTSI}+\gamma \mathrm{EBOB}+\gamma \mathrm{SD}+\gamma \mathrm{FOOD}+\gamma \mathrm{GAR} \\
\mathbf{O B}= & \alpha_{2}+\beta \mathrm{PFO}+\gamma \mathrm{ND}+\gamma \mathrm{DM}+\gamma \mathrm{PFO} * \mathrm{ND}+\gamma \mathrm{PFO} * \mathrm{DM} \\
& +\gamma \mathrm{AGE}+\gamma \mathrm{RTSI}+\gamma \mathrm{EBOB}+\gamma \mathrm{SD}+\gamma \mathrm{FOOD}+\gamma \mathrm{GAR}
\end{array}\right\} \begin{aligned}
& \text { CONTROL } \\
& \mathrm{VAR} .
\end{aligned}
$$

\section{Overall Model Fit}

Overall model fit was evaluated using criteria described in the previous chapter (Table 5.3). The model Chi-square value was significant $(\mathrm{p}=.07)$, as the cutoff recommended by Bagozzi and Yi (1988) is $>.05$. Relative chi-square was also within the recommended value $(\mathrm{CMIN} / \mathrm{DF}=1.20) . \mathrm{NNFI}, \mathrm{CFI}$, and IFI were all above the recommended .90 (Bagozzi and Yi 1988). Although NFI was slightly below the recommended .90 , it is still adequate for a small sample (Ullman 2000). RMSEA was significantly low $\{.04, \mathrm{p}($ close $)=.89\}$. In all, the fit indices suggest that the model fits well.

\section{Results}

In the following section, maximum likelihood (ML) estimations of the hypothesized path coefficients are discussed. Table 6.3 shows the aggregated results.

\section{Determinants of PFO: Individual Level}

Hypotheses one through thirteen dealt with the determinants of PFO. PFO generally refers to the extent to which franchisees are inclined to behave opportunistically 
against their franchisors, and in the survey franchisees rated their propensity (willing, motivated, tempted, provoked, and compelled) to behave opportunistically, specifically against their franchisors. $\mathrm{H}_{1}, \mathrm{H}_{2}$, and $\mathrm{H}_{3}$ specifically concerned with franchisees' individual traits, namely, Machiavellianism $\left(\mathrm{MACH} ; \mathrm{H}_{1}\right)$, External Locus of Control (ELC; $\mathrm{H}_{3}$ ), and Cognitive Moral Development (CMD; $\mathrm{H}_{3}$ ). Higher levels of MACH and ELC were posited to be related to higher levels of PFO. Individuals with higher levels of CMD were expected to exhibit lower levels of PFO. As shown in Table 6.3, none of these variables were related to PFO: MACH $\left(\gamma_{1,1}=.06, \mathrm{p}=.45\right)$, ELC $\left(\gamma_{1,2}=.02, \mathrm{p}=.76\right)$, and $\operatorname{CMD}\left(\gamma_{1,3}=.00, \mathrm{p}=.99\right)$.

\section{Determinants of PFO: Dyadic Level}

Hypotheses four through ten focused on dyadic-level characteristics' impact on PFO. $\mathrm{H}_{4}$ through $\mathrm{H}_{7}$ were developed based on a rational-actor framework (i.e., TCE and agency theory), and the relationship structures covered were Interdependence (IDEP; $\mathrm{H}_{4}$ ), Asymmetric Dependence (ADEP; $\mathrm{H}_{5}$ ), Franchisee TSIs (ETSI; $\mathrm{H}_{6}$ ), and Economies of Continuation $\left(\mathrm{EC} ; \mathrm{H}_{7}\right)$. It was generally posited that lower levels of propensity for opportunism would be present when franchisees have much to lose. Thus, highly dependent franchisees, as reflected in overall dependence $\left(\mathrm{H}_{4}\right)$ or asymmetric dependence $\left(\mathrm{H}_{5}\right)$, would incur less desire to engage in OB. However, the results show that neither variable contributes significantly to PFO: $\operatorname{IDEP}\left(\gamma_{1,4}=-.05, \mathrm{p}=.56\right)$ and $\operatorname{ADEP}\left(\gamma_{1,5}=-.07\right.$, $\mathrm{p}=.41)$

Similarly, neither ETSI $\left(\mathrm{H}_{6}\right)$ nor EC $\left(\mathrm{H}_{7}\right)$ was significantly related to PFO $\left(\gamma_{1,6}\right.$ $=.13, \mathrm{p}=.25$ and $\gamma_{1,7}=-.01, \mathrm{p}=.91$, respectively). Although I hypothesized that franchisees 
who encountered higher levels of TSIs would be likely to desire higher returns on their investment (hence exhibiting higher PFO), this was not the case. For EC, it was posited that those with a "shadow of future" (Heide and Miner 1992) would exhibit lower levels of PFO. Again, this path was found to be non-significant.

Hypotheses eight through eleven were inspired by the bounded morality framework described in Chapter Three, and the premise of this framework was that franchisees, rather than focusing on maximizing their own wealth whenever possible, instead are influenced by the degree of reciprocation and fairness in their relationship with their franchisors. I hypothesized that three types of fairness perceptions lessen franchisees' levels of PFO; namely, Distributive Justice (DJ; $\mathrm{H}_{8}$ ), Procedural Justice (PJ; $\mathrm{H}_{9}$ ), and Interactional Justice (IJ; $\left.\mathrm{H}_{10}\right)$. In addition, Crowding Out Effects of Monitoring (COEM: $\mathrm{H}_{11}$ ) was also expected to increase one's PFO. Of these, I did not find support for $\mathrm{H}_{8}, \mathrm{H}_{9}$, or $\mathrm{H}_{11}$ : DJ $\left(\gamma_{1,8}=.11, \mathrm{p}=.23\right), \mathrm{PJ}\left(\gamma_{1,9}=.07, \mathrm{p}=.52\right)$, and $\operatorname{COEM}\left(\gamma_{1,11}=-.07\right.$, $\mathrm{p}=.49)$. However, it was found that IJ was a significant predictor of PFO $\left(\gamma_{1,10}=-.26\right.$, $\mathrm{p}=.04)$. The results suggest that the more franchisees perceive that their franchisors interact with them with respect, kindness, and truthfulness, the lower their levels of PFO are.

\section{Determinants of PFO: Extra-Dyadic Level}

At the extra-dyadic level of analysis, I hypothesized that higher levels of Negative Professional Ethical Climate (NPEC; $\mathrm{H}_{12}$ ) would indicate higher levels of franchisee PFO. As expected, the path was significant $\left(\gamma_{1,12}=.17, \mathrm{p}=.06\right)$, though somewhat marginal. The results suggest that those franchisees in the negative professional 
environment (individualistic rather than collective, lack of respect for corporate policies and/or professional codes) are more likely to exhibit higher levels of PFO.

I also hypothesized that NPEC's impact on PFO was moderated by CMD, the level of cognitive moral development, in $\mathrm{H}_{13}$. Specifically, I posited that as franchisees' CMD scores increase, the magnitude of the positive effects of a negative professional ethical climate on PFO would be reduced. The results indicated that this was not the case. In other words, NPEC's positive effects on PFO are not moderated by franchisees' CMD $\left(\gamma_{1,13}=-.02, \mathrm{p}=.55\right)$.

\section{Determinants of $\mathrm{OB}$}

OB generally refers to franchisees' guileful behaviors that unilaterally improve the party's term of trade. In the survey, franchisees rated their actual opportunistic behaviors in terms of noncompliance to explicit contract terms and informally agreed upon terms, as well as giving empty excuses. Hypotheses fourteen through sixteen deal with the determinants of OB. The premise of the conceptual model was that PFO and OB are positively related, and that the actual occurrence of $\mathrm{OB}$ is moderated by several factors (i.e., constraints) that reflect both the social and the economic costs of OB.

$\mathrm{H}_{14}$ posited that $\mathrm{PFO}$ has positive effects on $\mathrm{OB}$. Indeed, support was found for this hypothesis $\left(\beta_{2,1}=.16, \mathrm{p}=.04\right)$. The results indicate that as franchisees exhibit higher levels of PFO, they are more likely to engage in opportunistic behaviors. I did not find support for either $\mathrm{H}_{15}$ or $\mathrm{H}_{16}$, while both dealt with interactions. I hypothesized in $\mathrm{H}_{15}$ that Disciplinary Monitoring (DM) would both directly influence OB and also reduce the positive effects of $\mathrm{PFO}$ on $\mathrm{OB}$. The predicted interaction was not significant, but, the 
results do show that DM is a predictor of $\mathrm{OB}$ by itself $\left(\gamma_{2,14}=-.20, \mathrm{p}=.02\right)$. This finding suggests that DM directly reduces one's level of $\mathrm{OB}$, and DM does not interact with $\mathrm{PFO}$ $\left(\gamma_{1,2}=.03, p=.67\right)$.

$\mathrm{H}_{16}$ posited that Network Density (ND) would interact with PFO, such that Network density reduces the magnitude of positive effects between PFO and OB. There was no support for this hypothesis $\left(\gamma_{2,17}=.00, \mathrm{p}=.98\right)$, nor did ND alone contributed to OB $\left(\gamma_{2,16}=-.06, p=.47\right)$.

\section{The Effect of Control Variables}

As described previously, a total of six control variables were included in the model. Of these, two (FOOD, GAR) were dummy-coded as they represent industry categories. No hypotheses were pre-specified as the main objectives were to determine the impact of focal predictor variables on the dependent variables while partialing out effects of the control variables. Nonetheless, the results suggest an interesting pattern which is worth noting. Age of relationship (AGE) was negatively related to PFO $(\gamma=-.14$, $\mathrm{p}=.05$ ), indicating that a lower level of PFO may be expected for a longer relationship. The dummy-coded FOOD $(\gamma=.19, \mathrm{p}=.04)$ indicates that those franchisees in the food industry exhibit a slightly higher level of PFO than the franchisees in the other two industries. Both Franchisor's TSIs (RTSI) and Economic Benefits of OB (EBOB) were found to be positively related to $\mathrm{OB}(\gamma=.18, \mathrm{p}=.04$ and $\gamma=.13, \mathrm{p}=.04$, respectively $)$. I wanted to partial out the effects of $\mathrm{EBOB} \rightarrow \mathrm{OB}$ in determining the impact of the focal predictors on $\mathrm{OB}$. As expected, $\mathrm{EBOB}$ does have a significant effect on $\mathrm{OB}$, such that the more economically beneficial it is to engage in $\mathrm{OB}$, the more likely that the franchisee 
will engage in OB. This was an important control variable as I wanted to discern nonopportunistic franchisees from the franchisees who don't behave opportunistically simply because doing so do not lead to economic benefits. The finding of the positive effects of RTSI on OB is in line with the extant literature, as Ghosh and John (1999, P.134) call transaction-specific investments "valuable but vulnerable" because of the possibility of being expropriated.

\section{Mediation Test Results}

As I conceptualized the research model such a way that PFO mediates the relationships between exogenous variables and $\mathrm{OB}$, it was necessary to test for mediation. I tested the degree to which PFO mediated the influence of IJ and NPEC (two significant variables from hypotheses test) on OB by using the three-step method recommended by Barron and Kenny (1988).

Three separate structural path models were created for the mediation test. The first model linked exogenous variables (IJ and NPEC) directly to OB, the criterion variable. After confirming that the paths are positive and significant, the second model linking the exogenous variables to mediator variable (i.e., PFO) was tested and again I confirmed the significant association between the two. The last model included both the exogenous variables and the mediator variable as exogenous variable linked directly to the criterion variable. Here I confirmed positive and significant association between the mediator variables and the criterion variable $\left(\gamma_{\mathrm{PFO}, \mathrm{OB}}=.12\right)$. NPEC's effect on the criterion reduced slightly to $\gamma_{\mathrm{NPEC}, \mathrm{OB}}=.22$ from $\gamma_{\mathrm{NPEC}, \mathrm{OB}}=.25$ when $\mathrm{PFO}$ was present. IJ's effect on OB disappeared $\left(\gamma_{\mathrm{IJ}, \mathrm{OB}}=-.03\right)$. These results suggest that the influence of IJ on 
OB is fully mediated by PFO, and that of NPEC on OB is only partially mediated by PFO.

\section{A Comparison with Bootstrapping Results}

Small sample sizes often lead to limited power to reject the null hypothesis (Type II error). A Bootstrapping procedure (Efron 1979) has been frequently used in the marketing literature (e.g., Bone, Sharma, and Shimp 1989; Inman and McAlister 1993; Van Trijp, Hoyer, and Inman 1996; Brown, Homer, and Inman 1998; Subin and Workman 2004; Hennig-Thurau, Houston, and Walsh 2006), and it has been found useful in overcoming this type of issue. In addition, the research model includes interaction terms to test moderators, which tend to be multivariate non-normal, and the lack of distributional assumptions makes bootstrapping suitable (Yuan, Chan, and Bentler 2000). When data normality was checked, all variables including interaction terms exhibited skewness within one, indicating skewness was not an issue. Similar results were found for kurtosis, except the CMD*NPEC interaction term exhibited kurtosis of 3.56, which is above recommended by Hutcheson and Sofroniou (1999) that kurtosis be within -2 to +2 range.

Hence I took additional steps to ensure that the estimations are not biased due to small size and/or multivariate non-normality. With a bootstrap re-sampling procedure, the input dataset is assumed to be the total population of responses and the bootstrap program draws samples, with replacement, of size $\mathrm{N}$ from this pseudo-population repeatedly. 2000 bootstrap samples were used, for which the means serve as a proxy for the sampling 
Table 6.4 Summary of Research Hypotheses Results

\section{Hypothesis}

Empirical

support?

$\mathbf{H}_{1} \quad$ Managers with higher Machiavellianism exhibit higher levels of PFO...

No

$\mathbf{H}_{2}$ Managers with an external locus of control are more likely to exhibit higher levels of PFO than their internal counterparts.

No

$\mathbf{H}_{3} \quad \mathrm{CMD}$ and $\mathrm{PFO}$ are negatively related, such that as mangers exhibit more advanced CMD, the magnitude of PFO decreases.

No

$\mathbf{H}_{4} \quad$ Managers exhibit lower levels of PFO as interdependence magnitude grows larger....

$\mathbf{H}_{5} \quad$ Managers exhibit lower levels of PFO as interdependence asymmetry favoring their partner firms grows larger.

$\mathbf{H}_{6} \quad$ Managers exhibit higher levels of PFO when they have invested higher levels of TSIs......

$\mathbf{H}_{7} \quad$ Managers exhibit lower levels of PFO when their perceptions of economies of

continuation with the same exchange partners are higher.

No

No

No

No

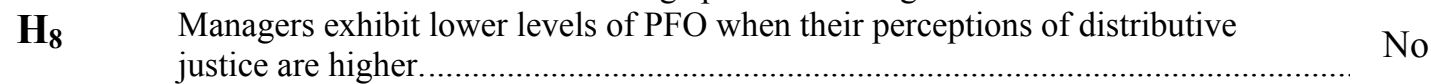

$\mathbf{H}_{9} \quad$ Managers exhibit lower levels of PFO when their perceptions of procedural justice are higher.

No

$\mathbf{H}_{10}$ Managers exhibit lower levels of PFO when their perceptions of interactional justice are higher.

Yes

$\mathbf{H}_{11}$ Managers, as a result of higher levels of the crowding out effect of monitoring, exhibit higher levels of PFO.

$\mathbf{H}_{12}$ Managers exhibit higher levels of PFO under higher levels of negative professional ethical climate.

Yes

$\mathbf{H}_{13}$ As managers' CMD scores increase, the magnitude of the positive effects of a negative professional ethical climate on PFO reduces.

$\mathbf{H}_{14}$ Managers with higher levels of PFO exhibit higher levels of $\mathrm{OB} . .$.

Yes

$\mathbf{H}_{15}$ Disciplinary monitoring reduces the magnitude of positive effects between PFO and OB. 
distribution of the population. The standard error estimated from original sample and the mean of estimates across bootstrap samples were remarkably close, with standard error bias less than 0.001 in most cases. The results show that the regular ML estimation as reported here is statistically equivalent to that using bootstrapped ML estimation.

In summary, many of the hypothesized paths were not significant. Table 6.4 provides a list of research hypotheses and outcome. $\mathrm{H}_{10}, \mathrm{H}_{12}, \mathrm{H}_{14}$ were the only hypotheses for which I found support. The results suggest that Interactional Justice (IJ) and Negative Professional Ethical Climate (NPEC) contribute to a franchisee's level of PFO. IJ's influence on OB was fully mediated by PFO, while that of NPEC is partially mediated by PFO. AGE and FOOD were also significant variables that contributed to overall PFO. As for OB, on one hand, $\mathrm{PFO}$ was positively related to OB. On the other hand, DM was negatively related to OB. I also found that both RTSI and EBOB were positively related to $\mathrm{OB}$.

\section{ALTERNATIVE MODEL}

In the preceding analysis, PFO referred to propensity for opportunism within the specific franchisor-franchisee relationship. The alternative model adds a new construct termed Individual $P F O$, which is meant to distinguish individual-specific propensity for opportunism from relationship- (or context-) specific propensity for opportunism. The overall structural path model is shown in Figure 6.2. In this model, I refer to two types of PFO: individual-specific (i.e., IPFO) and relationship-specific (i.e., RPFO). The rationale 
Figure 6.2: Alternative Model

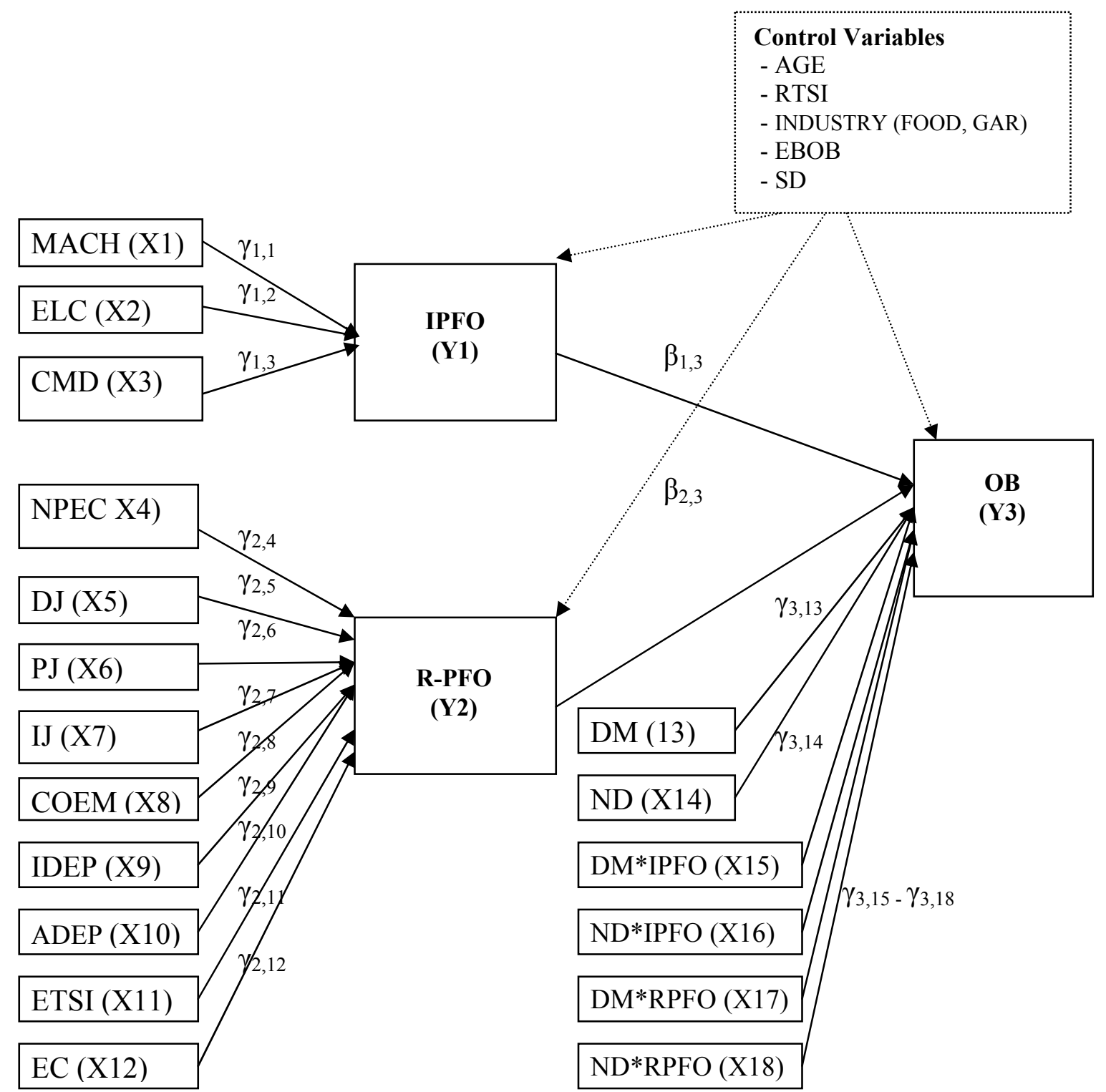


for the addition of IPFO as an alternative model was discussed in Chapter Five. IPFO is a distinct, general attitude toward opportunistic behaviors, and RPFO is the franchisee's relationship-specific attitude toward opportunistic behaviors against his/her franchisor, which was referred to earlier as PFO.

In directly comparing with the original hypothesized model, this alternative model could possibly explain more variance in OB, as well as variance unexplained by RPFO alone. As shown in Figure 6.2, this alternative model posits that MACH, ELC, and CMD are individual traits that franchisees bring to the relationship, and IPFO is posited to be independent of the relationship context. RPFO, then, is influenced by relationshipspecific characteristics, in terms of both relationship structure (IDEP, ADEP, ETSI, and EC) and relationship quality (DJ, PJ, IJ, and COEB). In model specification, although IPFO and RPFO share a correlation of $\mathrm{r}=.25(\mathrm{p}<.05)$, their error terms were not allowed to correlate in the model as they do not share the same antecedents.

Because this was an alternative model that came to light after dissertation proposal, I had no pre-specified hypotheses. Even without hypotheses, I expected the same patterns of effects for $\mathrm{PFO}$ and $\mathrm{OB}$, only that some of the predictor variables for RPFO specified previously (i.e., MACH, ELC, and CMD) would be now directed to IPFO instead of RPFO.

\section{Structural Path Equations}

The hypothesized paths in the alternative model can be summarized in the following regression equations. As with the originally-hypothesized model, I tested these structural paths simultaneously using maximum likelihood estimation. 
$\left.\begin{array}{l}\text { Individual PFO }=\alpha_{1}+\gamma \mathrm{MACH}+\gamma \mathrm{ELC}+\gamma \mathrm{CMD} \\ +\gamma \mathrm{AGE}+\gamma \mathrm{RTSI}+\gamma \mathrm{EBOB}+\gamma \mathrm{SD}+\gamma \mathrm{FOOD}+\gamma \mathrm{GAR}\end{array}\right\} \begin{aligned} & \text { CONTROL } \\ & \mathrm{VAR} .\end{aligned}$

Relational PFO $=\alpha_{2}+\gamma \mathrm{DJ}+\gamma \mathrm{PJ}+\gamma \mathrm{IJ}+\gamma \mathrm{COEM}+\gamma \mathrm{NPEC}+\gamma \mathrm{IDEP}+\gamma \mathrm{ADEP}$

$+\gamma \mathrm{ETSI}+\gamma \mathrm{EC}$

$+\gamma \mathrm{AGE}+\gamma \mathrm{RTSI}+\gamma \mathrm{EBOB}+\gamma \mathrm{SD}+\gamma \mathrm{FOOD}+\gamma \mathrm{GAR}\} \begin{aligned} & \text { CONTROL } \\ & \text { VAR. }\end{aligned}$

$$
\begin{aligned}
& \mathbf{O B}=\alpha_{3}+\beta \mathrm{IPFO}+\beta \mathrm{RPFO}+\gamma \mathrm{DM}+\gamma \mathrm{ND}+\gamma \mathrm{DM} * \mathrm{IPFO}+\gamma \mathrm{ND} * \mathrm{IPFO}+\gamma \\
& \quad \mathrm{DM} * \mathrm{RPFO}+\mathrm{ND} * \mathrm{RPFO} \\
& \quad+\gamma \mathrm{AGE}+\gamma \mathrm{RTSI}+\gamma \mathrm{EBOB}+\gamma \mathrm{SD}+\gamma \mathrm{FOOD}+\gamma \mathrm{GAR}\} \begin{array}{l}
\text { CONTROL } \\
\mathrm{VAR} .
\end{array}
\end{aligned}
$$

\section{Overall Model Fit}

Overall, the model fit was adequate. Model fit indices values as well as aggregated results for path analysis results are provided in Table 6.5. Although chi-square value for the model was below the recommended level $(p=.01)$, all other fit indices indicated an adequate fit of the model. Relative chi-square value of 1.31 is well within the recommended 3.0 (Klein 1998). NFI was slightly lower than traditionallyrecommended .90 . Though, given small sample size, .85 should be adequate (Ullman 2000). NNFI, CFI, and IFI are all above recommended .90 (Bagozzi and Yi 1988).

RMSEA of .04 is also significant $\{\mathrm{p}(\mathrm{close})=.73\}$. 
Table 6.5: Structural Model Results - Alternative Model

IPFO

Standard. Coeff. t-value

$\begin{array}{llcc}\text { MACH } & \left(\gamma_{1,1}\right) & .33 * * & 4.54 \\ \text { ELC } & \left(\gamma_{1,2}\right) & .10 & 1.29 \\ \text { CMD } & \left(\gamma_{1,3}\right) & .05 & .74 \\ \text { NPEC } & \left(\gamma_{2,4}\right) & - & - \\ \text { DJ } & \left(\gamma_{2,5}\right) & - & - \\ \text { PJ } & \left(\gamma_{2,6}\right) & - & - \\ \text { IJ } & \left(\gamma_{2,7}\right) & - & - \\ \text { COEM } & \left(\gamma_{2,8}\right) & - & - \\ \text { IDEP } & \left(\gamma_{2,9}\right) & - & - \\ \text { ADEP } & \left(\gamma_{2,10}\right) & - & - \\ \text { ETSI } & \left(\gamma_{2,11}\right) & - & - \\ \text { EC } & \left(\gamma_{2,12}\right) & - & - \\ \text { DM } & \left(\gamma_{3,13}\right) & - & - \\ \text { ND } & \left(\gamma_{3,14}\right) & - & - \\ \text { IPFO } & \left(\beta_{3,1}\right) & - & - \\ \text { RPFO } & \left(\beta_{3,2}\right) & - & - \\ \text { DM*IPFO } & \left(\gamma_{3,15}\right) & - & - \\ \text { ND*IPFO } & \left(\gamma_{3,16}\right) & - & - \\ \text { DM*RPFO } & \left(\gamma_{3,17}\right) & - & - \\ \text { ND*RPFO } & \left(\gamma_{3,18}\right) & - & -\end{array}$

Control Variables

$\begin{array}{llrlrrr}\text { AGE } & -.02 & -.30 & -.15^{* *} & -2.03 & .01 & .17 \\ \text { RTSI } & .04 & .49 & .14 & 1.45 & .20^{* *} & 2.41 \\ \text { EBOB } & .16^{* *} & 2.11 & .10 & 1.18 & .14^{*} & 1.68 \\ \text { SD } & .02 & .29 & -.03 & -.41 & -.12^{*} & -1.68 \\ \text { FOOD } & .07 & .83 & .19 * * & 2.15 & -.01 & -.01 \\ \text { GAR } & .07 & 1.08 & .04 & .52 & -.01 & -.85\end{array}$

RPFO

Standard. Coeff. t-value

OB

Standard. Coeff. t-value

$\begin{array}{cccc}- & - & - & - \\ - & - & - & - \\ - & - & - & - \\ .16^{*} & 1.95 & - & - \\ -.10 & 1.08 & - & - \\ -.06 & -.53 & - & - \\ -.25^{* *} & -2.03 & - & - \\ -.04 & -.44 & - & - \\ -.06 & -.66 & - & - \\ -.07 & -.77 & - & - \\ .14 & 1.22 & - & - \\ -.03 & -.21 & - & - \\ - & - & -.21^{* *} & -2.63 \\ - & - & -.07 & -.94 \\ - & - & .16^{* *} & 2.11 \\ - & - & .13^{*} & 1.68 \\ - & - & -.11 & -1.34 \\ - & - & .03 & .46 \\ - & - & .06 & .30 \\ - & - & -.02 & -.21\end{array}$

SMC (variance explained): IPFO = .22 $(\mathrm{p}<.05) ; \mathrm{RPFO}=.21(\mathrm{p}<.05) ; \mathrm{OB}=.18(\mathrm{p}<.05)$

Overall Model Fit: $\chi 2(172)=224.04 ; \mathrm{p}=.01 \quad \mathrm{CMIN} / \mathrm{DF}=1.31 \quad \mathrm{NFI}=.85$

$\mathrm{NNFI}=.91 \quad \mathrm{CFI}=.95 \quad \mathrm{IFI}=.96 \quad \mathrm{RMSEA}=.04 \quad \mathrm{p}($ close $)=.73$

Note: $*=\mathrm{p}<.10$ (two-tailed), $* *=\mathrm{p}<.05$ (two-tailed) 


\section{Results}

\section{Determinants of IPFO}

MACH, ELC, and CMD were expected to contribute to franchisees' general attitude towards OB (i.e., IPFO). Of these, MACH was significantly related to IPFO $\left(\gamma_{1,1}=.33, p=.00\right)$. The results indicate that the higher the Machiavellian tendencies franchisees exhibit, the more likely that they accept opportunistic behaviors as common and that they take place out of necessity. The other two variables (ELC and CMD) were not significantly related to IPFO $\left(\gamma_{1,2}=.10, \mathrm{p}=1.29\right.$ and $\gamma_{1,3}=.05, \mathrm{p}=.74$, respectively).

\section{Determinants of RPFO}

Similar to the results obtained in the originally hypothesized model, again NPEC and IJ were significant predictor variables. NEPC was positively related to RPFO $\left(\gamma_{2,4}=.16, p=.05\right)$. IJ was negatively related to RPFO $\left(\gamma_{2,7}=-.25, p=.04\right)$. No other predictor variables were significantly related to RPFO.

\section{Determinants of $\mathrm{OB}$}

The results were again very similar to the originally hypothesized model results. However, this time, IPFO was added as an endogenous predictor variable, and it was significantly related to $\mathrm{OB}\left(\beta_{3,1}=.16, \mathrm{p}=.05\right)$. RPFO was again positively related to $\mathrm{OB}$, with $\beta_{3,1}=.13(p=.10)$. The effect of DM on OB was again significant $\left(\gamma_{3,13}=-.21, p=.01\right)$. Just like the original model results, I did not find any interaction effects. 


\section{The Effects of Control Variable}

I postulated that one's level of IPFO is independent of the franchising relationship context. Notably, EBOB was the only control variable that was significantly related to IPFO $(\gamma=.16, p=.04)$. The significant path may suggest that the EBOB is more salient to those franchisees with high levels of IPFO, or it is possible that high-IPFO individuals self-selected into a particular franchising relationships in which they could easily take advantage of high EBOB situation. However, the directionality of cause-and-effect is not clear enough draw a conclusion. AGE and RTSI were not relevant to IPFO. Taken together, those franchisees with high levels of MACH will exhibit high levels of IPFO regardless of the context. As with the originally hypothesized model, AGE and FOOD were two control variables that were related to RPFO $(\gamma=-.15, p=.05$ and $\gamma=.19, p=.04$, respectively). Similarly, RTSI and EBOB were positively related to $\mathrm{OB}(\gamma=.20, \mathrm{p}=.02$ and $\gamma=.14, \mathrm{p}=.08$, respectively).

\section{Mediation Test Results}

As I had conceptualized that both IPFO and RPFO mediate their exogenous variables' effects on OB, I employed a mediation test using the three-step method recommended by Barron and Kenny (1988). After confirming that (1) both exogenous and mediator variables are individually associated with the criterion variable and (2) the exogenous variables are associated with the mediator variables, I compared the exogenous variables' effects on the criterion variable controlling for the mediator variables. As with the prior mediation test results, IJ's effect on OB was again fully mediated by RPFO, as its effect on OB disappeared when RPFO was present $\left(\gamma_{\mathrm{IJ}}\right.$, OB$=-$ 
.04). NPEC's effect on OB was only partially mediated by RPFO as NPEC's effect on $\mathrm{OB}$ remained present, though reduced slightly to $\gamma_{\mathrm{NPEC}, \mathrm{OB}}=.17$ from $\gamma_{\mathrm{NPEC}, \mathrm{OB}}=.19$ when RPFO was present. The results were the same for MACH, whose effect on OB is only partially mediated by IPFO as $\gamma_{\mathrm{MACH}}$ OB was reduced to. 17 when IPFO was present from $\gamma_{\mathrm{MACH}, \mathrm{OB}}=.19$.

\section{A Comparison with Bootstrapping Results}

As with the original hypothesized model testing, I took additional steps to ensure that the ML estimation is not biased due to small sample size or multivariate nonnormality. I again used 2000 bootstrap samples, for which the means serve as a proxy for the sampling distribution of the population. The standard error estimated from original sample and the mean of estimates across bootstrap samples were remarkably close, with standard error bias less than 0.001 in most cases. The results show that the regular ML estimation as reported here is statistically equivalent to that using bootstrapped ML estimation.

In summary, the alternative model adds some value to the research model. It became clear that individual-specific traits are directly related to whether franchisees generally view $\mathrm{OB}$ as acceptable, common, and taking place out of necessity. When it comes to relationship-specific PFO, the results were the same as the originally hypothesized model. IPFO was also a significant predictor variable for OB. Together, IPFO and RPFO were found to individually contribute to $\mathrm{OB}$, while DM was again found to deter franchisees from actually engaging in $\mathrm{OB}$. 


\section{CHAPTER VII}

\section{DISCUSSION AND RESEARCH IMPLICATIONS}

This chapter is devoted to the discussion of research findings and implications in light of research contributions and limitations. This chapter extends Chapter Six, which focused on hypothesis testing results, by evaluating the overall results of the study, followed by the theoretical and managerial implications. The chapter ends with a discussion of directions for future research.

\section{Discussion}

This research challenges the standard microeconomic theories' assumption that business managers seek to serve their self-interests at the partner firm's (principal's) expense whenever possible. Instead, it conceptualizes opportunistic behavior as a function of Propensity for Opportunism (PFO) and economic and social costs. This research makes several contributions to our understanding of opportunistic behavior in marketing channels. The first is to distinguish between opportunistic behaviors and propensity for opportunism, which was broadly defined as the degree of inclination to behave opportunistically. Propensity reflects desires, which strongly influence intentions about behavior (Bagozzi and Edwards 1998). This distinction between propensity and behavior is important because it acknowledges individual differences among channel members that impact behavior and highlights the fact that individuals who are inclined in a particular direction do not necessarily act on it.

In addition, this research shows that PFO is sensitive to context. Specifically, a new construct of relationship-specific PFO (RPFO) reflects the extent to which 
franchisees are willing, motivated, tempted, provoked, or compelled to engage in opportunistic actions specifically against their franchisors. As hypothesized, the results show that individuals with higher levels of RPFO exhibited higher levels of OB. In my alternative research model, I also developed a new construct to capture individualspecific PFO (IPFO), or one's attitude toward opportunistic behaviors in general business settings. IPFO also influences one's level of opportunism, yet IPFO is different from RPFO in that IPFO is the propensity for opportunism that individual managers bring into any relationship, as opposed to being specific to a relationship.

A second contribution of this research is that it extends the level of analysis for influences on opportunistic behavior. The marketing channel literature has typically examined opportunism only at a dyadic level. This dissertation extends the literature to include constructs from both individual and extra-dyadic levels of analysis. Within each level of analysis, including the more thoroughly studied dyadic level, this research proposes and tests new relationships involving concepts not previously considered with respect to opportunistic behavior. A discussion of these at each level of analysis follows.

At the individual-level of analysis, I implemented a bad apple perspective, hypothesizing that individual characteristics such as Machiavellianism, External Locus of Control, and Cognitive Moral Development would be related to one's RPFO. The results suggest that, neither External Locus of Control nor Cognitive Moral Development have any direct or indirect effects on RPFO or OB. Instead, my alternative research model identified that Machiavellianism was positively related to individual-specific PFO (IPFO), which reflect franchisees' general attitude toward OB. I also found that the impact of Machiavellianism on OB was partially mediated by IPFO. The finding offers a 
piece of evidence that individual-specific traits do have impact on how they behave in business-to-business exchange relationships. Specifically, one's Machiavellian tendencies have large impact on propensity for and actual engagement in opportunism.

Although in the hypothesis testing one's external locus of control orientation did not have a direct impact on opportunism, it may still shape one's perceptions and reactions in business relationships. For example, the correlation analysis suggests that external locus of control is positively related to Negative Professional Ethical Climate, Crowding Out Effects of Monitoring, and Individual PFO (r=.16, r=.20, r=.24, respectively). It is possible that managers with higher external locus of control exhibit different viewpoints than those with lower external locus of control, which may in turn impact their feelings toward certain relationship-specific variables. Such speculation may provide useful guidelines in future research in further scrutinizing the role of locus of control in dyadic relationships.

At the dyadic level, two frameworks based on two different behavioral assumptions of business managers were simultaneously subjected to empirical tests of determinants for RPFO and OB: a rational actor framework and a bounded morality framework (discussed in Chapter Three). The bounded morality framework was inspired by the extant literature that suggests a non-trivial impact of individuals' sensitivity to and the need for fairness within an exchange relationship on their behaviors. The behavioral assumption of this framework contrasts with that of the rational actor framework, such that managers are not solely focused on economic utility. Rather, the bounded morality framework recognizes that managers are also social actors whose judgment of what constitutes acceptable behaviors is influenced by the situation. Based on this assumption, 
four factors were identified that might impact propensity for and actual opportunism: Crowding Out Effects of Monitoring (COEM), Distributive Justice (DJ), Procedural Justice (PJ), and Interactional Justice (IJ).

First, COEM was one of the newly developed constructs for this dissertation and was proposed to be related to RPFO. The previous studies have indicated that lack of autonomy and self-control creates frustration, which in turn may lead to reactance behaviors to undermine the constraints threatening their freedom of action. I did not find support for the hypothesis that COEM was directly related to RPFO. However, the research also indicated that COEM correlates highly negatively with justice perceptions. In particular, COEM was highly correlated with Interactional Justice ( $\mathrm{r}=-.62)$, which indeed had significant effects on relationship-specific propensity for opportunism (RPFO).

Niehoff and Moorman (1993) argued that methods of monitoring influence fairness perceptions in the relationship, such that perceptions as to whether monitoring is fair depend on the context. Following this line of thinking, it is possible that the COEM impact on RPFO may be offset by other relationship characteristics contingencies such as Interactional Justice. Similarly, the extensive review of justice perceptions studies by Brockner and Wiesenfeld (1996) provide some evidence that, the implications of one type of justice perception depends on the level of another type of justice perceptions. According to Brockner and Wiesenfeld (1996), when individuals are satisfied with outcome distribution (i.e., distributive justice), they are somewhat unconcerned with the fairness of the procedures (i.e., procedural justice). Similarly, when the perceptions of procedural justice are high, they are less concerned with the outcome favorability. A 
similar conclusion may be inferred for the present study for its lack of support for the direct effect of COEM on relationship-specific opportunism propensity (RPFO), such that the presence of interactional justice can overcome otherwise negative feelings induced by monitoring activities.

Similarly, among the three justice perceptions, only Interactional Justice was significantly related to RPFO. It may be that, when it comes to RPFO, Interactional Justice perceptions can supplement any reduced distributive or procedural justice perceptions in such a way that high levels of interactional justice can overshadow the other types of justice perceptions. The results for Interactional Justice suggest that individuals' levels of RPFO are reduced when they find themselves in a business exchange relationship in which the exchange partner treats him/her with respect, kindness, and truthfulness. The mediation tests also revealed that the impact of Interactional Justice on OB is fully mediated by RPFO. The other two justice variables, Distributive Justice and Procedural Justice, were found to be non-significant predictors of RPFO. The extant organizational justice literature as reviewed in Chapter Two suggests each type of justice perceptions has dissimilar implications. To briefly revisit, distributive justice has been shown to relate most positively with job satisfaction and negatively related with turnover intention. Procedural justice has been shown to impact organizational commitment as well as exchange partner and relationship evaluation (e.g., trust, commitment, conflict). The previous findings for the effects of Interactional Justice have been mixed, and in the present study I found that Interactional Justice perceptions reduce franchisees' RPFO, which in turn impact their actual opportunistic behaviors. 
As for the rational actor framework, variables which had traditionally been used in marketing channels literature were included: Interdependence (IDEP), Asymmetric Dependence (ADEP), Transaction-specific Investments (ETSI), and Economies of Continuation (EC). Interdependence has previously been shown to be a significant indicator for relational behaviors (e.g., Lusch and Brown 1996; Kumar et al. 1995a). As for Asymmetric Dependence, previous studies have produced mixed results on the role of one-sided dependence in deterring opportunism (e.g., Provan and Skinner 1989; Joshi and Arnold 1997). Transaction Specific Investments have also previously been shown to produce mixed results on OB (i.e., can increase or decrease opportunism, or no effect) (e.g., Brown, Dev, and Lee 2000; Rokkan, Heide, and Wathne 2003).

The results show that none of these variables have direct impact on RPFO. Given that previous studies have shown mixed findings, the results may not be too surprising. The results highlight the complex nature of business relationships in which many contingencies prevent straightforward, one-on-one correspondence of relationships between economic variables and opportunism. It also seems that a better approach for future extension would be to identify the contingencies in which these variables may lead to opportunism. Rokkan, et al. (2003), for example, show that TSIs can have both bonding and expropriation effects, depending on levels of expected future transactions.

Disciplinary Monitoring was a newly developed construct to capture the degree of monitoring effectiveness. It was proposed to be a moderator variable, reducing the magnitude of impact of RPFO on OB. Based on the rational actor assumption, it was suspected that rational actors would refrain from engaging in opportunistic behaviors if they determine that the chance of being caught is high. Indeed, the results indicated that 
Disciplinary Monitoring actually curbs opportunism by itself, without interacting with RPFO or IPFO. The finding seems to suggest that monitoring acts only as an external constraint that independently affects opportunistic behavior.

At the extra-dyadic level, based on a bad barrel perspective, I hypothesized that Negative Professional Ethical Climate (NPEC) would be positively related to RPFO. The results indeed show that extra-dyadic ethical climate does impact how individuals behave in dyadic relationships, and that they are more likely to be inclined to behave opportunistically (i.e., $\mathrm{RPFO}^{15}$ ) and actually engage in those behaviors (i.e., OB) when they observe others in their social network behaving in individualistic manners, disrespecting corporate rules and professional codes. The finding highlights the nontrivial influence of extra-dyadic ethical climate in determining the opportunism within a dyadic relationship.

Network Density (ND), or strength of relationships within a social network, was hypothesized as a moderator variable reducing the impact of RPFO on OB; however, the results did not find that Network Density either directly or indirectly impact PFO and OB. Interestingly, the bivariate correlation analysis shows that this variable is highly correlated with NEPC ( $\mathrm{r}=-.37)$, as well as distributive, procedural, and interactional justice perceptions $(\mathrm{r}=.47, \mathrm{r}=.59, \mathrm{r}=.46$, respectively) and Crowding Out Effects of Monitoring (COEM; $\mathrm{r}=.31)$. The results indicate that, although ND is not directly related with either RPFO or OB, it still captures dyadic relationship quality and that of the social network. In the current research context of franchising relationships, a cohesive franchisee network is less likely to coincide with negative ethical climate, and social

\footnotetext{
${ }^{15}$ The p-value for the path between NPEC and RPFO was .06 in the originally model, and .051 in the alternative model, which is slightly above the usual standard of $\mathrm{p} \leq .05$, and therefore their parameters' significance may be said to be marginal.
} 
network density is more likely to be developed in a franchise that offers fair treatments of franchisees. It may be interesting in future research to investigate the implications of ND other than opportunism in future research.

The present study also found some interesting pattern of relationships between the control variables and the criterion variables. The results show that Economic Benefits of $\mathrm{OB}(\mathrm{EBOB})$ are positively related to both IPFO and OB, but it is not significantly related to RPFO. This finding that the degree of RPFO is determined only by relationship quality (both dyadic and extra-dyadic) highlights the evidence that business managers are social actors after all. They are sensitive to interpersonal treatment and susceptible to behavioral referencing by observing others in the social network. Age of relationship was also found to be negatively related to RPFO only. A longer relationship may be a sign of higher quality relationship between exchange partners. The result seems to suggest that business managers are less inclined to behave opportunistically in long-term, successful relationships. Higher levels of franchisor's TSIs were also related positively to OB. This finding is consistent with the TCE (Transaction Cost Economics) framework (Williamson 1975, 1985), in that increases in TSIs make the investing firm more vulnerable.

However, Rokkan, et al. (2003) show that the degree to which TSIs may be expropriated depends on the expected future business opportunities. In the current study, this particular contingency effect was not investigated.

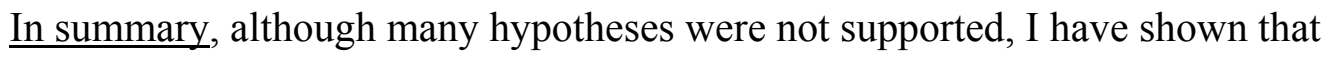
individual franchisees do incur differing levels of propensity for opportunism. I investigated the determinants of RPFO, and in alternative research model, IPFO. I found that Machiavellianism is an individual-specific characteristic that franchisees can bring to 
a business relationship, which in turn influences their actual opportunistic behaviors within the exchange relationship. Within dyadic relationships, Interactional Justice is a variable that can influence the degree of RPFO. From a mediation analysis I found that Interactional Justice is related to OB only with RPFO as a mediator. Negative Professional Ethical Climate was another variable that was found to be positively related to RPFO. Taken together, the results suggest that franchisees actively use the relationship quality at a dyadic level (Interactional Justice) and the social environment (Negative Professional Ethical Climate) as guidelines for determining appropriate behaviors within a dyad, which can be reflected in their levels of RPFO. Rather than invariably assuming that individuals are purely opportunistic in nature, the present research offers alternative perspective that there are individual, relational, and macro-environmental factors that can determine one's level of propensity for opportunism, both in terms of general attitude toward OB (i.e., IPFO) and relationship-specific propensity (i.e., RPFO).

\section{Implications}

The present research argued that marketing channel managers exhibit differing propensities for opportunism. Overall, the research contributes to the existing literature by re-examining a fundamental behavioral assumption about marketing channel managers and providing an alternative framework that can meaningfully inform us as to when and why opportunism occurs. At the same time, this research contributes to the literature by implementing both the bad apple and the bad barrel perspectives. The extant research studied the determinants of opportunism by examining the relationships 
characteristics only at the dyadic level. Important implications for both marketing channel managers as well as researchers are discussed in following sections.

\section{Managerial Implications}

This dissertation's findings will be relevant to many business relationships, in which opportunism is possible (i.e., in bilateral, monopolistic exchange within marketing channels). I have shown empirical evidence that individuals do exhibit differing levels of

propensity for opportunism. In addition, this research establishes that there is a distinction between an individual's general propensity to be opportunistic and their propensity to be opportunistic within a particular relationship. I have identified some factors that influence one's level of propensity for opportunism, both in general and with respect to specific relationships. Such a perspective helps marketing channel managers in informing when and why opportunistic behaviors take places.

In addition, ultimately, the findings of this dissertation should provide guidance on the extent to which explicit control mechanisms (e.g., explicit contracts and stringent monitoring) are really necessary in a given exchange relationship. Such managerial implications were much needed, as these control mechanisms are designed and implemented with the assumption that channel managers are guileful and self-interest seeking. However, when excessively used, these managers can incur unintended costs, both economic and social. With enhanced understanding of the determinants of PFO, marketing channel managers can determine effective and efficient levels of safeguarding - both explicit control measures and less explicit ones. 
Explicit control measures would be direct monitoring of activities. The present research has shown that monitoring that is able to detect and sanction the exchange partner's opportunism (i.e., Disciplinary Monitoring in the present research model) effectively decreases opportunism. However, one of the implicit control measures the present study highlights is the perceptions of fairness in interpersonal treatment (i.e., Interactional Justice). The present research suggests that establishing solid communications with the exchange partner with respect, kindness, and truthfulness reduce the partnering firm's manager's inclination to behave opportunistically.

In addition, efforts to reduce negative influences in the environment should be made to deter opportunism. The present research has shown that the degree of opportunism can be influenced by a larger social network in which the dyadic exchange is embedded. If the environment is such that encourages opportunistic behaviors (i.e., Negative Professional Ethical Climate in the model) it can increase the partner firm's manager's propensity for opportunism. Using the current study context of franchising, efforts to reduce that negative influence, such as increasing interactional justice, may foster an environment in which franchisees are better able to communicate among themselves to develop cohesiveness, as well as provide incentives in such a way that cooperative behaviors lead to intrinsic and extrinsic rewards.

Specifically, the present research highlights the pivotal role of relationship quality both at the dyadic and the extra-dyadic level. At the dyadic level, the perceptions of interactional justice stood out as the determining factor for relationship-specific PFO. These perceptions stem from ongoing communication, whether the manager is being treated with respect, dignity, and given truthful communication. Such treatment of 
exchange partners is crucial in deterring opportunism, while there may be other benefits such as a long, profitable, and satisfying relationship.

This research also highlights the impact of extra-dyadic ethical climate. Dyadic exchange relationships never exist in a vacuum. This dissertation offers empirical evidence that the extra-dyadic environment has influence over the dyad. Specifically, franchisees in the present study exhibited higher levels of propensity to behave opportunistically when they see other franchisees acting individualistically, disrespecting corporate rules and professional standards. This finding supports the notion of the "bad barrel" argument, in that business managers learn to behave in an opportunistic manner. In my pretest interviews with franchisees, I observed that the nature of franchise networks vary greatly. Some franchise firms offer more opportunities than others to facilitate conversations with franchisees as well as among franchises with online message boards, periodic regional meetings, mentoring programs, a franchisee board; all of which determining overall quality of the relationships within the franchise network. The primary data reinforce the idea that efforts to improve the franchise network relationship quality can pay off by enhancing relationships at dyadic level by reducing opportunism.

Furthermore, I have also shown evidence for the "bad apple" argument, holding responsible business managers' individual traits on their behaviors in business-tobusiness relationships. Although implementing Machiavellianism test scores in hiring or partnering decisions may be far from being practical, some degree of socialization may be strongly advised to help influence their likelihood in pursuing individual or collective welfare in future transactions. In my pretest interviews, there appeared to be a consensus that (1) franchisees rarely go through any type of socialization processes prior to signing 
the partnering agreement and that (2) qualification procedures involved determining financial capabilities for the largest part. The present study context of franchising relationships reinforces the importance of partner selection, as selecting exchange partners who exhibit higher tendencies to act opportunistically can be costly not only financially but also in terms of possible damages to franchise brand equity, as well the possible impact these individual have over other franchisees in the network in behavioral referencing.

\section{Research Implications}

In investigating opportunistic behaviors within marketing channel relationships, the extant literature had largely relied upon the traditional microeconomic theories (i.e., Transaction Economic Theory, or TCE, and Agency Theory) and their assumption that a marketing channel member is motivated to pursue his/her own economic interest whenever possible even at the expense of the exchange partner. The present research employed not only this rational actor framework, but also what I termed the bounded morality framework, which primarily benefits from the organizational justice literature. Orr's (1998) remarks should not be a surprise to researchers whose studies investigate human behaviors. After all:

"It seems palpably obvious that humans, unlike birds and bees, bring all variety of 'irrational' cultural beliefs to bear on decisions about cooperation a fact, perhaps, that could count as news only to economists and evolutionary biologists" (p. 4).

My research findings provide evidence that business managers' behaviors in business settings are influence by both rational and other factors that are not based on 
economic rationality. Namely, when effective monitoring (i.e., able to detect and punish non-compliance) is in place I have shown that it can deter opportunism. At the same time, managers value interpersonal treatment with honesty and respect, even though such factors offer no conceivable economic benefits. From the perspective of microeconomic theories that assume economic actors are only interested in maximizing their own profits, the sensitivity to fairness perceptions in an interfirm relationship would be considered irrational. My research has shown that a lack of such fair interpersonal treatment can induce managers to incline to behave opportunistically. As Kahneman et al. (1986a, 1986b) call for the need to modify standard microeconomic models to incorporate norms of fairness, the present research contributes to the extant literature by specifically examining the role of fairness perceptions in interfirm opportunism. The findings of the importance of fairness perceptions parallel with the relational exchange paradigm of business exchange, which emphasizes the importance of "socialization" (Wathne and Heide 2000) and relationalism (Macneil 1980) or relational norms (Heide and John 1992).

The dissertation also contributes to the extant literature by investigating the impact of individual differences in business conduct. Prior research focusing on ex ante partner selection had not examined individual-level characteristics. The present research also makes a contribution by exploring social embeddedness in the dyadic relationship and the role of the ethical environment and social network in which the dyadic relationship is embedded. The literature reviews in Chapter Two supported the idea that all three levels of analysis were needed to gain a more complete picture of the complex nature of opportunism in marketing channel relationships. Indeed this research shows that 
dyadic relationships involve far more than the traditionally-examined dyadic relationship structures. I have offered empirical evidence that business managers' individual characteristics as well as extra-dyadic characteristics impact the way they behave at dyadic relationships. Integrating the scattered literature streams was much needed not only to enhance our understandings of interfirm opportunism but also to provide some insights as to the boundaries of the traditionally used normative frameworks for opportunism, which are based on rational-actor assumptions.

In the present research model I have also included other newly developed scales such as Disciplinary Monitoring (DM), Economic Benefits of Opportunistic Behaviors (EBOB), Crowding Out Effects of Monitoring (COEM), Negative Professional Ethical Climate (NPEC), as well as Propensity for Opportunism (PFO). Each of these new constructs offers unique contribution to the extant literature, and each is discussed in following paragraphs.

First, DM is an original construct pertaining to monitoring. Previously, the literature has examined monitoring by either (1) simply measuring the amount of monitoring (Zajac and Westpal 1994) or (2) the degree of stringency in monitoring (Murry and Heide 1998). In the microeconomic framework, monitoring is postulated as an imperfect control mechanism due to differing degrees of information asymmetry (or task programmability), and Williamson (1975) uses the term bounded rationality to describe a principal's limited competence in specifying comprehensive contracting and monitoring to preempt opportunism. My DM construct focuses on the principal's ability to detect and sanction opportunism from the agent's perspective, which is directly proportionate to the agent's perceived ability to carry out opportunistic behaviors without 
suffering economic consequences. The construct can also be said to capture perceived behavioral control, or individuals' perceptions of their ability to perform a given behavior, in Theory of Planned Behavior (Ajzen and Madden 1986). As reviewed by Ajzen and Fishbein (2005), numerous studies conducted in the past decade have shown that taking into account perceived behavioral control can improve prediction of behavior. In the present study, DM was a significant predictor of agents' behavior (i.e., OB).

EBOB was another variable that had not previously been examined. The extant literature has implicitly treated opportunistic behaviors as having economic benefits. In other words, the extent to which an economic actor gains from opportunistic behaviors has been ignored in the literature. I developed and included this variable out of suspicion that not all franchisees may actually perceive that they benefit from OB in terms of decreased costs, increased profits, and reduced hours in performing required tasks. During my pretest interviews it became clear that for some franchisees, opportunism such as non-compliance to previously agreed upon terms could be a tool to greatly benefit self, and for others these behaviors produce little or no benefits. One without a high level of economic benefits of $\mathrm{OB}$ who subsequently engages in less $\mathrm{OB}$ should not be considered more relationally-oriented, and such possibility of confounding effects must be controlled. Within a small literature investigating the determinants of opportunism, the present research was the first to include such variable as a control variable, and the results suggest that it can greatly impact one's propensity for and actual opportunistic behaviors.

As for COEM, previous researchers have argued that the act of monitoring may inadvertently exacerbate the problem of opportunism (John 1984; Perrow 1986; Deci and Ryan 1987; Jacobides and Croson 2001). In particular, Frey (1993) argued that 
monitoring can crowd out work efforts if (1) an agent feels that the extent of selfdetermination is unduly restricted by the principal and (2) the agent's self-evaluation is reduced as $\mathrm{s} / \mathrm{he}$ is convinced that the principle believes $\mathrm{s} / \mathrm{he}$ is unable or unwilling to fulfill the assigned task to the principal's satisfaction. Based on Frey's conceptualization, I developed the COEM construct aiming to capture the degree to which monitoring crowd out agents' work motivation. A few studies have previously shown that monitoring can have negative consequences, for example, Murry and Heide (1998) show that stringent monitoring efforts by manufactures decreased their retailers' compliance with established agreements and their cooperation in participating programs developed by the manufacturers. To the best of my knowledge, COEM was the first construct to directly measure the negative affect caused by monitoring.

At the extra-dyadic level, I investigated the role of ethical climate on dyadic opportunistic behaviors. I developed a new scale labeled Negative Professional Ethical Climate (NPEC), capturing the degree of one's perceptions that others in their social network behaving in individualistic manners, disrespecting corporate rules and professional codes. Previous interfirm opportunism research has neglected the environmental influence, and I have shown that professional negative ethical climate can encourage opportunism within a dyad.

\section{Future Research Direction}

The findings of this research offer some evidence that the various control mechanisms based on the traditional microeconomic framework have limited benefits. Indeed, I found that variables such as transaction-specific investments, interdependence, 
dependence asymmetry, and economies of continuation do not increase or decrease propensity for opportunism. A post hoc analysis also revealed that they did not have direct effects on opportunism in the presence of other proposed determinants of opportunism. Future research may further scrutinize the contingency effects of these control mechanism as effective deterrence of opportunism, as the extant literature have shown mixed results, and sometimes no effects.

The present research focused around my conceptualization that business managers exhibit differing levels of propensity for opportunism. As such, the present research model primarily focused on the determinants of propensity for opportunism. Future research may expend some efforts in re-specifying research model investigating the relationship between propensity for opportunism and actual opportunistic behaviors in more detail. I also distinguished between individual-specific and relationship-specific propensities for opportunism (IPFO and RPFO, respectively) in my alternative research model, and it may be interesting to examine the implications of these variables in terms of their relationships with other variables such as satisfaction and relational norms. Particularly, because IPFO captures individual-specific world view, it would be interesting to determine the role of IPFO in terms of the individual's reactions to particular situations. For example, managers with high levels of IPFO may well react differently to monitoring than others with low levels of IPFO. In the alternative model, I also did not explicitly examine the relationship between IPFO and RPFO. In a post hoc analysis, a path between IPFO and RPFO was added to the alternative model, and the results indicated a path coefficient of $\gamma_{\mathrm{IPFO}, \mathrm{RPFO}}=.19,(\mathrm{p}<.01)$. Further studies are needed 
to determine the relationship between the two by re-specifying the model, including possible interactions.

My dissertation suggests that managers who wish to deter opportunism may carefully examine the firm's monitoring procedures and determine their effectiveness. I developed a measurement scale for Disciplinary Monitoring, which was measured from the party being monitored. As the extant literature has suggested that monitoring can have both positive and negative consequences, future studies may extend the present research to more carefully investigate the antecedents and the consequences of disciplinary monitoring beyond opportunism. For example, the correlation analysis suggests that Disciplinary Monitoring is related positively with distributive and procedural justice, but at the same time it is also related to dependence asymmetry and the monitored party's transaction-specific investments. Future research is needed to determine the boundary conditions of Disciplinary Monitoring as an effective control mechanism, as well as to determine the possible interactions with other control mechanisms.

Both theoretically and methodologically, future research may extend the present research by examining the proposed model in a different study context. I chose the study context primarily on the fact that franchising offers a clearly defined extra-dyadic relationships (i.e., franchisee networks) compared to other types of business-to-business relationships. My use of franchising was then justified in terms of their sufficient variance in the key research variables. However, empirically testing the research model in other types of business-to-business relationship would be the only way to ultimately determine the generalizeability of the present research findings to other contexts. 
In retrospect, choosing franchising as the present research context could have contributed to the weak mail survey response rate. As evidenced in difficulties in trying to reach unit franchisees by phone during pre-tests and primary data collection, it is highly possible that other study contexts would have produced more responses. In particular, as reviewed in Chapter Four, the previous studies done in the franchising context with reasonable response rates benefited from research sponsorship. The dissertation could have benefited from sponsorship by such entities as professional associations or other business network contacts in encouraging the members to participate. Although I described possible drawbacks of such sponsorship in Chapter Four, such as limiting the sampling frame to the members of a sponsoring entity, a higher response rate could have been achieved with a sponsor.

From a statistical point of view, all else equal, a larger sample size is always better. The present research's statistical analyses were also limited by the fact that the sample size was less-than-adequate to run a full confirmatory factor analysis (CFA) and exploratory factor analysis (EFA), as well as full structural equation modeling analyses. I substituted these analyses with group-wise CFA and EFA, and structural path analyses for research model testing. With small sample size, there is always a concern for type II error, by which sample may not be big enough to identify the falseness of the null hypothesis (i.e., low statistical power). Future studies with larger sample size would also be desirable for an application of hierarchical linear modeling (HLM), in which multilevel analyses can be more readily analyzed. 


\section{REFERENCES}

Adams, J. Stacey (1965), "Inequity in Social Exchanges," in Advances in Experimental Social Psychology, ed. L. Berkowiz, New York: Academic Press, 267-299.

Adler, Paul S. and Bryan Borys (1996), "Two Types of Bureaucracy: Enabling and Coercive," Administrative Science Quarterly, 41 (1), 61-89.

Agrawal, Deepak and Rajiv Lal (1995), "Contractual Arrangements in Franchising: An Empirical Investigation," Journal of Marketing Research, 32 (May), 213-221.

Agrawal, James and David Cruise Malloy (1999), "Ethical Work Climate Dimensions in a Not-for-profit Organization: An Empirical Study," Journal of Business Ethics, $20(1), 1-14$.

Ahmadjian, Christina and Joanne Oxley (2006), "Using Hostages to Support Exchange: Dependence Balancing and Partial Equity Stakes in Japanese Automotive Supply Relationships," Journal of Law, Economics, \& Organization, 22 (1), 213-233.

Aiken, Leona S. and Stephen G. West (1991), Multiple Regression: Testing and Interpreting Interactions, Newbury Park, CA: Sage Publications.

Ajzen, Icek (1991), "The Theory of Planned Behavior," Organizational Behavior and Human Decision Processes, 50, 179-211.

Ajzen, Icek and Martin Fishbein (2005), "The Influence of Attitudes on Behavior," in The Handbook of Attitudes, ed. D. Albarracín, B. T. Johnson and M. P. Zanna, MahWah, NJ: Lawrence Erlbaum Associates, 173-221.

Ajzen, Icek and Thomas J. Madden (1986), "Prediction of Goal-Directed Behavior: Attitudes, Intentions, and Perceived Behavioral Control," Journal of Experimental Social Psychology, 22, 453-474.

Akerlof, George A. (1982), "Labor Contracts as Partial Gift Exchange," Quarterly Journal of Economics, 97 (4), 543-569.

Akerloff, George (1970), "The Market for 'Lemons': Quality and the Market Mechanism," Quarterly Journal of Economics, 84 (August), 488-500.

Ambrose, Maureen L., G. Stoney Alder, and Terry W. Noel (1998), "Electronic Performance Monitoring: A Consideration of Rights," in Managerial Ethics: Moral Management of People and Processes, ed. Marshall Schminke, Mehwah, NJ: Erlbaum, 61-80. 
Anderson, Erin (1985), "The Salesperson as Outside Agent or Employee: A Transaction Cost Analysis," Marketing Science, 4 (3), 234-254.

Anderson, Erin (1988), "Transaction Costs As Determinants of Opportunism in Integrated and Independent Sales Forces," Journal of Economic Behavior and Organization, 9 (3), 247-264.

Anderson, Erin and Barton Weitz (1992), "The Use of Pledges to Build and Sustain Commitment in Distribution Channels," Journal of Marketing Research, 29 (February), 18-34.

Anderson, James C. and David W. Gerbing (1988), "Structural Equation Modeling in Practice: A Review and Recommended Two-Step Approach," Psychological Bulletin, 103 (3), 411-423.

Anderson, James C., David W. Gerbing, and John E. Hunter (1987), "On Assessment of Unidimensional Measurement: Internal and External Consistency, and Overall Consistency Criteria," Journal of Marketing Research, 24 (November), 432-437.

Anderson, Shannon W. and Henri C. Dekker (2005), "Management Control for Market Transactions: The Relation between Transaction Characteristics, Incomplete Contract Design, and Subsequent Performance," Management Science, 51 (12), 1734-1752.

Antia, Kersi D. and Gary L. Frazier (2001), "The Severity of Contract Enforcement in Interfirm Channel Relationships," Journal of Marketing, 65 (October), 67-81.

Aquino, Karl, Margaret U. Lewis, and Murray Bradfield (1999), "Justice Constructs, Negative Affectivity, and Employee Deviance: A Proposed Model and Empirical Test," Journal of Organizational Behavior, 20 (7), 1073-1091.

Arbuckle, James L. (2006), Amos 7.0 Users' Guide, Chicago, IL: SPSS.

Armstrong, J. Scott and Terry S. Overton (1977), "Estimating Nonresponse Bias in Mail Surveys," Journal of Marketing Research, 14 (August), 396-402.

Arnold, Hugh J. and Daniel C. Feldman (1981), "Social Desirability Response Bias in Self-Report Choice Situations," Academy of Management Journal, 24 (2), 377385.

Arrow, Kenneth J. (1985), "The Economics of Agency," in Principals and Agents: The Structure of Business, ed. John W. Pratt and Richard J. Zeckhauser, Boston, MA: Harvard Business School Press, 37-51. 
Aryee, Samuel, Pawan S. Budhwar, and Zhen Ziong Chen (2002), "Trust as a Mediator of the Relationship between Organizational Justice and Work Outcomes: Test of a Social Exchange Model," Journal of Organizational Behavior, 23 (May), 267285.

Asanuma, Banri (1985), "The organization of parts purchases in the Japanese automotive industry," Japanese Economic Studies, 13 (Summer), 32-78.

Ashford, Susan J., Cynthia Lee, and Philip Bobko (1989), "Content, Causes, and Consequences of Job Insecurity: A Theory-Based Measure and Substantive Test," Academy of Management Journal, 32 (4), 803-829.

Atuahene-Gima, Kwaku and Haiyang Li (2002), "When Does Trust Matter? Antecedents and Contingent Effects of Supervisee Trust on Performance in Selling New products in China and the United States," Journal of Marketing, 66 (July), 61-81.

Bagozzi, Richard P. (1994), "Structural Equation Models in Marketing Research: Basic Principles," in Principles of Marketing Research, ed. Richard P. Bagozzi, Cambridge, MA: Blackwell Publishers, 317-385.

Bagozzi, Richard P. (2000), "On the Concept of Intentional Social Action in Consumer Behavior," Journal of Consumer Research, 27 (3), 388-396.

Bagozzi, Richard P. and Hans Baumgartner (1994), "The Evaluation of Structural Equation Models and Hypothesis Testing," in Principles of Marketing Research, ed. Richard P. Bagozzi, Cambridge, MA: Blackwell, 386-422.

Bagozzi, Richard P., Massimo Bergami, and Luigi Leone (2003), "Hierarchical Representation of Motives in Goal Setting," Journal of Applied Psychology, 88 (5), 915-943.

Bagozzi, Richard P. and Elizabeth A. Edwards (1988), "Goal Setting and Goal Pursuit in the Regulation of Body Weight," Psychology and Health, 13, 593-621.

Bagozzi, Richard P. and Youjae Yi (1988), "On the Evaluation of Structural Equation Models," Journal of the Academy of Marketing Science, 16 (Spring), 74-94.

Baker, George P. (1992), "Incentive Contracts and Performance Measurement," Journal of Political Economy, 100 (5), 598-614.

Ballard, Rebecca (1992), "Short Forms of the Marlowe-Crowne Social Desirability Scale," Psychological Reports, 71, 1155-1160.

Ballard, Rebecca, Michael D. Crino, and Stephen Rubenfeld (1988), "Social Desirability Response Bias and the Marlowe-Crowne Social Desirability Scale," Psychological Reports, 63, 227-237. 
Banker, Rajiv, Seok-Young Lee, and Dhinu Srinivasan (1996), "Contextual Analysis of Performance Impacts of Outcome-based Incentive Compensation," Academy of Management Journal, 39 (4), 920-948.

Barnett, Tim (2001), "Dimensions of Moral Intensity and Ethical Decision Making: An Empirical Study," Journal of Applied Social Psychology, 31 (5), 1038-1057.

Barnett, Tim, Ken Bass, Gene Brown, and Frederic J. Herbert (1998), "Ethical Ideiology and the Ethical Judgments of Marketing Professionals," Journal of Business Ethics, 17 (7), 715-723.

Barney, Jay and Mark Hansen (1994), "Trustworthiness as a Source of Competitive Advantage," Strategic Management Journal, 15 (Special Issue), 175-190.

Baron, James N. and Michael T. Hannan (1994), "The Impact of Economics on Contemporary Sociology," Journal of Economic Literature, 32 (3), 1111-1146.

Barthélemy, Jerome and Bertrand V. Quélin (2006), "Complexity of Outsourcing Contracts and Ex Post Transaction Costs: An Empirical Investigation," Journal of Management Studies, 43 (8), 1775-1797.

Bebeau (2002), "The Defining Issues Test and the Four Component Model: Contributions to Professional Education," Journal of Moral Education, 31 (3), 271-295.

Becker, Lawrence C. (1996), "Trust as Noncognitive Security about Motives," Ethics, 107 (October), 43-61.

Begley, Thomas M., Cynthia Lee, Yongqing Fang, and Jianfeng Li (2002), "Power Distance as a Moderator of the Relationship between Justice and Employee Outcomes in a Sample of Chinese Employees," Journal of Managerial Psychology, 17 (7/8), 692-711.

Beitz, Charles R. (1979), "Bounded Morality: Justice and the State in World Politics," International Organization, 33 (3), 405-424.

Belk, Russell W., Guliz Ger, and Soren Askegaard (2003), "The Fire of Desire: A Multisited Inquiry into Consumer Passion," Journal of Consumer Research, 30 (December), 326-351.

Bello, Daniel C. and Favid I. Gilliland (1997), "The Effect of Output Controls, Process Controls, and Flexibility on Export Channel Performance," Journal of Marketing Research, 61 (January), 22-38.

Bentler, Peter M. and Chih-Ping Chou (1987), "Practical Issues in Structural Modeling," Sociological Methods and Research, 16 (August), 78-117. 
Bergen, M., S. Dutta, and O. Walker (1992), "Agency Relationships in Marketing: A Review of the Implications and Applications of Agency and Related Theories," Journal of Marketing, 56 (July), 1-24.

Bies, Robert J. and Joseph S. (1986), "Interactional justice: Communication Criteria of Fairness," Research on Negotiations in Organizations," Research on Negotiations in Organizations, 1, 43-55.

Bies, Robert J. and Thomas M. Tripp (1996), "Beyond Distrust: 'Getting Even' and the Need for Revenge," in Trust in Organizations: Frontiers of Theory and Research, ed. Roderick M. Kramer and Tom R. Tyler, Thousand Oaks, CA: Sage Publication, 246-259.

Bies, Robert J. and Thomas M. Tripp (2000), "A Passion for Justice: The Rationality and Morality of Revenge," in Justice in the Workplace, Vol. 2, ed. R. Cropanzano, Mahwah, NJ: Lawrence Erlbaum Associates, 197-208.

Bies, Robert J., Thomas M. Tripp, and Roderick M. Kramer (1997), "At the Breaking Point: Cognitive and Social Dynamics of Revenge in Organizations," in Antisocial Behavior in Organizations, ed. Robert A. Giacalone and Jerald Greenberg, Thousand Oaks, CA: Sage Publications, 18-36.

Bies, Robert J. and Tom R. Tyler (1993), "The 'Litigation Mentality' in Organizations: A Test of Alternative Psychological Explanations," Organization Science, 4 (3), 352-366.

Blau, Peter M. (1964), Exchange and Power in Social Life, New York, NY: Wiley.

Blau, Peter M. and W. Richard Scott (1962), Formal Organizations: A Comparative Analysis, San Francisco, CA: Chandler.

Blois, Keith J. (1999), "Trust in Business to Business Relationships: An Evaluation of Its Status," Journal of Management Studies, 36 (2), 197-215.

Blois, Keith J. and Bjoern S. Ivens (2006), "Measuring Relationship Norms: Some Methodological Issues," European Journal of Marketing, 40 (3/4), 352-365.

Blumberg, Boris F. (2001), "Cooperation Contracts between Embedded Firms," Organization Studies, 22 (5), 825-852.

Bollen, Kenneth and Richard Lennox (1991), "Conventional Wisdom on Measurement: A Structural Equation Perspective," Psychological Bulletin, 110 (2), 205-314.

Bollen, Kenneth and J. Scott Long (1993), Testing Structural Equation Models, Newbury Park, CA: Sage. 
Bone, Paula Fitzgerald and Robert John Corey (2000), "Packaging Ethics: Perceptual Differences Among Packaging Professionals, Brand Managers and EthicallyInterested Consumers," Journal of Business Ethics, 24 (3), 199-213.

Bowie, Norman E. and R. Edward Freeman (1992), "Ethics and Agency Theory: An Introduction," in Ethics and Agency Theory, ed. N. E. Bowie and R. E. Freeman, New York: NY: Oxford University Press, 3-22.

Bowles, Samuel and Herbert Gintis (1988), "Contested Exchange: Political Economy and Modern Economic Theory," The American Economic Review, 78 (2), 145-150.

Brass, Daniel J., Kenneth D. Butterfield, and Bruce C. Skaggs (1998), "Relationships and Unethical Behavior: A Social Network Perspective," Academy of Management Review, 23 (1), 14-31.

Brehm, Jack W. (1966), A Theory of Psychological Reactance, New York, NY: Academic Press.

Brewer, Marilynn B. (1979), "In-group Bias in the Minimal Intergroup Situation: A Cognitive-Motivational Analysis," Psychological Bulletin, 86 (2), 307-324.

Brockner, Joel and Phyllis SIegel (1996), "Understanding the Interaction between Procedural and Distributive Justice," in Trust in Organizations: Frontiers of Theory and Research, ed. Roderick M. Kramer and Tom R. Tyler, Thousand Oaks, CA: Sage Publications, 390-413.

Brockner, Joel and Batia M. Weisnfield (1996), "An Integrative Framework for Explaining Reactions to Decision: Interactive Effects of Outcomes and Procedures," Psychological Bulletin, 120 (2), 189-208.

Brown, James R., Chekitan S. Dev, and Dong-Jin Lee (2000), "Managing Marketing Channel Opportunism: The Efficacy of Alternative Governance Mechanisms," Journal of Marketing, 64 (April), 51-65.

Brown, James R., Anjala S. Krishen, and Chekitan S. Dev (2007), "Managing Opportunism in Marketing Channels: A Dyadic Analysis of Intra-Brand Relationships: Working Paper."

Brown, Steven P., Pamela M. Homer, and J. Jeffrey Inman (1998), "A Meta-Analysis of Relationships between Ad-Evoked Feelings and Advertising Responses," Journal of Marketing Research, 35 (February), 114-126.

Bryne, B. M. (2000), Structural Equation Modeling with AMOS: Basic Concepts, Applications, and Programming, Mahwah, NJ: Lawrence Erlbaum Associates. 
Bryne, Edmund F. (2002), "Business Ethics: A Helpful Hybrid in Search of Integrity," Journal of Business Ethics, 37 (2), 121-133.

Buchanan, Lauranne (1992), "Vertical Trade Relationships: The Role of Dependence and Symmetry in Attaining Organizational Goals," Journal of Marketing Research, 26 (February), 65-75.

Burns, Alvin C. and Ronald F. Bush (2005), Marketing Research, Upper Saddle River, NJ: Prentice-Hall.

Burns, Jane O. and Pamela Kiecker (1995), "Tax Practitioner Ethics: An Empirical Investigation of Organizational Consequences," The Journal of the American Taxation Association, 17 (2), 20-49.

Burroughs, James E. and David Glen Mick (2004), "Exploring Antecedents and Consequences of Consumer Creativity in a Problem-Solving Context," Journal of Consumer Research, 31 (September), 402-411.

Burt, Ronald (1992), Structural Holes: The Social Structure of Competition, Cambridge, MA: Harvard University Press.

Buvik, Arnt and George John (2000), "When does vertical coordination improve industrial purchasing relationships?," Journal of Marketing, 64 (October), 52-64.

Cadotte, Ernest R. and Louis Stern (1979), "A Process Model of Interorganizational Relations in Marketing Channels," in Research in Marketing, Vol. 2, Greenwich, CT: JAI Press, Inc.

Campbell, D. and D. Fiske (1959), "Convergent and Discriminant Validation by the Multitrait-Multimethod Matrix," Psychological Bulletin, 56 (2), 81-105.

Campbell, John P. and Robert D. Pritchard (1976), "Motivational Theory in Industrial and Organizational Psychology," in Handbook of Industrial and Organizational Psychology, ed. Edwin E. Ghiselli and Rand McNally, Chicago, IL: Collegy Publishing, 63-130.

Cannon, Joseph P. and Jr. William D. Perreault (1999), "Buyer-Seller Relationships in Business Markets," Journal of Marketing Research, 36 (November), 439-460.

Carson, Stephen J., Anoop Madhok, and Tao Wu (2006), "Uncertainty, Opportunism, and Governance: The Effects of Volatility and Ambiguity on Formal and Relational Contracting," Academy of Management Journal, 49 (5), 1058-1077.

Castleberry, Stephen B., Warren French, and Barbara A. Carlin (1993), "The Ethical Framework of Advertising and Marketing Research Practitioners: A Moral Development Perspective," Journal of Advertising, 22 (2), 39-46. 
Cavusgil, S. Tamer, Seyda Deligonoul, and Chun Zhang (2004), "Curbing Foreign Distributor Opportunism: An Examination of Trust, Contracts, and Legal Environment in International Channel Relationships," Journal of International Marketing, 12 (2), 7-27.

Celly, Kirti Sawhney and Gary L. Frazier (1996), "Outcome-Based and Behavior-Based Coordination Efforts in Channel Relationships," Journal of Marketing Research, 33 (May), 200-210.

Chasse, John Dennis (1991), "John R. Commons and John Maynard Keynes: Two Philosophies of Action," Journal of Economic Issues, 25 (2), 441-448.

Chen, Al. Y. S., Roby B. Sawyers, and Paul F. Williams (1997), "Reinforcing Ethical Decision Making Through Corporate Culture," Journal of Business Ethics, 16 (8), 855-865.

Chen, Chao C., James R. Meindl, and Harry Hui (1998), "Deciding on Equity or Parity: A Test of Situational, Cultural, and Individual Factors," Journal of Organizational Behavior, 19, 115-129.

Chen, Chao C., Mike W. Peng, and Patrick A. Saparito (2002), "Individualism, Collectivism, and Opportunism: A Cultural Perspective on Transaction Cost Economics," Journal of Management, 28 (4), 567-583.

Cherry, John and John Fraedrich (2000), "An Empirical Investigation of Locus of Control and the Structure of Moral Reasoning: Examining the Ethical Decision-Making Processes of Sales Managers," Journal of Personal Selling \& Sales Management, 20 (3), 173-188.

Chow, Lilly and Lorelle Frazer (2003), "Servicing Customers Directly: Mobile Franchising Arrangements in Australia," Journal of Marketing, 37 (3/4), 596-613.

Christie, P. Maria Joseph, Ik-Whan G. Kwon, Phillipp A. Stoeberl, and Raymond Baumhart (2003), "A Cross-Cultural Comparison of Ethical Attitudes of Business Managers: India, Korea, and United States," Journal of Business Ethics, 46 (3), 263-387.

Christie, Richard and Florence Geis (1970), Studies in Machiavellianism, New York, NY: Academic Press.

Churchill, Gilbert A. (1979), "A Paradigm for Developing Better Measures of Marketing Constructs " Journal of Marketing Research, 16 (February), 64-73.

Cobb, Anthony T., Robert Folger, and Kevin Wooten (1995), "The Role Justice Plays in Organizational Change," Public Administration Quarterly, 19 (2), 135-152. 
Cobb, Anthony T. and Francis M. Frey (1996), "The Effects of Leader Fairness and Pay Outcomes on Superior/Subordinate Relations," Journal of Applied Social Psychology, 26 (16), 1401-1426.

Coff, Russell W. (1997), "Human Assets and Management Dilemmas: Coping With Hazards on the Road to Resource-Based Theory," Academy of Management Review, 22 (2), 374-402.

Cohen, Jacob (1969), Statistical Power Analysis for the Behavioral Sciences, New York: Academic Press.

Cohen, Patricia, Jacob Cohen, Jeanne Teresi, Margaret Marchi, and Noemi Verez (1990), "Problems in the Measurement of Latent Variables in Structural Equations Casual Models," Applied Psychological Measurement, 14 (June), 183-196.

Cohen-Charash and Paul E. Spector (2001), "The Role of Justice in Organizations: A Meta-Analysis," Organizational Behavior and Human Decision Processes, 86 (2), 278-321.

Colby, Ann and Lawrence Kohlberg (1987), The Measurement of Moral Judgment: Theoretical Validation and Research Validation, Cambridge, UK: Cambridge University Press.

Colby, Ann, Lawrence Kohlberg, John Gibbs, and Marcus Lieberman (1983), "A Longitudinal Study of Moral Judgment," Monographs of the Society for Research in Child Development, 48 (1/2).

Coleman, James S. (1988), "Social Capital in the Creation of Human Capital," American Journal of Sociology, 94 (Supplement), S95-S120.

Coleman, James S. (1990), Foundations of Social Theory, Cambridge, MA: Harvard University Press.

Collins, Alan and Steve Burt (2003a), "Market Sanctions, Monitoring and Vertical Coordination within Retailer-Manufacturer Relationships," Journal of Marketing, $47(5 / 6), 668-689$.

Collins, Alan and Steve Burt (2003b), "Market Sanctions, Monitoring and Vertical Coordination within Retailer-Manufacturer Relationships: The Case of Retail Brand Suppliers," European Journal of Marketing, 37 (5/6), 668-689.

Colquitt, Jason A. (2001), "On the Dimensionality of Organizational Justice: A Construct Validation of a Measure," Journal of Applied Psychology, 86 (3), 386-400. 
Colquitt, Jason A., Donald E. Conlon, Michael J. Wesson, Christopher O. L. H. Porter, and K. Yee Ng (2001), "Justice at the Millennium: A Meta-Analytic Review of 25 years of Organizational Justice Research," Journal of Applied Psychology, 86 (3), 425-429.

Conlon, Edward J. and Judi McLean Parks (1990), "Effects of Monitoring and Tradition on Compensation Arrangements: An Experiment with Principal-Agent Dyads," Academy of Management Journal, 33 (3), 603-622.

Conner, Mark and Christopher J. Armitage (1998), "Extending the Theory of Planned Behavior: A Review and Avenues for Further Research," Journal of Applied Social Psychology, 28 (15), 1429-1464.

Connolly, J. and M. McCarrey (1978), "The Relationship between Levels of Moral Judgment Maturity and Locus of Control," Canadian Journal of Behavioral Sciences, 10 (2), 162-175.

Connolly, Terry (1976), "Some Conceptual and Methodological Issues in Expectancy Models of Work Performance Motivation," Academy of Management Review, 1 (4), 37-42.

Cook, Karen S. and Richard M. Emerson (1978), "Power, Equity, and Commitment in Exchange Networks," American Sociological Review, 43 (3), 721-739.

Cook, Karen S. and Toshio Yamagishi (1983), "Social Determinants of Equity Judgments: The Problem of Multidimentional Input," in Equity Theory, ed. David M. Messick and Karen S. Cook, New York, NY: Praeger Publishers, 95-126.

Cordano, Mark and Irene Hanson Frieze (2000), "Pollution Reducion Preferences of U.S. Environmental Managers: Applying Ajzen's Theory of Planned Behavior," Academy of Management Journal, 43 (4), 627-641.

Corsten, Daniel and Nirmalya Kumar (2005), "Do Suppliers Benefit from Collaborative Relationships with Large Retailers? An Empirical Investigation of Efficient Consumer Response Adoption," Journal of Marketing, 69 (July), 80-94.

Cote, Joseph and M. Ronald Buckley (1987), "Estimating Trait, Method, and Error Variance: Generalizing Across Construct Validation Studies," Journal of Marketing Research, 24 (August), 315-318.

Cote, Jane and Jerry Goodstein (1998), "A Breed Apart? Security Analysts and Herding Behavior," Journal of Business Ethics, 18 (3), 305-314.

Cowen, Tyler and Amihai Glazer (1996), "More Monitoring can Induce Less Effort," Journal of Economic Behavior \& Organizations, 30 (1), 113-123. 
Coyle-Shapiro and Jacqueline A-M. (2002), "A Psychological Contract Perspective on Organizational Citizenship Behavior," Journal of Organizational Behavior, 23 (8), 927-946.

Cronbach, Lee J. (1971), "Test Validation," in Educational Measurement ed. Robert L. Thorndike, Washington, D.C.: American Council on Education, 443-507.

Cropanzano, Russell and Marjorie L. Randall (1993), "Injustice and Work Behavior: A Historical Review," in Justice in the Workplace: Approaching Fairness in Human Resource Management, ed. R. Cropanzano, Hillsdale, NJ: Lawrence Erlbaum Associates, 3-20.

Cullen, John B., Bart Victor, and James W. Bronson (1993), "The Ethical Climate Questionnaire: An Assessment of Its Development and Validity," Psychological Reports, 73, 667-674.

Cyriac, K. and R. Dharmaraj (1994), "Machiavellianism in Indian Management," Journal of Business Ethics, 13 (4), 281-286.

Dahlstrom, Robert and Arne Nygaard (1999), "An Empirical Investigation of Ex Post Transaction Costs in Franchised Distribution Channels," Journal of Marketing Research, 36 (May), 160-170.

Dailym, Catherine M., Dan R. Dalton, and Mandini Rajagopalan (2003), "Governance Through Ownership: Centuries of Practice, Decades of Research," Academy of Management Journal, 46 (2), 151-158.

Dal Bo, Pedro (2005), "Cooperation Under the Shadow of the Future: Experimental Evidence from Infinitely Repeated Games," American Economic Review, 95 (5), 1591-1603.

Das, T. K. and Bing-Sheng Teng (1998), "Between Trust and Control: Developing Confidence in Partner Cooperation in Alliances," Academy of Management Review, 23 (3), 491-512.

Das, T. K. and Bing-Sheng Teng (2000), "Instabilities of Strategic Alliances: An Internal Tensions Perspective," Organization Science, 11 (1), 77-101.

Davenport, Thomas, Robert G. Eccles, and Laurence Prusak (1992), "Information Politics," Sloan Management Review, 34 (1), 53-65.

Davis, James H., F. David Schoorman, and Lex Donaldson (1997), "Toward A Stewardship Theory of Management," Academy of Management Review, 22 (1), $20-47$. 
Davis, Mark A., Mark G. Anderson, and Mary B. Curtis (2001), "Measuring Ethical Ideology in Business Ethics: A Critical Analysis of the Ethics Position Questionnaire," Journal of Business Ethics, 32 (1), 35-53.

Davison, Mark L. and Stephen Robbins (1978), "The Reliability and Validity of Objective Indices of Moral Development," Applied Psychological Measurement, 2 (3), 391-403.

Deci, Edward L. and Richard M. Ryan (1985), Intrinsic Motivation and SelfDetermination in Human Behavior, New York, NY: Plenum Press.

Deci, Edward L. and Richard M. Ryan (1987), "The Support of Autonomy and the Control of Behavior," Journal of Personality and Social Psychology, 53 (6), 1024-1037.

Deeds, David L. and Charles W. L. Hill (1998), "An Examination of Opportunistic Action Within Research Alliances: Evidence from the Biotechnology Industry," Journal of Business Venturing, 14 (2), 141-163.

Dees, J. Gregory (1992), "Principals, Agents, and Ethics," in Ethics and Agency Theory, ed. N. E. Bowie and R. E. Freeman, New York, NY: Oxford University Press, 2558.

Deflumeri , J. (1982), "Teachers' Moral Reasoning," Unpublished Doctoral Dissertation.

DeGeorge, Richard T. (1992), "Agency Theory and the Ethics of Agency," in Ethics and Agency Theory, ed. N. E. Bowie and R. E. Freeman, New York, NY: Oxford University Press, 59-72.

DeGeorge, Richard T. (1992), "Agency Theory and the Ethics of Agency," in Ethics and Agency Theory, ed. N. E. Bowie and R. E. Freeman, New York, NY: Oxford University Press, 59-72.

Deligonul, Seyda, Daekwan Kim, Anthony S. Roath, and Erin Cavusgil (2006), "The Achilles' Heel of an Enduring Relationship: Appropriation of Rents between A Manufacturer and its Foreign Distributor," Journal of Business Research, 59 (7), 802-810.

Deutsch, Morton (1975), "Equity, Equality, and Need: What Determines Which Value Will Be Used as the Basis of Distributive Justice," Journal of Social Issues, 31 (3), 137-149.

Doll, Jorg and Icek Ajzen (1992), "Accessibility and Stability of Predictors in the Theory of Planned Behavior," Journal of Personality and Social Psychology, 63 (5), 754765. 
Donaldson, Thomas and Thomas W. Dunfee (1994), "Toward A Unified Conception of Business Ethics: Integrative Social Contracts Theory," Academy of Management Review, 19 (2), 252-284.

Dore, Ronald (1983), "Goodwill and the Spirit of Market Capitalism," The British Journal of Sociology, 36 (4), 459-482.

Douglas, Mary (1990), "Converging on Autonomy: Anthropology and Institutional Economics," in Organization Theory: From Chester Barnard to the Present and Beyond, ed. Oliver Williamson, 98-115.

Downey, Ronald G. and Craig V. King (1995), "Missing Data in Likert Ratings: A Comparison of Substitution Techniques," in 11th Annual Conference of the Society for Industrial and Organizational Psychology, San Diego, CA.

Dozier, Janelle Brinker and Marcia P. Miceli (1985), "Potential Predictors of WhistleBlowing: A Prosocial Behavior Perspective," Academy of Management Review, $10(4), 823-836$.

Dunfee, Thomas W., N. Craig Smith, and William T. Ross (1999), "Social Contracts and Marketing Ethics," Journal of Marketing, 63 (July), 14-32.

Duska, Ronald F. (1992), "Why Be a Loyal Agent? A Systematic Ethical Analysis," in Ethics and Agency Theory, ed. N. E. Bowie and R. E. Freeman, New York: NY: Oxford University Press, 143-168.

Dwyer, F. Robert and Sejo Oh (1987), "Output sector Munificence Effects on the Internal Political Economy of Marketing Channels," Journal of Marketing Research, 24 (November), 347-358.

Dwyer, Robert F., Paul H. Schurr, and Sejo Oh (1987), "Developing Buyer-Seller Relationships," Journal of Marketing, 51 (April), 11-27.

Dyer, Jeffrey F. (1996), "Specialized Supplier Networks as a Source of Competitive Advantage: Evidence from the Auto Industry," Strategic Management Journal, 17 (4), 271-291.

Eagly, Alice H. and Shelly Chaiken (1993), The Psychology of Attitudes, Fort Worth, TX: Harcourt Brace Jovanovich.

Eisenhardt, Kathleen and Claudia Bird Schoonhoven (1996), "Resource-Based View of Strategic Alliance Formation: Strategic and Social Effects in Entrepreneurial Firms," Organization Science, 7 (2), 136-150.

Eisenhardt, Kathleen M. (1985), "Control: Organizational and Economic Approaches," Management Science, 31 (February), 134-149. 
Eisenhardt, Kathleen M. (1989), "Agency Theory: An Assessment and Review," Academy of Management Review, 14 (1), 57-74.

Elangovan, A. R. and Debra L. Shapiro (1998), "Betrayal of Trust in Organizations," Academy of Management Review, 23 (3), 547-566.

Emerson, Richard M. (1962), "Power-Dependence Relations," American Sociological Review, 27 (February), 31-41.

Etheredge, John M. (1999), "The Perceived Role of Ethics and Social Responsibility: An Alternative Scale Structure," Journal of Business Ethics, 18 (1), 51-64.

Excline, Ralph V., John Thibaut, Carole B. Hickey, and Peter Gumpert (1970), "Visual Interaction in Relation to Machiavellianism and an Unethical Act," in Studies in Machiavellianism, ed. Richard Christie and Florence L. Geise: New York, NY, 53-75.

Fama, Eugene F. (1980), "Agency Problems and the Theory of the Firm," Journal of Political Economy, 88 (April), 288-307.

Fama, Eugene F. and Michael C. Jensen (1983), "Agency Problems and Residual Claims," Journal of Law and Economics, 26 (June), 327-379.

Fein, Adam J. and Erin Anderson (1997), "Patterns of Credible Commitments: Territory and Brand Selectivity in Industrial Distribution Channels," Journal of Marketing, 61 (April), 19-34.

Ferrell, O. C. and Larry G. Gresham (1985), "A Contingency Framework for Understanding Ethical Decision Making in Marketing," Journal of Marketing, 49 (Summer), 87-96.

Ferrell, O. C., Larry G. Gresham, and John Fraedrich (1989), "A Synthesis of Ethical Decision Models for Marketing," Journal of Macromarketing, 9 (Fall), 55-64.

Festinger, Leon (1957), A Theory of Cognitive Dissonance, Evanston, IL: Row Peterson $\&$ Co.

Finkbeiner, Carl (1979), "Estimation for the Multiple Factor Model When Data are Missing," Psychometrika, 44 (4), 409-420.

Fischer, Donald G. and Carol Fick (1993), "Measuring Social Desirability: Short Forms of the Marlowe-Crowne Social Desirability Scale," Educational and Psychological Measurement, 53, 417-424. 
Fishbein, Martin (1967), "Attitude and Prediction of Behavior," in Readings in Attitude Theory and Measurement, ed. Martin Fishbain, New York John Wiley \& Sons, 477-492.

Fishbein, Martin and Icek Ajzen (1975), Belief, Attitude, Intention, and Behavior: An Introduction to Theory and Research. Reading, Reading, MA: Addison-Wesley Publishing, Co.

Flannery, Brenda L. and Douglas R. May (2000), "Environmental Ethical Decision Making in the U.S. Metal-Finishing Industry," Academy of Management Journal, 43 (4), 642-662.

Folger, Robert and Jerald Greenberg (1985), "Procedural Justice: An Interpretive Analysis of Personnel Systems," Research in Personnel and Human Resources Management, 3 (141-183).

Folger, Robert and Mary A. Konovsky (1989), "Effects of Procedural and Distributive Justice on Reactions to Pay Raise Decisions," Academy of Management Journal, 32 (1), 115-130.

Ford, Robert C. and Woodrow D. Richardson (1994), "Ethical Decision Making: A Review of the Empirical Literature," Journal of Business Ethics, 13 (3), 205-221.

Fornell, Claes and David F. Larcker (1981), "Structural Equation Models with Unobservable Variables and Measurement Error: Algebra and Statistics," Journal of Marketing Research, 18 (August), 382-388.

Forsyth, Donelson R. (1981), "Moral Judgment: The Influence of Ethical Ideology," Personality and Social Psychology Bulletin, 7 (June), 218-223.

Forsyth, Donelson R. (1992), "Judging the Morality of Business Practices: The Influence of Personal Moral Philosophies," Journal of Business Ethics, 11 (May), 461-470.

Fort, Timothy L. (2001), Ethics and Governance, New York, NY: Oxford University Press.

Forte, Almerinda (2005), "Locus of Control and the Moral Reasoning of Managers," Journal of Business Ethics, 58 (1), 65-77.

Fraedrich, John and O. C. Ferrell (1992), "Cognitive Consistency of Marketing Managers in Ethical Situations," Journal of the Academy of Marketing Science, 20 (Summer), 245-252.

Fraedrich, John, Debbie M. Thorne, and O. C. Ferrell (1993), "Assessing the Application of Cognitive Moral Development Theory to Business Ethics," Journal of Business Ethics, 13 (10), 829-838. 
Frances-Gomez, Pedro (2003), "Some Difficulties in Sacconi's View about Corporate Ethics," Journal of Business Ethics, 42 (2), 165-180.

Frank, Robert H. (1988), Passions Within Reasons: The Strategic Roles of Emotions, New York, NY: W. W. Norton \& Company.

Frankel, M. S. (1989), "Professional Codes: Why, How, and WIth What Impact?," Journal of Business Ethics, 8 (2/3), 109-115.

Frankena, William (1963), Ethics, Englewood Cliffs, NJ: Prentice-Hall.

Frazier, Gary L., James D. Gill, and Sudhir H. Kale (1989), "Dealer Dependence Levels and Reciprocal Actions in a Channel of Distribution in a Developing Country," Journal of Marketing, 53 (January), 50-69.

Frazier, Gary L., Robert E. Spekman, and Charles R. O'Neal (1988), "Just-In-Time Exchange Relationships in Industrial Markets," Journal of Marketing, 52 (October), 52-67.

Frey, Bruno S. (1993), "Does Monitoring Increase Work Effort? The Rivalry with Trust and Loyalty," Economic Inquiry, 31 (4), 663-670.

Friedkin, Noah (1984), "Structural Cohesion and Equivalence Explanations of Social Homogeneity," Sociological Methods and Research, 12 (September), 235-261.

Fritzsche, David J. (2000), "Ethical Climates and the Ethical Dimension of Decision Making," Journal of Business Ethics, 24 (2), 125-140.

Fritzsche, David J. and Helmut Becker (1984), "Linking Management Behavior to Ethical Philosophy - An Empirical Investigation," Academy of Management Journal, 27 (1), 166-175.

Gable, M., C. Hollon, and F. Dangello (1990), "Relating Locus of Control to Machiavellianism and Managerial Achievement," Psychological Reports, 67, 339-343.

Galaskiewicz, Joseph and Stanley Wasserman (1989), "Mimetic Processes Within an Interorganizational Field: An Empirical Test," Administrative Science Quarterly, 34 (September), 454-479.

Ganesan, Shankar (1994), "Determinants of Long-Term Orientation in Buyer-Seller Relationships," Journal of Marketing, 58 (April), 1-19.

Garbarino, Ellen and Mark S. Johnson (1999), "The Different Roles of Satisfaction, Trust, and Commitment in Customer Relationships," Journal of Marketing, 63 (April), 70-89. 
Gassenheimer, Jule B., Franklin S. Houston, and J. Charlene Davis (1998), "The Role of Economic Value, Social Value, and Perceptions of Fairness in Interorganizational Relationship Retention Decisions," Journal of the Academy of Marketing Science, 26 (4), 322-327.

Geis, Florence L. and Tae Hyun Moon (1981), "Machiavellianism and Deception," Journal of Personality and Social Psychology, 63 (August), 451-457.

Geyskens, Inge, Jan-Benedict E.M. Steenkamp, and Nirmalya Kumar (1999), "A MetaAnalysis of Satisfaction in Marketing Channel Relationships," Journal of Marketing Research, 36 (May), 223-238.

Ghosh, Mrinal and George John (2000), "Experimental Evidence for Agency Models of Salesforce Compensation," Marketing Science, 19 (4), 348-365.

Ghoshal, Sumantra and Peter Moran (1996), "Bad For Practice: A Critique of the Transaction Cost Theory," Academy of Management Review, 21 (1), 13-47.

Gibbons, Robert (2001), "Trust in Social Structures: Hobbes and Coase Meet Repeated Games," in Trust in Society, ed. Karen S. Cook, New York, NY: Russell Sage Publication, 332-353.

Gilbert, Daniel R. (1996), "The Prisoner's Dilemma and the Prisoners of the Prisoner's Dilemma," Business Ethics Quarterly, 6 (2), 165-178.

Gilliland, David I. and Daniel Bello (2002), "Two sides to Attitudinal Commitment: The Effect of Calculative and Loyalty Commitment on Enforcement Mechanisms in Distribution Channels," Journal of the Academy of Marketing Science, 30 (1), 2443.

Gnyawali, Devi R. and Ravindranath Madhavan (2001), "Cooperative Networks and Competitive Dynamics: A Structural Embeddedness Perspective," Academy of Management Review, 26 (3), 431-445.

Goolsby, Jerry R. and Shelby D. Hunt (1992), "Cognitive Moral Development and Marketing," Journal of Marketing, 56 (January), 55-68.

Gouldner, Alvin W. (1960), "The Norm of Reciprocity: A Preliminary Statement," American Sociological Review, 25 (2), 161-178.

Granitz, Neil A. (2003), "Individual, Social and Organizational Sources of Sharing and Variation in the Ethical Reasoning of Managers," Journal of Business Ethics, 42, 101-124.

Granovetter, Mark (1985), "Economic Action and Social Structure: The Problem of Embeddedness," American Journal of Sociology, 91 (3), 481-510. 
Gray, Brendan, Sheelagh Matear, Christo Boshoff, and Phil Matheson (1998),

"Developing A Better Measure of Market Orientation," European Journal of Marketing, 32 (9/10), 884-903.

Greenberg, Jerald (1982), "Approaching Equity and Avoiding Inequity in Groups and Organizations," in Equity and Justice in Social Behavior, ed. Jerald Greenberg and Ronald R. Cohen, New York, NY: Academic Press, 389-435.

Greenberg, Jerald (1984), "On the Apocryphal Nature of Inequity Distress," in The Sense of Injustice: Social Psychological Perspective, ed. Robert Folger, New York, NY: Plenum Press, 166-186.

Greenberg, Jerald (1987), "A Taxonomy of Organizational Justice Theories," Academy of Management Review, 12 (1), 9-22.

Greenberg, Jerald (1990), "Organizational Justice: Yesterday, Today, and Tomorrow," Journal of Management, 16 (2), 399-432.

Greenberg, Liane and Julian Barling (1999), "Predicting Employee Aggression Against Coworkers, Subordinates and Supervisors: The Roles of Person Behaviors and Perceived Workplace Factors," Journal of Organizational Behavior, 20 (6), 897913.

Griesinger, Donald W. (1990), "The Human Side of Economic Organization," Academy of Management Review, 15 (3), 478-499.

Gross, Michael (1999), "Ethics Education and Physician Morality," Social Science \& Medicine, 49, 329-342.

Gross, Michael L. (1997), Ethics and Activism: The Theory and Practice of Political Morality, New York, NY: Cambridge University Press.

Grunhagen, Marko, Michael J Dorsch, and James W Gentry (2002), "Does the Franchisor Provide Value to Franchisees? Past, Current, and Future Value Assessments of Two Franchisee Types," in Winter Educators' Conference: Marketing Theory and Applications, Vol. 13, ed. Kenneth R. Evans and Lisa K. Scheer, Austin, TX: American Marketing Association, 506.

Guilford, J. P. (1954), Psychometric Methods, New York, NY: McGraw-Hill.

Gundlach, Gregory and Ernest R. Cadotte (1994), "Exchange Interdependence and Interfirm Interaction: Research in a Simulated Channel Setting," Journal of Marketing Research, 31 (November), 516-532.

Gundlach, Gregory T. and Patrick E. Murphy (1993), "Ethical and Legal Foundations of Relational Marketing Exchanges," Journal of Marketing, 57 (October), 35-46. 
Guth, Werner, Rolf Sdhmittberger, and Bernd Schwarze (1982), "An Experimental Analysis of Ultimatum Game," Journal of Economic Behavior and Organization, $3,367-388$.

Hackett, Steven C. (1994), "Is Relational Exchange Possible in the Absence of Reputations and Repeated Contract?," Journal of Law, Economics, and Organization, 10 (2), 360-389.

Hagen, James M. and Soonkyoo Choe (1998), "Trust in Japanese Interfirm Relations: Institutional Sanctions Matter," Academy of Management Review, 23 (3), 589600 .

Häkansson, Häkan and Jan Johanson (1993), "Industrial Functions of Business Relationships," in Advances in International Marketing, Vol. 5, D. Deo Sharma, ed. Greenwich, CT: JAI Press, 15-31.

Hardin, Russell (2001), "Conceptions and Explanations of Trust," in Trust in Society, ed. Karen S. Cook, New York, NY: Russell Sage Publication, 3-39.

Hegarty, W. Harvey and Henry P. Sims (1978), "Some Determinants of Unethical Decision Behavior: An Experiment," Journal of Applied Psychology, 63 (4), 451457.

Hegarty, W. Harvey and Henry P. Sims (1979), "Organizational Philosophy, Policies, and Objectives Related to Unethical Decision Behavior: A Laboratory Experiment," Journal of Applied Psychology, 64 (3), 331-338.

Heide, Jan B. and George John (1990), "Alliances in Industrial Purchasing: The Determinants of Joint Action in Buyer-Supplier Relationships," Journal of Marketing Research, 27 (February), 24-36.

Heide, Jan B. and George John (1992), "Do Norms Matter in Marketing Relationships?," Journal of Marketing, 56 (April), 32-44.

Heide, Jan B. and Anne S. Miner (1992), "The Shadow of the Future: Effects of Anticipated Interaction and Frequency of Contact on Buyer-Seller Cooperation," Academy of Management Journal, 35 (2), 265-291.

Heide, Jan B. and Allen M. Weiss (1995), "Vendor Consideration and Switching Behavior for Buyers in High-Technology Markets," Journal of Marketing, 59 (July), 30-43.

Heiman, Bruce and Jack A. Nickerson (2002), "Towards Reconciling Transaction Cost Economics and the Knowledge-based View of the Firm," International Journal of Economics of Businesses, 9 (1), 97-116. 
Henderson, Andrew D. and James W. Fredrickson (2001), "Top Management Team Coordination Needs and the CEO Pay Gap: A Competitive Test of Economic and Behavioral Views," Academy of Management Journal, 44 (1), 96-117.

Hennig-Thurau, Thorsten, Mark B Houston, and Gianfranco Walsh (2006), "The Differing Roles of Success Drivers Across Sequential Channels: An Application to the Motion Picture Industry," Journal of the Academy of Marketing Science, 34 (Fall), 559-575.

Herndon, Neil C., John P. Fraedrich, and Quey-Jen Yeh (2001), "An Investigation of Moral Values and the Ethical Content of the Corporate Culture: Taiwanese versus U.S. Sales People," Journal of Business Ethics, 30 (1), 73-85.

Hibbard, Jonathan D., Nirmalya Kumar, and Louis W. Stern (2001), "Examining the Impact of Destructive Acts in Marketing Channel Relationships," Journal of Marketing Research, 38 (February), 45-61.

Ho, Foo Nin, Scott J. Vitell, James H. Barnes, and Rene Desborde (1997), "Ethical Correlates of Role Conflict and Ambiguity in Marketing: The Mediating Role of Cognitive Moral Development," Journal of the Academy of Marketing Science, 25 (Spring), 117-126.

Holmstrom, Bengt (1979), "Moral Hazard and Observability," Bell Journal of Economics, 10 (Spring), 74-91.

Holmstrom, Begt and John Roberts (1998), "The Boundaries of the Firm Revisited," Journal of Economic Perspectives, 12, 73-94.

Homans, George (1961), Social Behavior: Its Elementary Form, New York, NY: Harcourt, Brace \& World.

Homans, George C. (1958), "Social Behavior as Exchange," American Journal of Sociology, 63, 597-606.

Hopkinson, Gillian C. and Sandra Hogarth-Scott (1999), "Franchise Relationship Quality: Micro-Economic Explanations," European Journal of Marketing, 33 (9/10), 827-843.

Hosmer, Larue Tone (1995), "Trust: The Connecting Link Between Organizational Theory and Philosophical Ethics," Academy of Management Review, 20 (2), 379403.

Hovorka-Mead, William H. Audra, Tracy Whipple Ross, and Michella B. Benchin (2002), "Watching the Detectives: Seasonal Student Employee Reactions to Electronic Monitoring with and without Advance Notification," Personnel Psychology, 55 (2), 329-362. 
Howell, Roy (1987), "Covariance Structure Modeling and Measurement Issues: A Note on 'Interrelations Among A Channel Entity's Power Sources," Journal of Marketing Research, 24 (February), 119-126.

Hu, L. and P. M. Bentler (1995), "Evaluating Model Fit," in Structural Equation Modeling: Concepts, Issues, and Application, ed. R. Hoyle, Thousand Oaks, CA: Sage 76-99.

Huff, Lenard and Lane Kelley (2003), "Levels of Organizational Trust in Individualist Versus Collectivist Societies: A Seven-Nation Study," Organization Science, 14 (1), 81-90.

Hunt, Herbert G. (1986), "The Separation of Corporate Ownership and Control: Theory, Evidence, and Implications," Journal of Accounting Literature, 5, 85-124.

Hunt, Shelby D. and Lawrence B. Chonko (1984), "Marketing and Machiavellianism," Journal of Marketing, 48 (Summer), 30-42.

Hunt, Shelby D. and Arturo Z. Vasquez-Parraga (1993), "Organizational Consequences, Marketing Ethics, and Salesforce Supervision," Journal of Marketing Research, 30 (February), 78-90.

Hunt, Shelby D. and Scott Vitell (1986), "A General Theory of Marketing Ethics," Journal of Macromarketing, 6 (Spring), 5-16.

Hunt, Shelby D. and Scott Vitell (1991), "The General Theory of Marketing Ethics: A Retrospective and Revision," in Ethics in Marketing, ed. John A. Quelch and N. Craig Smith, Chicago, IL: Richard D. Irwin, 775-784.

Hunter, John E., David W. Gerbing, and Franklin J. Boster (1982), "Machiavellian Beliefs and Personality: Construct Invalidity of the Machiavellianism Dimension," Journal of Personality and Social Psychology, 43 (December), 1293-1305.

Huseman, Richard C., John D. Hatfield, and Edward W. Miles (1987), "A New Perspective on Equity Theory: The Equity Sensitivity Construct," Academy of Management Review, 12 (2), 222-234.

Hutcheson, Graeme and Nick Sofroniou (1999), The Multivariate Social Scientist: Introductory Statistics Using Generalized Linear Models, Thousand Oaks, CA: Sage Publications.

Igalens, Jacques and Patrice Roussel (1999), "A Study of the Relationships between Compensation Package, Work Motivation, and Job Satisfaction," Journal of Organizational Behavior, 20 (7), 1003-1025. 
Im, Subin and Jr. John P. Workman (2004), "Market Orientation, Creativity, and New Product Performance in High-Technology Firms," Journal of Marketing, 68 (April), 114-132.

Imar, Ogenyi Ejye (1998), "Franchising Agreements in New Car Retailing: An Empirical Investigation," The Service Industries Journal, 18 (2), 144-160.

Ingram, Paul (1996), "Organizational Form as a Mechanism for Generating Credible Commitment: The Evolution of Naming Strategy in the U.S. Hospitality Industry," Strategic Management Journal,, 17 (Summer), 85-98.

Issac, Robert G., Wilfred J. Zerbe, and Douglass C. Pitt (2001), "Leadership and Motivation: The Effective Application of Expectancy Theory," Journal of Managerial Issues, 13 (2), 212-226.

Jackson, Susan E. and Randall S. Schuler (1985), "A Meta-Analysis and Conceptual Critique of Research on Role Ambiguity and Role Conflict in Work Settings," Organizational Behavior and Human Decision Processes, 36, 11-78.

Jacobides, Michael G. and David C. Croson (2001), "Information Policy: Shaping the Value of Agency Relationships," Academy of Management Review, 25 (2), 202223.

Jamshidian, Mortaza and Peter M. Bentler (1999), "ML Estimation of Mean and Covariance Structures with Missing Data Using Complete Data Routines," Journal of Educational and Behavioral Statistics, 24 (1), 21-41.

Janssen, Onne (2001), "Fairness Perceptions as a Moderator in the Curvilinear Relationships Between Job Demands, and Job Performance and Job Performance," Academy of Management Journal, 44 (5), 1039-1050.

Jap, Sandy D. (1999), "Pie-Expansion Efforts: Collaboration Processes in Buyer-Supplier Relationships," Journal of Marketing Research, 36 (November), 461-475.

Jap, Sandy D. (2001), "'Pie sharing" in Complex Collaboration Contexts " Journal of Marketing Research, 38 (February), 86-99.

Jap, Sandy D. (2007), "The Impact of Online Reverse Auction Design on Buyer-Supplier Relationships," Journal of Marketing, 71 (January), 146-159.

Jap, Sandy D. and Erin Anderson (2003), "Safeguarding Interorganizational Performance and Continuity Under Ex Post Opportunism," Management Science, 49 (12), 1684-1701. 
Jarvis, Cheryl B., Scott B. MacKenzie, and Philip M. Podsakoff (2003), "A Critical Review of Construct Indicators and Measurement Model Misspecification in Marketing and Consumer Research," Journal of Consumer Research, 30 (September), 199-218.

Jaworski, Bernard J. and Deborah J. MacInnis (1989), "Marketing Jobs and Management Controls: Toward A Framework," Journal of Marketing Research, 26 (November), 406-419.

Jencks, Christopher (1990), "Varieties of Altruism. In Beyond Self-Interest," in Beyond Self-Interest, ed. Jane J. Mansbridge, Chicago, IL: University of Chicago, 53-67.

Jensen, Michael C. (1983), "Agency Costs of Free Cash Flow, Corporate Finance, and Takeovers," American Economic Review, 76 (2), 323-339.

Jensen, Michael C. and William Meckling (1976), "Theory of the Firm: Managerial Behavior, Agency Costs, and Capital Structure," Journal of Financial Economics, 3 (October), 305-360.

Jeuland, Abel P. and Steve M. Shugan (1983), "Managing Channel Profits," Marketing Science, 2 (2), 239-272.

John, George (1984), "An Empirical Investigation of Some Antecedents of Opportunism in A Marketing Channel," Journal of Marketing Research, 21 (August), 278-289.

John, George and Arnt Buvik (2000), "When Does Vertical Coordination Improve Industrial Purchasing Relationships?," Journal of Marketing, 64 (October), 52-64.

John, George and Bart Weitz (1988), "Forward Integration into Distribution: An Empirical Test of Transaction Cost Analysis," Journal of Law, Economics, and Organization, 4 (Fall), 121-139.

Johnson, Jean L., Ravipreet S. Sohi, and Rajdeep Grewal (2004), "The Role of Relational Knowledge Stores in Interfirm Partnering," Journal of Marketing, 68 (July), 2136.

Jones, Candace, William S. Hesterly, and Stephen P. Borgatti (1997), "A General Theory of Network Governance: Exchange Conditions and Social Mechanisms," Academy of Management Review, 22 (4), 911-945.

Jones, E. E. (1985), "Major Developments in Social Psychology during the Past Five Decades," in The Handbook of Social Psychology, ed. G. Lindzey and E. Aronson, New York, NY: Random House, 47-108. 
Jones, Gwen E. (1993), "Unethical Behavioral Intentions in Organizations: Empirical Exploration of an Integrative Model," Unpublished Doctoral Dissertation, State University of New York at Albany.

Jones, Gwen E. and Michael J. Kavanagh (1996), "An Experimental Examination of the Effects of Individual and Situational Factors on Unethical Behavioral Intensions in the Workplace," Journal of Business Ethics, 15, 511-523.

Jones, Thomas M. (1991), "Ethical Decision Making by Individuals in Organizations: An Issue-Contingent Model," Academy of Management Review, 16 (2), 366-395.

Jöreskog, Karl and Dag Sörbom (1995), LISREL 8: New Statistical Features, Chicago: Scientific Software International.

Joshi, Ashwin W. (1998), "How and Why Do Relatively Dependent Manufacturers Resist Supplier Power?," Journal of Marketing Theory and Practice, 6 (4), 61-77.

Joshi, Ashwin W. and Stephen J. Arnold (1997), "The Impact of Buyer Dependence on Buyer Opportunism in Buyer-Supplier Relationships: The Moderating Role of Relational Norms," Psychology \& Marketing, 14 (8), 823-845.

Julian, Scott D. (1993), "Franchise Failure Rates: An Assessment of Magnitude and Influencing Factors," Journal of Small Business Management, 31 (April), 105114.

Jung, Carl G. (1923), Psychological Types, New York, NY: Hartcourt and Brace.

Kabanoff, Boris (1991), "Equity, Equality, Power, and Conflict," Academy of Management Review, 16 (2), 416-441.

Kahn, Robert L., Donald M. Wolfe, Robert P. Quinn, J. Diedrick Snoek, and Robert A. Rosenthal (1964), Organizational Stress, New York, NY: Wiley.

Kahneman, Daniel, Jack Knetsch, and Richard H. Thaler (1986a), "Fairness and the Assumptions of Economics," Journal of Business, 59 (4), S285-S300.

Kahneman, Daniel, Jack Knetsch, and Richard H. Thaler (1986b), "Fairness as a Constraint on Profit-Seeking: Entitlements in the Market," American Economic Review, 76, 728-741.

Kanfer, Ruth (1990), "Motivation theory and Industrial and Organizational Psychology," in Handbook of Industrial and Organizational Psychology, ed. Marvin D. Dunnette and Leaetta Hough, Paolo Alto, CA: Consulting Psychologists Press, 75-170. 
Kanuk, Leslie and Conrad Berenson (1975), "Mail Surveys and Response Rates: A Literature Review," Journal of Marketing Research, 12 (November), 440-453.

Kaplan, Robert S. (1989), "Management Accounting for Advanced Technological Environments," Science, 245, 819-823.

Karande, Kiran, C. P. Rao, and Anusorn Singhapakdi (2002), "Moral Philosophies of Marketing Managers: A Comparison of American, Australian, and Malaysian Culture," European Journal of Marketing, 36 (7/8), 768-791.

Kaufmann, Patrick and Louis W. Stern (1988), "Relational Exchange Norms, Perceptions of Unfairness, and Relational Hostility in Commercial Litigation," Journal of Conflict Resolution, 32 (3), 534-552.

Kaufmann, Patrick. J. and Franchine Lafontaine (1994), "Costs of Control: The Source of Economic Rents for McDonald's Franchisees," Journal of Law and Economics, 37 (October), 417-453.

Kelley, Patricia C. and Dawn R. Elm (2003), "The Effect of Context on Moral Intensity of Ethical Issues: Revising Jones's Issue-Contingent Model," Journal of Business Ethics, 48, 139-154.

Kickul, Jill and Scott W. Lester (2001), "Broken Promises: Equity Sensitivity as a Moderator Between Psychological Contract Breach And Employee Attitudes and a Behavior," Journal of Business and Psychology, 16 (2), 191-217.

Kidwell, Blair and Robert D. Jewell (2003), "An Examination of Perceived Behavioral Control: Internal and External Influences on Intention," Psychology \& Marketing, 20 (7), 625-642.

Kidwell, Roland E. and Nathan Bennett (1993), "Employee Propensity to Withhold Effort: A Conceptual Model to Intersect Three Avenues to Research," Academy of Management Review, 18 (3), 429-456.

Kim, Keysuk and Gary L. Frazier (1997), "Measurement of Distributor Commitment in Industrial Channels of Distribution," Journal of Business Research, 40, 139-154.

King, Wesley C. and Edward W. Miles (1994), "The Measurement of Equity Sensitivity," Journal of Occupational and Organizational Psychology, 67, 133-142.

King, Wesley C., Edward W. Miles, and D. David Day (1993), "A Test and Refinement of the Equity Sensitivity Construct," Journal of Organizational Behavior, 14 (4), 301-317. 
Klein, Benjamin, Robert A. Crawford, and Armen A. Alchian (1978), "Vertical Integration, Appropriable Rents and the Competitive Contracting Process," Journal of Law \& Economics, 21 (October), 297-326.

Klein, Benjamin and Keith B. Leffler (1981), "The Role of Market Forces in Assuring Contractual Performance," Journal of Political Economy, 89 (41), 615-641.

Klein, Benjamin and Kevin M. Murphy (1988), "Vertical Restraints as Contract Enforcement Mechanisms," Journal of Law \& Economics, 31 (October), 265-297.

Klein, Rex B. (1998), Principles and Practice of Structural Equation Modeling, New York: Guilford Press.

Kleindorfer, Paul R. and Murat R. Sertel (1979), "Profit-Maximizing Design of Enterprises Through Incentives," Journal of Economic Theory, 20 (3), 318-399.

Kleindorfer, Paul R. and Murat R. Sertel (1994), "Auctioning the Provision of an Indivisible Public Good," Journal of Economic Theory, 64, 20-34.

Kleiser, Susan B., Eugene Sivadas, James J. Kellaris, and Robert F. Dahlstrom (2003), "Ethical Ideologies: Efficient Assessment and Influence on Ethical Judgments of Marketing Practices," Psychology \& Marketing, 20 (January), 1-21.

Knight, Russell M. (1986), "Franchising From the Franchisor and Franchisee Points of View.," Journal of Small Business Management, 24 (July), 8-15.

Knouse, S. and R. Giacalone (1992), "Ethical Decision-Making in Business: Behavioral Issues and Concerns," Journal of Business Ethics, 11, 369-377.

Koford, Kenneth and Mark Penno (1992), "Accounting, Principal-Agent Theory, and Self-Interested Behavior," in Ethics and Agency Theory, ed. N. E. Bowie and R. E. Freeman: New York, NY, 127-142.

Kohlberg, Lawrence (1965), "Relationships between the Development of Moral Judgment and Moral Conduct," in the Society for Research in Child Development, Minneapolis, MN.

Kohlberg, Lawrence (1969), "Stages and Sequence: the Cognitive-Developmental Approach to Socialization," in Handbook of Socialization Theory and Research, ed. David A. Goslin, Chicago, IL: Rand McNally, 347-480.

Kohlberg, Lawrence (1981), The Philosophy of Moral Development, New York, NY: Harper \& Row.

Kohlberg, Lawrence (1984), The Psychology of Moral Development; Moral Stages and the Life Cycle, Vol. 2, San Francisco, CA: Harper \& Row. 
Kohlberg, Lawrence and D. Candee (1984), "The Relationship of Moral Judgment to Moral Action," in Morality, Moral Behavior and Moral Development, New York, NY: Wiley, 52-73.

Kohli, Ajay K. (1985), "Some Unexpected Supervisory Behaviors and Their Influence on Salespeople's Role Clarity, Specific Self-Esteem, Job Satisfaction, and Motivation," Journal of Marketing Research, 22 (November), 424-433.

Kramer, Roderick M. and Marilynn B. Brewer (1984), "Effects of Group Identity on Resource Use in a Simulated Commons Dilemma," Journal of Personality and Social Psychology, 46 (5), 1044-1057.

Krebs, Dennis L. and Kathy Denton (2005), "Toward a More Pragmatic Approach to Morality: A Critical Evaluation of Kohlberg's Model," Psychological Review, 112 (3), 629-649.

Kreps, David M. (1990), A Course in Microeconomic Theory, Princeton, NJ: The Princeton University Press.

Kuechler, Manfred (1998), "The Survey Method: An Indispensable Tool for Social Science Research Everywhere?," American Behavioral Scientist, 42 (2), 178-200.

Kuhl, Julius and John W. Atkinson (1986), Motivation, Thought, and Action, New York, NY: Praeger Scientific.

Kulik, Carl T. and Maureen L. Ambrose (1993), "Category-Based and Feature-Based Processes in Performance Appraisal: Integrating Visual and Computerized Sources of Performance Data," Journal of Applied Psychology, 78, 821-830.

Kumar, Nirmalya, Lisa K. Scheer, and Jan-Benedict E. M. Steenkamp (1995a), "The Effects of Perceived Interdependence on Dealer Attitudes," Journal of Marketing Research, 32 (August), 348-356.

Kumar, Nirmalya, Lisa K. Scheer, and Jan-Benedict E. M. Steenkamp (1995b), "The Effects of Supplier Fairness on Vulnerable Resellers," Journal of Marketing Research, 32 (February), 54-65.

Kumar, Nirmalya, Lisa K. Scheer, and Jan-Benedict E. M. Steenkamp (1998), "Interdependence, Punitive Capability, and the Reciprocation of Punitive Actions in Channel Relationships," Journal of Marketing Research, 35 (May), 225-235.

Kumar, Nirmalya, Louis W. Stern, and James C. Anderson (1993), "Conducting Interorganizational Research Using Key Informants," Academy of Management Journal, 36 (6), 1633-1645. 
Kurland, Nancy B. (1996), "Sales Agents and Clients: Ethics, Incentives, and a Modified Theory of Planned Behavior," Human Relations, 49 (1), 51-74.

Lafontaine, Francine (1992), "Agency Theory and Franchising: Some Empirical Results," RAND Journal of Economics, 23 (2), 263-283.

Lafontaine, Francine and Margaret E. Slade (1996), "Retail Contracting and Costly Monitoring: Theory and Evidence," European Economic Review, 40, 923-932.

Lal, Rajiv (1990), "Improving Channel Coordination Through Franchising," Marketing Science, 10 (4), 299-318.

Lane, Peter J., Jr. Albert J. Cannella, and Michael H. Lubatkin (1999), "Ownership Structure and Corporate Strategy: One Question Viewed from Two Different Worlds," Strategic Management Journal, 20 (11), 1077-1086.

Lasson, Elliot D. and Alan R. Bass (1997), "Integrity Testing and Deviance: Construct Validity Issues and the Role of Situational Factors," Journal of Business and Psychology, 12 (2), 121-148.

Latif, David A. (2000), "The Link Between Moral Reasoning Scores, Social Desirability, and Patient Care Performance Scores: Empirical Evidence from the Retail Pharmacy Setting," Journal of Business Ethics, 25 (3), 255-269.

Learly, Mark R., Paul D. Knight, and Byron D. Barnes (1996), "Ethical Ideologies of the Machiavellian," Personality and Social Psychology Bulletin, 12 (1), 75-80.

Lee, Dong-Jin, M. Joseph Sirgy, James R. Brown, and Monroe M. Bird (2004), "Importers' Benevolence Toward Their Foreign Export Suppliers," Journal of the Academy of Marketing Science, 32 (1), 32-48.

Lefcourt, Herbert M. (1981), Research with the Locus of Control Construct, New York, NY: Academic Press.

Lefcourt, Herbert M. (1982), Research with the Locus of Control Construct, New York, NY: Academic Press.

Lefcourt, Herbert M. and J. Wine (1969), "Internal versus External Control of Reinforcement and the Deployment of Attention in Experimental Situations," Canadian Journal of Behavioral Sciences, 1, 167-181.

Leone, Luigi, Marco Perugini, and Anna P. Ercolani (1999), "A Comparison of Three Models of Attitude-Behavior Relationships on Studying Behavior Domain," European Journal of Social Psychology, 29, 161-189. 
Leventhal, Gerald S. (1980), "What Should be done with Equity Theory? New Approaches to the Study of Fairness in Social Relationships," in Social Exchange: Advances in theory and Research, ed. Kenneth J. Gergen, Martin S. Greenberg and Richard H. Wills, New York: Plenum, 27-55.

Levin, J. and I. Montag (1987), "The Effect of Testing Instructions for Handling Social Desirability on the Eysenck Personality Questionnaire," Personality and Individual Differences, 8, 163-167.

Lind, A. Allen and Tom R. Tyler (1988), The Social Psychology of Procedural Justice, New York, NY: Plenum Press.

Loe, Terry W., Linda Ferrell, and Phylis Manfield (2000), "A Review of Empirical Studies Assessing Ethical Decision Making in Business," Journal of Business Ethics, 25, 185-204.

Lusch, Robert F. and James R. Brown (1996), "Interdependency, Contracting, and Relational Behavior in Marketing Channels," Journal of Marketing, 60 (October), 19-38.

Macaulay, Stewart (1963), "Non-Contractual Relations in Business: A Preliminary Study," American Sociological Review, 28, 55-70.

Machiavelli, Niccolo (1992/1513), The Prince: A Revised Translation, Backgrounds, Interpretations, Marginalia, New York, NY: Norton.

Macneil, Ian R. (1978), "Contracts: Adjustment of Long-Term Economic Relations Under Classical, Neoclassical, and Relational Contract Law," Northwestern University Law Review, 72 (6), 854-905.

Macneil, Ian R. (1980), The New Social Contract: an Inquiry into Modern Contractual Relations, New Haven, CT: Yale University Press.

Macneil, Ian R. (1981), "Economic Analysis of Contractual Relations: Its Shortfalls and the Need for a "Rich Classificatory Apparatus," Northwestern University Law Review, 75 (6), 1018-1063.

Manolis, Chris, Jule B. Gassenheimer, and Robert D. Winsor (2004), "The Moderating Effect of Solidarity as Conduct: A Theoretical and Empirical Perspective " Journal of Marketing Theory and Practice, 12 (3), 48-60.

Marnburg, Einar (2001), "The Questionable Use of Moral Development Theory in Studies of Business Ethics: Discussion and Empirical Findings," Journal of Business Ethics, 32, 275-283. 
Marshall, Robert C. (2003), "The Culture of Cooperation in Three Japanese Worker Cooperatives," Economic and Industrial Democracy, 24 (4), 543-572.

Maslow, A. H. (1943), "A Theory of Human Motivation," Psychological Review, 50, 370-396.

Masten, Scott E. (1988), "Equity, Opportunism, and the Design of Contractual Relations," Journal of Institutional and Theoretical Economics, 144 (1), 180-195.

Masterson, Suzanne S., Kyle Lewis, Barry M. Goldman, and M. Susan Taylor (2000), "Integrating Justice and Social Exchange: The Differing Effects of Fair Procedures and Treatment on Work Relationships," Academy of Management Journal, 43 (4), 738-748.

Mayer, Hoger C., James H. Davis, and F. David Schoorman (1995), "An Integrative Model of Organization Trust," Academy of Management Review, 20 (3), 709-734.

Mayo, Michael A. and Lawrence J. Marks (1990), "An Empirical Investigation of a General Theory of Marketing Ethics," Journal of the Academy of Marketing Science, 18 (2), 163-171.

McCracken, Janet and Bill Shaw (1995), "Virtue Ethics and Contractarianism: Towards A Reconciliation," Business Ethics Quarterly, 5 (2), 297-312.

McCutcheon, Lynn E. (1999), "Machiavellianism, Belief in a Just World, and the Tendency to Worship Celebrities," Current Research in Social Psychology, 8 (9), 131-139.

McEvily, Bill, Vincenzo Perrone, and Akbar Zaheer (2003), "Trust as an Organizing Principle," Organization Science, 14 (1), 91-103.

McFarlin, Dean B. and Paul D. Sweeney (1992), "Distributive and Procedural Justice as Predictors of Satisfaction with Personal and Organizational Outcomes," Academy of Management Journal, 35 (March), 626-637.

McGraw, Kenneth O. (1978), "The Detrimental Effects of Reward on Performance: A Literature Review and a Prediction Model," in The Hidden Costs of Reward: New Perspectives of Human Behavior, ed. M. R. Lepper and D. Greene, New York, NY: Erlbaum, 33-60.

Meindl, James R. (1989), "Managing to be Fair: An Exploration of Values, Motives, and Leadership," Administrative Science Quarterly, 34 (2), 252-276.

Mele, Alfred R. (1996), "Motivation and Intention," Journal of Philosophical Research, 21, 51-67. 
Menguc, Bulent (1998), "Organizational Consequences, Marketing Ethics and Salesforce Supervision: Further Empirical Evidence," Journal of Business Ethics, 17 (4), 220-252.

Merton, Robert K. (1957), Social Theory and Social Structure, New York, NY: Free Press.

Meyer, John and Brian Rowan (1977), "Institutional Organizations: Formal Structure as Myth and Ceremony," American Journal of Sociology, 83 (September), 340-363.

Michael, Steven C. (2000), "The Effect of Organizational Form on Quality: the Case of Franchising," Journal of Economic Behavior \& Organizations, 43, 295-318.

Milgrom, Paul and John Roberts (1989), "An Economic Approach to Influence Activities in Organizations," American Journal of Sociology, 94, 154-179.

Mishra, Debi Prasad, Jan B. Heide, and Stanton G. Cort. (1998), "Information Asymmetry and Levels of Agency Relationships," Journal of Marketing Research, 35 (August), 277-295.

Mitchell, Terence R. and Amy E. Mickel (1999), "The Making of Money: An IndividualDifference Perspective," Academy of Management Review, 24 (3), 568-578.

Mitnick, Barry M. (1992), "The Theory of Agency and Organizational Analysis," in Ethics and Agency Theory, ed. N. E. Bowie and R. E. Freeman, New York, NY: Oxford University Press, 75-96.

Mochandreas, Maria (1997), "The Role of Opportunism in Transaction Cost Economics," Journal of Economic Issues, 31 (March), 39-57.

Moody, James and Douglas R. White (2003), "Structural Cohesion and Embeddedness: A Hierarchical Concept of Social Groups," American Sociological Review, 68 (1), 103-127.

Moorman, Robert H. (1991), "Relationship Between Organizational Justice and Organizational Citizenship Behaviors: Do Fairness Perceptions Influence Employee Citizenship?," Journal of Applied Psychology, 76 (6), 845-855.

Morrison, Elizabeth W. and Sandra L. Robinson (1997), "When Employees Feel Betrayed: A Model of How Psychological Contract Violation Develops," Academy of Management Review, 22 (1), 228-256.

Mossholder, Kevin W., Nathan Bennett, Edward R. Kemery, and Mark A. Wesolowski (1998), "Relationships Between Bases of Power and Work Reactions: The Mediational Role of Procedural Justice," Journal of Management, 24 (4), 533552. 
Mudrack, P. E. (1990), "Machiavellianism and Locus of Control: A Meta-Analytic Review," The Journal of Social Psychology, 130 (1), 125-126.

Mudrack, Peter E. (1993), "An Investigation into the Acceptability of Workplace Behaviors of a Dubious Ethical Nature," Journal of Business Ethics, 12 (7), 517 524.

Mudrack, Peter E. (2003), "The Untapped Relevance of Moral Development Theory in the Study of Business Ethics," Journal of Business Ethics, 42, 225-236.

Mudrack, Peter E., E. Sharon Mason, and Kim M. Stepanski (1999), "Equity Sensitivity and Business Ethics," Journal of Occupational and Organizational Psychology, $72,539-560$.

Mueller, Stephen L. and Linda D. Clarke (1998), "Political-Economic context and sensitivity to equity: Differences between the United States and the Transition Economies of Central and Eastern Europe," Academy of Management Journal, 41 (2), 319-329.

Mumby, Dennis K. and Linda L. Putnam (1992), "The Politics of Emotion: A Feminist Reading of Bounded Rationality," Academy of Management Review, 17 (3), 465 486.

Muris, Timothy J. (1981), "Opportunistic Behavior and the Law of Contract," Minnesota Law Review, 65, 521-590.

Murphy, Patrick E. (1995), "Corporate Ethics Statements: Current Status and Future Prospects," Journal of Business Ethics, 14 (9), 727-740.

Murphy, William H., Peter A. Dacin, and Neil M. Ford (2004), "Sales Contest Effectiveness: An Examination of Sales Contest Design Preferences of Field Sales Forces," Journal of the Academy of Marketing Science, 32 (2), 127-143.

Murry, John P. and Jan B. Heide (1998), "Managing Promotion Program Participation Within Manufacturer-Retailer Relationships," Journal of Marketing, 62 (January), 58-68.

Muthen, B., D. Kaplan, and M. Hollins (19871), "On Structural Equation Modeling with Data that are not missing Completely at Random," Psychometrika, 52, 431-462.

Nagin, Daniel S., James B. Rebitzer, Seth Sanders, and Lowell J. Taylor (2002), "Monitoring, Motivation, and Management: The Determinants of Opportunistic Behavior in a Field Experiment," The American Economic Review, 92 (4), 850873. 
Narayandas, Das and V. Katsuri Rangan (2004), "Building and Sustaining Buyer-Seller Relationships in Mature Industrial Markets," Journal of Marketing, 68 (July), 6377.

Niehoff, Brian P. and Robert H. Moorman (1993), "Justice as a Mediator of the Relationship Between Methods of Monitoring and Organizational Citizenship Behavior," Academy of Management Journal, 36 (3), 527-556.

Nielsen, Richard P. (2003), "Corruption Networks and Implications for Ethical Corruption Reform," Journal of Business Ethics, 42, 125-149.

Noordewier, T., G. John, and J. Nevin (1990), "Performance Outcomes of Purchasing Arrangements in Industrial Buyer-Vendor Relationships," Journal of Marketing, 54 (October), 80-93.

Noreen, E. (1987), "The Economics of Ethics: A New Perspective on Agency Theory," Seattle: University of Washington, April 2.

Nunnally, Jum C. (1978), Psychometric Theory, New York: McGraw-Hill.

O'Donnell (2000), "Managing Foreign Subsidiaries: Agents of Headquarters, or an Interdependent Network?," Strategic Management Journal, 21 (5), 525-539.

Oliver, C. (1991), "Strategic Responses to Institutional Processes," Academy of Management Review, 16 (1), 145-179.

Oliver, Richard L. (1974), "Expectancy Theory Predictions of Salesmen's Performance," Journal of Marketing Research, 11 (August), 243-253.

Omar, Ogenyi Ejye (1998), "Franchising Agreements in New Car Retailing: An Empirical Investigation," The Services Industries Journal, 18 (2), 144-160.

Ones, Deniz S., Chockalingham Viswesvaran, and Angelika D. Reiss (1996), "Role of Social Desirability in Personality Testing for Personnel Selection: The Red Herring," Journal of Applied Psychology, 81 (6), 660-679.

O'Reilly, Charles A. and Jennifer A. Chatman (1994), "Working Smarter and Harder: A Longitudinal Study of Managerial Success," Administrative Science Quarterly, 39 (4), 603-627.

Ottensmeyer, Edward J. and Mark A. Heroux (1991), "Ethics, Public Policy, and Managing Advanced Technologies: The Case of Electronic Surveillance," Journal of Business Ethics, 10, 519-526.

Ouchi, William G. (1979), "A Conceptual Framework for the Design of Organizational Control Mechanisms," Management Science, 25 (9), 833-848. 
Palmer, Adrian (2000), "Co-operation and Competition: A Darwinian Synthesis of Relationship Marketing," European Journal of Marketing, 34 (5/6), 687-704.

Parayitam, Satyanarayana Parayitam, Margaret A. White, and Jill R. Hough (2002), "Juxtaposition of Chester I. Barnard and Frederick W. Taylor: Forerunners of Management," Management Decision, 40 (10), 1003-1012.

Parkhe, Arvind (1991), "Interfirm Diversity, Organizational Learning, and Longevity in Global Strategic Alliances," Journal of International Business Studies, 20, 579601.

Parks, Judi McLean and Faye L. Smith (1998), "Organizational Contracting: A "Rational" Exchange?," in Debating Rationality: Nonrational Aspects of Organizational Decision Making, ed. Jeccifer J. Halpern and Robert N. Stern, Ithaca, NY: ILR Press, 125-155.

Parsa, H. G. (1999), "Interaction of Strategy Implementation and Power Perceptions in Franchise Systems: An Empirical Investigation," Journal of Business Research, 45 (2), 173-185.

Patterson, Denise M. (2001), "Causal Effects of Regulatory, Organizational and Personal Factors on Ethical Sensitivity," Journal of Business Ethics, 30 (2), 123-159.

Pearce, Jone, Imre Branyiczi, and Gregory A. Bigley (2000), "Insufficient Bureaucracy: Trust and Commitment in Particularistic Organizations," Organization Science, $11(2), 148-162$.

Pelton, Lou E., Jhinuk Chowdhury, and Jr. Scott J. Vitell (1999), "A Framework for the Examination of Relational Ethics: An Interactionist Perspective," Journal of Business Ethics, 19, 241-253.

Perrow, Charles (1982), "Markets, Hierarchies, and Hegemony," in Perspectives on Organization Design and Behavior, ed. A H. Van de Van and W. T. Joyce, New York, NY: John Wiley \& Sons, 371-386.

Perrow, Charles (1986), Complex Organizations: A Critical Essay, New York, NY: Random House.

Perugini, Marco and Richard P. Bagozzi (2001), "The Role of Desires and Anticipated Emotions in Goal-Desired Behaviours: Broadening and Deepening the Theory of Planned Behaviour," British Journal of Social Psychology, 40, 79-98.

Perugini, Marco and Richard P. Bagozzi (2004), "The Role of Desires and Anticipated Emotions in Goal-Directed Behaviours: Broadening and deepening the Theory of Planned Behaviour," British Journal of Social Psychology, 40, 79-98. 
Peterson, Dane K. (2002), "Deviant Workplace Behavior and the Organization's Ethical Climate," Journal of Business and Psychology, 17 (1), 47-61.

Peterson, Dane K. (2002), "The Relationship Between Unethical Behavior and the Dimensions of the Ethical Climate Questionnaire," Journal of Business Ethics, 41 (4), 313-326.

Phillips, Antoinete S. and Arthur G. Bedeian (1994), "Leader-Follower Exchange Quality: The Role of Personal and Interpersonal Attributes," Academy of Management Journal, 37 (August), 990-1001.

Pilling, Bruce K., Lawrence A. Crosby, and Donald W. Jackson Jr. (1994), "Relational Bonds in Industrial Exchange: An Experimental Test of the Transaction Cost Economic Framework," Journal of Business Research, 30, 237-251.

Pillutla, Madan M. and J. Keith Murnighan (1995), "Being Fair or Appearing Fair: Strategic Behavior in Ultimatum Bargaining," Academy of Management Journal, 38 (5), 1408-1426.

Ping, Robert (2007), "Salesperson-Employer Relationships: Salesperson Responses to Relationship Problems and Their Antecedents," Journal of Personal Selling \& Sales Management, 27 (1), 39-57.

Podsakoff, Philip M., Scott B. MacKenzie, Jeong-Yeon Lee, and Nathan P. Podsakoff (2003), "Common Method Biases in Behavioral Research: A Critical Review of the Literature and Recommended Remedies," Journal of Applied Psychology, 88 (5), 879-903.

Podsakoff, Philip M. and Dennis W. Organ (1986), "Self-reports in Organizational Research: Problems and Prospects," Journal of Management, 12, 531-544.

Porter, M. E. (1980), Competitive Strategy, New York, NY: Free Press.

Powell, Walter W. (1990), "Neither Market nor Hierarchy: Network Forms of Organization," Research in Organizational Behavior, 12, 295-336.

Power, F., A. Higgins, and L. Kohlberg (1989), Lawrence Kohlberg's Approach to Moral Education, New York, NY: Columbia University Press.

Pratt, John W. and Richard J. Zeckhauser (1985), "Principals and Agents: An Overview," in Principals and Agents: The Structure of Business, ed. John W. Pratt and Richard J. Zeckhauser, Boston, MA: Harvard Business School Press.

Preble, John F. and Richard C. Hoffman (1999), "The Nature of Ethics Codes in Franchise Associations Around the Globe," Journal of Business Ethics, 18 (3), 239-253. 
Price, James L. (1972), Handbook of Organizational Measurement, Lexington, MA: Heath and Company.

Price, James L. and Charles W. Mueller (1986), Handbook of Organizational Measurement, Marshfield, MA: Pitman.

Provan, Keith G. and Steven J. Skinner (1989), "Interorganizational Dependence and Control as Predictors of Opportunism in Dealer-Seller Relations," Academy of Management Journal, 32 (February), 202-212.

Quinn, J. Kevin, J. David Reed, M. Neil Browne, and Wesley J. Hiers (1997), "Honesty, Individualism, and Pragmatic Business Ethics: Implications for Corporate Hierarchy," Journal of Business Ethics, 16 (2/3), 1419-1430.

Raats, Monique M., Richard Shepherd, and Paul Sparks (1995), "Including Moral Dimensions of Choice Within the Structure of the Theory of Planned Behavior," Journal of Applied Social Psychology, 25 (6), 484-494.

Rabin, Jack (1994), "Barnard and Morality in Organizations," International Journal of Public Administration, 17 (6), 1239-1297.

Ramaswami, Srindhar N. (1996), "Marketing Controls and Dysfunctional Employee Behaviors: A Test of Traditional and Contingency Theory Postulates," Journal of Marketing, 60 (April), 105-120.

Ramaswami, Srindhar N. and Jagdip Singh (2003), "Antecedents and Consequences of Merit Pay Fairness for Industrial Salespeople," Journal of Marketing, 67 (October), 46-66.

Randall, Donna M. and Maria F. Fernandes (1991), "The Social Desirability Response Bias in Ethics Research," Journal of Business Ethics, 10 (11), 805-817.

Rangan, Subramanian (2000), "The Problem of Search and Deliberation in Economic Action: When Social Networks Really Matter," Academy of Management Review, 25 (4), 813-828.

Rao, Hayagreeva, Gerald F. Davis, and Andrew Ward (2000), "Embeddedness, Social Identity and Mobility: Why Firms Leave the NASDAQ and Join the New York Stock Exchange," Administrative Science Quarterly, 45, 268-292.

Rawls, John (1999), A Theory of Justice, Cambridge, MA: Harvard University Press.

Reidenbach, R. E. and D. P. Robin (1990), "Toward the Development of a Multidimensional Scale for Improving Evaluations of Business Ethics," Journal of Business Ethics, 9 (8), 639-653. 
Rest, James (1986), DIT Manual: Manual for the Defining Issues Test. Third Edition. Center for the study of Ethical Development: University of Minnesota.

Rest, James, Darcia Narvaez, Muriel J. Bebeau, and Stephen J. Thoma (1999), Postconventional Moral Thinking: A Neo-Kohlbergian Approach, Mahwah: NJ.: Lawrence Erlbaum Associates Publishers.

Rest, James, Stephen J. Thoma, and Lynne Edwards (1997), "Designing and Validating a Measure of Moral Judgment: Stage Preference and Stage Consistency Approaches," Journal of Educational Psychology, 89 (10), 5-28.

Rest, James, Stephen J. Thoma, Darcia Narvaez, and Muriel J. Bebeau (1997), "Alchemy and Beyond: Indexing the Defining Issues Test," Journal of Educational Psychology, 89 (3), 498-507.

Rest, James R. (1979), Development in Judging Moral Issues, Minneapolis, MN: University of Minnesota Press.

Rest, James R., Darcia Narvaez, Stephen J. Thoma, and Muriel Bebeau (2000), "A NeoKohlbergian Approach to Morality Research," Journal of Moral Education, 29 (4), 381-395.

Rest, James R., Stephen J. Thoma, Darcia Narvaez, and Muriel J. Bebeau (1999), Postconventional Moral Thinking: A Neo-Kohlbergian Approach, Mahwah, NJ: Erlbaum.

Rich, Joseph M. and Joseph L. DeVitis (1985), "Moral Development Through the Life Span," in Theories of Moral Development, Springfield, Il: Charles C. Thomas Publisher.

Rindfleisch, Aric and David X Crockett. (1999), "Cigarette Smoking and Perceived Risk: A Multidimensional Investigation," Journal of Public Policy \& Marketing, 18 (Fall), 159-171.

Rindfleisch, Aric and Jan B. Heide (1997), "Transaction Cost Analysis: Past, Present, and Future Applications," Journal of Marketing, 61 (October), 30-54.

Rindfleisch, Aric and Christine Moorman (2001), "The Acquisition and Utilization of Information in New Product Alliances: A Strength-of-Ties Perspective " Journal of Marketing, 65 (April), 1-18.

Ring, Peter S. and Andrew H. Van de Ven (1994), "Developmental Processes of Cooperative Interorganizational Relationships," Academy of Management Review, $19(1), 90-118$. 
Robertson, Diana C. and Erin Anderson (1993), "Control System and Task Environment Effects on Ethical Judgment: An Exploratory Study of Industrial Salespeople," Organization Science, 4 (November), 617-644.

Robinson, J. P. and P. R. Shaver (1973), Measures of Social Psychological Attitudes, Ann Arbor, MI: Institute for Social Research.

Rokkan, Aksel I., Jan B. Heide, and Kenneth H. Wathne (2003), "Specific Investments in Marketing Relationships: Expropriation and Bonding Effects," Journal of Marketing Research, 35 (May), 210-224.

Rosanas, Josep M. and Manuel Velilla (2003), "Loyalty and Trust as the Ethical Bases of Organization," Journal of Business Ethics, 44 (1), 49-59.

Ross, Stephen A. (1973), "The economic theory of agency: The principal's problem," American Economic Review, 63, 134-139.

Ross, William T. and Diana C. Robertson (2000), "Lying: The Impact of Decision Context," Business Ethics Quarterly, 10 (2), 409-440.

Rotter, Julian (1966), "Generalized Expectancies For Internal Versus External Control of Reinforcement," Psychological Monographs, 80 (1), 1-28.

Rousseau, Denise M. (1995), Psychological Contracts in Organizations: Understanding Written and Unwritten Agreements, Thousand Oaks, CA: Sage.

Rowley, Timothy J. (1997), "Moving Beyond Dyadic Ties: A Network Theory of Stakeholder Influences," Academy of Management Review, 22 (4), 887-910.

Rowley, Timothy J., Dean Behrens, and David Krackhardt (2000), "Redundant Governance Structures: An Analysis of Structural and Relational Embeddedness in the Steel and Semiconductor Industries," Strategic Management Journal, 21 (3), 369-386.

Salancik, G. R. and J. Pfeffer (1977), "An Examination of the Need-Satisfaction Models of Job Attitudes," Administrative Science Quarterly, 22, 427-456.

Sanders, Wm. Gerard and Mason A. Carpenter (2003), "Strategic Satisficing? A Behavioral-Agency Theory Perspective on Stock Repurchase Program Announcements," Academy of Management Journal, 46 (2), 160-178.

Sapienza, Harry J. and Audrey M. Korsgaard (1996), "Procedural Justice in Entrepreneur-Investor Relations," Academy of Management Journal, 39 (3), 554574. 
Sarin, S. and V. Mahajan (2001), "The Effect of Reward Structures on the Performance of Cross-Functional Product Development Teams," Journal of Marketing, 65 (April), 35-53.

Schepers, Donald H. (2003), "Machiavellianism, profit, and the dimensions of ethical judgment: A study of Impact," Journal of Business Ethics, 42 (4), 339-352.

Schlenker, Barry R. and Donelson Forsyth, R. (1977), "On the Ethics of Psychological Research," Journal of Experimental Social Psychology, 13 (4), 369-396.

Schminke, Marshall, Maureen L. Ambrose, and Terry W. Noel (1997), "The Effect of Ethical Frameworks on Perceptions of Organizational Justice," Academy of Management Journal, 40 (5), 1190-1207.

Seidler, John (1974), "On Using Informants: A Technique for Collecting Quantitative Data and Controlling for Measurement Error in Organizational Analysis," American Sociological Review, 39, 816-831.

Senjem, J. C. and K. Reed (2002), "Social Capital and Network Entrepreneurs," in Frontiers of Entrepreneurship Research, ed. Paul Reynolds, Kelly G. Shaver, William D. Bygrave, Nancy M. Carter, Sophie Manigart and Dale Meyers, Babson Park, MA: Babson College - Center for Entrepreneurial Studies, 140-148.

Sethi, S. Prakash (1994), "Imperfect Markets: Business Ethics as an Easy Virtue," Journal of Business Ethics, 13 (10), 803-815.

Shane, Scott A. (1996), "Hybrid Organizational Arrangements and Their Implications for Firm Growth and Survival: A Study of New Franchisors," Academy of Management Journal, 39 (1), 216-234.

Shane, Scott A. (2001), "Organizational Incentives and Organizational Mortality," Organization Science, 12 (March/April), 136-160.

Shapiro, Jacqueline A-M (2002), "A Psychological Contract Perspective on Organizational Citizenship Behavior," Journal of Organizational Behavior, 23 (December), 927-946.

Sharma, Subhash, Richard M. Durand, and Oded Gur-Arie (1981), "Identification and Analysis of Moderator Variables," Journal of Marketing Research, 18 (August), 291-300.

Sheeran, Paschal (2002), "Intention-Behaviour Relations: A Conceptual and Empirical Review," in European Review of Social Psychology, Vol. 12, ed. W. Stroebe and M. Hewstone, Chichester, UK: Wiley, 1-36. 
Sheerman, Paschal, Paul Norman, and Sheina Orbell (1999), "Evidence that Intentions based on Attitudes better Predict Behaviour than Intentions based on Subjective Norms," European Journal of Social Psychology, 29, 403-406.

Shell, G. Richard (1991), "Opportunism and Trust in the Negotiation of Commercial Contracts: Toward a New Cause of Action," Vanderbilt Law Review, 44 (2), 221282.

Shepelak, Norma J. and Duane F. Alwin (1986), "Beliefs About Inequality and Perceptions of Distributive Justice," American Sociological Review, 51 (February), 30-46.

Sheppard, Blair H. and Marla Tuchinsky (1996), "Micro-OB and the Network Organization," in Trust in Organizations: Frontiers of Theory and Research, ed. Roderick M. Kramer and Tom R. Tyler, Thousand Oaks, CA: Sage Publication, $140-165$.

Sheth, Jagdish N. and Atul Parvatiyar (1995), "Relationship Marketing in Consumer Markets: Antecedents and Consequences," Journal of the Academy of Marketing Science, 23 (4), 255-271.

Sigmund, Wagner-Tsukamoto (2007), "An Institutional Economic Reconstruction of Scientific Management: On the Lost Theoretical Logic of Taylorism," Academy of Management Review, 32 (1), 105-117.

Simon, Herbert A. (1947), Administrative Behavior. New York, NY: MacMillan.

Simon, Herbert A. (1955), "A Behavioral Model of Rational Choice," The Quarterly Journal of Economics, 69 (1), 99-118.

Simon, Herbert A. (1985), "Human Nature in Politics: The Dialogue of Psychology with Political Science," The American Political Science Review, 79, 293-304.

Singh, Jagdip (1998), "Striking a Balance in Boundary-Spanning Positions: An Investigation of Some Unconventional Influences of Role Stressors and Job Characteristics on Job Outcomes of Salespeople," Journal of Marketing, 62 (July), 69-86.

Singhapakdi, Anusorn and Scott J. Vitell (1991), "Research Note: Selected Factors Influencing Marketers' Deontological Norms," Journal of the Academy of Marketing Science, 19 (1), 37-42.

Singhapakdi, Anusorn, Scott J. Vitell, and Kenneth L. Kraft (1996), "Moral Intensity and Ethical Decision-Making of Marketing Professionals," Journal of Business Research, 36, 245-255. 
Sitter, Victoria L. (2003), "Communication Style as a Predictor of Interactional Justice," in International Leadership Studies Conference, Virginia Beach, VA: Regent University.

Sivadas, Eugene and F Robert Dwyer (2000), "An Examination of Organizational Factors Influencing New Product Success in Internal and Alliance-Based Processes," Journal of Marketing, 64 (January), 31-49.

Skarlicki, Daniel P. and Robert Folger (1997), "Retaliation in the Workplace; The Roles of Distributive, Procedural, and Interactional Justice," Journal of Applied Psychology, 82 (3), 434-443.

Skarlicki, Daniel P., Robert Folger, and Paul Tesluk (1998), "Personality as a Moderator in the Relationship Between Fairness and Retaliation," Academy of Management Journal, 42 (1), 100-108.

Slater, Gary and David A. Spencer (2000), "The Uncertain Foundations of Transaction Costs Economics," Journal of Economic Issues, 34 (1), 61-87.

Snell, Robin Stanley (1996), "Complementing Kohlberg: Mapping the Ethical Reasoning Used by Managers for Their Own Dilemma Cases," Human Relations, 49 (1), 23 49.

Snell, Robin S. and Jr. Neil C. Herndon (2004), "Hong Kong's Code of Ethics Initiative: Some Differences between Theory and Practice," Journal of Business Ethics, 51 (1), 75-89.

Solomon, Robert C. (1999), A Better Way to Think about Business, Oxford, NY: Oxford University Press.

Sparks, John R. and Shelby D. Hunt (1998), "Marketing Researcher Ethical Sensitivity: Conceptualization, Measurement, and Exploratory Investigation," Journal of Marketing, 62 (2), 92-109.

Spector, Paul E. (1982), "Behavior in Organizations as a Function of Employee's Locus of Control," Psychological Bulletin, 91 (3), 482-497.

Spector, Paul E. (1988), "Development of the Work Locus of Control Scale," Journal of Occupational Psychology, 61, 335-340.

Speier, Cheri and Viswanath Venkatesh (2002), "The Hidden Minefields in the Adoption of Sales Force Automation Technologies," Journal of Marketing, 66 (3), 98-111.

Spekman, Robert E. (1988), "Strategic Supplier Selection: Understanding Long-Term Buyer Relationships," Business Horizons, 31 (July-August), 75-81. 
Spence, Michael (1973), "Job Market Signaling," Quarterly Journal of Economics, 87 (3), 355-374.

Srnka, Katharina J. (2004), "Culture's Role in Marketer's Ethical Decision Making: An Integrated Theoretical Framework," Academy of Marketing Science Review (1), 132.

Stajkovic, Alexander D. and Fred Luthans (1997), "A Meta-Analysis of the Effects of Organizational Behavior Modification on Task Performance, 1975-1995," Academy of Management Journal, 40 (5), 1122-1149.

Stephens, Carroll U. and Arie Y. Lewin (1992), "Bounded Morality: A Cross-Level Model of the Determinants of Ethical Choice in Organizations," in Contemporary Issues in the Business Environment, ed. D. Ludwig and D. Paul, Wales, UK: The Edwin Mellen Press.

Stevens, Edward (1979), Business Ethics, New York, NY: Paulist Press.

Stevens, James (1992), Applied Multivariate Statistics for the Social Sciences, Hillsdale, NJ: Lawrence Erlbaum Associates.

Stratton, W. E., W. R. Flynn, and G. A. Johnson (1981), "Moral Development and Decision-Making: A Study of Student Ethics," Journal of Enterprise Management, 3, 35-41.

Stratton, W. E., W. R. Flynn, and G. A. Johnson (1981), "Moral Development and Decision-Making: A Study of Student Ethics," Journal of Enterprise Management, 3, 35-41.

Stump, Rodney L. and Jan B. Heide (1996), "Controlling Supplier Opportunism in Industrial Relationships," Journal of Marketing Research, 33 (November), 431441.

Suchman, Mark C. (1995), "Managing Legitimacy: Strategic and Institutional Approaches," Academy of Management Review, 20 (3), 571-610.

Sweeney, Paul D. and Dean B. McFarlin (1993), "Worker's Evaluations of the "Ends" and the "Means": An Examination of Four Models of Distributive and Procedural Justice," Organizational Behavior and Human Decision Processes, 55, 23-40.

Telser, Lester G. (1980), "A Theory of Self-Enforcing Agreements," Journal of Business and Psychology, 53 (1), 27-44.

Telser, Lester G. (1981), "Why There Are Organized Futures Markets," Journal of Law and Economics, 24, 1-24. 
Tenbrunsel, Ann E. and David M. Messick (1999), "Sanctioning, Systems, Decision Frames, and Cooperation," Administrative Science Quarterly, 44 (4), 684-707.

Thibaut, John and Laurence Walker (1975), Procedural Justice: A Psychological Analysis, Hillsdale, NJ: Erlbaum.

Thoma, Stephen, Robert Barnett, James Rest, and Darcia Narvaez (1999), "What does the DIT Measure?," British Journal of Social Psychology, 38, 103-111.

Thoma, Stephen J. (2002), "An Overview of the Minnesota Approach to Research in Moral Development," Journal of Moral Education, 31 (3), 225-245.

Thompson, J. D. (1967), Organizations in Action, New York, NY: McGraw-Hill.

Tosi, Henry L. and Louis R. Gomez-Mejia (1994), "Compensation Monitoring and Firm Performance," Academy of Management Journal, 37, 1002-1016.

Tosi, Henry L., Jeffrey P. Katz, and Luis R. Gomez-Mejia (1997), "Disaggregating the Agency Contract: The Effects of Monitoring, Incentive Alignment, and Term in Office on Agent Decision Making," Academy of Management Journal, 40 (3), 584-602.

Traub, S. H. (1996), "Battling Employee Crime: A Review of Corporate Strategies and Programs," Crime and Delinquency, 42, 244-252.

Trevino, Linda Klebe (1986), "Ethical Decision Making in Organizations: A PersonSituation Interactionist Model," Academy of Management Review, 11 (3), 601617.

Trevino, Linda Klebe, Kenneth D. Butterfield, and Donald L. McCabe (1998), "The Ethical Context in Organizations: Influences on Employee Attitudes and Behaviors," Business Ethics Quarterly, 8 (3), 447-476.

Trevino, Linda Klebe and Stuart A. Youngblood (1990), "Bad Apples in Bad Barrels: A Causal Analysis of Ethical Decision-Making Behavior," Journal of Applied Psychology, 75 (4), 378-385.

Trivers, Robert L. (1971), "The Evolution of Reciprocal Altruism," The Quarterly Review of Biology, 46, 35-57.

Tyagi, Pradeep K. (1982), "Perceived Organizational Climate and the Process of Salesperson Motivation," Journal of Marketing Research, 19 (May), 240-254.

Tyler, Tom R. and Robert J. Bies (1990), "Interpersonal aspects of procedural justice," in Applied Social Psychology in Business Settings, ed. J.S. Carroll, Hillsdale, NJ: Erlbaum. 
Ullman, J. B. (2001), "Structural Equation Modeling," in Using Multivariate Statistics, ed. B.G. Tabachnick and L.S. Fidell, Needham Heights, MA: Allyn \& Bacon, 653- 771.

Ulrich, Peter and Ulrich Thielemann (1993), "How Do Managers Think About Market Economies and Morality? Empirical Enquiries into Business-Ethical Thinking Patterns," Journal of Business Ethics, 12, 879-898.

Upchurch, Randall S. (1998), "A Conceptual Foundation for Ethical Decision Making: A stakeholder perspective in lodging industry," Journal of Business Ethics, 17 (12), 1349-1361.

Uzzi, Brian (1997), "Social Structure and Competition in Interfirm Networks: The Paradox of Embeddedness," Administrative Science Quarterly, 42, 35-67.

Valecha, Gopal K. (1972), "Construct Validation of Internal-External Locus of Control as Measured by an Abbreviated 11-Item IE Scale," Unpublished Doctoral Dissertation, Psychology Department, The Ohio State University, Columbus, OH.

Valecha, Gopal K. (1972), "Construct Validation of Internal-External Locus of Reinforcement Related to Work-Related Variables," in the 80th Annual Convention of the American Psychological Association, Vol. 7, 455-457.

Valecha, Gopal K. and Thomas M. Ostrom (1974), "An Abbreviated Measure of InternalExternal Locus of Control," Journal of Personality Assessment, 38, 369-376.

Van Breukelen, Wim, Rene Van der Vlist, and Herman Steensma (2004), "Voluntary Employee Turnover: Combining Variables from the 'traditional' turnover literature with the Theory of Planned Behavior," Journal of Organizational Behavior, 25, 893-914.

Van Trijp, Hans C M, Wayne D Hoyer, and J Jeffrey Inman (1996), "Why Switch? Product Category-Level Explanations for True Variety-Seeking Behavior," Journal of Marketing Research, 33 (August), 281-292.

Verbeke, A. (2003), "The Evolutionary View of the MNE and the Future of Internalization Theory," Journal of International Business Studies, 34 (6), 498504.

Verbeke, Willem, Cok Ouwerkerk, and Ed Peelem (1996), "Exploring the Contextual and Individual Factors on Ethical Decision Making of Salespeople," Journal of Business Ethics, 15, 1175-1187. 
Vermillion, Leslie J., Walfried M. Lasser, and Robert D. Winsor (2002), "The HuntVitell General Theory of Marketing Ethics: Can It Enhance our Understanding of Principal-Agent Relationships in Channels of Distribution?," Journal of Business Ethics, 41, 267-285.

Veugelers, Reinhilde (1993), "Reputation as a Mechanism Alleviating Opportunistic Host Government Behavior against MNEs," Journal of Industrial Economics, 41 (1), 117.

Victor, Bart and John B. Cullen (1988), "The Organizational Bases of Ethical Work Climates," Administrative Science Quarterly, 33 (1), 101-125.

Victor, Bart and John B. Cullen (1987), "A Theory and Measure of Ethical Climate in Organizations," Research in Corporate Social Performance and Policy, 9, 51-71.

Vidaver-Cohen, Deborah (1997), "Moral Climate in Business Firms: A Conceptual Framework for Analysis and Change," Journal of Business Ethics, 17 (11), 12111226.

Vitell, S. J., J. R. Lumpkin, and M. Y. A. Rawwas (1991), "Consumer Ethics: An Investigation of the Ethical Beliefs of Elderly Consumers," Journal of Business Ethics, 10, 365-375.

Vroom, Victor H. (1964), Work and Motivation, New York, NY: Wiley.

Walker, G., B. Kogut, and W. Shan (1997), "Social Capital, Structural Holes and the Formation of Industry Networks," Organization Science, 8 (2), 109-125.

Wathne, Kenneth H., Herald Biong, and Jan B. Heide (2001), "Choice of Supplier in Embedded Markets: Relationship and Marketing Program Effects," Journal of Marketing, 65 (April), 54-66.

Wathne, Kenneth H. and Jan B. Heide (2000), "Opportunism in Interfirm Relationships: Forms, Outcomes, and Solutions," Journal of Marketing, 64 (October), 36-51.

Wathne, Kenneth H. and Jan B. Heide (2004), "Relationship Governance in a Supply Chain Network," Journal of Marketing, 68 (January), 73-89.

Wayne, Sandy J., Lynn M. Shore, and William H. Bommer (2002), "The Role of Fair Treatment and Rewards in Perceptions of Organizational Support and LeaderMember Exchange," Journal of Applied Psychology, 87 (3), 590-598.

Weaver, Gary R., Linda Klebe Trevino, and Philip L. Cochran (1999), "Corporate Ethics Programs as Control Systems: Influences of Executive Commitment and Environmental Factors," Academy of Management Journal, 42 (1), 41-57. 
Weber, James (1995), "Influences upon Organizational Ethical Subclimates: A Multidepartmental Analysis of a Single Firm," Organization Science, 6 (5), 509-523.

Weber, James (1996), "Influences upon Managerial Moral Decision Making: Nature of Harm and Magnitude of Consequences," Human Relations, 49 (1), 1-22.

Weber, J. and J. Gillespie (1998), Ethical Initiatives in Southwestern Pennsylvania: A Benchmark Report from the Beard Center for Leadership in Ethics, Pittsburgh, PA: Duquesne University Press.

Weigelt, Keith and Colin Camerer (1988), "Reputation and corporate strategy: A review of recent theory and application," Strategic Management Journal, 9 (5), 443-454.

Weiss, Allen M. and Erin Anderson (1992), "Converting From Independent to Employee Salesforces: The Role of Perceived Switching Costs," Journal of Marketing Research, 36 (February), 101-115.

Weiss, Allen M., Erin Anderson, and Deborah J. MacInnis (1999), "Reputation Management as a Motivation for Sales Structure Decisions," Journal of Marketing, 63 (October), 74-89.

Wenzel, Michael (2002), "The Impact of Outcome Orientation and Justice Concerns on Tax Compliance: The Role of Taxpayer's Identity," Journal of Applied Psychology, 87 (4), 629-645.

White, J. Chris, P. Rajan Varadarajan, and Peter A. Dacin. (2003), "Market Situation Interpretation and Response: The Role of Cognitive Style, Organizational Culture, and Information Use," Journal of Marketing, 67 (July), 63-79.

White, Richard D. (2002), "Do Employees Act Like They Think? Exploring the Dichotomy between Moral Judgment and Ethical Behavior," Public Administration Quarterly, 25 (3/4), 391-412.

White, Steven and Steven Siu-Yun Lui (2005), "Distinguishing Costs of Cooperation and Control in Alliances," Strategic Management Journal, 26 (10), 913-932.

Wicks, Andrew, Shawn L. Berman, and Thomas M. Jones (1999), "The Structure of Optimal Trust: Moral and Strategic Implications," Academy of Management Review, 24 (1), 99-116.

Williamson, Oliver E. (1975), Markets and Hierarchies: Analysis and Antitrust Implications., New York, NY: Free Press.

Williamson, Oliver E. (1983), "Credible Commitments: Using Hostages to Support Exchange," The American Economic Review, 73 (4), 519-540. 
Williamson, Oliver E. (1985), The Economic Institutions of Capitalism, New York, NY: Free Press.

Williamson, Oliver E. (1993), "Opportunism and Its Critics," Managerial and Decision Economics, 14, 97-107.

Williamson, Oliver E. (1996), The Mechanisms of Governance, Oxford, NY: Oxford University Press.

Wimbush, James C. and Jon M. Shepard (1994), "Toward an Understanding of Ethical Climate: Its relationship to Ethical Behavior and Supervisory Influence," Journal of Business Ethics, 13 (8), 637-647.

Wiseman, Robert M. and Luis R. Gomez-Mejia (1998), "A Behavioral Agency Model of Managerial Risk Taking," Academy of Management Review, 23 (1), 133-153.

Wittmer, Dennis P. (2000), "Ethical Sensitivity in Management Decisions: Developing and Testing A Perceptual Measure Among Management and Professional Student Groups," Teaching Business Ethics, 4 (2), 181-205.

Wong, Alfred, Dean Tjosvold, and Zi-you Yu (2005), "Organizational Partnerships in China: Self-Interest, Goal Interdependence, and Opportunism," Journal of Applied Psychology, 90 (4), 782-791.

Wulf, Kristof de, Gaby Odekerken-Schroder, and Dawn Iacobucci (2001), "Investments in Consumer Relationships: A Cross-Country and Cross Industry Exploration," Journal of Marketing, 65 (October), 33-50.

Wuyts, Stephan and Inge Geyskens (2005), "The Formation of Buyer-Supplier Relationships: Detailed Contract Drafting and Close Partner Selection," Journal of Marketing, 69 (October), 103-117.

Yamagishi, Toshio (1988), "The Provision of a Sanctioning System in the United States and Japan," Social Psychology Quarterly, 51 (3), 265-271.

Yamagishi, Toshio (2001), "Trust as a Form of Social Intelligence," in Trust in Society, ed. Karen S. Cook, New York, NY: Russell Sage Publications, 121-147.

Yilmaz, Cengiz and Shelby D. Hunt (2001), "Salesperson Cooperation: The Influence of Relational, Task, Organizational, and Personal Factors," Journal of the Academy of Marketing Science, 29 (4), 335-357.

Yin, Xiaoli and Edward J. Zajac (2004), "The Strategy/Governance Structure Fit Relationship: Theory and Evidence in Franchising Arrangements," Strategic Management Journal, 25 (April), 365-383. 
Younts, C. Wesley and Charles W. Mueller (2001), "Justice Processes: Specifying the Mediating Role of Perceptions of Distributive Justice," American Sociological Review, 66 (1), 125-145.

Yuan, K. H., W. Chan, and P Bentler, M. (2000), "Robust Transformation with Applications to Structural Equation Modeling," British Journal of Mathematical and Statistical Psychology, 53, 31-50.

Zahra, Shaker A. (1989), "Executive Values and the Ethics of Company Politics: Some Preliminary Findings," Journal of Business Ethics, 8 (1), 15-29.

Zajac, Edward J. and James D. Westphal (1994), "The Costs and Benefits of Managerial Incentives and Monitoring in Large U.S. Corporations: When is More not Better?," Strategic Management Journal, 15, 121-142. 
National Survey

of

Franchisees

Conducted by:

Virginia

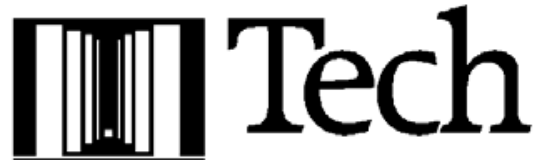

$\begin{array}{lllll}1 & 8 & 7 & 2\end{array}$

VIRGINIA POLYTECHNIC INSTITUTE

AND STATE UNIVERSITY 


\section{APPENDIX A \\ SURVEY INSTRUMENT: PAGE TWO}

\section{IIVirginiaTech}

\section{National Survev of Franchisees}

Dear Unit Franchisees:

How can you improve franchisor-franchisee relationships? Although franchises contribute over $\$ 1$ trillion to our economy, we know very little about franchisor-franchisee relationships from the franchisees' point of view. We are marketing researchers conducting a nation-wide survey of franchisees, such as yourself, and with your help we hope to discover what makes franchising relationships work well.

The only way to understand franchising relationships is to get information directly from people like you, and so we hope that you will do us the tremendous favor of answering our survey. We know that this is asking a lot - it should take 30 to 35 minutes to complete and return (with postage paid) - but we will provide you with a summary of our results as a small thanks for your help. Please respond within 10 days.

For the research results to be meaningful, we need honest answers to all of the survey questions. A few may seem repetitive, but that's to make sure that we have a complete picture of your opinions. There are no right or wrong answers, and we guarantee that your responses are strictly confidential. No response will be revealed to any third party, including your franchisor. To ensure anonymity, you will be identified only by a code, which is stored securely in a database that only the researchers can access. If you have any questions, please call (540-231-9618) or email (cishida@vt.edu) us.

We thank you for taking the time to consider our request, and we hope that yours will be one of the voices that shape our findings.
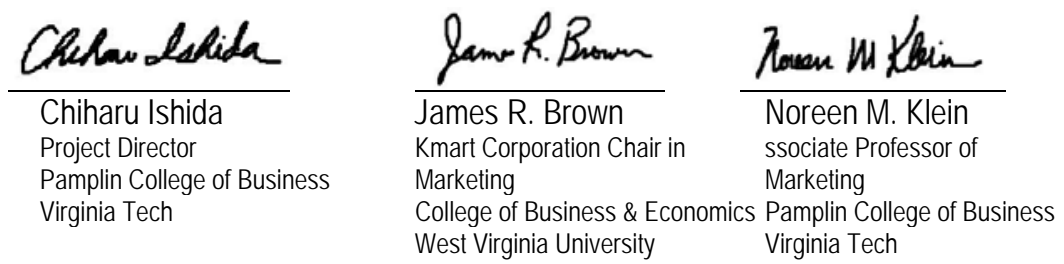


\title{
APPENDIX A \\ SURVEY INSTRUMENT: PAGE THREE
}

\author{
What is your title or position within your firm? \\ (e.g., Owner, General Manager, etc.) \\ About how long have you managed this franchise unit? ..........__ (years)

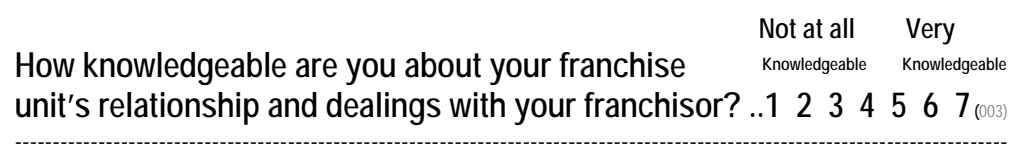

Please express your agreement or disagreement with each of the following statements. It is very important that you try carefully, but quickly, to answer each question. Please circle the number that best represents your opinion.

\section{Part 1. The following questions/statements relate to your franchisor}

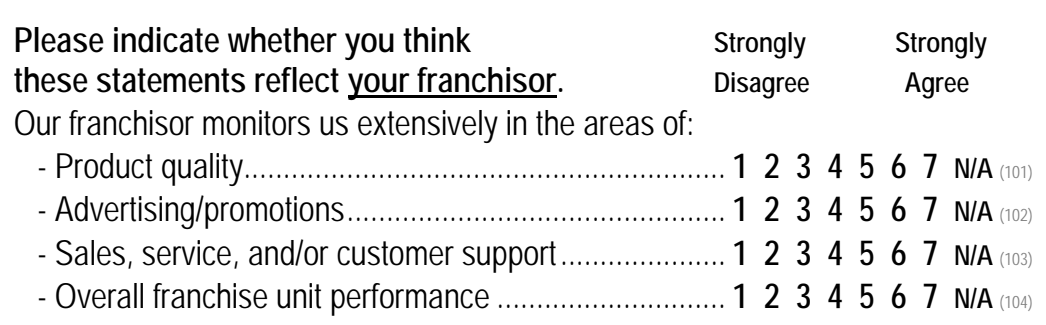

If this relationship were to terminate, it would be difficult for them to recoup investments made in this franchise unit... $123345567_{(105)}$

Sales from our unit account for a high percentage of our franchisor's profits in market. $1234567_{(106)}$

Training and qualifying us has involved considerable commitments of time and money on their part.

They have invested a great deal in building up this franchise unit's business.

They do not have a good alternative to replace us.....

If we were to terminate this relationship, the franchisor would lose a lot of their investment..

For our franchisor, it would be difficult to replace us .

Sales from our unit account for a high percentage of their sales in the market

They are very dependent on our franchise unit.

They need to maintain a good relationship with us.

Our franchisor compensates us fairly:

- Considering the responsibilities that we have. $1234567_{(115)}$

- Taking into account the investment we have made. ....... $122344567_{(116)}$

- In view of the amount of effort we put forth in building this business.

- For work that we do well.

- For the stresses and strains of our job. 


\section{APPENDIX A \\ SURVEY INSTRUMENT: PAGE FOUR}

Please indicate whether you think these
statements reflect your franchisor.

In making decisions affecting our business, our franchisor's

general policies:

- Strive to collect accurate information so that the decisions are based on as much good information and informed opinion as possible.

- Provide opportunities to challenge the decisions.

- Generate standards so that decisions could be made with consistency.

- Pay attention to the concerns of all those affected by the decisions.

- Are designed to have all sides affected by the decision represented

- Allow for requests for clarification or additional information about the decision

Strongly

Disagree
$1234567_{(120)}$

$12334567_{(12}$

$1234567_{(122)}$

$1234567_{(123)}$

$1234567_{(124)}$ $1234567_{(125)}$

Our franchisor:

- considers our viewpoint whenever s/he is communicating with us.

$1234567_{(126)}$

- is able to suppress personal biases in dealing with us.... $\begin{array}{lllllll}2 & 2 & 4 & 5 & 6 & 7_{(127)}\end{array}$

- provides us with timely feedback whenever we express concerns about our job.

$1234567_{(128)}$

- treats us with kindness and consideration

$\begin{array}{lllllll}1 & 2 & 4 & 6 & 7_{(129)}\end{array}$

- shows concern for our rights as a franchisee.

$\begin{array}{lllllll}1 & 2 & 4 & 5 & 6 & 7_{(130)}\end{array}$

- takes steps to deal with us in a truthful manner. $\begin{array}{lllllll}12 & 3 & 5 & 6 & 7_{(131)}\end{array}$

Our franchisor would take tough measures against us if we were discovered withholding certain critical information from them. $1234567_{(132)}$

We perform so many different tasks that this franchisor finds it difficult to determine whether we are doing a good job.

This franchisor's response to any baseless excuses for not meeting our obligations would be firm $1234567_{(134)}$

It is easy for our franchisor to determine whether we adhere to agreed upon quality standards and specifications.

Our franchisor would take strict disciplinary action against us if we don't act in accordance with our contracts.

Our franchisor easily detects when we promise to do some things without actually following through $122345667_{(137)}$

If we don't adhere to our informally agreed upon terms, this franchisor would take severe action against us. $1234567_{(138)}$ 


\section{APPENDIX A \\ SURVEY INSTRUMENT: PAGE FIVE}

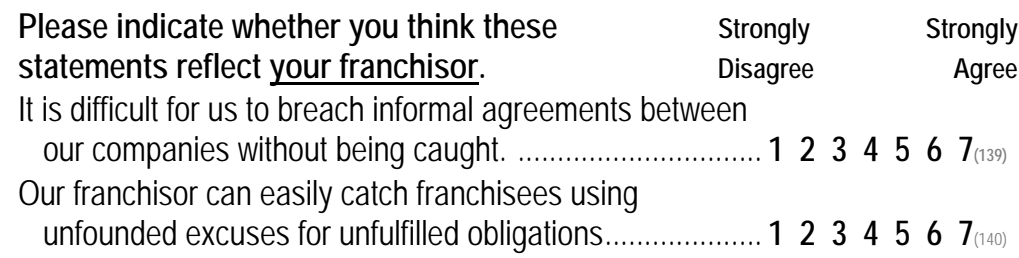

Part 2. The following statements relate to your franchise unit.

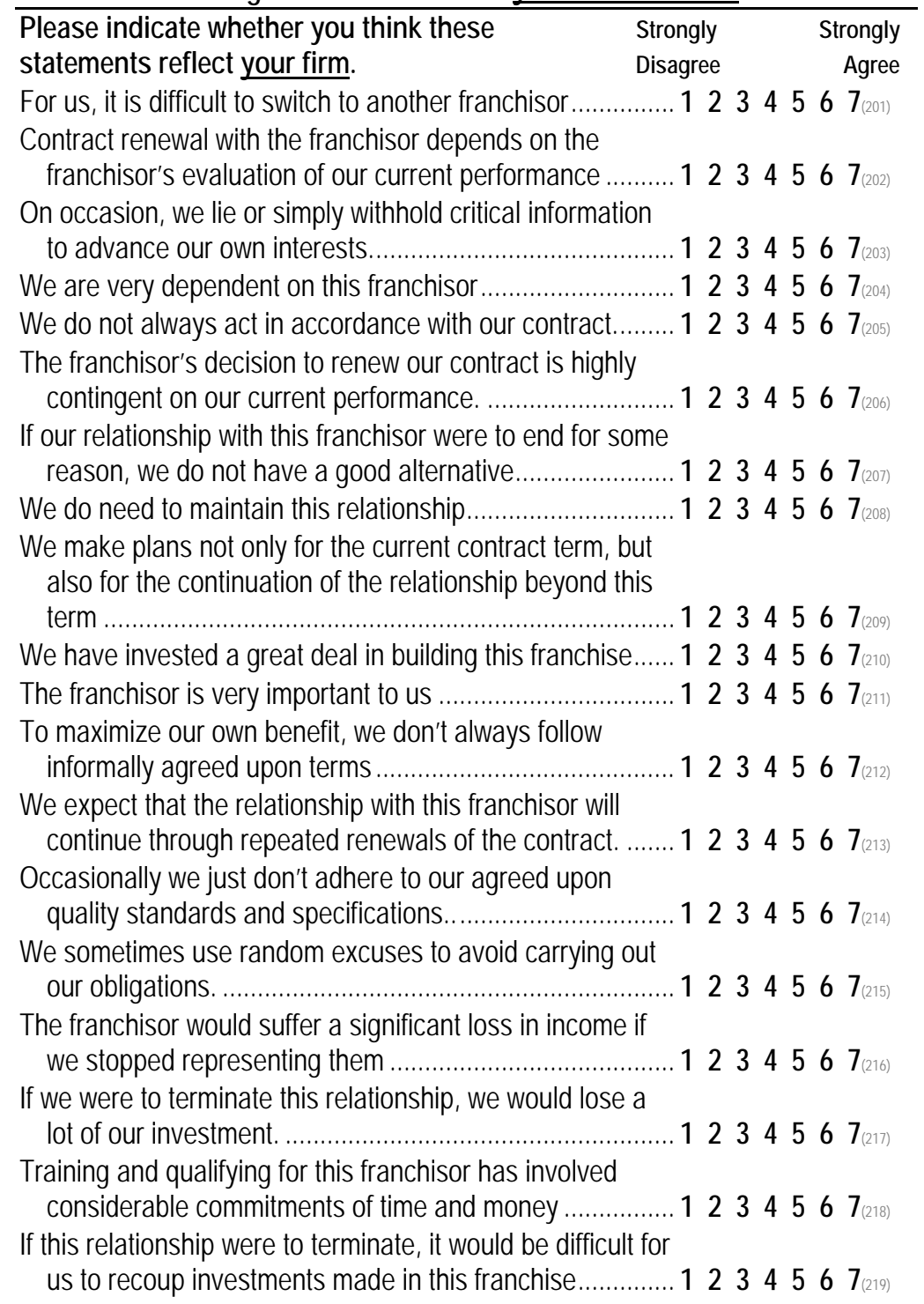




\section{APPENDIX A \\ SURVEY INSTRUMENT: PAGE SIX}

Part 3. The following statements relate to the relationship between your firm and franchisor

Please indicate whether you think these statements reflect your relationship.

Strongly Strongly

Disagree Agree

Our franchisor and we are generally able to resolve disagreements to both parties' satisfaction $1234567_{(301)}$

There are standard procedures for resolving disputes between us that do not involve third party intervention $1234567_{(302)}$

Problems that arise in the course of this relationship are treated by the parties as joint rather than individual responsibilities $1234567_{(303)}$

Both parties try to resolve any disagreements that arise between us in good faith $1234567_{(304)}$

The high level of mutual trust between the parties enable us to settle our disagreements to everyone's satisfaction.

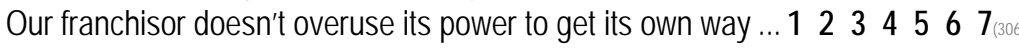

The parties are committed to improvements that may benefit the relationship as a whole, and not just the individual parties.

We don't expect our franchisor to use what power it has over us.

Rather than abusing its power, our franchisor shows restraint in dealing with us....

The parties in this relationship do not mind owing each other favors.

We are very pleased with what our franchisor does for us.......1 $12344567_{(311)}$

Overall, we are very satisfied with our franchisor ....

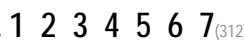

If we had to do it all over again, we would still choose this franchisor $1234567_{(313)}$

We find our franchisor's new ideas about products and promotions to be very effective

$1234567_{(314)}$

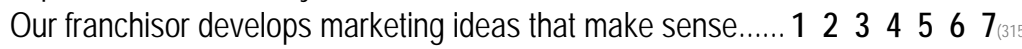

Our franchisor's policies on how to sell our products have helped us increase our sales volume $1234567_{(316)}$

Our relationship with the franchisor is governed mainly by written contracts $1234567_{(317)}$

The only way we seem to communicate effectively with our franchisor is when everything is spelled out in writing ......... $1 \begin{array}{lllllll}2 & 3 & 4 & 5 & 6 & 7_{(318)}\end{array}$ Over time we found the best ways of doing things is to rely on formal agreements $1234567_{(319)}$ 


\section{APPENDIX A \\ SURVEY INSTRUMENT: PAGE SEVEN}

Part 4. The following statements relate to your franchisee network.

\begin{tabular}{|c|}
\hline $\begin{array}{l}\text { Please indicate whether you think these } \\
\text { statements accurately reflect your franchise network. Disagree }\end{array}$ \\
\hline
\end{tabular}

People in the franchise business don't really comply with

the law or professional standards of conduct

$1234567_{(401)}$

It is not important to follow the company's rules and

procedures in this business.

Successful people in this business don't go by the book.... $1 \begin{array}{llllll}2 & 3 & 4 & 5 & 6 & 7_{(403)}\end{array}$

Members of our franchise share close ties.

$\begin{array}{llllll}1 & 2 & 3 & 5 & 6 & 7 \\ (404) & \end{array}$

In this business, people are not really expected to strictly

follow legal or professional standards.

$1234567_{(405)}$

Not everyone in this business sticks by company rules and

procedures at all times.

$1234567_{(400)}$

People in this business don't strictly obey the company policies

$1234567_{(407)}$

Members of our franchise network are extremely cohesive $\begin{array}{lllllll}1 & 2 & 3 & 4 & 5 & 6 & 7_{(408)}\end{array}$

In this business, the law or ethical codes in our profession

are not a major consideration.

$1234567_{(409)}$

There is much interaction among the members of our franchise

The good of all people in the franchise system as a whole

is the most important concern for all involved

What is best for the franchise network is not the major consideration is this business.

$1234567_{(411)}$

this business we are not at all con

$1234567_{(412)}$

best for other members of the profession

$1234567_{(413)}$

In this franchise system, people protect their own interests above all else

In this business, people are mostly out for themselves........ $\begin{array}{lllllll}1 & 2 & 3 & 4 & 5 & 6 & 7_{(415)}\end{array}$

There is no room for one's own personal morals or ethics

in this business.

$1234567_{(416)}$

Members of our franchise network frequently share communications.

Members of our franchise network frequently discuss common problems $1234567_{(418)}$

Relations among members of our franchise network are very close.

$1234567_{(419)}$ 


\section{APPENDIX A \\ SURVEY INSTRUMENT: PAGE EIGHT}

Part 5. The following statements relate to your own personal feelings toward the franchisor

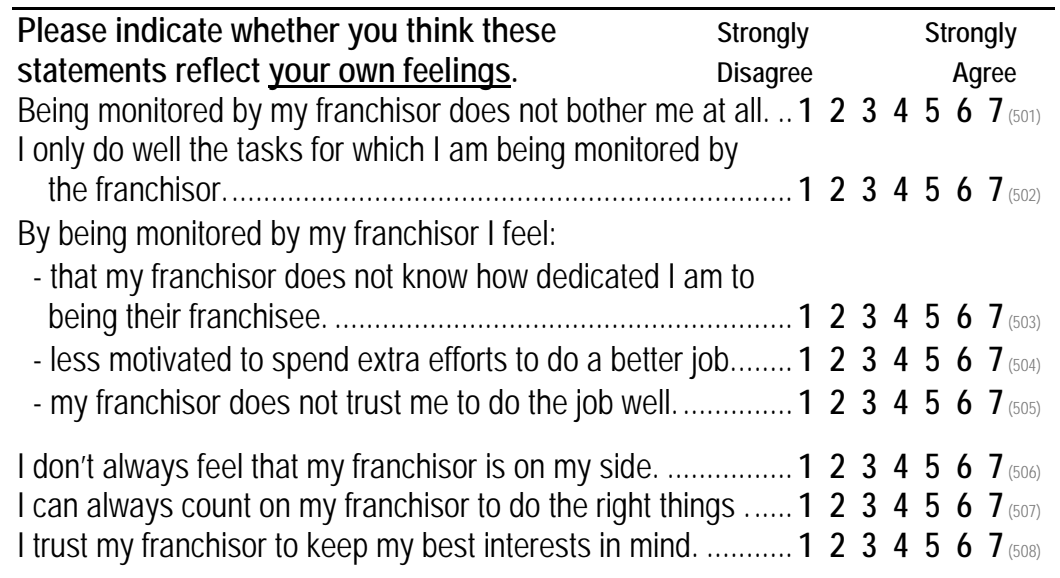

In any given business relationship, a party may engage in certain actions to improve their terms of trade such as:

- Giving empty promises

- Breaching formal and/or informal agreements to maximize gains

- Taking advantage of "holes" in the contract

- Using excuses to re-negotiate terms of trade at the partner's expense

- Withholding important information from the partner

My history with my franchisor tells me they are capable of

these behaviors

$\begin{array}{lr}\text { Strongly } & \text { Strongly } \\ \text { Disagree } & \text { Agree }\end{array}$

It would not surprise me if my franchisor were to engage in

this type of action against us.

I would expect these behaviors from my franchisor.

$1234567_{(509)}$

These behaviors describe my franchisor well

$.11234567_{(510)}$

122345567

If a franchisee behaves this way without being detected by the franchisor, it could gain:

- Increased profits for a franchise unit.

$1234567_{(513)}$

- Decreased costs for a franchise unit.

$12334567_{(514)}$

- Decreased hours necessary to perform required tasks..... $123344567_{(515)}$

Specific to your franchisor, please circle the number below that indicates how you feel about using this type of behavior:

$\begin{array}{llllllllll}\text { Unwilling } & -3 & -2 & -1 & 0 & +1 & +2 & +3 & \text { Willing } & \\ \text { Unmotivated } & -3 & -2 & -1 & 0 & +1 & +2 & +3 & \text { Motivated } & \text { (516) } \\ \text { Reluctant } & -3 & -2 & -1 & 0 & +1 & +2 & +3 & \text { Tempted } & (517) \\ \text { Unprovoked } & -3 & -2 & -1 & 0 & +1 & +2 & +3 & \text { Provoked } & (518) \\ \text { Not compelled }-3 & -2 & -1 & 0 & +1 & +2 & +3 & \text { Compelled } & (520)\end{array}$




\section{APPENDIX A \\ SURVEY INSTRUMENT: PAGE NINE}

Part 6. Managers' attitudes play an important role in work relationships. The next questions ask about some of your attitudes, so that we can later group the answers of franchisees with similar attitudes.

Behaviors such as giving empty promises and taking Strongly Strongly advantage of holes in the contract:

Disagree Agree

- are very common in business.

1234567

- are acceptable in most cases.

$1234567{ }_{(602)}$

- often times take place out of necessity 1234567

For each of the following pairs of statements, please circle one (a or b) with which you more strongly agree:

1 a) Many of unhappy things in people's lives are partly due to bad luck.

b) People's misfortunes result from the mistakes they make.

2 a) In the long run, people get the respect they deserve in this world.

b) Unfortunately, an individual's worth often passes unrecognized no matter how hard s/he works.

3 a) Without the right breaks, one cannot be an effective leader.

b) Capable people who fail to become leaders have not taken advantage of their opportunities.

4 a) Becoming a success is a matter of hard work; luck has little or to do with it.

b) Being in the right place at the right time is what determines success.

5 a) What happens to me is my own doing.

b) Sometimes I feel that I don't have enough control over the direction my life is taking.

6 a) When I make plans, I am almost certain that I can make them work.

b) It is not always wise to plan too far ahead because many things turn out to be a matter of good or bad fortune anyhow.

7 a) In my case getting what I want has little or nothing to do with luck.

b) Many times we might just as well decide what to do by flipping a coin.

8 a) Who gets to be the boss often depends on who was in the right place first.

b) Getting people to do the right thing depends upon ability; luck has little or nothing to do with it

9 a) Most people don't realize the extent to which their lives are controlled by accidental happenings

b) There really is no such thing as "luck."

10 a) In the long run the bad things happen in life are balanced by the good

b) Most misfortunes are the result of ignorance, laziness, or luck of ability (613)

11 a) Many times I feel I have little influence over the things happen to me

b) It is impossible for me to believe that chance or luck plays an important role in my life 


\title{
APPENDIX A \\ SURVEY INSTRUMENT: PAGE TEN
}

\author{
Please indicate whether you think following \\ statements reflect your own personal views \\ Strongly Strongly \\ Disagree Agree
}

If one works hard enough, s/he is likely to make a good life for him/herself $1234567(615)$ Hard work is fulfilling in itself. $\begin{array}{lllllll}1 & 2 & 4 & 5 & 6 & 7\end{array}$

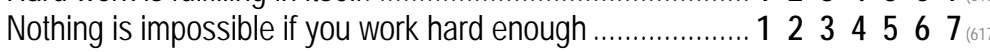

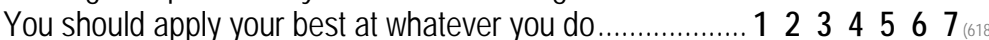

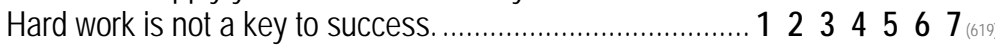
Any person who is able and willing to work hard has a good chance of succeeding. $1234567_{(620)}$

Never tell anyone the real reason you did something unless it is useful to do so $1234567_{(621)}$

The best way to handle people is to tell them what they want to hear..... $1234567_{(622)}$

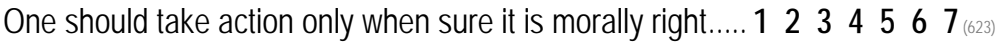
Most people are basically good and kind.....

It is safest to assume that all people have a vicious streak.. $\begin{array}{lllllll}2 & 3 & 4 & 5 & 6 & 7 & 7625\end{array}$ Honesty is the best policy in all cases. $12345677_{(626)}$

There is no excuse for lying to someone else

Generally speaking, people won't work hard unless they are forced to do so

All in all, it is better to be humble and honest than to be important and dishonest.....

When you ask someone to do something for you, it is best to give the real reasons for wanting it rather than reasons that carry more weight.

Most people who get ahead in the world lead clean, moral lives

Anyone who completely trusts anyone else is asking for trouble.

The biggest difference between most criminals and other people is that the criminals are stupid enough to get caught......

Most of us are brave.

$\begin{array}{lllllll}12 & 3 & 4 & 6 & 7_{(634)}\end{array}$

It is wise to flatter important people ...................................12 $1345677_{(635)}$

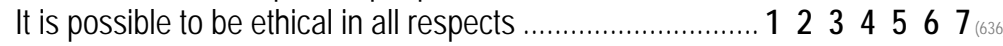

Barnum was wrong when he said "there's a sucker born every minute"......

$1234567_{(637)}$

It is hard to get ahead without cutting corners here and there ......

People suffering from incurable diseases should have the choice of being put painlessly to death. $1234567_{(638)}$ Most people forget more easily the death of their parents than the loss of their property. 


\section{APPENDIX A \\ SURVEY INSTRUMENT: PAGE ELEVEN}

Franchisees face many difficult decisions, and we want to know something about your decision making approach. But, you may be surprised that the situations we ask you about next have nothing to do with your business. However, they do capture what you think is important when you face a tough decision.

These questions are challenging, but we think you may also find it fascinating to discover what you really do think is most important in making critical decisions.

We describe two situations and, for each one, show you a list of questions that the person deciding to take action might consider. Please read one question at a time, and then check the category on the left that shows how important you think that question is to making the decision. The categories are:

Great importance - check this if the question concerns something that makes a big, crucial difference one way or the other in making a decision about the problem.

Much importance - check this if the question concerns something that a person should clearly be aware of in making a decision, and one way or the other, it would make a difference in your decision, but not a big, crucial difference.

Someimportance - check this if the question concerns something you generally care about, but something that is not of crucial importance in deciding about this problem.

Little importance - check this if the question concerns something that is not sufficiently important to consider in this case.

No importance - check this if the question is about something that has no importance in making a decision, and that you'd be wasting time in thinking about this when trying to make a difficult decision. Some of the questions are apt to seem foolish or make no sense - check here on those questions

\section{SCHOOL NEWSPAPER CASE}

Fred, a senior in high school, wanted to publish a newspaper for students to speak out against the war in Iraq and to speak out against some of the school's rules, like the rule forbidding students from wearing particular clothing. Fred asked his principal for permission. The principal said it would be OK if before every publication Fred would turn in all his articles for the principal's approval. Fred agreed and turned in several articles for approval, which the principal subsequently approved.

Fred published two issues of the paper in the next two weeks. But the principal had not expected that Fred's newspaper would receive so much attention. Students were so excited by the paper that they began to organize protests against the clothing regulation and other school rules. Angry parents objected to Fred's opinions and phoned the principal telling him that the newspaper should not be published.

As a result of the rising excitement, the principal ordered Fred to stop publishing, giving a reason that Fred's activities were disruptive to the operation of the school. 


\section{APPENDIX A \\ SURVEY INSTRUMENT: PAGE TWELVE}

SCHOOL NEWSPAPER CASE continued...

Should the principal stop the newspaper? (Check one)

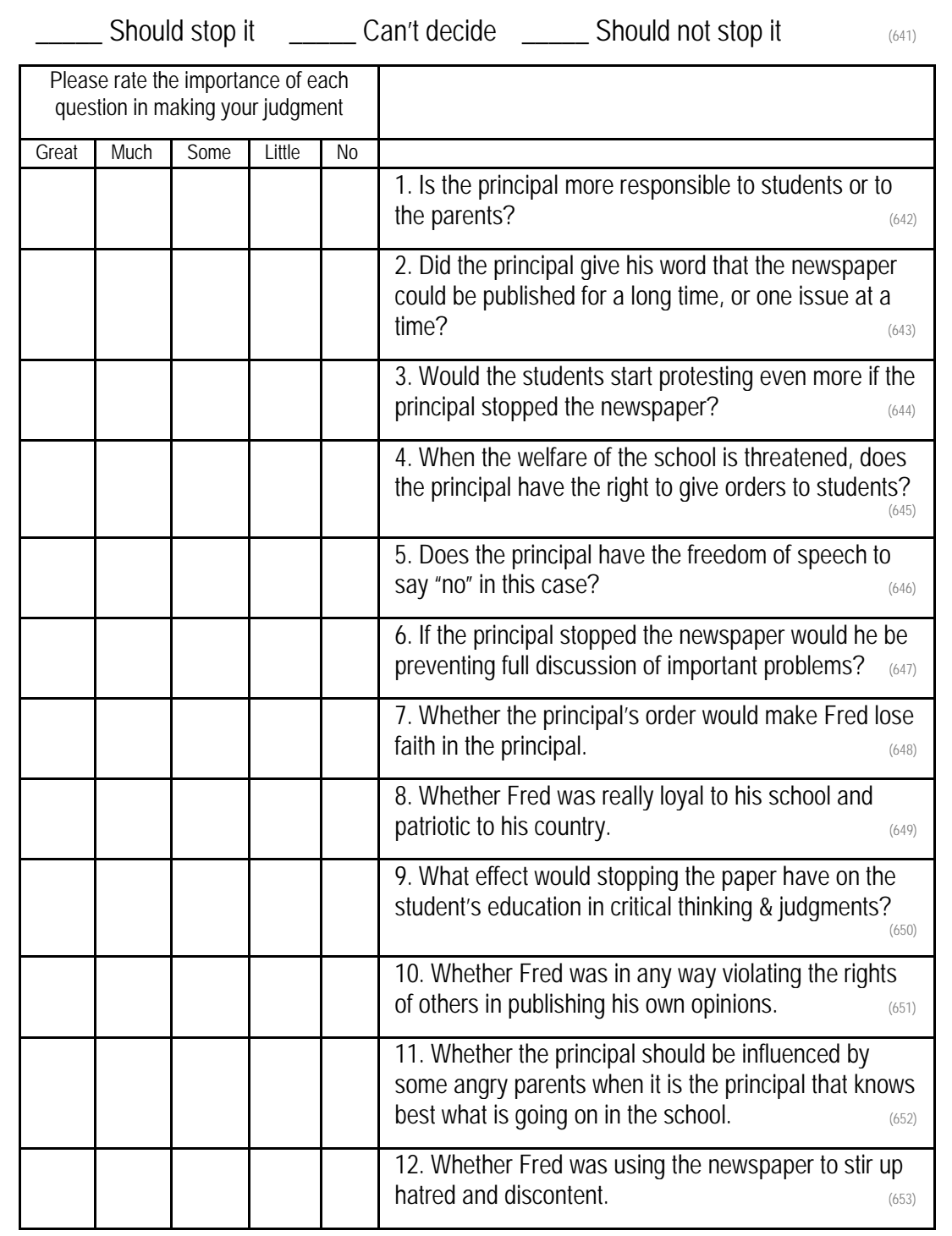

From the list of questions above, please select the four most important:

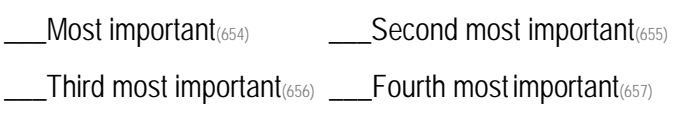




\section{APPENDIX A \\ SURVEY INSTRUMENT: PAGE THIRTEEN}

\section{ESCAPED PRISONNER CASE}

A man had been sentenced to prison for 10 years. After one year, however, he escaped from prison, moved to a new area of the country, and took on the name of Thompson. For 8 years he worked hard, and gradually he saved enough money to buy his own business. He was fair to his customers, gave his employees top wages, and gave most of his own profits to charity. Then one day, Mrs. Jones, an old neighbor, recognized him as the man who had escaped from prison 8 years before, and whom the police had been looking for.

Should Mrs. Jones report Mr. Thompson to the police and have him sent back to prison? (Check one)

\begin{tabular}{|c|c|c|c|c|c|}
\hline & \multicolumn{3}{|c|}{ Should report him } & & \multirow[t]{2}{*}{ Can't decide __ Should not report him ${ }_{(658)}$} \\
\hline Great & Much & Some & Little & No & \\
\hline & & & & & $\begin{array}{l}\text { 1. Hasn't Mr. Thompson been good enough for such a } \\
\text { long time to prove he isn't a bad person? }\end{array}$ \\
\hline & & & & & $\begin{array}{l}\text { 2. Every time someone escapes punishment for a } \\
\text { crime, doesn't that just encourage more crime? }\end{array}$ \\
\hline & & & & & $\begin{array}{l}\text { 3. Wouldn't we be better off without prisons and the } \\
\text { oppression of our legal systems? }\end{array}$ \\
\hline & & & & & 4. Has Mr. Thompson really paid his debt to society? \\
\hline & & & & & $\begin{array}{l}\text { 5. Would society be failing what Mr. Thompson should } \\
\text { fairly expect? }\end{array}$ \\
\hline & & & & & 6. Which prison would he be sent to this time? \\
\hline & & & & & $\begin{array}{l}\text { 7. How could anyone be so cruel and heartless as to } \\
\text { send Mr. Thompson to prison? }\end{array}$ \\
\hline & & & & & $\begin{array}{l}\text { 8. Would it be fair to all the prisoners who had to serve } \\
\text { out their full sentences if Mr. Thompson was let off? }\end{array}$ \\
\hline & & & & & 9. Was Mrs. Jones a good friend of Mr. Thompson? \\
\hline & & & & & $\begin{array}{l}\text { 10. Wouldn't it be a citizen's duty to report an escaped } \\
\text { criminal, regardless of the circumstances? }\end{array}$ \\
\hline & & & & & $\begin{array}{l}\text { 11. How would the will of the people and the public } \\
\text { good best be served? }\end{array}$ \\
\hline & & & & & $\begin{array}{l}\text { 12. Would going to prison do any good for Mr. } \\
\text { Thompson or protect anybody? }\end{array}$ \\
\hline
\end{tabular}

From the list of questions above, please select the four most important questions:
Most important ${ }_{(671)}$ Second most important ${ }_{(672)}$
_Third most important ${ }_{(673)}$ Fourth most important(674) 


\section{APPENDIX A \\ SURVEY INSTRUMENT: PAGE FOURTEEN}

For each of the following statements, please circle either True or False with which you more strongly agree:

I sometimes feel resentful when I don't get my way.

On a few occasions, I have given up doing something because I thought too little of my ability..... True False There have been times when I felt like rebelling against people in authority even though I knew they were right No matter who I'm talking to, I'm always a good listener..... I can remember "playing sick" to get out of something. There have been occasions when I took advantage of someone. True False ${ }_{(676)}$

I'm always willing to admit it when I make a mistake. True False

I sometimes try to get even, rather than forgive and forget.... True False ${ }_{(78)}$ When I don't know something, I don't at all mind admitting ..... True False I am sometimes irritated by people who ask favors of me. True False ${ }_{680}$ I have never deliberately said something that hurt someone's feelings True False True False ${ }_{(82)}$ True False ${ }_{(683)}$ True False True False

Part 7. Finally, we would like you to give us some information about your firm and your background.

Are you a member of any of the following professional associations? American Franchisee Association

— International Franchise Association

— other, please specify:

— not a member of any group.

About how many employees do you now have? Full time: Part time: (count) (703)

About how many hours per week does the average part-time employee work? (count) (704)

What was your franchise unit's total sales volume last year? (hrs./week) (705) Up to $\$ 499 \mathrm{k}$ $\$ 3 \mathrm{M}-\$ 4.99 \mathrm{M}$

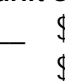
$\$ 500 \mathrm{k}$ - \$999k $\$ 5 \mathrm{M}-\$ 9.99 \mathrm{M}$ $\$ 1 \mathrm{M}-\$ 2.99 \mathrm{M}$ $\$ 10$ million and up

What is your industry sector? Auto repair/maintenance Food: full service Financial services Personal services Electronics repair/maintenance Food - quick service (specify): General printing Commercial/residential services

Other (specify): 


\section{APPENDIX A \\ SURVEY INSTRUMENT: PAGE FIFTEEN}

What percentage of your necessary supplies do you buy

from your franchisor?

$\%(708)$

Does your franchisor require you to buy your necessary supplies from them?

...Yes-all Yes-some No ${ }_{(709)}$

About how long have you been in the franchise business? .....

Which other franchise(s) have you previously worked for? (years)

About how long have you been affiliated with your

franchisor?.

About how long has the franchisee store affiliated with your

franchisor?. (years) (712)

Were you born in the United States? (years) (113)

If you were not born in the U.S:

- About how long have you lived here? (years) $(715)$

- Where did you receive your formal education? Yes No ${ }^{(714)}$

What is your gender? Male Female ${ }_{(717)}$

How old are you? 18-24yrs 45-54yrs 25-34yrs 55-64yrs

Lastly, please use the space below if there is anything else you would like to share about your relationship with your franchisor.

THANK YOU FOR COMPLETING THIS SURVEY. Your time and effort are greatly appreciated. If you would like a summary of the results, please enclose a business card with this survey. We will see that you get a copy.

PLEASE TAPE SURVEY SHUT AT BOTTOM SO THAT RETURN ADDRESS IS SHOWING, AND PLACE IN THE MAIL. POSTAGE IS PREPAID. 


\section{APPENDIX A \\ SURVEY INSTRUMENT: PAGE SIXTEEN}

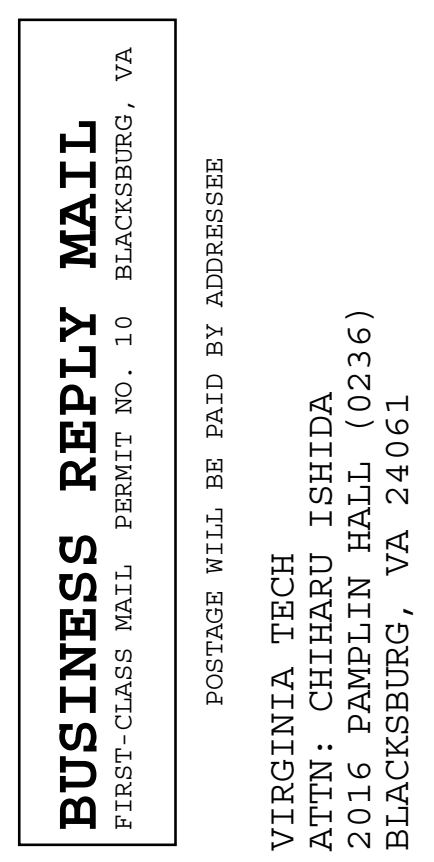




\section{APPENDIX B: SUMMARY OF SCALES, THEIR MEASUREMENT ITEMS AND DESCRIPTIVES}

\section{Individual-Level Scales}

Machiavellianism: 7-point Likert-type scale (1 = "strongly disagree" to 7 = "strongly agree”); Mach IV scores ranged from -14.00 to 60.00 (M=22.24, SD=14.70)

(Coded 621 through 640)

1. Never tell anyone the real reason you did something unless it is useful to do so.

2. The best way to handle people is to tell them what they want to hear

3. One should take action only when sure it is morally right $(\mathrm{R})^{1}$

4. Most people are basically good and kind(R)

5. It is safest to assume that all people have a vicious streak

6. Honesty is the best policy in all cases(R)

7. There is no excuse for lying to someone else(R)

8. Generally speaking, men won't work hard unless they are forced to do so

9. All in all, it is better to be humble and honest than to be important and dishonest( $\mathrm{R})$

10. When you ask someone to do something for you, it is best to give the real reasons for wanting it rather than reasons that carry more weight( $\mathrm{R})$

11. Most people who get ahead in the world lead clean, moral lives(R)

12. Anyone who completely trusts anyone else is asking for trouble

13. The biggest difference between most criminals and other people is that the criminals are stupid enough to get caught

14. Most men are brave(R)

15. It is wise to flatter important people

16. It is possible to be good in all respects(R)

17. Barnum was wrong when he said that there's a sucker born every minute(R)

18. It is hard to get ahead without cutting corners here and there

19. People suffering from incurable diseases should have the choice of being put painless to death

20. Most men forget more easily the death of their father than the loss of their property

\section{External Locus of Control}

Score ranged from .00 to $7.00(\mathrm{M}=1.78, \mathrm{SD}=1.67)$.

(Coded 604 through 614)

For each of the following pairs of statements, please circle one ( $a$ or $b$ ) with which you more strongly agree:

\footnotetext{
${ }^{1}$ Reverse-coded
} 


\section{APPENDIX B: Individual-Level Scales}

1 a) Many of the unhappy things in people's lives are partly due to bad luck.

b) People's misfortunes result from the mistakes they make.

2 a) In the long run, people get the respect they deserve in this world.

b) Unfortunately, an individual's worth often passes unrecognized no matter how hoard s/he tries.

3 a) Without the right breaks, one cannot be an effective leader.

b) Capable people who fail to become leaders have not taken advantage of their opportunities.

4 a) Becoming a success is a matter of hard work, luck has little or nothing to do with it.

b) Getting a good job depends mainly on being in the right place at the right time.

5 a) What happens to me is my own doing.

b) Sometimes I feel that I don't have enough control over the direction my life is taking.

6 a) When I make plans, I am almost certain that I can make them work.

b) It is not always wise to plan too far ahead because many things turn out to be a matter of good or bad fortune anyhow.

7 a) In my case getting what I want has little or nothing to do with luck.

b) Many times we might just as well decide what to do by flipping a coin.

8 a) Who gets to be the boss often depends on who was lucky enough to be in the right place first.

b) Getting people to do the right thing depends upon ability; luck has little or nothing to do with it.

9 a) Most people don't realize the extent to which their lives are controlled by accidental happenings.

b) There really is no such thing as "luck."

10 a) In the long run the bad things that happen to us are balanced by the good ones.

b) Most misfortunes are the result of lack of ability, ignorance, laziness, or all.

11 a) Many times I feel that I have little influence over the things that happen to me.

b) It is impossible for me to believe that chance or luck plays an important role in my life. 


\title{
APPENDIX B: Individual-Level Scales
}

\author{
Cognitive Moral Development \\ Score ranged from zero to $75(\mathrm{M}=30.78, \mathrm{SD}=17.06)$.
}

(Coded 641 through 674)

Franchisees face many difficult decisions, and we want to know something about your decision making approach. But, you may be surprised that the situations we ask you about next have nothing to do with your business. However, they do capture what you think is important when you face a tough decision. These questions are challenging, but we think you may also find it fascinating to discover what you really do think is most important in making critical decisions. We describe two situations and, for each one, show you a list of questions that the person deciding to take action might consider. Please read one question at a time, and then check the category on the left that shows how important you think that question is to making the decision.

The categories are:

Great importance - check this if the question concerns something that makes a big, crucial difference one way or the other in making a decision about the problem.

Much importance - check this if the question concerns something that a person should clearly be aware of in making a decision, and one way or the other, it would make a difference in your decision, but not a big, crucial difference.

Some importance - check this if the question concerns something you generally care about, but something that is not of crucial importance in deciding about this problem.

Little importance - check this if the question concerns something that is not sufficiently important to consider in this case.

No importance - check this if the question is about something that has no importance in making a decision, and that you'd be wasting time in thinking about this when trying to make a difficult decision. Some of the questions are apt to seem foolish or make no sense - check here on those questions

\section{NEWSPAPER}

Fred, a senior in high school, wanted to publish a newspaper for students to speak out against the war in Iraq and to speak out against some of the school's rules, like the rule 
forbidding students from wearing particular clothing. Fred asked his principal for permission. The principal said it would be OK if before every publication Fred would turn in all his articles for the principal's approval. Fred agreed and turned in several articles for approval, which the principal subsequently approved.

Fred published two issues of the paper in the next two weeks. But the principal had not expected that Fred's newspaper would receive so much attention. Students were so excited by the paper that they began to organize protests against the clothing regulation and other school rules. Angry parents objected to Fred's opinions and phoned the principal telling him that the newspaper should not be published.

As a result of the rising excitement, the principal ordered Fred to stop publishing, giving a reason that Fred's activities were disruptive to the operation of the school.

Should the principal stop the newspaper? (Check one) Should stop it Can’t decide Should not stop it

\begin{tabular}{|l|l|l|l|l|l|}
\hline Great & Much & Some & Little & No & \\
\hline & & & & & 1. Is the principal more responsible to students or to the parents? \\
\hline & & & & $\begin{array}{l}\text { 2. Did the principal give his word that the newspaper could be } \\
\text { published for a long time, or did he just promise to approve the } \\
\text { newspaper one issue at a time? }\end{array}$ \\
\hline & & & & $\begin{array}{l}\text { 3. Would the students start protesting even more if the principal } \\
\text { stopped the newspaper? }\end{array}$ \\
\hline & & & & $\begin{array}{l}\text { 4. When the welfare of the school is threatened, does the principal } \\
\text { have the right to give orders to students? } \\
\text { case? }\end{array}$ \\
\hline & & & $\begin{array}{l}\text { 6. If the principal stopped the newspaper would he be preventing } \\
\text { full discussion of important problems? }\end{array}$ \\
\hline & & & $\begin{array}{l}\text { 7. Whether the principal's order would make Fred lose faith in the } \\
\text { principal. }\end{array}$ \\
\hline & & & $\begin{array}{l}\text { 8. Whether Fred was really loyal to his school and patriotic to his } \\
\text { country. }\end{array}$ \\
\hline & & & $\begin{array}{l}\text { 9. What effect would stopping the paper have on the student's } \\
\text { education in critical thinking and judgments? }\end{array}$ \\
\hline & & & $\begin{array}{l}\text { 10. Whether Fred was in any way violating the rights of others in } \\
\text { publishing his own opinions. }\end{array}$ \\
\hline & & & $\begin{array}{l}\text { 11. Whether the principal should be influenced by some angry } \\
\text { parents when it is the principal that knows best what is going on } \\
\text { in the school. }\end{array}$ \\
\hline & & & $\begin{array}{l}\text { 12. Whether Fred was using the newspaper to stir up hatred and } \\
\text { disconnect. }\end{array}$ \\
\hline
\end{tabular}

From the list of questions above, select the four most important: 


\section{APPENDIX B: Individual-Level Scales}

Most important

Second most important

Third most important

Fourth most important

\section{ESCAPED PRISONER}

A man had been sentenced to prison for 10 years. After one year, however, he escaped from prison, moved to anew area of the country, and took on the name of Thompson. For 8 years he worked hard, and gradually he saved enough money to buy his own business. He was fair to his customers, gave his employees top wages, and gave most of his own profits to charity. Then one day, Mrs. Jones, an old neighbor, recognized him as the man who had escaped from prison 8 years before, and whom the police had been looking for.

Should Mrs. Jones report Mr. Thompson to the police and have him sent back to prison? (Check one)

Should report him Can’t decide Should not report him

Please rate the importance of each question in making your judgment.

\begin{tabular}{|l|l|l|l|l|l|}
\hline Great & Much & Some & Little & No & \\
\hline & & & & $\begin{array}{l}\text { 1. Hasn't Mr. Thompson been good enough for such a long time to } \\
\text { prove he isn't a bad person? }\end{array}$ \\
\hline & & & & & $\begin{array}{l}\text { 2. Every time someone escapes punishment for a crime, doesn't } \\
\text { that just encourage more crime? }\end{array}$ \\
\hline & & & & & $\begin{array}{l}\text { 3. Wouldn't we be better off without prisons and the oppression of } \\
\text { our legal systems? }\end{array}$ \\
\hline & & & & $\begin{array}{l}\text { 4. Has Mr. Thompson really paid his debt to society? } \\
\text { expect? }\end{array}$ \\
\hline & & & & $\begin{array}{l}\text { 6. What benefits would prisons be apart from society, especially for } \\
\text { a charitable man? }\end{array}$ \\
\hline & & & & $\begin{array}{l}\text { 7. How could anyone be so cruel and heartless as to send Mr. } \\
\text { Thompson to prison? }\end{array}$ \\
\hline & & & & $\begin{array}{l}\text { 8. Would it be fair to all the prisoners who had to serve out their } \\
\text { full sentences if Mr. Thompson was let off? }\end{array}$ \\
\hline & & & & $\begin{array}{l}\text { 9. Was Mrs. Jones a good friend of Mr. Thompson? } \\
\text { regardless of the circumstances? }\end{array}$ \\
\hline & & & & $\begin{array}{l}\text { 11. How would the will of the people and the public good best be } \\
\text { served? }\end{array}$ \\
\hline & & & $\begin{array}{l}\text { 12. Would going to prison do any good for Mr. Thompson or } \\
\text { protect anybody? }\end{array}$ \\
\hline
\end{tabular}




\section{APPENDIX B: Individual-Level Scales}

From the list of questions above, select the four most important:

Most important

Second most important

Third most important

Fourth most important 


\section{APPENDIX B: Dvadic-Level Scales}

\section{Dyadic-Level Scales ${ }^{23}$}

\begin{tabular}{|c|c|c|c|}
\hline Scale Item & Codes & Mean & S.D. \\
\hline \multicolumn{4}{|l|}{ Franchisor Dependence } \\
\hline 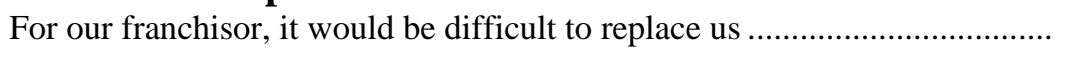 & RDEP111 & 3.83 & 2.02 \\
\hline 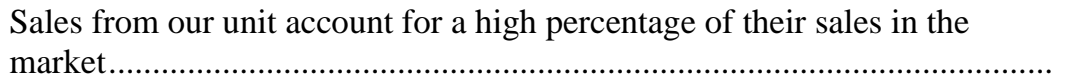 & RDEP112 & 3.42 & 2.00 \\
\hline $\begin{array}{l}\text { Sales from our unit account for a high percentage of our franchisor's } \\
\text { profits in market }\end{array}$ & RDEP106 & 3.41 & 2.02 \\
\hline 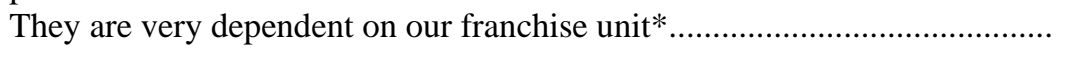 & RDEP113 & 2.79 & 1.82 \\
\hline 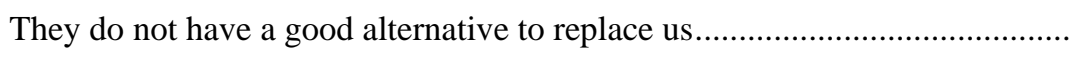 & RDEP109 & 4.37 & 1.99 \\
\hline 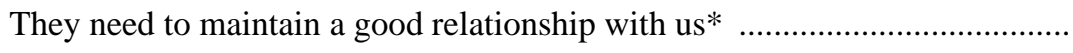 & RDEP114 & 4.43 & 2.05 \\
\hline
\end{tabular}

\section{Distributive Justice}

Our franchisor compensates us fairly:

- considering the responsibilities that we have

DJ115

$3.76 \quad 1.86$

- taking into account the investment we have made

DJ116

$3.57 \quad 1.96$

- in view of the amount of effort we put forth

DJ117

$3.54 \quad 1.90$

- for work that we do well

DJ118

$3.63 \quad 1.94$

- for the stresses and strains of our job

DJ119 3.33

1.91

\section{Procedural Justice}

In making decisions affecting our business, our franchisor's general

policies:

- strive to collect accurate information so tat the decisions are based on as much good information and informed opinion as possible.

PJ120

- provide opportunities to challenge the decisions.

- generate standards so that decisions could be made with consistency

- pay attention to the concerns of all those affected by the decisions

- are designed to have all sides affected by the decision represented

- allow for requests for clarification or additional information about the

PJ125

$4.36 \quad 1.78$
decision

\section{Interactional Justice}

Our franchisor: $\quad$ IJ126

- considers our viewpoint whenever s/he is communicating with us

- is able to suppress personal biases in dealing with us

- treats us with kindness and consideration

- shows concern for our rights as a franchisee.

IJ130

- takes steps to deal with us in a truthful manner.

\footnotetext{
${ }^{2}$ All scales except PFO used a 7-point Likert-type scale (1= "strongly disagree” and 7= "strongly agree”)

${ }^{3}$ Items with asterisk $(*)$ are items dropped after measure purification procedures.
} 


\section{APPENDIX B: Dvadic-Level Scales}

\begin{tabular}{|c|c|c|c|}
\hline Scale Item & Codes & Mean & S.D. \\
\hline \multicolumn{4}{|l|}{$\begin{array}{l}\text { Disciplinary Monitoring } \\
\text { Franchisor's Ability to Detect Opportunism }\end{array}$} \\
\hline 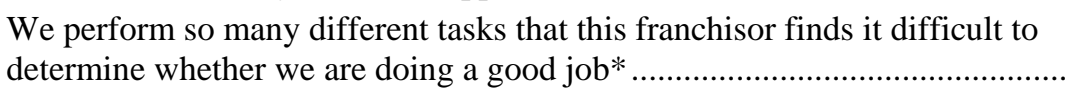 & FADO133 & 4.60 & 1.70 \\
\hline $\begin{array}{l}\text { It is easy for our franchisor to determine whether we adhere to agreed } \\
\text { upon quality standards and specifications }\end{array}$ & FADO135 & 4.73 & 1.68 \\
\hline $\begin{array}{l}\text { Our franchisor easily detects when we promise to do something without } \\
\text { actually following through }\end{array}$ & FADO137 & 4.14 & 1.69 \\
\hline $\begin{array}{l}\text { It is difficult for us to breach informal agreements between our companies } \\
\text { without being caught }\end{array}$ & FADO139 & 4.38 & 1.75 \\
\hline $\begin{array}{l}\text { Our franchisor can easily catch franchisees using unfound excuses for } \\
\text { unfulfilled obligations }\end{array}$ & FADO140 & 4.43 & 1.52 \\
\hline \multicolumn{4}{|l|}{ Franchisor's Ability to Sanction Opportunism } \\
\hline $\begin{array}{l}\text { Our franchisor would take tough measures against us if we were } \\
\text { discovered withholding certain critical information from them }\end{array}$ & FASO132 & 5.57 & 1.58 \\
\hline $\begin{array}{l}\text { This franchisor's response to any baseless excuses for not meeting our } \\
\text { obligations would be firm }\end{array}$ & FASO134 & 4.62 & 1.70 \\
\hline 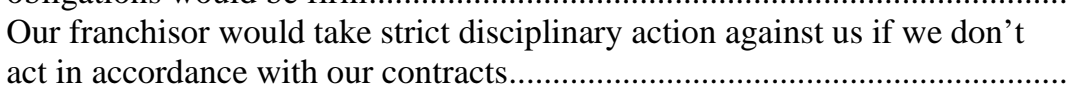 & FASO136 & 5.16 & 1.66 \\
\hline 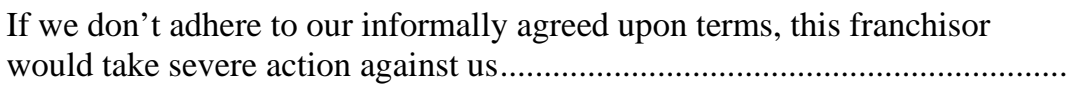 & FASO138 & 4.48 & 1.87 \\
\hline \multicolumn{4}{|l|}{ Franchisee Dependence } \\
\hline 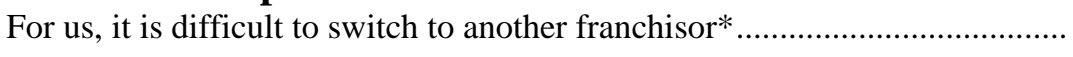 & EDEP201 & 5.98 & 1.61 \\
\hline 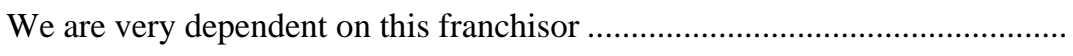 & EDEP204 & 4.06 & 2.04 \\
\hline $\begin{array}{l}\text { If our relationship with this franchisor were to end for some reason, we do } \\
\text { not have a good alternative }\end{array}$ & EDEP207 & 4.20 & 2.23 \\
\hline 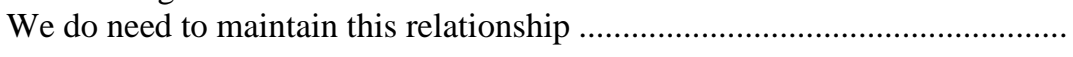 & EDEP208 & 4.89 & 2.07 \\
\hline 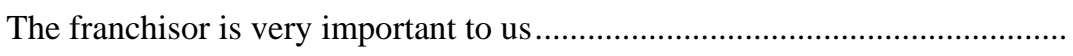 & EDEP211 & 5.19 & 1.90 \\
\hline $\begin{array}{l}\text { The franchisor would suffer a significant loss in income if we stopped } \\
\text { representing them* }\end{array}$ & EDEP216 & 3.09 & 1.97 \\
\hline \multicolumn{4}{|l|}{ Franchisee TSIs } \\
\hline $\begin{array}{l}\text { If this relationship were to terminate, it would be difficult for us to recoup } \\
\text { investments made in this franchise }\end{array}$ & ETSI219 & 4.91 & 1.98 \\
\hline $\begin{array}{l}\text { Training and qualifying for this franchisor has involved considerable } \\
\text { commitments of time and money }\end{array}$ & ETSI218 & 4.99 & 1.99 \\
\hline 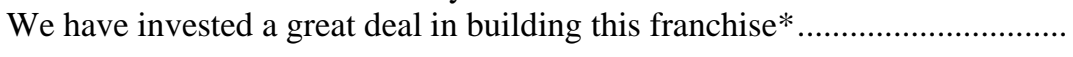 & ETSI210 & 6.31 & 1.13 \\
\hline If we were to terminate this relationship, we would lose a lot of investment.. & ETSI217 & 4.98 & 2.04 \\
\hline
\end{tabular}


APPENDIX B: Dvadic-Level Scales

\begin{tabular}{|c|c|c|c|}
\hline Scale Item & Codes & Mean & S.D. \\
\hline \multicolumn{4}{|l|}{ Economies of Continuation } \\
\hline $\begin{array}{l}\text { Contract renewal with the franchisor depends on the franchisor's } \\
\text { evaluation of our current performance* }\end{array}$ & EC202 & 3.95 & 2.22 \\
\hline $\begin{array}{l}\text { The franchisor's decision to renew our contract is highly contingent on our } \\
\text { current performance* }\end{array}$ & EC206 & 3.74 & 2.12 \\
\hline $\begin{array}{l}\text { We make plans not only for the current contract term, but also for the } \\
\text { continuation of the relationship beyond this term }\end{array}$ & EC209 & 4.82 & 2.01 \\
\hline 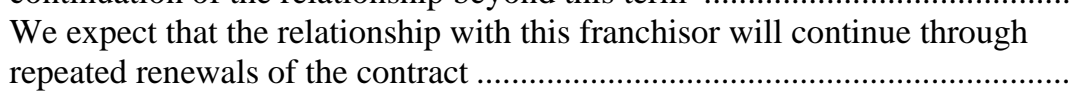 & EC213 & 5.25 & 2.06 \\
\hline \multicolumn{4}{|l|}{ Crowding Out Effects of Monitoring } \\
\hline Being monitored by my franchisor does not bother me at & COEM501 & 2.77 & 1.74 \\
\hline $\begin{array}{l}\text { I only do well the tasks for which I am being monitored by the franchisor*.. } \\
\text { By being monitored by franchisor I feel: }\end{array}$ & COEM502 & 1.81 & 1.39 \\
\hline - that my franchisor does not know how dedicated I am to being their & COEM503 & 3.14 & 1.87 \\
\hline 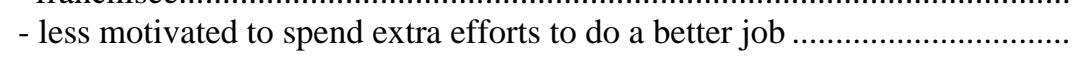 & COEM504 & 2.29 & 1.26 \\
\hline 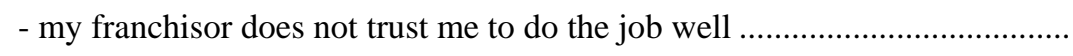 & COEM505 & 2.45 & 1.79 \\
\hline
\end{tabular}

\section{Propensity for Opportunism}

In any given business relationship, a party may engage in certain actions to improve their terms of trade such as:

- $\quad$ Giving empty promises

- Breaching formal and/or informal agreements to maximize gains

- $\quad$ Taking advantage of "holes" in the contract

- Using excuses to re-negotiate terms of trade at the partner's expense

- Withholding important information from the partner

Specific to your franchisor, please circle the number below that indicates how you feel about using this type of behavior:

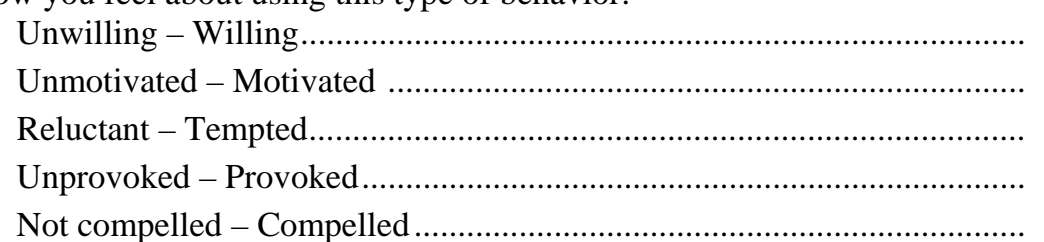

\section{Opportunistic Behaviors}

On occasion, we lie or simply withhold critical information to advance our own interests*.

We do not always act in accordance with our contract.

OB205

To maximize our own benefit, we don’t always follow informally agreed upon terms

Occasionally we just don’t adhere to our agreed upon quality standards and specifications ......

OB214 
APPENDIX B: Dvadic-Level Scales

\begin{tabular}{|c|c|c|c|}
\hline Scale Item & Codes & Mean & S.D. \\
\hline \multicolumn{4}{|l|}{ Franchisor TSIs } \\
\hline $\begin{array}{l}\text { If this relationship were to terminate, it would be difficult for them to } \\
\text { recoup investments made in this franchise unit }\end{array}$ & RTSI105 & 3.21 & 2.09 \\
\hline $\begin{array}{l}\text { Training and qualifying us has involved considerable commitments of } \\
\text { time and money on their part }\end{array}$ & RTSI107 & 3.42 & 2.01 \\
\hline They have invested a great deal in building up this franchise unit's & RTSI108 & 3.19 & 1.90 \\
\hline $\begin{array}{l}\text { If we were to terminate this relationship, the franchisor would lose a lot of } \\
\text { their investment }\end{array}$ & RTSI110 & 2.71 & 1.85 \\
\hline \multicolumn{4}{|l|}{ Economic Benefits of OB } \\
\hline \multicolumn{4}{|l|}{$\begin{array}{l}\text { In any given business relationship, a party may engage in certain actions to } \\
\text { improve their terms of trade such as: }\end{array}$} \\
\hline - Giving empty promises & & & \\
\hline - Breaching formal and/or informal agreements to maximize gains & & & \\
\hline - $\quad$ Taking advantage of "holes" in the contract & & & \\
\hline - Using excuses to re-negotiate terms of trade at the partner's expense & & & \\
\hline - Withholding important information from the partner & & & \\
\hline \multicolumn{4}{|l|}{$\begin{array}{l}\text { If a franchisee behaves this way without being detected by the franchisor, } \\
\text { it could gain: }\end{array}$} \\
\hline 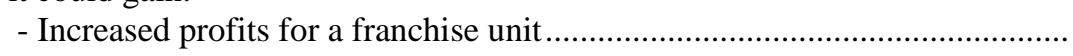 & EBOB513 & 3.36 & 1.94 \\
\hline 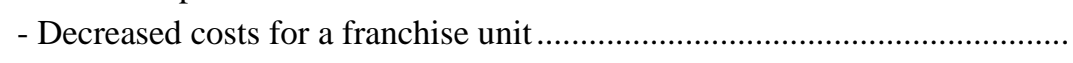 & EBOB514 & 3.54 & 1.97 \\
\hline 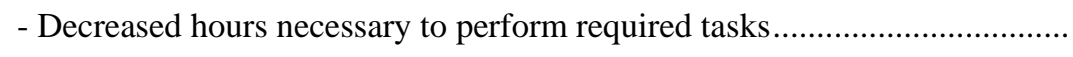 & EBOB515 & 2.91 & 1.81 \\
\hline \multicolumn{4}{|l|}{ Individual Propensity for Opportunism } \\
\hline \multicolumn{4}{|l|}{$\begin{array}{l}\text { Behaviors such as giving empty promises and taking advantages of holes } \\
\text { in the contract: }\end{array}$} \\
\hline - are very common in business & IPFO601 & 3.28 & 1.85 \\
\hline 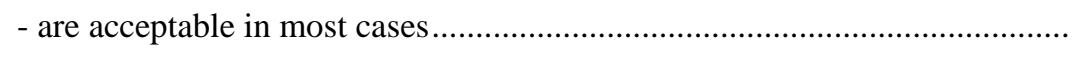 & IPFO602 & 1.99 & 1.23 \\
\hline - often times take place out of necessity & IPFO603 & 2.81 & 1.64 \\
\hline
\end{tabular}




\section{APPENDIX B: Extra-Dyadic Level Scales}

\section{Extra-Dyadic Level Scales ${ }^{45}$}

\begin{tabular}{|c|c|c|c|}
\hline Scale Item & Codes & Mean & S.D. \\
\hline \multicolumn{4}{|l|}{$\begin{array}{l}\text { Negative Professional Ethical Climate } \\
\text { Individualism }\end{array}$} \\
\hline $\begin{array}{l}\text { What is best for the franchise network is not the major consideration in } \\
\text { this business* }\end{array}$ & IN412 & 3.68 & 1.74 \\
\hline $\begin{array}{l}\text { The good of all people in the franchise system as a hole is the most } \\
\text { important concern for all involved (R)* }\end{array}$ & IN411 & 3.77 & 1.76 \\
\hline 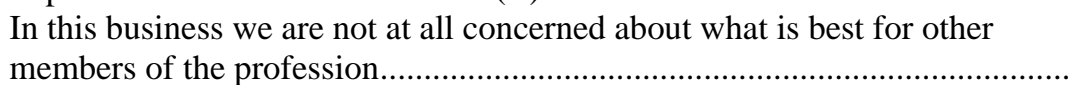 & IN413 & 3.20 & 1.63 \\
\hline In this franchise system, people protect their own interests above all else....... & IN414 & 4.25 & 1.77 \\
\hline 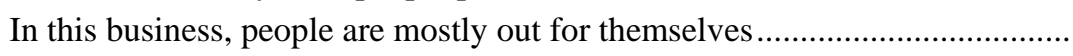 & IN415 & 3.94 & 1.86 \\
\hline 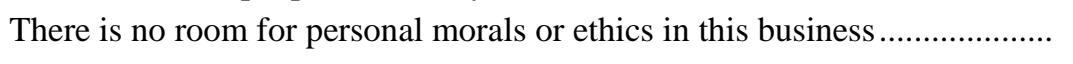 & IN416 & 2.09 & 1.49 \\
\hline \multicolumn{4}{|l|}{ Corporate Rules } \\
\hline $\begin{array}{l}\text { It is not important to follow the company's rules and procedures in this } \\
\text { business* }\end{array}$ & CR402 & 2.30 & 1.66 \\
\hline $\begin{array}{l}\text { Not everyone in this business sticks by company rules and procedures at } \\
\text { all times }\end{array}$ & CR406 & 3.89 & 1.79 \\
\hline 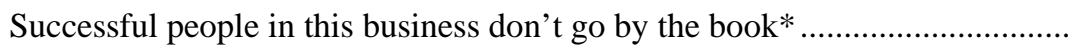 & CR403 & 2.70 & 1.76 \\
\hline People in this business don't strictly obey the company policies ......................... & CR407 & 3.35 & 1.74 \\
\hline \multicolumn{4}{|l|}{ Professional Codes of Ethics } \\
\hline 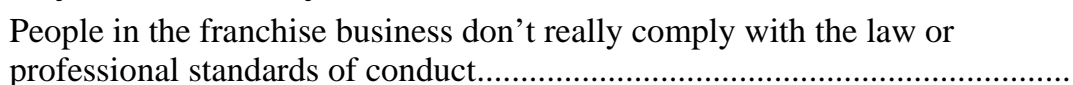 & PCE401 & 2.39 & 1.66 \\
\hline $\begin{array}{l}\text { In this business, the law or ethical codes in our profession are not a major } \\
\text { consideration* }\end{array}$ & PCE409 & 2.32 & 1.61 \\
\hline $\begin{array}{l}\text { In this business, people are not really expected to strictly follow legal or } \\
\text { professional standards }\end{array}$ & PCE405 & 2.07 & 1.42 \\
\hline \multicolumn{4}{|l|}{ Network Density } \\
\hline 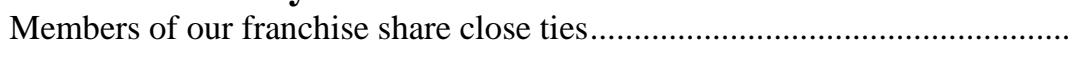 & ND404 & 4.59 & 1.80 \\
\hline There is much interaction among the members of our franchise .......................... & ND410 & 4.39 & 1.90 \\
\hline 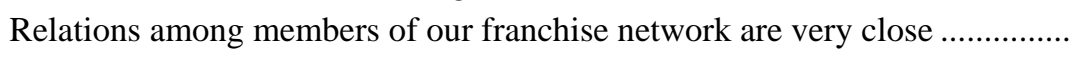 & ND419 & 4.45 & 1.83 \\
\hline Members of our franchise network frequently share communications.............. & ND417 & 4.91 & 1.65 \\
\hline Members of our franchise network frequently discuss common problems ..... & ND418 & 5.08 & 1.67 \\
\hline 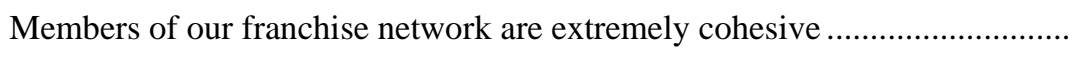 & ND408 & 4.15 & 1.74 \\
\hline
\end{tabular}

\footnotetext{
${ }^{4}$ All scales used a 7-point Likert-type scale (1= "strongly disagree” and 7= "strongly agree”)

${ }^{5}$ Items with asterisk $(*)$ are items dropped after measure purification procedures.
} 


\section{APPENDIX C: VITA}

Chiharu Ishida is currently an assistant professor at Illinois State University. Her research interests focus on the development and management of business-to-business relationships, such as those of strategic alliances and marketing channels. Ishida completed her Ph.D. from Virginia Tech in the spring of 2007 under the guidance of Dr. James R. Brown and Dr. Noreen M. Klein.

She received the Doctoral Dissertation Award in May 2005 from the Academy of Marketing Science in recognition of the quality of her dissertation proposal. In 2006 she was awarded Outstanding Graduate Student Teaching Award by the Pamplin College of Business at Virginia Tech.

A native of Niigata, Japan, Ishida worked for five years at a U.S. engineering firm, managing and developing business-to-business relationships in Japan as well as in France, Germany, and Britain. 